\title{
EVALUATION OF BIOLOGICAL NUTRIENT REMOVAL BY ANAMMOX IN A THREE PHASE FLUIDIZED BED BIOREACTOR
}

by

\author{
Nicholas Jones, BEng \\ Chemical Engineering \\ Ryerson University, 2012
}

A thesis presented to Ryerson University

In partial fulfillment of the requirements for the degree of

Master of Applied Science

in the program of

Chemical Engineering

Toronto, Ontario, Canada, 2015

CNicholas Jones, 2015 


\section{AUTHOR'S DECLARATION FOR ELECTRONIC SUBMISSION OF A THESIS}

I hereby declare that I am the sole author of this thesis. This is a true copy of the thesis, including any required final revisions, as accepted by my examiners.

I authorize Ryerson University to lend this thesis to other institutions or individuals for the purpose of scholarly research.

I further authorize Ryerson University to reproduce this thesis by photocopying or by other means, in total or in part, at the request of other institutions or individuals for the purpose of scholarly research.

I understand that my thesis may be made electronically available to the public.

Nicholas Jones 


\author{
ABSTRACT \\ EVALUATION OF BIOLOGICAL NUTRIENT REMOVAL BY \\ ANAMMOX IN A THREE PHASE FLUIDIZED BED BIOREACTOR \\ Nicholas Jones \\ Master of Applied Science, 2015 \\ School of Graduate Studies, Ryerson University
}

The purpose of this study was to show the viability of a $0.70 \mathrm{~m}^{3}$ three phase aerobic fluidized bed bioreactor for the denitrification of wastewater by anammox bacteria. The reactor was monitored for 343 days, operating in a batch mode for 50 days, with a continuous flow of wastewater being fed for the remaining 293 days. It was determined that anammox contributed up to $5.5 \pm 0.5 \%$ of the ammonia removal during the batch mode of operation, and up to $14.2 \pm 3.7 \%$ of the ammonia removal during the continuous mode of operation. The highest ammonia and total nitrogen removals of $90.9 \pm 1.6 \%$ and $20.8 \pm 4.1 \%$ were measured under high recycle rates. Up to $63.1 \pm 5.2 \%$ and $19.2 \pm 7.5 \%$ ammonia and total nitrogen removal was observed after a single pass through the reactor. At low COD concentrations and anoxic conditions, ammonia and nitrite were removed simultaneously. Under the evaluated conditions, the reactor was determined to contain anammox bacteria. 


\section{ACKNOWLEGEMENTS}

I would like to thank Dr. Alvarez-Cuenca for his continued support, guidance and patience during the completion of this thesis. His passion and knowledge on the topic of wastewater treatment was very encouraging, and helped to inspire long hours of study and research. As well, discussion and support from Ms. Maryam Reza was essential for the successful completion of this project. Without the enthusiastic support of Dr. Alvarez-Cuenca and Ms. Maryam Reza, the challenges in this study would have been insurmountable.

Additionally, the support from Dr. Doan, Ryerson University, and the Faculty and Staff of The Department of Chemical Engineering was indispensable during the completion of the project. The troubleshooting and technical support provided by Daniel Boothe and Ali Hemmati was very helpful for the successful understanding and configuration of the reaction system. Further, the welcoming and supportive conversation provided by all members of the Ryerson Faculty and Staff was very encouraging. A pleasant conversation was always welcomed between the long periods of study.

Finally, I would like to thank my family and friends for their support and understanding during the completion of this thesis. I appreciate your continued patience during the long periods of research. Your efforts to accommodate my hectic schedule definitely helped to reduce the stress of this project, and surely improved my enjoyment of further education. 


\title{
TABLE OF CONTENTS
}

\section{AUTHOR'S DECLARATION}

\author{
ABSTRACT
}

ACKNOWLEGEMENTS

TABLE OF CONTENTS

\section{LIST OF TABLES}

\section{LIST OF FIGURES}

1.0 Introduction. 1

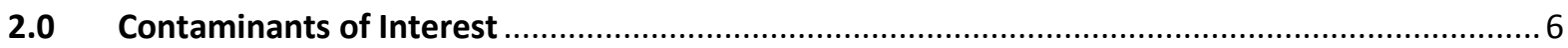

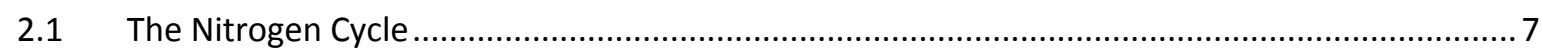

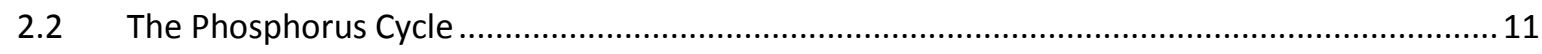

2.3 Biological Oxygen Demand and E. Coli............................................................................ 15

2.4 Comparison of Operating Conditions ................................................................................. 19

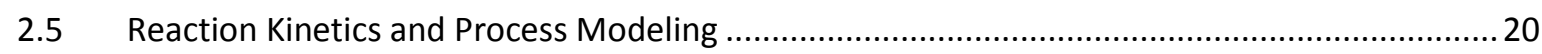

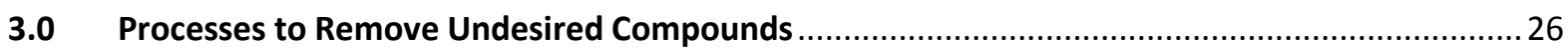

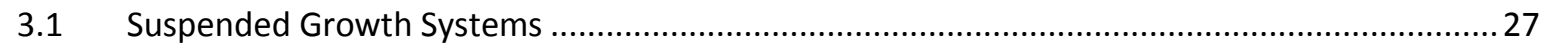

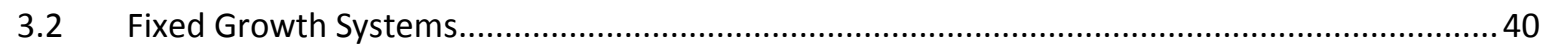

3.3 Advanced Wastewater Reactors ......................................................................................... 45

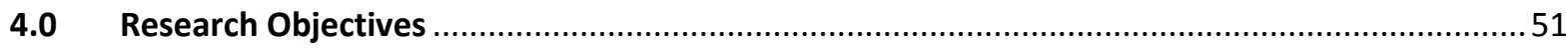




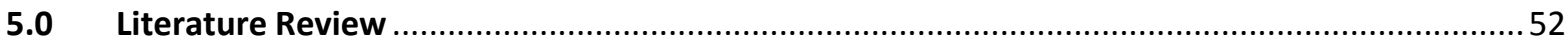

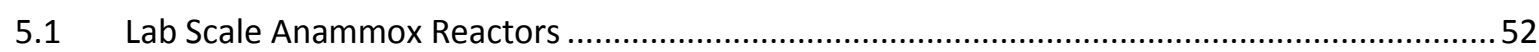

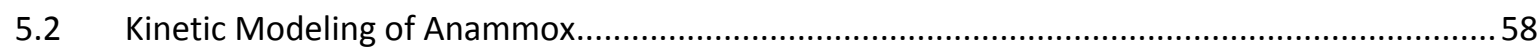

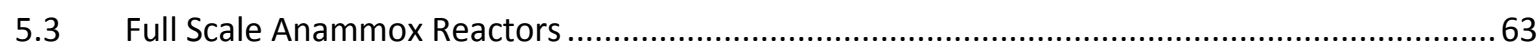

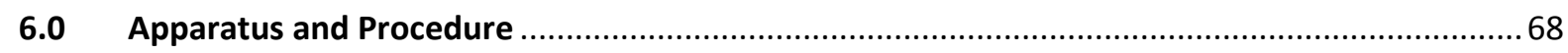

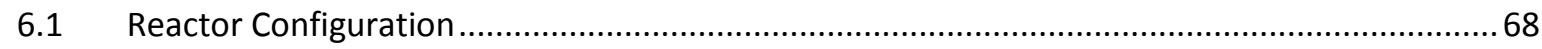

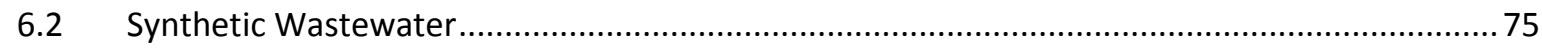

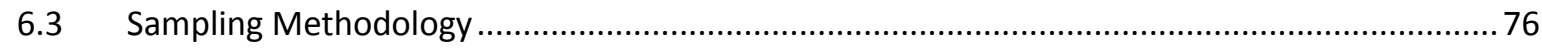

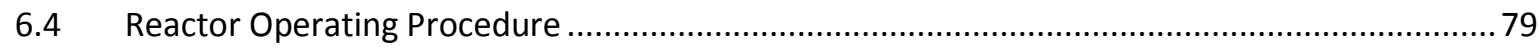

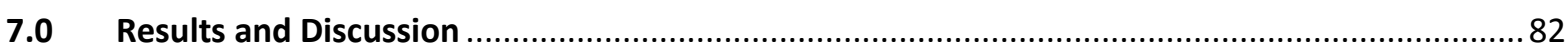

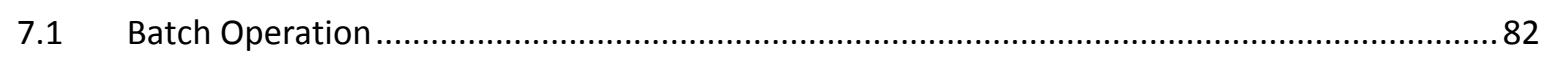

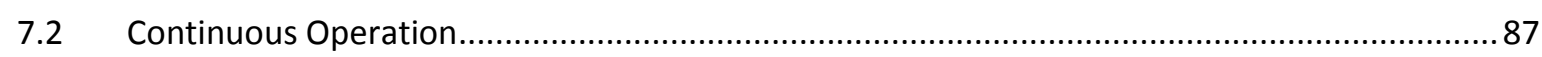

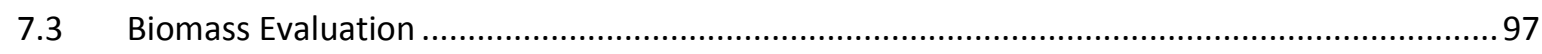

7.4 Further Evidence of Anammox Behaviour .............................................................................. 102

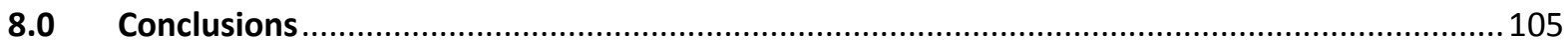

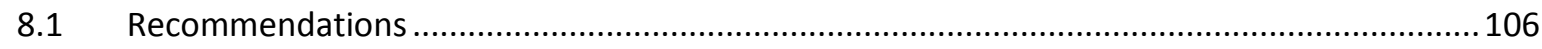

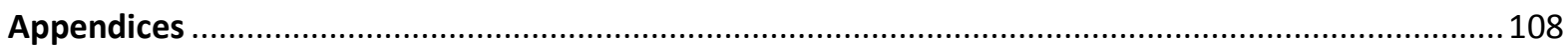

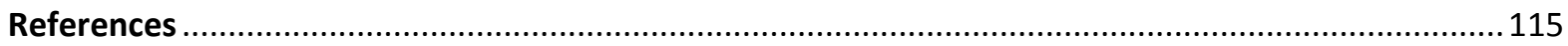




\section{LIST OF TABLES}

Table 2-1: Useful compounds for phosphorus precipitation .............................................................. 12

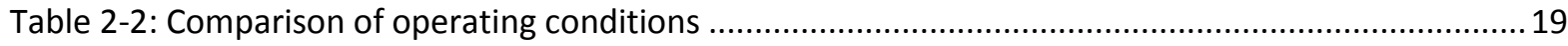

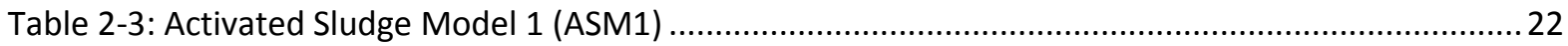

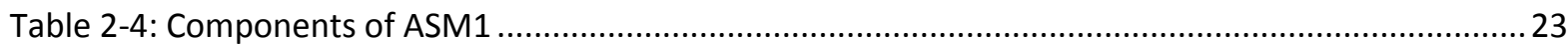

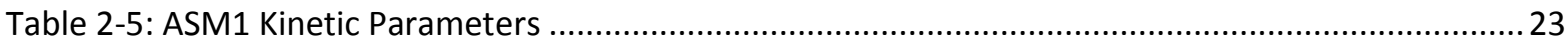

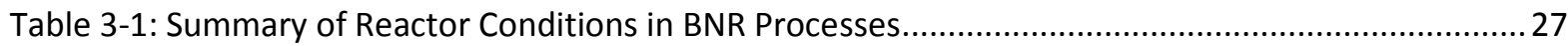

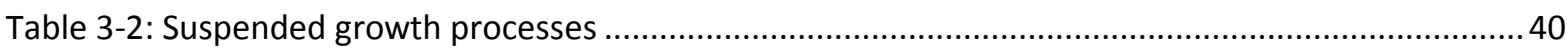

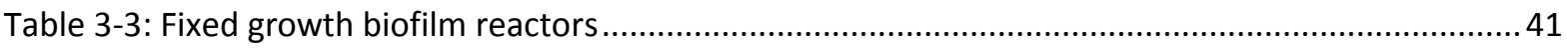

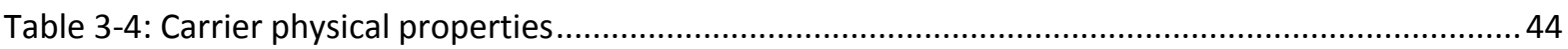

Table 5-1: Lab scale and pilot scale anammox reactors …..................................................................... 54

Table 5-2: Stoichiometric matrix compatible with ASM1, for anammox .................................................59

Table 5-3: Kinetic parameters for anammox with ASM1 ......................................................................... 59

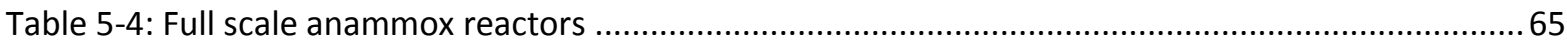

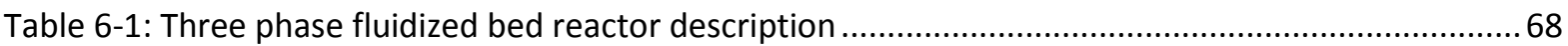

Table 6-2: Position of the sampling ports in the fluidized bed reactor ................................................... 70

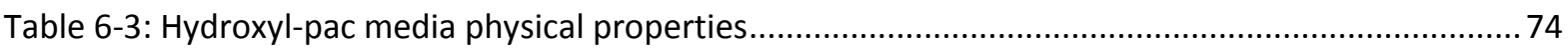

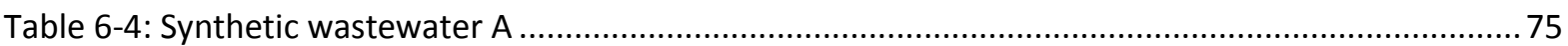

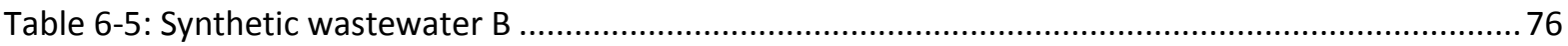

Table 6-6: Testing methods for COD, nitrogen compounds and phosphorus ........................................ 77

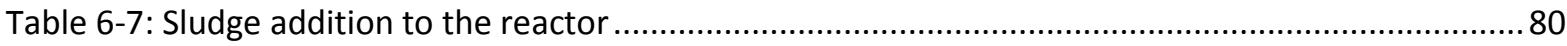

Table 6-8: Operation methodology for batch and continuous flow ....................................................... 80

Table 6-9: Time spent for investigation of biofilm characteristics in three phase fluidized bed biofilm

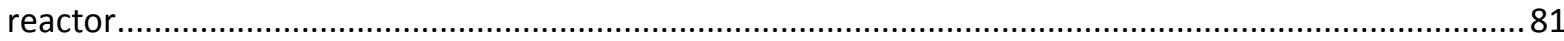

Table 6-10: Time spent for the investigation of anammox performance under reduced COD, DO

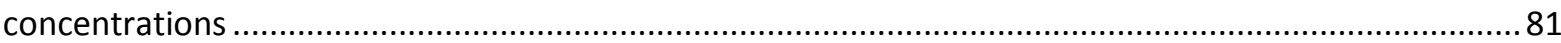

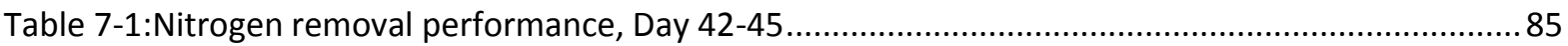

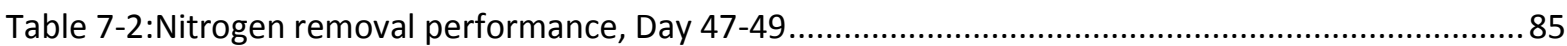

Table 7-3: Simulated results for nitrogen compounds removed between days $47-49$............................ 86

Table 7-4: Simulated results for nitrogen compounds removed between days $42-45$........................... 87

Table 7-5: Summary of nitrogen removal and nitrate production in three phase fluidized bed bioreactor 
Table 7-6: Nitrogen removal rate in three phase fluidized bed bioreactor ............................................ 95

Table 7-7: NRR comparison of the present study against previous studies ............................................96

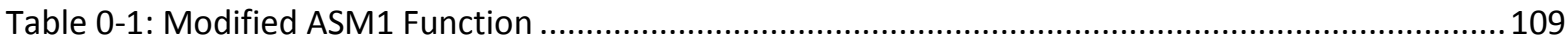

Table 0-2: Description of kinetic parameters for modified ASM1 function...........................................113 


\section{LIST OF FIGURES}

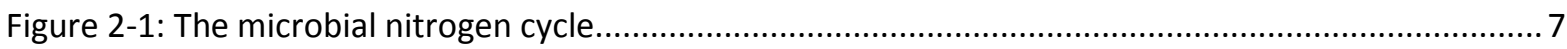

Figure 2-2: Interaction between nitrogen removing bacteria .......................................................... 11

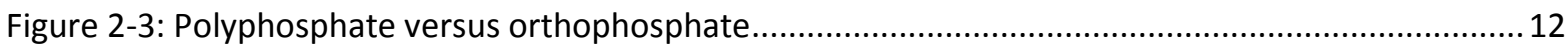

Figure 2-4: Operation of phosphorus accumulating organisms ........................................................... 14

Figure 2-5: Generalized municipal wastewater treatment process ....................................................... 18

Figure 2-6: Experimental growth rate of E.Coli on Glucose, with Monod predictions ...............................20

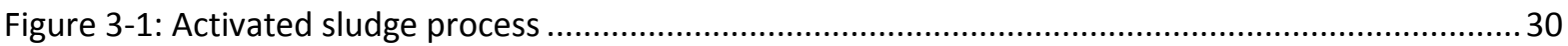

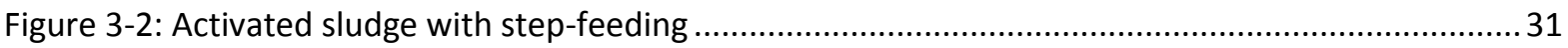

Figure 3-3: Activated sludge with contact stabilization ......................................................................... 32

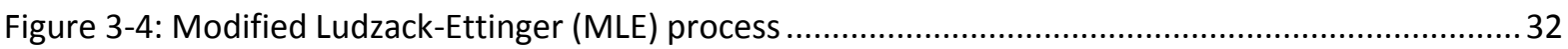

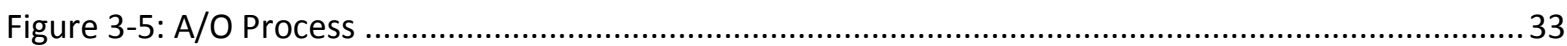

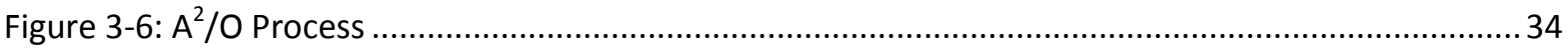

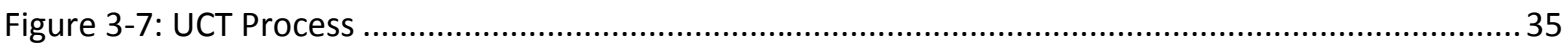

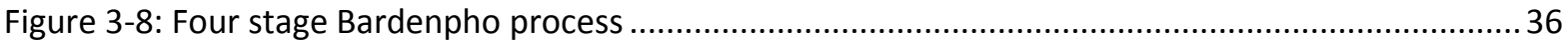

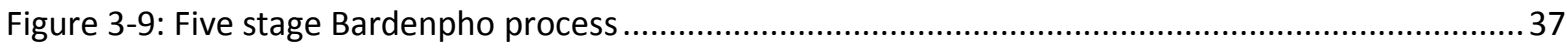

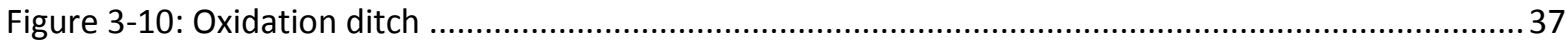

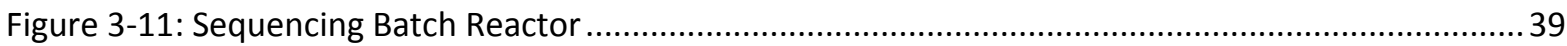

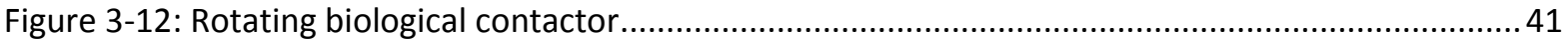

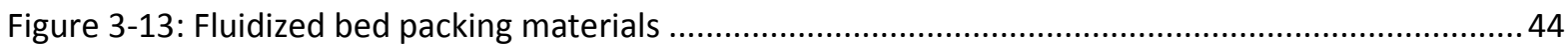

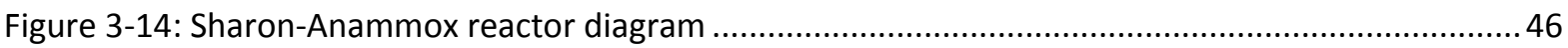

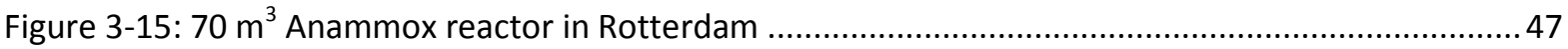

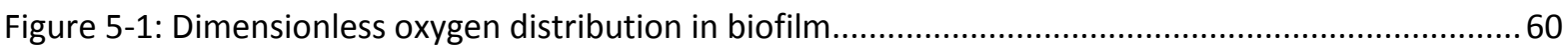

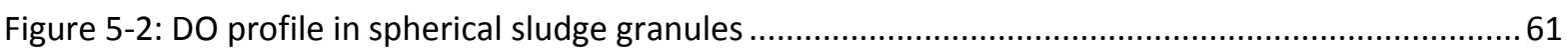

Figure 5-3: Steady state profile of ammonia, nitrite, nitrate, oxygen and $\mathrm{pH}$ in biofilm........................... 62

Figure 5-4: Number of full scale anammox reactors, and publications ..................................................67

Figure 6-1: Three phase fluidized bed reactor physical configuration .....................................................69

Figure 6-2: Three phase fluidized bed reactor, recycle and feed tank ................................................... 71

Figure 6-3: Three phase FBR size comparison ……........................................................................... 71

Figure 6-4: Three phase fluidized bed bioreactor system ..................................................................... 72

Figure 6-5: Configuration of the Laboratory of water and wastewater treatment technologies .............. 73

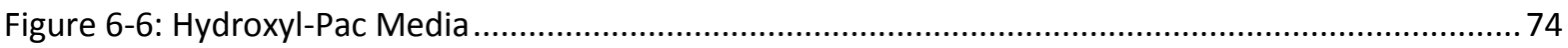




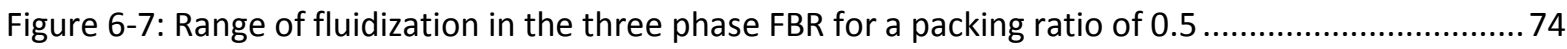

Figure 7-1: Batch operation of FBR. Grey shading represent days where aeration was provided............. 82

Figure 7-2: Predicted relative growth of NOBs in a batch system over 2 days at varying DO

concentrations

Figure 7-3: Predicted relative growth of AOBs in a batch system over 2 days at varying DO

concentrations... .84

Figure 7-4: Predicted concentration profile simulated by ASM1 during batch operation, Day 47-49.......86

Figure 7-5: Removal performance for continuous operation of three phase fluidized bed bioreactor..... 88

Figure 7-6: Removal performance of ammonia, COD and total nitrogen in the three phase fluidized bed

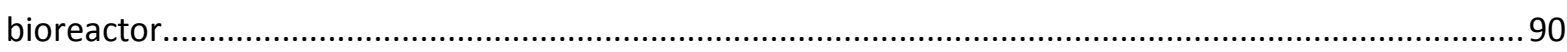

Figure 7-7: Comparison of anammox performance at various DO concentrations.................................. 91

Figure 7-8: Typical biofilm accumulation on carriers in three phase fluidized bed bioreactor ................. 92

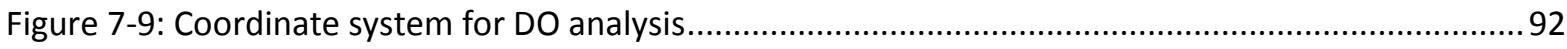

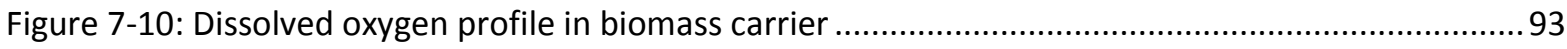

Figure 7-11: Red colour observed on biomass carriers, 3SCFM (5.1 SCMH) ……................................ 95

Figure 7-12: Sample locations from three phase fluidized bed bioreactor ............................................98

Figure 7-13: Biofilm density at three different locations and air flow rates .............................................99

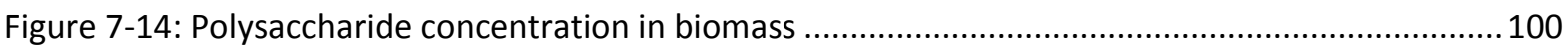

Figure 7-15: Oxygen consumption rate at varying air flow rates, $\mathrm{mg} / \mathrm{L} \mathrm{min}$......................................... 102

Figure 7-16: Removal performance of total nitrogen after deaeration column used .............................. 103 


\subsection{Introduction}

Wastewater is the liquid effluent from any industrial or commercial process, or the by-products of human sanitation which contain harmful substances. These substances must be removed prior to the discharge of wastewater to any environment, whether it be a lake, river, or other body of water. Significant damage will result from the release of untreated or undertreated wastewater, which could include environmental damage (eutrophication, changes in aquatic populations), economic losses (reduced fishery yield, tourism, and property values) and human health impacts (CCME, 2006).

All developed countries have specific guidelines for the treatment of wastewater, to ensure that deleterious substances do not enter larger bodies of water. In Canada, recent legislation has imposed national guidelines for the minimum treatment requirements prior to effluent discharge. This document is known as the Wastewater Systems Effluent Regulations, and was issued in 2012 (Government of Canada, 2012). These regulations were passed under the Fisheries Act, which aims to protect the sustainability and productivity of recreational and commercial fisheries (Government of Canada, 1985).

In the Province of Ontario, further legislation defines the minimum treatment requirement for effluent wastewater. Generally, the Ontario Water Resources Act controls the consumption of water and treatment requirements for municipal and sanitary usage (Province of Ontario, 1990). Additionally, the Environmental Protection Act controls the consumption and treatment of water, but addresses a more broad area (Province of Ontario, 1990). The Environmental Protection Act lists specific regulations for 9 different industrial sectors, including the:

- Electric Power Generating Sector

- Inorganic Chemicals Sector

- Industrial Minerals Sector

- Iron and Steel Manufacturing Sector

- Metal Casting Sector

- Metal Mining Sector

- Organic Chemical Manufacturing Sector 
- Petroleum Sector

- Pulp and Paper Sector

There are many more acts which could be applicable to the treatment and management of water in Ontario, such as the Nutrient Management Act, 2002, or the Clean Water Act, 2006, although they are less relevant in the general treatment of industrial or municipal wastewater (Province of Ontario, 2002) (Province of Ontario, 2006). Internationally, the Great Lakes Water Quality Agreement sets rules concerning phosphorus effluent into the Great Lakes, and must be considered (The Government of Canada; The Government of the United States of America, 2013).

Although the required documentation and recordkeeping for Federal and Provincial legislation may differ, both governing bodies are concerned about similar contaminants. Provincially, effluent limits are assigned on a case-by-case basis in the form of an Environmental Compliance Approval (ECA), formerly Certificate of Approval (CoA). For municipal wastewater treatment, contaminants of interest generally include total suspended solids (TSS), carbonaceous biochemical oxygen demand (cBOD), ammonia, and residual chlorine (Government of Canada, 2012). Further limitations are generally placed on total phosphorus (TP), E. Coli concentration and $\mathrm{pH}$ when ECAs or CoAs are assigned (Toronto Water, 2013). In more progressive countries, the total nitrogen (TN) concentration is also limited. This TN includes ammonia, nitrite and nitrate (The Council of the European Communities, 1991).

When considering industrial wastewater treatment, contaminants of interest vary between each industry. For example, the typical contaminants for organic chemical manufacturing, pulp and paper, and petroleum industries are listed below. Provincial legislation places limits on daily and average loadings (kg released per day), instead of concentration. In some municipalities, the total concentration of deleterious substances is also limited. This is done to prevent damage to the local infrastructure, and imposes large fines (exceeding $\$ 50,000$ ) to ensure compliance (City of Ottawa, 2011). 
Typical designated substances monitored in industrial wastewater include:

Organic Chemical Manufacturing (Province of Ontario, 1995)

- Ammonia + Ammonium

- Nitrite + Nitrate

- Total Kjeldahl Nitrogen (TKN)

- Dissolved Organic Carbon (DOC)

- Total Phosphorus (TP)

- Total Suspended Solids (TSS)

- Oil and Grease

- Phenols, Benzene, Toluene

- Mercury, Lead, Chromium and other heavy metals

- Production-specific organic chemicals

Pulp and Paper Manufacturing (Province of Ontario, 1993)

- Biological Oxygen Demand (BOD)

- Total Phosphorus (TP)

- Total Suspended Solids (TSS)

- Chloroform, Toluene, Phenol

- Dibenzofurans, Dioxins, Organic Halides

Petroleum Manufacturing (Province of Ontario, 1993)

- Ammonia + Ammonium

- Dissolved Organic Carbon (DOC)

- Total Phosphorus (TP)

- Total Suspended Solids (TSS)

- Volatile Suspended Solids (VSS)

- Oil and Grease

- Phenols, Benzene, Toluene, Sulphides

- Dibenzofurans, Dioxins 
There are a variety of contaminants monitored in each process, although most industries are concerned with a specific set of compounds. These include ammonia+ammonium, BOD or DOC, TP and TSS. Municipal wastewater treatment removes similar compounds, with additional focus on effluent $\mathrm{E}$. Coli concentrations. To elaborate on significant contaminants of interest, a detailed look at each will be provided in section 2 .

When considering the economic impact of wastewater treatment, the Great Lakes Basin can be used as a local example. The population surrounding the lakes rely on good water quality for a variety of applications, including recreational, commercial and industrial purposes. Because of this, there are substantial economic consequences associated with the decreased quality of water in the great lakes.

Economically, the Canadian recreational fisheries of the Great Lakes are estimated to be worth around $\$ 413$ million CAD per year, with approximately $\$ 228$ million CAD being spent on items directly used for fishing activities (boats, property/buildings, special vehicles etc.), and \$215 million CAD being distributed to local economies for fishing expenditures (transportation, food, fishing supplies etc.). These figures do not include the economic impact of any other recreational activities such as hunting, boating or lakefront activities, which also rely on the water quality of the Great Lakes (Fisheries and Oceans Canada, 2005). Further, the reported values do not include statistics of the American usage of the lakes.

Industrially, many processes rely on the clean supply of water as a reagent for various activities, or as a heating and cooling media for power generation. Moreover, agricultural uses of the clean freshwater further increase the economic value of the Great Lakes. A few examples of the value of water for each purpose is shown below (Marbek, 2010):

- Value of intake water for the manufacturing sector - up to $\$ 1.50 / \mathrm{m}^{3}$

- Value of intake water for thermal power generating plants - up to $\$ 0.39 / \mathrm{m}^{3}$

- Value of intake water for agriculture, sweet corn - up to $\$ 0.22 / \mathrm{m}^{3}$

- Value of intake water for agriculture, tomatoes - up to $\$ 1.26 / \mathrm{m}^{3}$ 
Finally, the value of commercial fisheries on the Great Lakes further increases the total economic value which comes from this clean water source. In Ontario, approximately 15,000 tonnes of fish are caught each year, with a dockside value of $\$ 29.3$ million CAD. When considering the processing, sale and restaurant use of this fish, the total contribution to the economy is estimated to be up to $\$ 216$ million CAD (Marbek, 2010). Generally, $80 \%$ of the commercial fisheries operate out of Lake Erie, which holds the largest walleye fishery in the world. Unfortunately, this lake is the most susceptible to eutrophication. 


\subsection{Contaminants of Interest}

Ammonia, BOD, TP and TSS are frequently encountered in wastewater. As shown previously, these streams can originate from municipal, commercial or industrial sources. It is important to remove these compounds from wastewater prior to discharge, as they have a deleterious effect on natural environments. Primarily, these components are the nutrients for microbial organisms in bodies of water. When exposed, these microbial organisms will consume the nitrogen compounds, BOD and TP, resulting in growth of algae (algal blooms). Their reproduction will consume the dissolved oxygen (DO) in the water, producing dead zones. In these dead zones, fish and other aquatic organisms cannot survive (Kahn \& Ansari, 2005). This phenomenon is known as eutrophication, and is a global problem.

In Lake Erie, eutrophication has been well documented, and continues to be a problem today. In the 1980s, high phosphorus loadings in Lake Erie was recognized as one of the leading causes of algal blooms. Subsequent changes in legislation, followed by investment in wastewater treatment facilities exceeding $\$ 7.5$ billion led to greater control of phosphorus in the lake (Makareqicz \& Bertram, 1991). The Great Lakes Water Quality Agreement, first signed in 1972, amended in 2012, helped to establish limits of phosphorus loadings in each of the Great Lakes. Currently, less than $10 \mu \mathrm{g} / \mathrm{L}$ must be maintained in the open waters of Lake Erie. A phosphorus loading of 11,000 tonnes TP per year is targeted (The Government of Canada; The Government of the United States of America, 2013). Most Ontario municipalities in the Great Lakes Region set the phosphorus effluent limit to $0.5 \mathrm{mg} / \mathrm{L} \mathrm{TP}$. This is generally achieved through chemical precipitation of phosphorus (Oleszkiewicz \& Barnard, 2006).

Recently, eutrophication in Lake Erie is becoming problematic once again. Although phosphorus concentrations are held below acceptable levels, higher concentrations of nitrite, nitrate and iron could be encouraging algae growth (North, Guildford, Smith, Havens, \& Twiss, 2007). It is known that iron addition can promote algae growth (Twiss, Auclair, \& Charlton, 2000). However, current studies are conflicted about the role of nitrate in Lake Erie (Kane, Conroy, Richards, Baker, \& Culver, 2014). Further study is needed to reduce and prevent eutrophication in the lake. 
Failure to prevent the spread of eutrophication can have substantial consequences on local populations. In August 2014, the city of Toledo, Ohio, were left without drinking water for two days. A no drink, no boil warning was issued, and the 400,000 people in northwestern Ohio were warned to avoid contact with the drinking water. Showering was discouraged for children and individuals with liver disease (CBSNews, 2014). This was a direct result of the eutrophication of Lake Erie, which caused the production of algae and a toxic by-product. Unfortunately, this problem was predicated one month earlier, and the creation of algae blooms is a well-known issue (The Associated Press, 2014).

When considering the fate of nutrients in effluent wastewater, the natural production and consumption cycles must be considered.

\subsection{The Nitrogen Cycle}

Nitrogen is commonplace in wastewater treatment. It is used in many forms in industrial and commercial processes. Municipally, the largest source of nitrogen is from by-products of organic waste. Biological materials from human sanitation will degrade into ammonia, entering the nitrogen cycle shown in Figure 2-1.

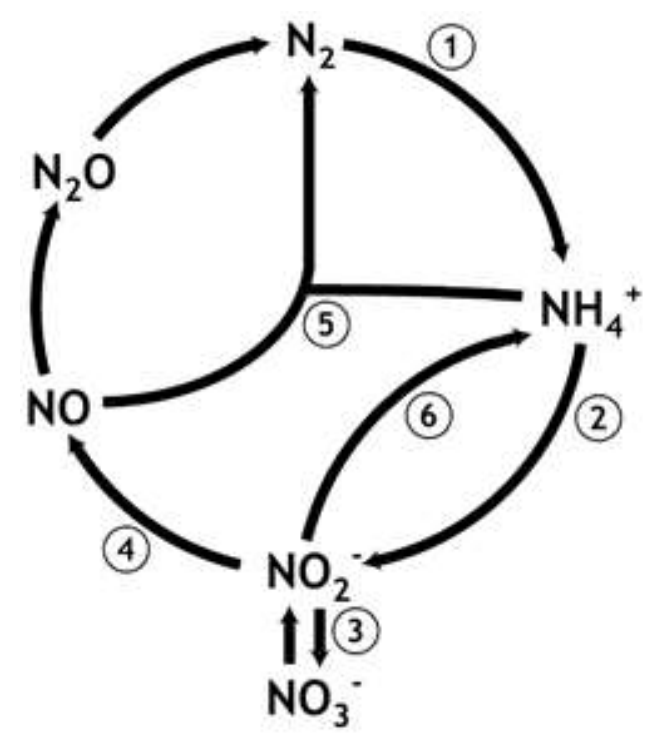

Figure 2-1: The microbial nitrogen cycle, from (Jetten, 2008). 1) Nitrogen fixation. 2) Ammonium oxidation. 3) Nitrite oxidation. 4) Denitrification. 5) Anaerobic ammonium oxidation. 6) Nitrate and nitrite reduction to ammonium 
Each transition in the nitrogen cycle is facilitated by a specific population of microorganisms (bacteria, archaea or fungi). These organisms may be autotrophic or heterotrophic, and may require aerobic, anoxic or anaerobic conditions. Generally, organic nitrogen decomposes into ammonia and ammonium, which are relatively stable in water. This concentration of ammonia $\left(\mathrm{NH}_{3}\right)$ and ammonium $\left(\mathrm{NH}_{4}{ }^{+}\right)$exist in an equilibrium, where the concentration of unionized ammonia is a function of both temperature and pH (US EPA, 1993). Henceforth, ammonia and ammonium will be referred to as ammonia, and all stated values of ammonia will include both ammonia and ammonium.

The conversion of nitrogen compounds in wastewater generally begins with the oxidation of ammonia to nitrite, as shown in step 2 of Figure 2-1. This oxidation is facilitated by ammonia oxidizing bacteria (AOBs), or ammonia oxidizing archaea (AOAs). A variety of organisms can oxidize ammonia, including Nitrosomonas, Nitrosospira or Nitrosopumilus (Third, Sliekers, Kuenen, \& Jetten, 2001) (Walker, et al., 2010). AOAs and AOBs operate in a similar way, and can be considered as a single entity in large scale wastewater systems. However, the biochemical pathways and intermediate chemical forms for the oxidation of ammonia are different for the two organisms. Also, it is suspected that AOAs may require slightly less oxygen per mole of ammonia converted (Walker, et al., 2010). The generalized stoichiometry of the oxidation of ammonia is shown below. Note that a portion of the oxidized ammonia is incorporated into the biomass of the microorganism (Henze, Harremoes, Arvin, \& Jansen, 2002).

$$
\begin{gathered}
\mathrm{NH}_{4}^{+}+1.5 \mathrm{O}_{2} \rightarrow \mathrm{NO}_{2}^{-}+2 \mathrm{H}^{+}+\mathrm{H}_{2} \mathrm{O} \\
\Delta G^{o}=-270 \mathrm{~kJ} / \text { reaction }
\end{gathered}
$$

After the oxidation of ammonium to nitrite, nitrite is further oxidized to nitrate. Although it is possible to achieve partial nitrification of ammonium to nitrite, without full nitrification to nitrate, this requires greater control of dissolved oxygen concentrations. Many reactors achieve partial nitrification, although it is not typical in Canadian wastewater treatment facilities. Examples such as the single reactor for high activity ammonia removal over nitrite (SHARON), utilize this partial nitrification to reduce aeration requirements (Milia, Cappai, Perra, \& Carucci, 
2012). Full nitrification of ammonia to nitrate requires 2 moles of oxygen per mole of ammonia. By utilizing partial nitrification, requiring just 1.5 moles of oxygen, a theoretical aeration reduction of $25 \%$ is possible.

The oxidation of nitrite to nitrate is facilitated by nitrite oxidizing bacteria (NOBs), as shown in step 3 of Figure 2-1. A variety of bacteria can be used for this process, including Nitrobacter or Nitrospira (Gerardi, 2002). The oxidation reaction is shown in equation 2 (Henze, Harremoes, Arvin, \& Jansen, 2002).

$$
\begin{gathered}
\mathrm{NO}_{2}^{-}+0.5 \mathrm{O}_{2} \rightarrow \mathrm{NO}_{3}^{-} \\
\Delta G^{o}=-80 \mathrm{~kJ} / \text { reaction }
\end{gathered}
$$

Equation 2

The reduction of nitrate is achieved through heterotrophic denitrification, as shown in step 4 of Figure 2-1. This process must occur in an anoxic environment, and requires sufficient organic carbon to complete the reduction of nitrite and nitrate. This reaction is shown in equation 3 , using methanol as a potential carbon source. In order for full denitrification to occur, a minimum ratio of soluble organic carbon to nitrite and nitrate (in terms of nitrogen, denoted $\mathrm{NO}_{2}-\mathrm{N}$ and $\mathrm{NO}_{3}-\mathrm{N}$ ) of 3:1 is needed (Gerardi, 2002). Some researchers suggest that higher ratios of 4-10:1 should be targeted for greater removal of nitrite and nitrate (Jinlong, Ying, Xiujuan, \& Zi-Peng, 2012).

$$
\begin{gathered}
\mathrm{NO}_{3}^{-}+\frac{5}{6} \mathrm{CH}_{3} \mathrm{OH}+\mathrm{H}^{+} \rightarrow \frac{1}{2} \mathrm{~N}_{2}+\frac{5}{6} \mathrm{CO}_{2}+\frac{13}{6} \mathrm{H}_{2} \mathrm{O} \\
\Delta G^{o}=-545.9 \mathrm{~kJ} / \text { reaction }
\end{gathered}
$$

However, the optimal C:N ratio depends on the organic carbon source. Materials such as methanol or ethanol may require $\mathrm{C}: \mathrm{N}$ ratios around 3.0-5.0, whereas acetate may require a $\mathrm{C}: \mathrm{N}$ ratio exceeding 14 (Canto, Ratusznei, Rodrigues, Zaiat, \& Foresti, 2012). Successful heterotrophic denitrification depends on a variety of conditions, and removal performance may change with varying inlet wastewater conditions. Most wastewater treatment plants 
performing denitrification need supplemental carbon addition, requiring sufficient onsite chemical storage (US EPA, 2013).

In addition to the traditional heterotrophic denitrification, which requires a carbon source for effective removal of nitrite and nitrate, there is a second method for denitrification. This newly discovered autotrophic denitrification is able to remove ammonia and nitrite, as shown in step 5 of Figure 2-1. Unlike traditional nitrification, this bacteria does not require aeration.

Moreover, the bacteria does not require an external carbon source for the reduction of nitrite. For these reasons, the autotrophic denitrification is a less expensive alternative to conventional heterotrophic denitrification.

This autotrophic denitrifying process, known as anaerobic ammonium oxidation or anammox, first patented in 1989, has become one of the most cost effective methods for the removal of ammonia and nitrite from wastewater (United States of America Patent No. US5078884 A, 1989). As shown in equation 4 , the bacteria consumes both ammonia and nitrite, producing nitrogen and some nitrate (Sliekers, Third, Abma, Kuenen, \& Jetten, 2003). Since the discovery of the bacteria 25 years ago, the process has been commercialized and a variety of industrial applications exist. Currently, over 100 treatment plants in The United States of America, Canada, Europe and Asia use this anammox technology (Lackner, et al., 2014).

$$
\begin{gathered}
\mathrm{NH}_{3}+1.32 \mathrm{NO}_{2}^{-}+\mathrm{H}^{+} \rightarrow 1.02 \mathrm{~N}_{2}+0.26 \mathrm{NO}_{3}^{-}+2 \mathrm{H}_{2} \mathrm{O} \\
\Delta G^{o}=-357.8 \mathrm{~kJ} / \text { reaction }
\end{gathered}
$$

In a reversible process, the Gibbs free energy change $\left(\Delta G^{\circ}\right)$ describes the maximum quantity of work which can be extracted from a closed system. The negative Gibbs free energy indicates that the oxidation of ammonia by nitrite is energetically favourable, and the process will release energy. Because this reaction is favourable (spontaneous reaction), the occurrence of anammox was predicted many years before the bacteria was physically identified. In 1977, Broda and Dv published their predictions, suggesting that this bacteria was a missing link in the nitrogen cycle (Broda \& Dv, 1977). Over 35 years later, the hypothetical process has become one of the most effective methods to remove nitrogen from wastewater. 
The advantages of the anammox process include up to $60 \%$ reduced operational costs, and up to $90 \%$ reduced greenhouse gas emissions through reduced $\mathrm{CO}_{2}$ and $\mathrm{N}_{2} \mathrm{O}$ production. However, the slow growth rate of anammox bacteria make it more difficult to apply in traditional reactor configurations (Hu, et al., 2010). Reactor configurations which have been successfully used for anammox bacteria will be discussed in section 3 of this report.

By avoiding complete nitrification followed by conventional denitrification, and instead using anammox for deammonification, it is possible to reduce the energy consumption of wastewater treatment. This process is shown in Figure 2-2. The magnitude of energy savings can bring substantial changes to the wastewater treatment industry. Some researchers have determined that it is possible to use anammox to convert current energy-consuming wastewater treatment plants into energy-producing facilities (Kartal, Kuenen, \& van Loosdrecht, 2010).

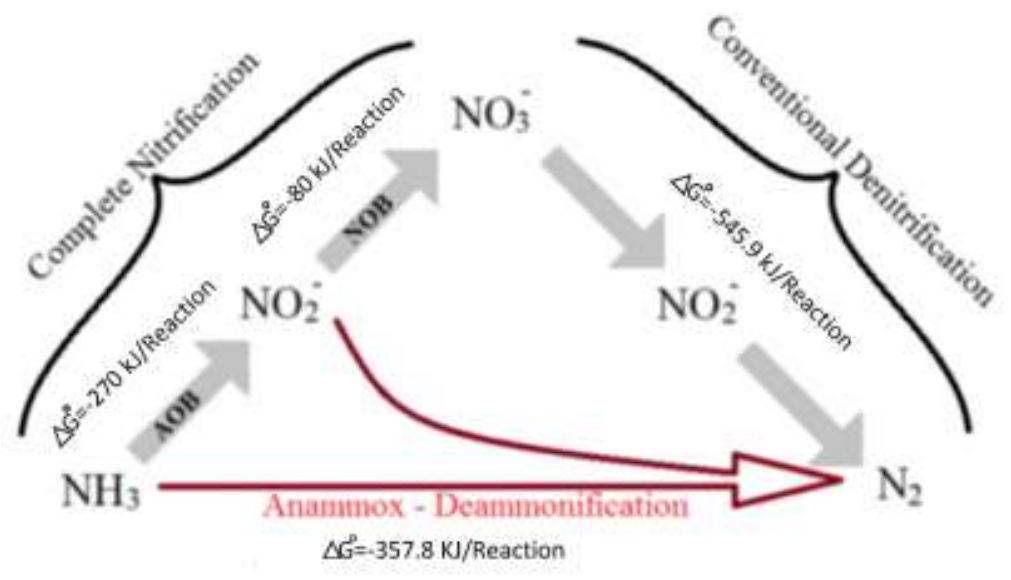

Figure 2-2: Interaction between nitrogen removing bacteria. Anammox in red

\subsection{The Phosphorus Cycle}

Phosphorus accumulation in natural bodies of water has been identified as one of the primary causes of eutrophication (IJC, 2014). For most purposes, phosphorus in wastewater can be divided into three categories: orthophosphate, polyphosphate and organic phosphorus. Orthophosphates are readily available for use in biological organisms, whereas polyphosphates are not. However, polyphosphates quickly transform to orthophosphate in water, and both compounds provide similar nutrition to aquatic organisms (Musig \& Boyd, 1980). The difference between the two compounds is shown in Figure 2-3. Organic phosphorus is the phosphorus contained in biological materials, and is converted into orthophosphate during the death/decay 
of biomass (lysis). Although this phosphorus is not directly available to biological organisms, it can be converted under the proper conditions (Henze, et al., 1999).

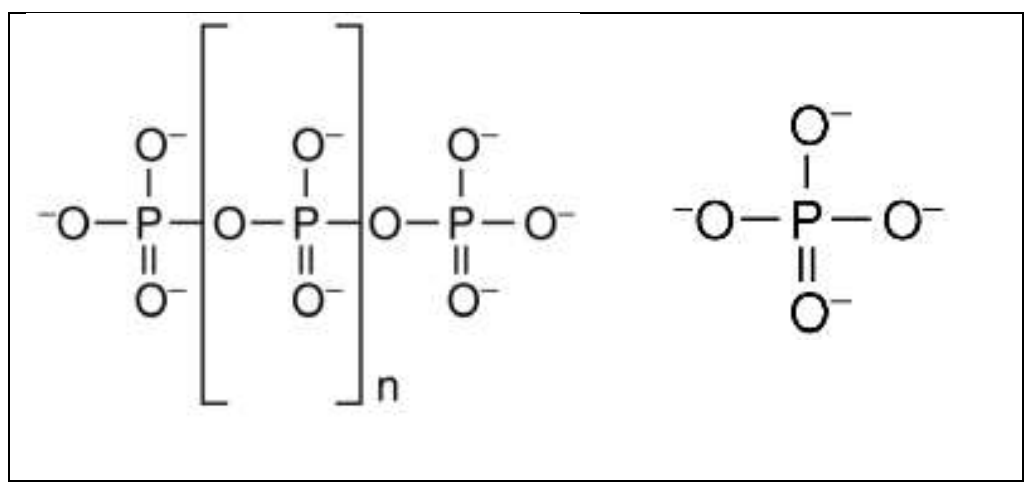

Figure 2-3: Polyphosphate (left) versus orthophosphate (right), from (McGrath \& Quinn, 2003).

There are a wide variety of methods to remove phosphorus from wastewater. However, most treatment facilities use chemical precipitation, biological phosphorus removal or a combination of the two (Yang, Li, Zhang, Qian, \& Chen, 2010).

Chemical precipitation is the most common method to remove phosphorus from wastewater in Canada, and is a well understood and reliable technology. Generally, aluminum sulphate (alum), ferric chloride and ferrous chloride are used (Jeganathan, 2011). Alternatively, a variety of iron, aluminum, calcium and magnesium compounds have been shown to remove phosphorus from wastewater, as shown in Table 2-1 (de-Bashan \& Bashan, 2004) (Argaman, et al., 1991). Any of the listed compounds can be added to wastewater containing soluble phosphorus. As a result, the added chemical will precipitate phosphorus, which then can be physically separated from the liquid.

Table 2-1: Useful compounds for phosphorus precipitation

\section{Iron Compounds Aluminum Compounds}

- Ferric Chloride

- Ferric Sulphate

- Ferrous Chloride

- Ferrous Sulphate

- Ferrous Hydroxide

- Iron/Calcium Oxides

- Blast Furnace Slag
- Aluminum Sulphate

- Aluminum Hydroxide

- Activated Alumina

- Sodium Aluminate
- Aluminum Oxide
Calcium Compounds

- Calcium Silicate Hydrate

- Limestone

- Calcite
Magnesium Compounds

- Magnesium Hydroxide

- Hydrotalcite 
Chemical phosphorus removal generates large volumes of sludge, thereby increasing treatment costs. It is estimated that $35 \%$ more sludge (by volume) is produced when using chemicals for the precipitation of phosphorus (Argaman, et al., 1991). Although chemical phosphorus removal is convenient, added costs for regular chemical addition, sludge processing and solids separation could make treatment costs unnecessarily high. Alternatively, biological phosphorus removal is an attractive option.

Biological phosphorus removal operates by exploiting phosphorus accumulating organisms (PAOs), which can be manipulated to store phosphorus. By alternating aerobic/anoxic zones with anaerobic zones, PAOs store phosphorus, which can then be physically separated from wastewater streams.

In the anaerobic phase, PAOs consume volatile fatty acids (VFAs), usually acetic acid, and generate energy through the consumption of glycogen and hydrolysis of polyphosphate into orthophosphate, as shown in equation 5 and Figure 2-4 (Junfeng, Guyuan, \& Xiang, 2007). The consumed organic matter is stored in the PAO as poly- $\beta$-hydroxybutyrate (PHB), and the orthophosphate is released to the surroundings.

$\left(\mathrm{CH}_{3} \mathrm{COOH}\right)_{1 / 2}+0.5\left(\mathrm{C}_{5} \mathrm{H}_{10} \mathrm{O}_{5}\right)_{1 / 6}+0.48 \mathrm{HPO}_{3}+0.023 \mathrm{H}_{2} \mathrm{O} \rightarrow 1.33\left(\mathrm{C}_{4} \mathrm{H}_{6} \mathrm{O}_{2}\right)_{1 / 4}+0.48 \mathrm{H}_{3} \mathrm{PO}_{4}+0.17 \mathrm{CO}_{2} \quad$ Equation 5 Acetic Acid Glycogen Polyphosphate PHB Orthophosphate

In the aerobic/anoxic phase, PHB accumulated in the PAOs is oxidized for the growth of the biomass, phosphate uptake, and polyphosphate accumulation. As the total quantity of biomass increases with reproduction of PAOs, net phosphorus removal will occur (Oehmen, et al., 2007). This process is shown in Figure 2-4. As a result of this accumulation, PAOs can have an approximate dry weight consisting of $35 \%$ phosphorus. This is compared to a standard wastewater biomass of $2 \%$ phosphorus (WEF, 2007). 


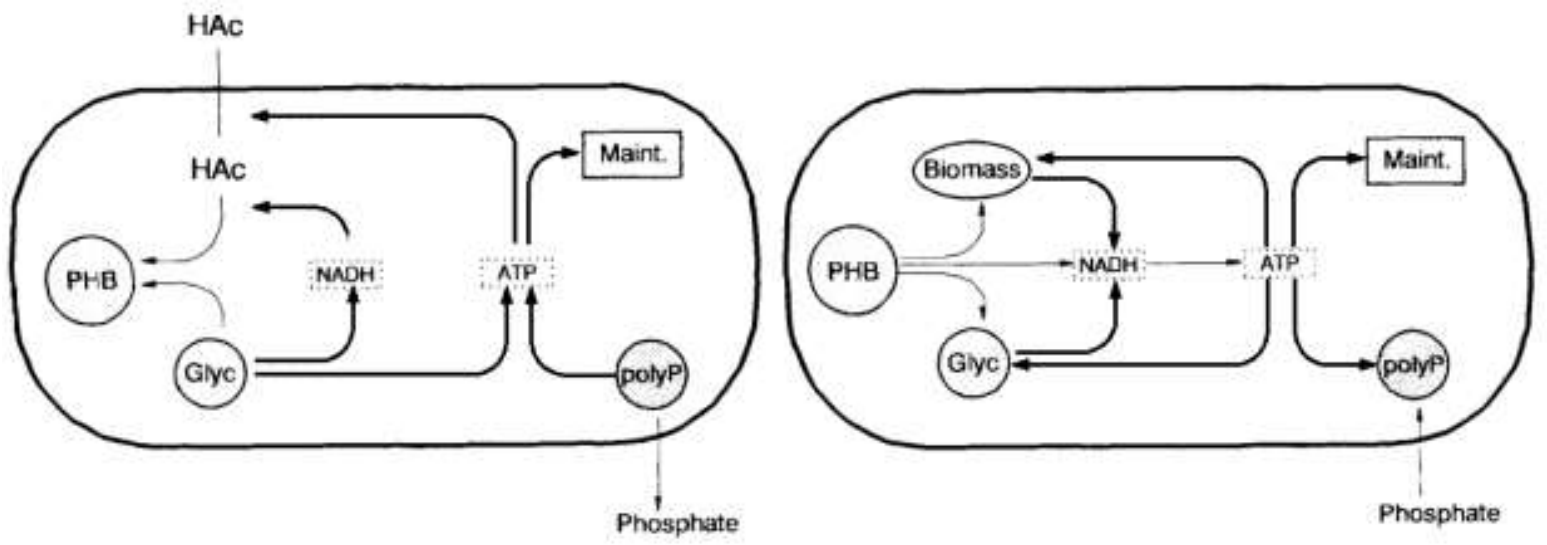

Figure 2-4: Operation of phosphorus accumulating organisms. Anaerobic on left, aerobic/anoxic on right. From (Smolders, van der Meij, van Loosdrecht, \& Heijnen, 1995)

Once phosphorus has been collected in PAOs, the phosphorus rich sludge must be removed from the liquid wastewater. Generally, wastewater sludge is stabilized in anaerobic digestion, where the biomass is broken down into smaller molecules. In this reaction, a large portion of the accumulated polyphosphates re-enter the liquid phase (Marti, Bouzas, Seco, \& Ferrer, 2008). The liquid effluent leaving the anaerobic digester then re-enters the main process. To ensure phosphorus removal meets the required effluent standards, this additional source of phosphorus must be considered, in addition to the phosphorus which enters with the incoming wastewater.

Alternative methods for phosphorus removal have been investigated which utilize a variety novel techniques. One group of methods use adsorbents to physically remove contaminants from wastewater. Phosphorus clings to the surface of these adsorbents, which can then be filtered out of water. Researchers have studied the effectiveness of materials such as activated carbon, industrial waste products, natural and modified clays, soil and minerals (Park \& Jung, 2011). Most adsorbents have been successful in their removal of contaminants such as phosphorus. However, as is the case with any phosphorus removal technology, their wide spread use is dependent on the treatment cost.

One final method of phosphorus removal is the physical recovery of phosphorus-containing minerals from wastewater. This material, known as struvite, is formed from the precipitation of magnesium, ammonium and phosphate, as shown in equation 5 (Yilmazel \& Demirer, 2013). 
Through the addition of magnesium hydroxide, phosphorus and ammonia can be removed from wastewater. In a specialized reactor, and under proper operating conditions, solid struvite (phosphate of ammonium and magnesium) can be recovered. This material can then be sold as a fertilizer.

$$
\mathrm{Mg}^{2+}+\mathrm{NH}_{4}^{+}+\mathrm{PO}_{4}^{3-}+6 \mathrm{H}_{2} \mathrm{O} \rightarrow \mathrm{MgNH}_{4} \mathrm{PO}_{4} \cdot 6 \mathrm{H}_{2} \mathrm{O} \quad \text { Equation } 6
$$

When compared to application of biosolids to farmland, struvite carries a substantially reduced risk of contamination. Struvite does not contain significant concentrations of heavy metals or pathogens (E. Coli, faecal coliforms etc.). Further, the solid particles dissolve slowly, reducing the heavy loading of nitrogen and phosphorus on farmland (Gell, Ruijter, Kuntke, Graaf, \& Smit, 2011). This in turn reduces the possibility of improper drainage causing eutrophication in bodies of water. As struvite can be sold as a byproduct of the wastewater treatment process (approximately \$225 USD per ton), recovering phosphorus may become a more attractive alternative to chemical or biological removal (Ueno \& Fujii, 2001).

\subsection{Biological Oxygen Demand and E. Coli}

Biological treatment of wastewater produces a highly diverse population of microorganisms. As shown in previous sections, multiple bacteria and archaea can be utilized for the removal of nitrogen and phosphorus. All bacteria consume carbon in some form, whether it be soluble or insoluble components in wastewater or $\mathrm{CO}_{2}$. Most wastewater treatment facilities require the removal of carbon in wastewater (commonly measured as $\mathrm{BOD}_{5}$, or chemical oxygen demand COD) beyond what is consumed by AOBs, NOBs, or denitrifying bacteria. To remove the majority of COD, a variety of bacteria will reproduce in the wastewater treatment system.

Populations of COD removing bacteria are highly diverse. Some studies have identified over 3,500 unique species operating in a lab-scale reactor removing COD and ammonia (Satoh, et al., 2013). These microorganisms consume the carbon, nitrogen and oxygen supplied to the reactor to reproduce, creating more biological material (biomass). Wastewater treatment plants often refer to this biomass as sludge. A potential reaction for the aerobic removal of carbon and ammonia is shown in equation 7 , and results in the creation of more biomass (average 
composition $\mathrm{C}_{5} \mathrm{H}_{7} \mathrm{NO}_{2}$ ). Note that the compound $\mathrm{C}_{18} \mathrm{H}_{19} \mathrm{O}_{9} \mathrm{~N}$ is used as an approximate chemical composition for organic matter in wastewater (Henze, Harremoes, Arvin, \& Jansen, 2002).

$$
\mathrm{C}_{18} \mathrm{H}_{19} \mathrm{O}_{9} \mathrm{~N}+0.74 \mathrm{NH}_{3}+8.8 \mathrm{O}_{2} \rightarrow 1.74 \mathrm{C}_{5} \mathrm{H}_{7} \mathrm{NO}_{2}+9.3 \mathrm{CO}_{2}+4.52 \mathrm{H}_{2} \mathrm{O} \quad \text { Equation } 7
$$

Similarly, nitrate can be used for the reproduction of biological materials, as shown in Equation 8. Note that this reaction uses nitrate as the electron acceptor, and does not occur if oxygen is present in the system.

$$
0.57 \mathrm{C}_{18} \mathrm{H}_{19} \mathrm{O}_{9} \mathrm{~N}+3.73 \mathrm{NO}_{3}^{-}+3.73 \mathrm{H}^{+} \rightarrow \mathrm{C}_{5} \mathrm{H}_{7} \mathrm{NO}_{2}+5.26 \mathrm{CO}_{2}+1.65 \mathrm{~N}_{2}+3.80 \mathrm{H}_{2} \mathrm{O} \quad \text { Equation } 8
$$

In addition to the simultaneous removal of COD and nitrogen compounds, the removal of suspended organic compounds without ammonia or nitrate may be necessary. This is performed as in equation 9. However, in this case, the biological material is broken down into more easily degradable components. The breaking down and decay of biological material, or the lysis reaction, occurs at a much slower rate than the bacterial growth. Typically, the rate constant for growth is over ten times greater than the decay constant. The lysis reaction is shown in equation 9 (Henze, Harremoes, Arvin, \& Jansen, 2002).

$$
\mathrm{C}_{18} \mathrm{H}_{19} \mathrm{O}_{9} \mathrm{~N}+17.5 \mathrm{O}_{2}+\mathrm{H}^{+} \rightarrow 18 \mathrm{CO}_{2}+8 \mathrm{H}_{2} \mathrm{O}+\mathrm{NH}_{4}^{+} \quad \text { Equation } 9
$$

Because of the slower reaction rate of the lysis reaction, some treatment processes add supplementary ammonia to reduce the treatment time. This is observed in brewing and pulp and paper processes, where high COD and low ammonia concentrations are expected (Davies, 2005).

To remove COD that exists as insoluble biological material, the biomass must be separated from the effluent wastewater. This is generally performed in settling or sedimentation tanks, where the biomass is allowed to settle to the bottom of the tank. A portion of the biomass is returned to the main reactor to ensure the process has sufficient biological material to continuously operate (return activated sludge). Usually, the remaining sludge (waste activated sludge) is sent for anaerobic digestion, where the biomass is broken down in a slowly occurring process 
(generally lasting 30 days). Anaerobic digestion allows a large variety of reactions to facilitate the breaking down of larger biological molecules. A simplified version of this process is shown below (Henze, Harremoes, Arvin, \& Jansen, 2002).

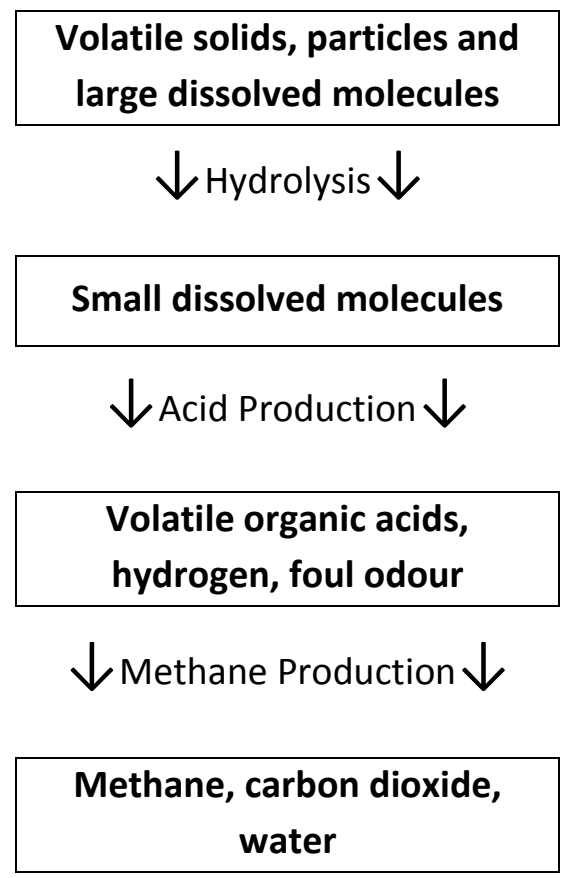

Anaerobic digestion consumes the biological material, and produces methane, carbon dioxide and ammonia. After digestion, the liquid and solid effluents are separated. The liquid effluent is re-introduced into the treatment process. The remaining solids can be disposed of in landfills, incinerators, or via land application to farms. The methane produced in the anaerobic digester can be used to heat the anaerobic digester, to produce energy, or flared off to prevent escape to the atmosphere (Tchobanoglous, Burton, \& Stensel, 2002). A generalized picture of a wastewater treatment process is shown in Figure 2-5, with anaerobic digestion treating the solids removed from the primary and secondary clarifiers. 


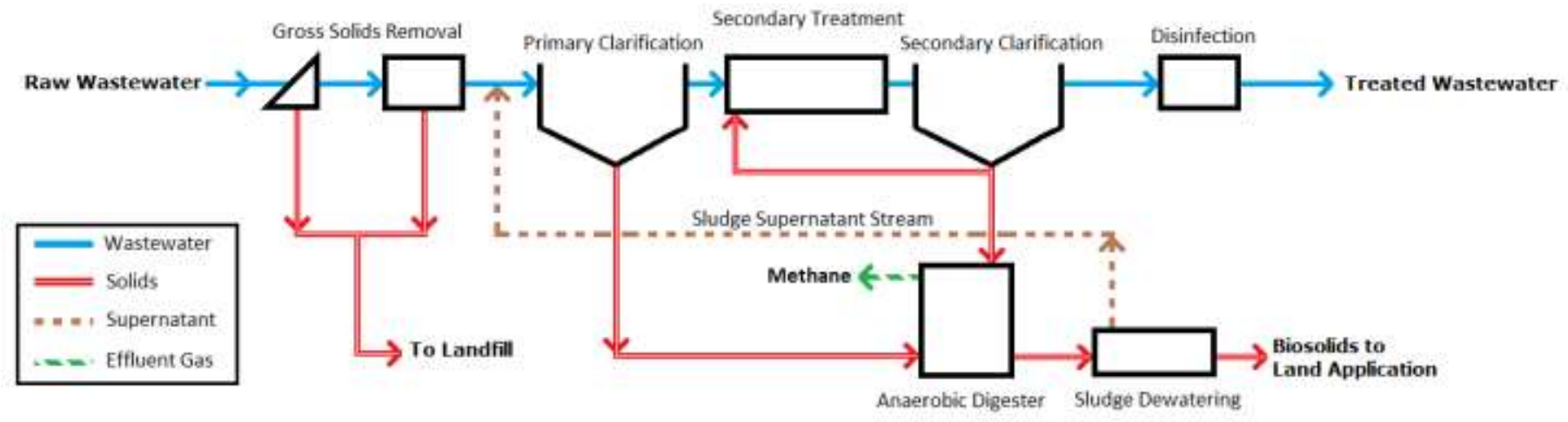

Figure 2-5: Generalized municipal wastewater treatment process

In Ontario, approximately 300,000 tons of dry biosolids are produced per year, where $40 \%$ is sent to landfills, $20 \%$ is incinerated, and $40 \%$ is used for land application to farmland. Land application as fertilizer has very specific requirements to ensure it is done in a safe and environmentally friendly manner (CIELAP, 2009). The Environmental Protection Act, 1990, and the Nutrient Management Act, 2002, regulate the use of biosolids, and must be considered (Province of Ontario, 2002). Improper application of wastewater biosolids can result in significant concentrations of pathogens, heavy metals and other pathogens in agricultural products. Furthermore, improper drainage of farmlands can re-introduce this nutrient-rich sludge back into the environment. Internationally, many progressive countries (Switzerland, Sweden, The Netherlands) have discontinued or banned the practice of land application of sludge for this reason (Oleszkiewicz \& Barnard, 2006).

In addition to the removal of COD and ammonia from wastewater, some treatment plants must also reduce the bacterial (e.g. E. Coli, faecal coliform, faecal streptococci) population in effluent wastewaters. This is done through the disinfection process, which occurs after the settling and removal of biosolids from liquid wastewater. Disinfection is the process by which active bacterial populations are reduced through the application of chemicals or other processes. 
Liquid chlorine addition is the most common method of disinfection in North America, although ultraviolet light, ozone, peracetic acid or sodium hypochlorite are possible alternatives (Tchobanoglous, Burton, \& Stensel, 2002). The ideal method of disinfection will depend on the wastewater conditions, specifically total suspended solids concentration. However, the chosen method must provide sufficient removal performance to ensure effluent limits are met.

\subsection{Comparison of Operating Conditions}

The various bacteria which operate in a wastewater treatment plant all have different ideal operating conditions. In order to maximize the efficiency of a process, or prevent specific bacteria from occurring in a plant, the specific operating conditions of each bacteria need to be considered. The ideal conditions for many common bacteria are shown in Table 2-2.

Table 2-2: Comparison of operating conditions

\begin{tabular}{|c|c|c|c|c|}
\hline & $\begin{array}{c}\text { DO } \\
\text { Requirements }\end{array}$ & $\begin{array}{c}\text { Optimum } \\
\text { pH }\end{array}$ & $\begin{array}{l}\text { Optimum } \\
\text { Temperature }\end{array}$ & Alkalinity Change \\
\hline $\begin{array}{l}\text { Aerobic Ammonium } \\
\text { Oxidation } \\
\text { (Partial Oxidation) }\end{array}$ & $<1.0 \mathrm{mg} / \mathrm{L}^{[1]}$ & $8.1^{[2]}$ & $35 \mathrm{C}^{[2]}$ & $\begin{array}{c}7.14 \mathrm{mg} \mathrm{CaCO}_{3} \text { removed } \\
\text { per mg } \mathrm{N} \text { oxidised }\end{array}$ \\
\hline $\begin{array}{c}\text { Aerobic Nitrite } \\
\text { Oxidation } \\
\text { (Complete Oxidation) }\end{array}$ & $>0.5 \mathrm{mg} / \mathrm{L}^{[1]}$ & $7.9^{[2]}$ & $38 C^{[2]}$ & No Change \\
\hline $\begin{array}{c}\text { Anaerobic } \\
\text { Nitrite/Nitrate } \\
\text { Reduction }\end{array}$ & $<0.2 \mathrm{mg} / \mathrm{L}^{[4]}$ & $7.5^{[1]}$ & $35 \mathrm{C}^{[2]}$ & $\begin{array}{c}3.57 \mathrm{mg} \mathrm{CaCO} 3 \text { produced } \\
\text { per mg N reduced }\end{array}$ \\
\hline $\begin{array}{c}\text { Anaerobic } \\
\text { Ammonium/Nitrite } \\
\text { Oxidation }\end{array}$ & $<0.2 \mathrm{mg} / \mathrm{L}^{[6]}$ & $8.0^{[5]}$ & $35 C^{[5]}$ & $\begin{array}{c}3.57 \mathrm{mg} \mathrm{CaCO} 3 \text { produced } \\
\text { per } \mathrm{mg} \mathrm{N} \text { reduced }^{[3]}\end{array}$ \\
\hline References: & \multicolumn{4}{|c|}{$\begin{array}{l}{ }^{1} \text { (Canto, Ratusznei, Rodrigues, Zaiat, \& Foresti, 2012) } \\
2 \text { (Grunditz \& Dalhammar, 2000) } \\
{ }^{3} \text { (WEF, 2007) } \\
{ }^{4} \text { (Tchobanoglous, Burton, \& Stensel, 2002) } \\
{ }^{5} \text { (Jin, Yang, Yu, \& Zheng, 2012) } \\
{ }^{6} \text { (Wett, et al., 2010) }\end{array}$} \\
\hline
\end{tabular}




\subsection{Reaction Kinetics and Process Modeling}

Many attempts have been made to approximate the numerous reactions occurring in wastewater treatment plants. Due to the variety of bacteria in wastewater, alongside variations in chemical and physical behaviour, successful modeling is a challenging task. However, standardized mathematical models have been developed which can be used to investigate the rate of change of various components in the wastewater system (ammonia, phosphorus, organic matter etc.). These models are known as the Activated Sludge Models (ASM), and have been in use since 1987 (US EPA, 1993). The models take a similar form as the Monod equation, as shown below. In this case $\mu$ is the specific growth rate of the microorganism, $\mu_{\text {MAX }}$ is the maximum specific growth rate, $\mathrm{S}$ is the substrate concentration (i.e. ammonia, nitrate, nitrate, carbon, etc.), and $\mathrm{K}$ is the half-saturation coefficient (Substrate concentration when $\left.\mu / \mu_{\mathrm{MAX}}=0.5\right)$.

$$
\mu=\mu_{\max }\left(\frac{S}{K+S}\right)
$$

The Monod equation is frequently used in the investigation of microbial systems, as it provides a good prediction for microbial growth rates. An example for the growth rate of E. Coli bacteria consuming a single essential nutrient (Glucose) is shown below, with the solid line representing the Monod prediction. In this case, the maximum growth rate was 1.35 hour $^{-1}$ and the halfsaturation coefficient was $2.22 \times 10^{-4} \mathrm{M}$ (Monod, 1949).

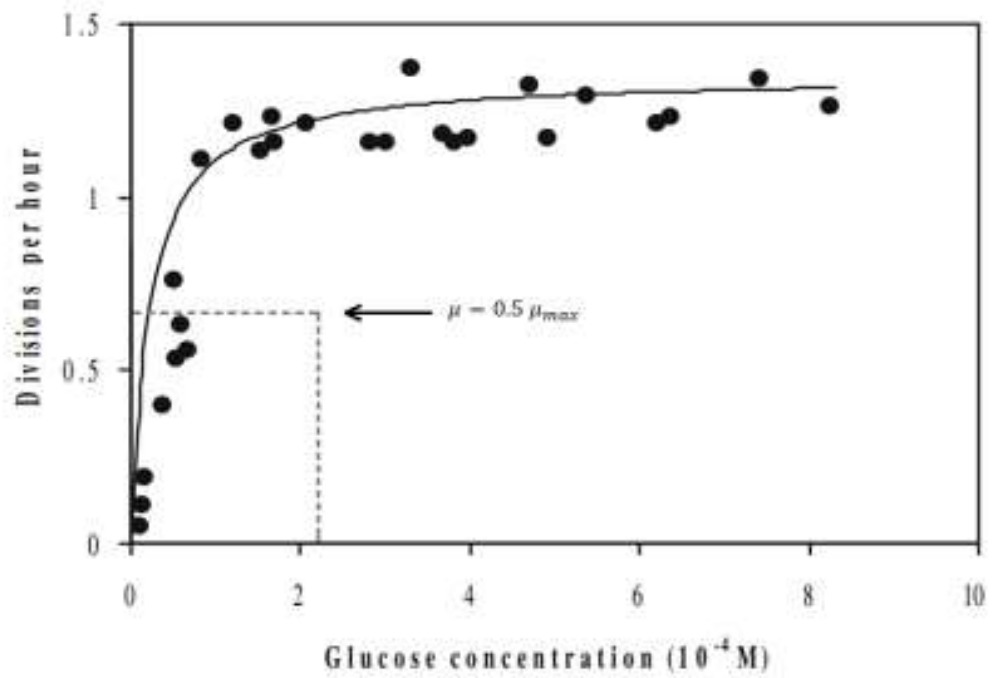

Figure 2-6: Experimental growth rate of E.Coli on Glucose, with Monod predictions (solid line). From (Liu Y., 2007). 
The model provides a reasonable approximation to measured data. However, when performing theoretical predictions or sizing calculations, prior experimentation is necessary to determine the maximum growth rate and half-saturation coefficients. With simple microbial processes with one essential nutrient, such as the growth of E.Coli on glucose shown in Figure 2-6, determination of the experimental constants is not exceptionally difficult. However, as the number of simultaneous processes and nutrients increase, the accurate determination of all coefficients becomes challenging. When considering a wastewater treatment process, many bacteria and nutrients change simultaneously, requiring many experimental coefficients.

The first activated sludge model, known as ASM1 investigated the growth, decay and hydrolysis of aerobic, anoxic, autotrophic and heterotrophic bacteria, with focus on nitrification and denitrification. This model provided a common notation which allowed for easy modification and expansion, known as the stoichiometric matrix. ASM1 investigated the fate of 13 different components through 8 different processes (Henze, Grady, Gujer, Marais, \& Matsuo, 2000). This process is shown below in the stoichiometric matrix format (Table 2-3). This format has been adopted in order to clearly identify the multiple components, and processes. The rate of change for each of the 13 components can be calculated with the following formula:

$$
r_{i}=\sum_{j} v_{i j} \rho_{j}
$$

Note that the $v_{i j}$ term represents the stoichiometric coefficient of component $i$ going through process $j$, and the $\rho_{j}$ term represents the rate of process $j$. The $r_{i}$ term is the rate of change of component $i$. For example, the rate of change of oxygen (component 8) can be described by applying the above formula to the stoichiometric matrix shown in Table 2-3:

$$
\frac{d S_{o}}{d t}=-\left(\frac{1-Y_{H}}{Y_{H}}\right) \hat{\mu}_{H}\left(\frac{S_{S}}{K_{S}+S_{S}}\right)\left(\frac{S_{O}}{K_{O, H}+S_{O}}\right) X_{B, H}-\left(\frac{4.57-Y_{A}}{Y_{A}}\right) \hat{\mu}_{A}\left(\frac{S_{N H}}{K_{N H}+S_{N H}}\right)\left(\frac{S_{O}}{K_{O, A}+S_{O}}\right) X_{B, A}
$$


Table 2-3: Activated Sludge Model 1 (ASM1)

\begin{tabular}{|c|c|c|c|c|c|c|c|c|c|c|c|c|c|c|c|}
\hline & Component & & & & & & & & & & & & & & \\
\hline & $\rightarrow 1$ & 1 & 2 & 3 & 4 & 5 & 6 & 7 & 8 & 9 & 10 & 11 & 12 & 13 & \\
\hline $\begin{array}{r}\text { Process } \\
\downarrow J\end{array}$ & & $\mathrm{~S}_{1}$ & $\mathrm{~S}_{\mathrm{s}}$ & $x_{1}$ & $x_{s}$ & $X_{B, H}$ & $X_{B, A}$ & $x_{p}$ & $\mathrm{~S}_{0}$ & $\mathrm{~S}_{\mathrm{NO}}$ & $\mathrm{S}_{\mathrm{NH}}$ & $\mathrm{S}_{\mathrm{ND}}$ & $\mathrm{x}_{\mathrm{ND}}$ & $\mathrm{S}_{\text {ALK }}$ & Process Rate, $\rho_{\mathrm{j}}$ \\
\hline 1 & $\begin{array}{l}\text { Aerobic growth } \\
\text { of heterotrophs }\end{array}$ & & $-\frac{1}{Y_{H}}$ & & & 1 & & & $-\frac{1-Y_{H}}{Y_{H}}$ & & $-i_{X B}$ & & & $-\frac{i_{X B}}{14}$ & $\hat{\mu}_{H}\left(\frac{S_{S}}{K_{S}+S_{S}}\right)\left(\frac{s_{O}}{K_{O, H}+S_{O}}\right) X_{B, H}$ \\
\hline 2 & $\begin{array}{l}\text { Anoxic growth } \\
\text { of heterotrophs }\end{array}$ & & $-\frac{1}{Y_{H}}$ & & & 1 & & & & $-\frac{1-Y_{H}}{2.88 Y_{H}}$ & $-i_{X B}$ & & & $\frac{1-Y_{H}}{14 \cdot 2.86 Y_{H}}$ & $\hat{\mu}_{H}\left(\frac{S_{S}}{K_{S}+S_{S}}\right)\left(\frac{K_{O, H}}{K_{O, H}+S_{O}}\right)\left(\frac{S_{N O}}{K_{N O}+S_{N O}}\right) \mathrm{\eta}_{g} X_{B, H}$ \\
\hline 3 & $\begin{array}{l}\text { Aerobic growth } \\
\text { of autotrophs }\end{array}$ & & & & & & 1 & & $\frac{4.57-Y_{A}}{Y_{A}}$ & $\frac{1}{Y_{A}}$ & $-i_{X B}-\frac{1}{Y_{A}}$ & & & $-\frac{i_{X B}}{14}$ & $\hat{\mu}_{A}\left(\frac{s_{N H}}{K_{N H}+S_{N H}}\right)\left(\frac{s_{O}}{K_{O, A}+S_{O}}\right) X_{B, A}$ \\
\hline 4 & $\begin{array}{c}\text { Decay of } \\
\text { heterotrophs }\end{array}$ & & & & $1-f_{p}$ & -1 & & $f_{p}$ & & & & & $i_{X B}-f_{p} i_{X P}$ & $-\frac{i_{X B}}{14}-\frac{1}{7 Y_{A}}$ & $b_{h} X_{B, H}$ \\
\hline 5 & $\begin{array}{l}\text { Decay of } \\
\text { autotrophs }\end{array}$ & & & & $1-f_{p}$ & & -1 & $f_{p}$ & & & & & $i_{X B}-f_{p} i_{X P}$ & & $b_{A} X_{B, A}$ \\
\hline 6 & $\begin{array}{c}\text { Ammonification } \\
\text { of soluble } \\
\text { organic nitrogen }\end{array}$ & & & & & & & & & & 1 & -1 & & $\frac{1}{14}$ & $k_{a} S_{N D} X_{B, H}$ \\
\hline 7 & $\begin{array}{l}\text { Hydrolysis of } \\
\text { entrapped } \\
\text { organics }\end{array}$ & & 1 & & -1 & & & & & & & & & & $\begin{array}{l}k_{h}\left(\frac{X_{S} / X_{B, H}}{K_{X}+\left(X_{S} / X_{B, H}\right)}\right)\left[\left(\frac{S_{O}}{K_{O, H}+S_{O}}\right)+\right. \\
\left.\eta_{h}\left(\frac{K_{O, H}}{K_{O, H}+S_{O}}\right)\left(\frac{S_{N O}}{K_{N O}+S_{N O}}\right)\right] X_{B, H}\end{array}$ \\
\hline 8 & $\begin{array}{l}\text { Hydrolysis of } \\
\text { entrapped } \\
\text { organic nitrogen }\end{array}$ & & & & & & & & & & & 1 & & & $\rho_{T}\left(\frac{X_{N D}}{X_{S}}\right)$ \\
\hline
\end{tabular}




\begin{tabular}{|c|l|c|}
\hline \multicolumn{1}{|c}{ Component } & \multicolumn{1}{c|}{ Description } & Units \\
\hline $\mathbf{S}_{\mathbf{I}}$ & Soluble Inert Organic Matter & $\mathrm{mg} \mathrm{COD} / \mathrm{L}$ \\
\hline $\mathbf{S}_{\mathbf{S}}$ & Readily Biodegradable Organic Matter & $\mathrm{mg} \mathrm{COD/L}$ \\
\hline $\mathbf{X}_{\mathbf{I}}$ & Particulate Inert Organic Matter & $\mathrm{mg} \mathrm{COD/L}$ \\
\hline $\mathbf{X}_{\mathbf{S}}$ & Slowly Biodegradable Substrate & $\mathrm{mg} \mathrm{COD/L}$ \\
\hline $\mathbf{X}_{\mathbf{B}, \mathbf{H}}$ & Active Heterotrophic Biomass & $\mathrm{mg} \mathrm{COD/L}$ \\
\hline $\mathbf{X}_{\mathbf{B}, \mathbf{A}}$ & Active Autotrophic Biomass & $\mathrm{mg} \mathrm{COD/L}$ \\
\hline $\mathbf{X}_{\mathbf{P}}$ & Particulate Products Arising from Biomass Decay & $\mathrm{mg} \mathrm{COD/L}$ \\
\hline $\mathbf{S}_{\mathbf{O}}$ & Oxygen (negative COD) & $\mathrm{mg} \mathrm{COD/L}$ \\
\hline $\mathbf{S}_{\mathbf{N O}}$ & Nitrate and Nitrite Nitrogen & $\mathrm{mg} \mathrm{COD/L}$ \\
\hline $\mathbf{S}_{\mathbf{N H}}$ & Ammonia and Ammonium Nitrogen & $\mathrm{mg} \mathrm{COD/L}$ \\
\hline $\mathbf{S}_{\mathbf{N D}}$ & Soluble Biodegradable Organic Nitrogen & $\mathrm{mg} \mathrm{COD/L}$ \\
\hline $\mathbf{X}_{\mathbf{N D}}$ & Particulate Biodegradable Organic Nitrogen & $\mathrm{mg} \mathrm{COD/L}$ \\
\hline $\mathbf{S}_{\mathbf{A L K}}$ & Alkalinity & $\mathrm{mol} / \mathrm{L}$ \\
\hline
\end{tabular}

Table 2-5: ASM1 Kinetic Parameters (Henze, Grady, Gujer, Marais, \& Matsuo, 2000), (US EPA, 1993)

\begin{tabular}{|c|c|c|c|}
\hline Parameter & Description & $\begin{array}{l}\text { Typical Value } \\
\text { at } 20^{\circ} \mathrm{C}\end{array}$ & Units \\
\hline $\mathbf{Y}_{\mathrm{H}}$ & Yield of Heterotrophic Biomass & 0.67 & g COD/g N \\
\hline $\mathbf{Y}_{\mathbf{A}}$ & Yield of Autotrophic Biomass & 0.24 & g COD/g COD \\
\hline $\mathrm{K}_{\mathrm{NH}}$ & $\begin{array}{l}\text { Ammonia Half-Saturation Coefficient for Autotrophic } \\
\text { Biomass }\end{array}$ & 1.0 & $\mathrm{~g} \mathrm{~N} / \mathrm{m}^{3}$ \\
\hline $\mathrm{K}_{\mathrm{NO}}$ & $\begin{array}{l}\text { Nitrite/Nitrate Half-Saturation Coefficient for Heterotrophic } \\
\text { Biomass }\end{array}$ & 0.5 & $\mathrm{~g} \mathrm{~N} / \mathrm{m}^{3}$ \\
\hline $\mathrm{K}_{\mathrm{O}, \mathrm{H}}$ & $\begin{array}{l}\text { Oxygen Half-Saturation Coefficient for Heterotrophic } \\
\text { Biomass }\end{array}$ & 0.2 & $\mathrm{~g} \mathrm{O}^{2} / \mathrm{m}^{3}$ \\
\hline$K_{0, A}$ & Oxygen Half-Saturation Coefficient for Autotrophic Biomass & 0.4 & $\mathrm{~g} \mathrm{O}^{2} / \mathrm{m}^{3}$ \\
\hline $\mathbf{K}_{\mathbf{x}}$ & $\begin{array}{l}\text { Half-Saturation Coefficient for Hydrolysis of Slowly } \\
\text { Biodegradable Substrate }\end{array}$ & 0.03 & g COD/g COD \\
\hline $\mathbf{K}_{\mathrm{s}}$ & Half-Saturation Coefficient for Heterotrophic Biomass & 20.0 & g COD/g COD \\
\hline$b_{A}$ & Decay Coefficient for Autotrophic Biomass & 0.05 & day $^{-1}$ \\
\hline $\mathbf{b}_{\mathrm{H}}$ & Decay Coefficient for Heterotrophic Biomass & 0.62 & day $^{-1}$ \\
\hline$\widehat{\mu}_{A}$ & Maximum Specific Growth Rate of Autotrophic Biomass & 0.45 & day $^{-1}$ \\
\hline$\widehat{\mu}_{H}$ & Maximum Specific Growth Rate of Heterotrophic Biomass & 6.0 & day $^{-1}$ \\
\hline$\eta_{h}$ & Correction Factor for Hydrolysis under Anoxic Conditions & 0.4 & dimensionless \\
\hline$\eta_{g}$ & Correction Factor for $\hat{\mu}_{H}$ under Anoxic Conditions & 0.8 & dimensionless \\
\hline $\boldsymbol{k}_{h}$ & Maximum Specific Hydrolysis Rate & 3.0 & g COD/g COD॰day \\
\hline $\boldsymbol{k}_{\boldsymbol{a}}$ & Ammonification Rate & 0.08 & $\mathrm{~m}^{3} /(\mathrm{g} \mathrm{COD} / \mathrm{d})$ \\
\hline$i_{X B}$ & Mass of Nitrogen per Mass of COD in Biomass & 0.086 & g N/g COD \\
\hline$i_{X P}$ & Mass of Nitrogen per Mass of COD in Products from Biomass & 0.06 & g N/g COD \\
\hline$f_{p}$ & Fraction of Biomass Leading to Particulate Products & 0.08 & dimensionless \\
\hline
\end{tabular}


Table 2-5 shows that ASM1 requires a variety of coefficients, many of which must be measured in an operational wastewater treatment plant. Generally, the model must be calibrated for the accurate use in any specific wastewater treatment plant. In most cases, only minor modifications are made to the maximum growth rates and decay coefficients (US EPA, 1993). A brief description of the physical meaning of each parameter is given below:

\section{Yield Coefficients, $Y_{H} Y_{A}$}

The yield coefficients describe the mass of biological material created per mass of substrate consumed.

\section{Maximum Specific Growth Rate, $\mu_{H} \mu_{A}$}

The maximum specific growth rate is the maximum observed growth rate of the microorganism. The general growth rate of any bacteria can be expressed as the ratio of the amount of bacteria grown per day and the amount of bacteria present.

\section{Half Saturation Coefficients, $\mathrm{K}_{\mathrm{NH}} \mathrm{K}_{\mathrm{NO}} \mathrm{K}_{\mathrm{O}, \mathrm{H}} \mathrm{K}_{\mathrm{O}, \mathrm{A}} \mathrm{K}_{\mathrm{X}} \mathrm{K}_{\mathrm{s}}$}

The half saturation coefficients represent the substrate concentration when the specific growth rate of the microorganism is equal to half the maximum specific growth rate.

\section{Decay Coefficient, $b_{A} b_{H}$}

The decay coefficient describes the rate at which endogenous respiration occurs (the rate at which biomass oxidizes its own mass, instead of external substrate)

\section{Correction Factors, $\eta_{\mathrm{h}} \eta_{\mathrm{g}}$}

The correction factors account for the portion of bacteria which grow or decay under anoxic conditions versus aerobic conditions (growth occurs only when nitrate and/or DO is present).

\section{Stoichiometric Factors, $\mathrm{i}_{\mathrm{XB}} \mathrm{i}_{\mathrm{XP}} f_{\mathrm{P}}$}

These stoichiometric factors describe the fraction of various compounds in biomass or the products of biomass decay.

\section{Ammonification Rate, $k_{a}$}

The ammonification rate describes the maximum observed rate at which the soluble organic nitrogen converts into ammonia. 


\section{Maximum Specific Hydrolysis Rate, $\mathbf{k}_{\mathbf{h}}$}

The maximum specific hydrolysis rate describes the maximum rate at which the slowly biodegradable substrate is converted into readily biodegradable substrate.

To determine the value of each of the listed parameters, it is necessary to conduct various labscale tests. The specific procedures are readily available, and can be conducted if the equipment is provided. In the case of the ASM1, all kinetic parameters can be verified in less than one month. However, as the models become more complicated, verifying the parameters becomes more time consuming and expensive. Although these models may be more accurate, they can have a large number of constraints. In most cases, complicated models are not necessary. The typical application of ASM1 in municipal treatment plants is for the estimation of oxygen consumption, and does not require extremely detailed modeling (US EPA, 1993). If more detailed modeling can be justified, expansions to the first ASM1 can be investigated.

An expansion to the original ASM1, known as ASM2 added additional components and processes, which allowed for the modeling of chemical and biological phosphorus removal alongside nitrogen removal. ASM2 investigated 19 different components and 19 processes (Gujer, et al., 1994). Two additional processes were added to the ASM2d version of the activated sludge model, bringing the total number of processes to 21 . These additional processes were added to better model the biological phosphorus behaviour (Henze, et al., 1999). Similarly, ASM3 added consideration for the oxygen consumption in a wastewater system (Gujer, Henz, Mino, \& van Loosdrecht, 2000). It is similar to ASM1, but considers a different process for the behavior of nitrifiers and heterotrophs.

Due to the standardization of the ASM series of models, researchers can add, remove and modify coefficients to further develop the model for specific purposes. The addition of the anammox process to the stoichiometric matrix will be given in section 5.2 of this report. The revised ASM1 model will be used to support results obtained during experimentation. 


\subsection{Processes to Remove Undesired Compounds}

There are a variety of methods to remove deleterious substances from wastewater. Depending on what needs to be removed, specific bacterial populations will be targeted in the different sections of a reactor. When looking at the removal of nitrogen, phosphorus, or carbon containing compounds, a combination of the bacteria and archaea discussed in section 2 will be utilized. However, as each treatment process has different operating conditions and reaction rates, an appropriate reactor configuration must be designed.

Generally, biological wastewater treatment processes operate as suspended growth or fixed growth processes. Suspended growth processes keep microorganisms in a liquid suspension throughout the reactor, maintaining a high concentration of biomass (measured as total volatile suspended solids, TVSS or mixed liquor volatile suspended solids, MLVSS). The MLVSS in suspended growth systems can range from $1,000 \mathrm{mg} / \mathrm{L}$ to $10,000 \mathrm{mg} / \mathrm{L}$, depending on the reactor design and operating conditions. However, $1,500 \mathrm{mg} / \mathrm{L}$ to $3,000 \mathrm{mg} / \mathrm{L}$ is typical for most conventional systems (Bitton, 1998). This suspended solids concentration is maintained by the continuous recirculation of sludge into the reactor.

In fixed growth processes, the biomass is physically attached to an inert carrier material. This material can be plastic, wood, sand, rock, slag, or any other suitable carrier (Tchobanoglous, Burton, \& Stensel, 2002). Wastewater flows past this carrier material, and the deleterious substances are removed by the attached bacteria.

Depending on the operating conditions and number of reactors in a wastewater treatment plant, differing behaviour can be expected. For example, ammonia and COD removal requires only aerobic treatment. Denitrification or total nitrogen removal requires both aerobic and anoxic conditions. For biological phosphorus removal, anaerobic and aerobic/anoxic conditions are necessary. If it is desired to biologically remove phosphorus and nitrogen, all three reactor conditions must be provided. These requirements are listed in Table 3-1 (Linden, Hawkins, \& Bonislawsky, 2001). 
Table 3-1: Summary of Reactor Conditions in BNR Processes, from (Linden, Hawkins, \& Bonislawsky, 2001)

\begin{tabular}{|c|l|l|l||}
\hline \multirow{2}{*}{ Zone } & \multicolumn{1}{|c|}{ Function } & \multicolumn{1}{c|}{$\begin{array}{c}\text { Biochemical } \\
\text { Transformation }\end{array}$} & \multicolumn{1}{c||}{ Zone Required For } \\
\hline \hline \multirow{2}{*}{ Aerobic } & $\begin{array}{l}\text { Oxidation of ammonia to nitrite } \\
\text { and nitrate }\end{array}$ & Alkalinity consumption & Nitrogen Removal \\
\cline { 2 - 5 } & Formation of polyphosphate & $\begin{array}{l}\text { Consumption of PHBs, } \\
\text { Phosphorus uptake }\end{array}$ & Phosphorus Removal \\
\hline \hline Anoxic & $\begin{array}{l}\text { Reduction of nitrate and nitrite } \\
\text { to nitrogen }\end{array}$ & Alkalinity production & Nitrogen Removal \\
\hline \hline Anaerobic & Uptake of VFAs by PAOs & $\begin{array}{l}\text { Production of PHB, } \\
\text { Phosphorus release }\end{array}$ & Phosphorus Removal \\
\hline
\end{tabular}

Aerobic Reactor Conditions - Dissolved oxygen and oxygen containing compounds (nitrite, nitrate, etc.) available in wastewater.

Anoxic Reactor Conditions - No dissolved oxygen is available in wastewater. Oxygen containing compounds (nitrite, nitrate, etc.) available in wastewater.

Anaerobic Reactor Conditions - No dissolved oxygen, no oxygen containing compounds (nitrite, nitrate, etc.) available in water.

Many technologies have been developed to treat wastewater of varying compositions. A selection of the most common, and most effective follows.

\subsection{Suspended Growth Systems}

Most suspended growth treatment plants follow similar configurations, as shown in Figure 2-5 (See page 18). The different operations can be broken down into specific stages, generally known as preliminary treatment, primary treatment, secondary treatment, disinfection, tertiary treatment and solids handling. The purpose of each is shown below:

\section{Preliminary Treatment}

- Includes physical operations such as screening, flow equalization and solids/grit removal

- Purpose is to first remove large objects (sticks, rags, rocks etc) that may damage or clog subsequent processes 
- Smaller inorganic solids (sand, small rocks, grit) must also be removed to reduce maintenance of pumps

\section{Primary Treatment}

- Generally consists of large rectangular or circular sedimentation tanks for the removal of readily settleable solids

- $50-70 \%$ of solids are removed, with $25-40 \%$ reduction of BOD (Tchobanoglous, Burton, \& Stensel, 2002)

- Removed solids are sent to solids handling and disposal

\section{Secondary Treatment}

- The goal of secondary treatment is to remove the undesirable components in wastewater (generally nitrogen, BOD), and small amounts of phosphorus

- Can be done via biological processes. A variety of configurations exist, as will be shown

- After the secondary treatment stage, solids are removed in sedimentation tanks and recycled, or sent to solids handling

\section{Disinfection}

- Removes residual bacterial populations (E.Coli, Faecal Coliforms etc)

- Can be done via exposure to ultraviolet light, chlorine, ozone $\left(\mathrm{O}_{3}\right)$. Many alternatives exist

\section{Tertiary Treatment}

- Tertiary treatment involves the removal of phosphorus, hazardous metals and complex molecules not converted in secondary treatment

- Processes can include filtration, reverse osmosis, chemical precipitation, or use of phosphorous accumulating organisms (PAOs) or lagoons 


\section{Solids Management}

- The goal of solids handling processes is to prepare the treatment by-products for disposal

- Generally includes aerobic/anaerobic digestion and solids thickening

- The production of methane in anaerobic digestion can be used for reduction of heating and operational costs, or for the generation of electricity

When reviewing different suspended growth technologies, the preliminary treatment, primary treatment, disinfection and solids handling processes will not be considered. In North America, a variety of different configurations exist for the secondary treatment. A common method for the biological removal of ammonia and carbon compounds is the activated sludge process.

\section{Activated Sludge}

The activated sludge process is a common technology for nutrient removal from wastewater, and has been in use since the early 1900s. The process is used for the oxidation of ammonia (nitrification) and carbon (Tchobanoglous, Burton, \& Stensel, 2002). If needed, chemicals can be added to facilitate phosphorus removal. In an activated sludge process, wastewater is held in an aerated reactor, where the carbon and nitrogen compounds are oxidized. The vessel can be designed as a plug-flow reactor (PFR), or a continuously stirred tank reactor (CSTR), depending on the wastewater characteristics. An example is shown below. Typical removal performance for COD and ammonia in the activated sludge process are $88 \%$ and $50 \%$, respectively (Qiu, Shi, \& He, 2010). 


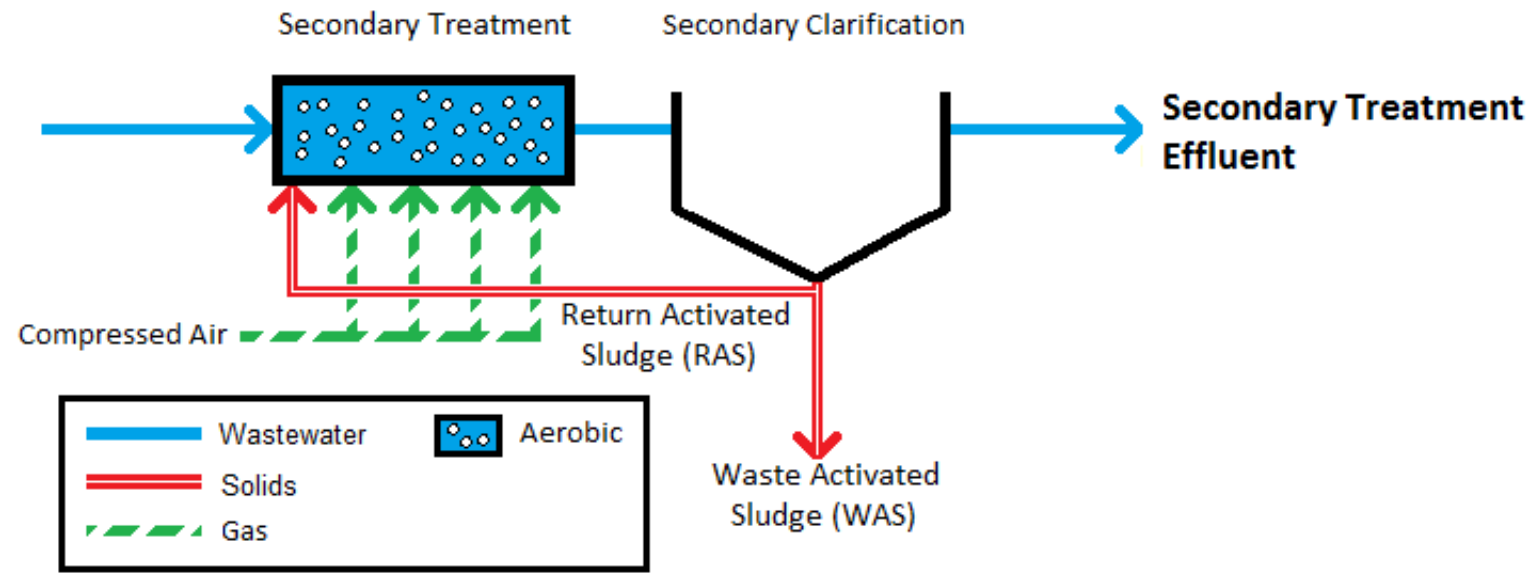

Figure 3-1: Activated sludge process

The management and characteristics of the biological materials (biomass, or sludge) becomes very important in activated sludge systems. A sufficient sludge residence time (SRT), and sludge concentration (Mixed Liquor Volatile Suspended Solids, or MLVSS) is necessary to ensure acceptable removal performance. If these values are too low, insufficient biomass is available to facilitate ammonia and carbon removal. Further, the addition of chemicals may impact the sludge volume index (SVI), which measures the settleability of the sludge. The SVI is an important parameter in activated sludge, as it impacts the operation of the clarifier, which in turn impacts the MLVSS concentration (New Mexico Environment Department, 2007).

\section{Activated Sludge with Step-Feed}

A variant on the activated sludge process, step feeding of wastewater is used to ensure all biological material in the aerobic reactor have access to sufficient dissolved oxygen (DO). In early activated sludge designs (see Figure 3-1), the oxygen demand of the incoming biomass frequently exceeded the oxygen supplied by the aeration system. To solve this, the step feeding strategy was implemented in the late 1930s (Moreno, 1987). 


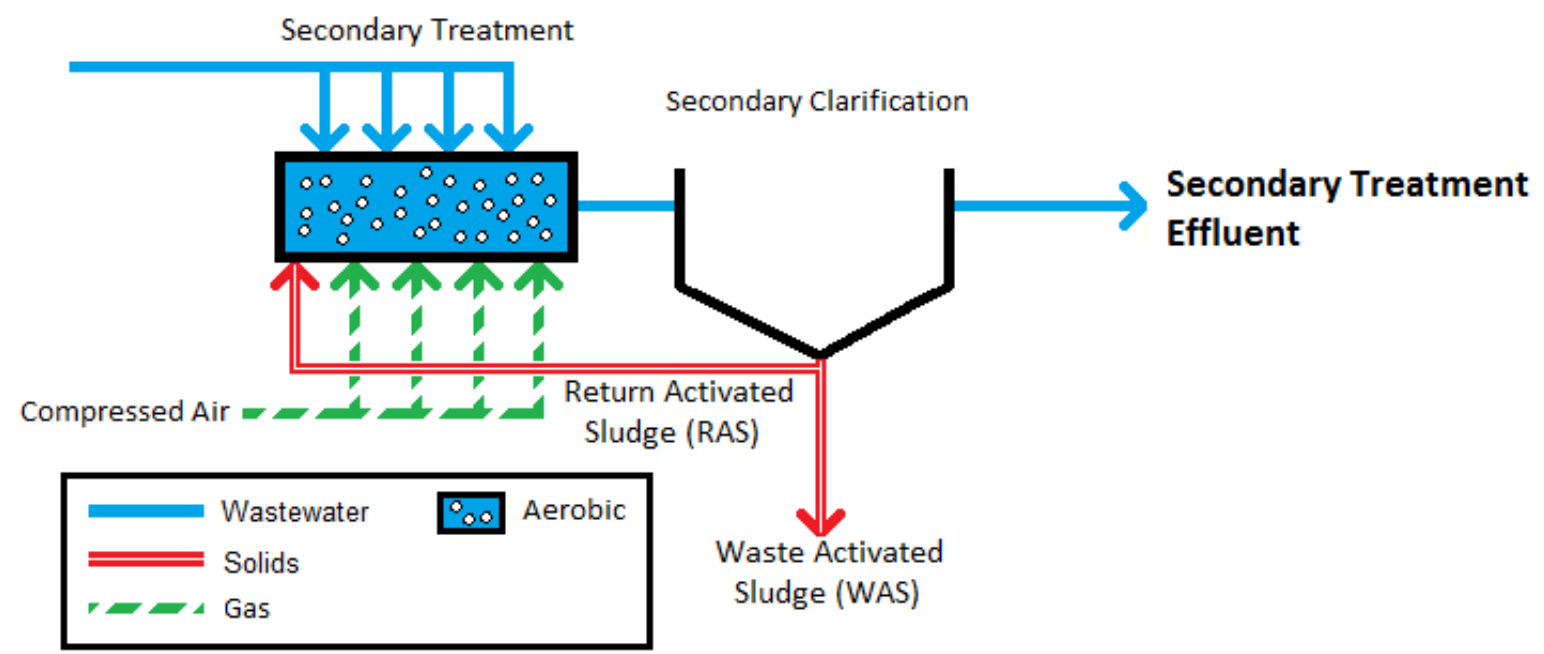

Figure 3-2: Activated sludge with step-feeding

There are many benefits to the step feeding system, including (Moreno, 1987):

- Reduced size of aeration tank

- More uniform oxygen demand along aeration tank

- Greater control of sludge and hydraulic residence time (SRT and HRT)

- Operational flexibility

\section{Activated Sludge with Contact Stabilization}

Another variant on the conventional activated sludge process, contact stabilization is a modification used to reduce total solids loading on the main stream process. An additional aeration tank is added to treat the return activated sludge (RAS), before the sludge is added back to the main stream process. By doing so, the majority of BOD and ammonia can be oxidized in a separate tank (Ragsdale \& Associates, 2008). This process is shown in Figure 3-3. 


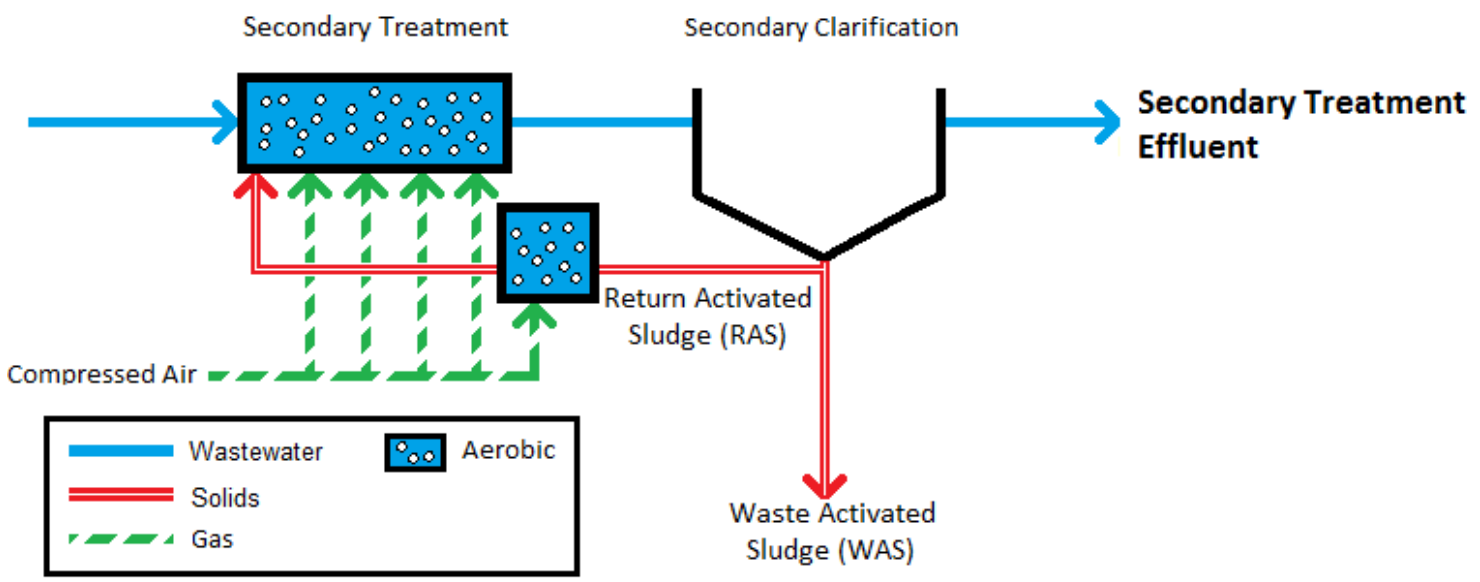

Figure 3-3: Activated sludge with contact stabilization

In the contact stabilization process, MLVSS in the side stream tank can be 2-10 times greater than in the main stream treatment vessel. Similarly, HRT in the stabilization tank is approximately 2-6 hours, compared to 0.5-1.5 hours in the main stream process (Sarria, Victoria, Lozada, \& Parra, 2011). This reduced HRT in the main stream can result in reduced total reactor volume.

\section{Modified Ludzack-Ettinger (MLE)}

The first Ludzack-Ettinger process was developed in the 1960s, and is a revised version of the activated sludge process. This revision added an anoxic tank prior to the aerobic vessel. The modified Ludzack-Ettinger process (MLE), added an internal recycle stream, which allowed for greater removal of total nitrogen (TN) via nitrification-denitrification (WEF, 2007). The MLE process is shown in Figure 3-4.

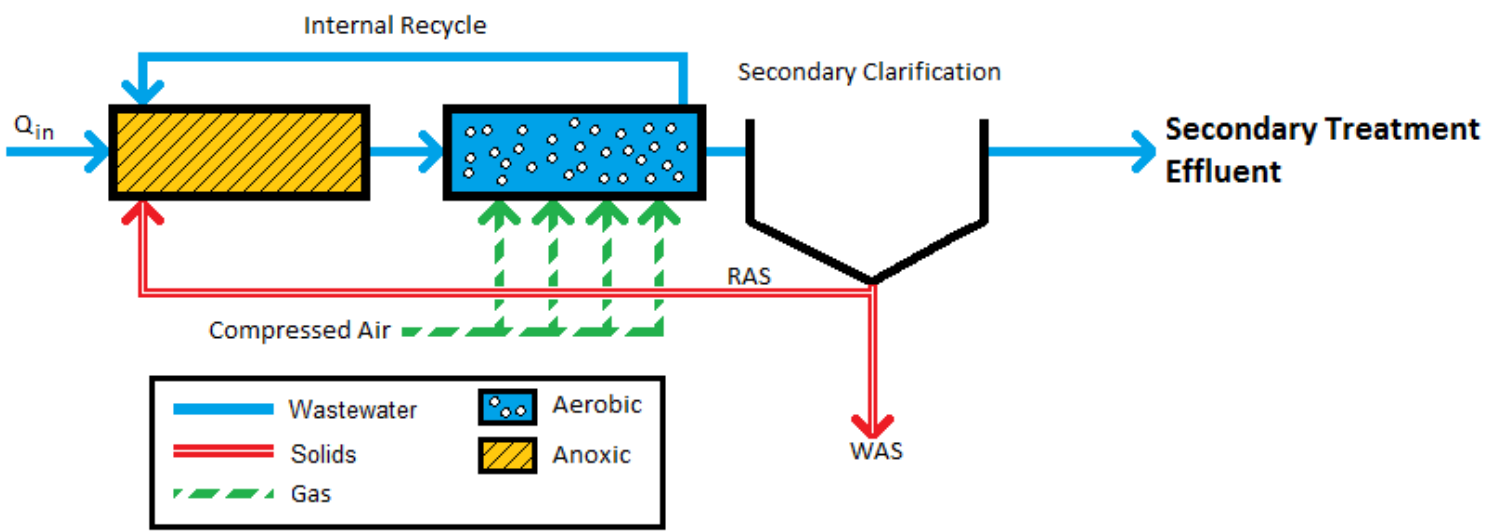

Figure 3-4: Modified Ludzack-Ettinger (MLE) process 
The high internal recycle and RAS flow allow for nitrification and denitrification to occur in the MLE process. Typical internal recycle flow rates are $400 \%$ of the incoming flow, $\mathrm{Q}_{\text {in }}$. Return activated sludge (RAS) flow rates are approximately $100 \%$ of the incoming flow (Wilson \& McGettigan, 2006). However, it is possible to achieve COD removal above $80 \%$ and TN removal above $90 \%$ using this reactor configuration. Additionally, some phosphorus removal does occur, at approximately 50-70\% removal when treating municipal wastewater (Lee, Jutidamrongphan, Park, Moon, \& Park, 2012). If more reliable phosphorus removal is necessary, a different reactor configuration should be chosen.

\section{Anaerobic/oxic (A/O) Process}

The A/O process uses an anaerobic stage and aerobic (oxic) stage in series for combined nitrogen and phosphorus removal. A/O was first developed in 1975 under the name of Phoredox (Linden, Hawkins, \& Bonislawsky, 2001). This process is shown in Figure 3-5.

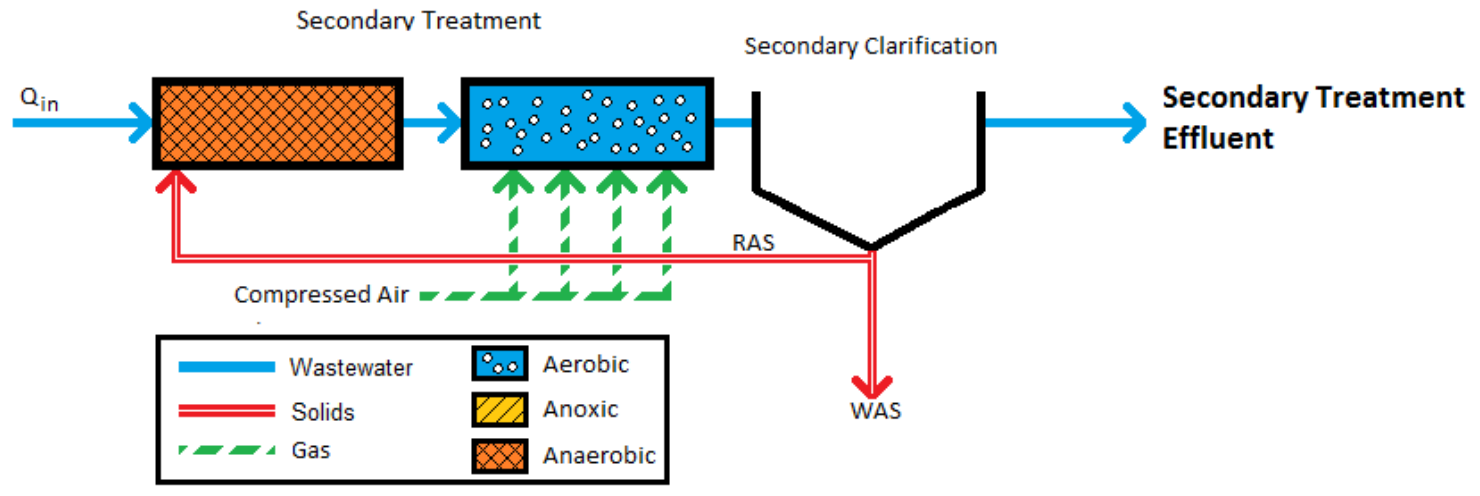

Figure 3-5: A/O Process

By providing anaerobic conditions, the $\mathrm{A} / \mathrm{O}$ reactor configuration allows for biological phosphorus removal. Typically, $80 \%$ of COD, $64 \%$ of ammonia, and $70 \%$ of TP can be removed (Qiu, Shi, \& He, 2010). However, like all biological phosphorus removal processes, the total phosphorus removal is dependent on the available VFA concentration (Tchobanoglous, Burton, \& Stensel, 2002).

When compared to the MLE process, which utilizes large internal recycle flow rates, the A/O process only returns materials via the RAS flow. Typical RAS flow rates are $20-50 \%$ of the 
incoming wastewater flow, $Q_{\text {in }}$ (Weston, Roy F. Inc, 1985). Although the recycle flow rates and associated pumping costs are reduced in the A/O process, greater removal performance is desired.

\section{Anaerobic/anoxic/oxic $\left(\mathrm{A}^{2} / 0\right)$ Process}

The $\mathrm{A}^{2} / \mathrm{O}$ process is similar to both the MLE and $\mathrm{A} / \mathrm{O}$ processes, and can be used for simultaneous biological phosphorus and nitrogen removal. Typical removal performance for COD, ammonia, TN and TP are 85\%, 75\%, 55\% and 78\% respectively (Qiu, Shi, \& He, 2010). To achieve this removal, an approximate internal recycle rate of $200 \%$ incoming wastewater flow, $\mathrm{Q}_{\mathrm{in}}$ is targeted (Linden, Hawkins, \& Bonislawsky, 2001).

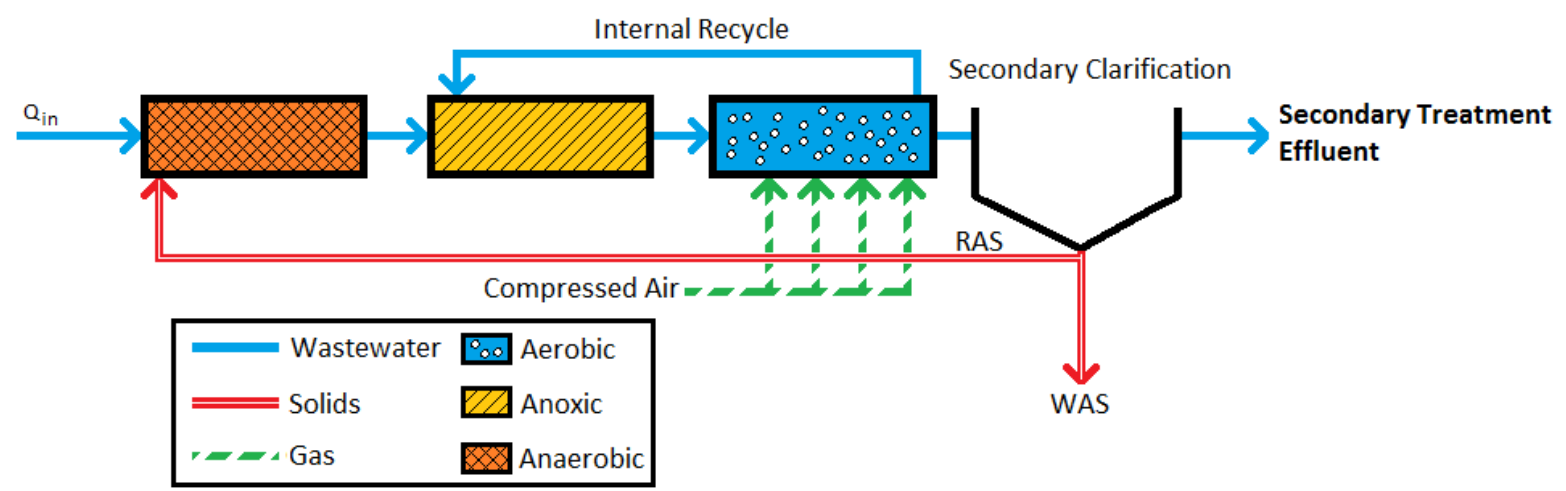

Figure 3-6: $A^{2} / O$ Process

However, higher phosphorus removal is dependent on the proper operating conditions. Nitrate concentration in the RAS flow must be kept as low as possible. In the anaerobic section of the process, PAOs and heterotrophic denitrifiers will compete for the VFAs (Linden, Hawkins, \& Bonislawsky, 2001). Therefore, if nitrate is present in large quantities, the VFAs available for the production of PHB in the PAOs will be reduced, causing impaired phosphorus removal.

\section{University of Cape Town (UCT) Process}

The UCT process was developed to reduce the impact of the nitrate recycle into the anaerobic reactor. By introducing the RAS flow into the anoxic reactor, denitrification can occur without the possibility of reducing PAO consumption of VFAs. After denitrification has occurred, the 
wastewater is sent to the anaerobic reactor, where the release of phosphorus and production of PHB can occur. This is shown in Figure 3-7.

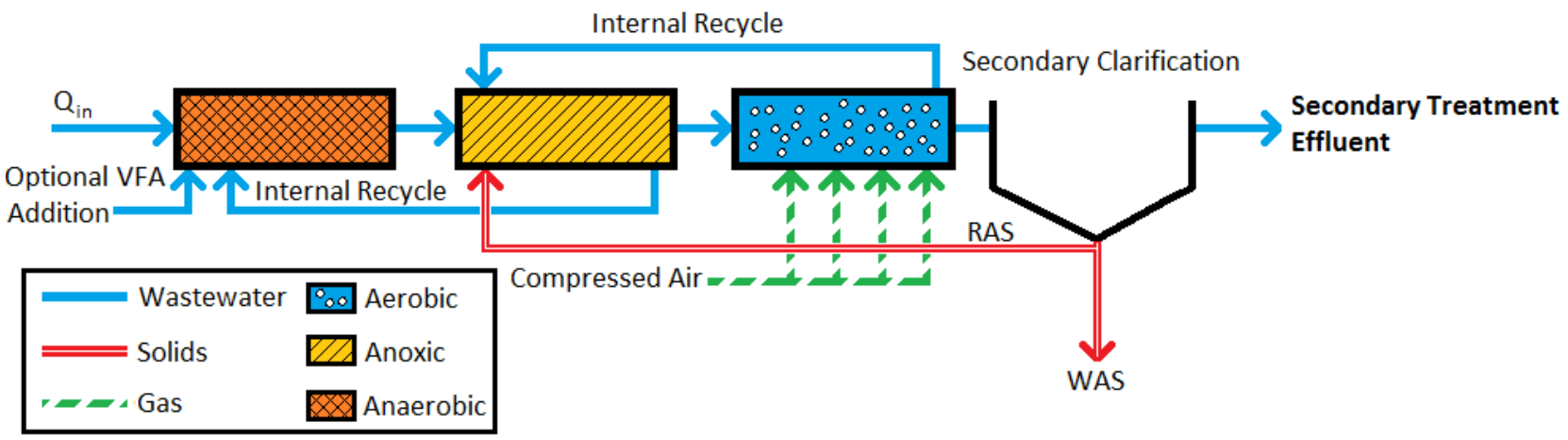

Figure 3-7: UCT Process

The removal performance for the UCT process is similar to the $\mathrm{A}^{2} / O$ process. COD, ammonia, TN and TP removals around 89\%,67\%,65\% and 80\% respectively (Wang, Liu, Liu, \& Wan, 2012). Although the UCT process may be less challenging to operate, the increased internal recycle flow rates and associated pumping costs are undesirable. Generally, internal recycle flows of $200 \% Q_{i n}$ are used (Linden, Hawkins, \& Bonislawsky, 2001).

\section{Bardenpho Process, 4 Stage}

The Bardenpho process was first patented in 1975, and was developed in South Africa (US Patent No. 3964998,1975$)$. The four stage process is similar to the MLE process, with two sets of aerobic and anoxic reactors in series. Because of the additional anoxic and aerobic zones, greater ammonia and total nitrogen removal can be achieved. However, the design does not contain anaerobic reactors, and cannot achieve reliable phosphorus removal. Furthermore, the greater number of reactors and large internal recycle flow rate may increase the capital and operating cost of a project. Generally, four stage Bardenpho processes are designed to accommodate a $400 \%$ internal recycle flow (US EPA, 2008). 


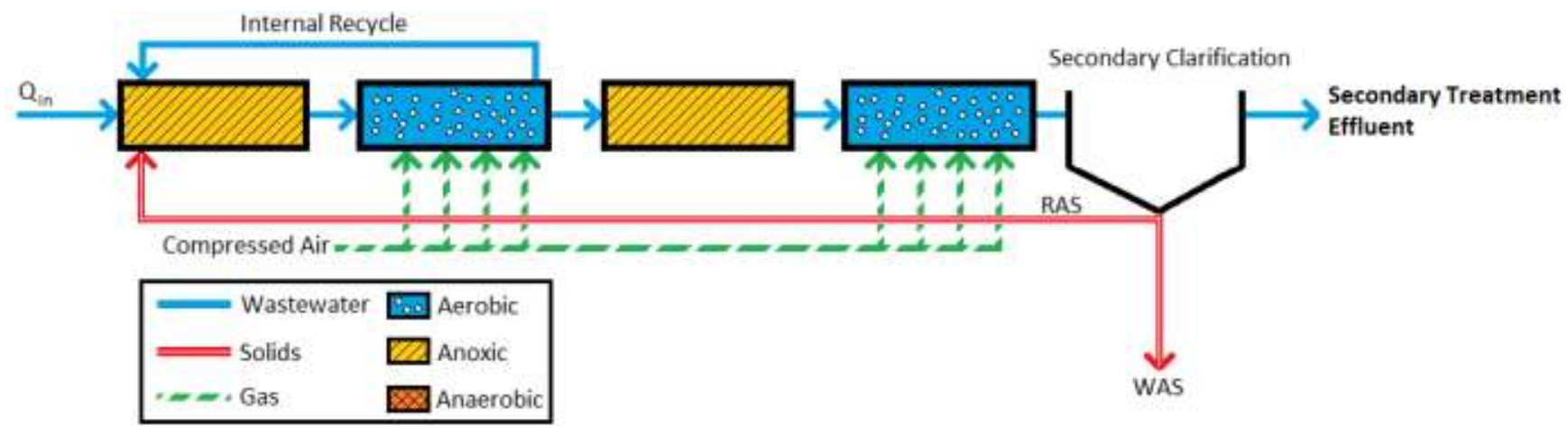

Figure 3-8: Four stage Bardenpho process

The ideal selection of reactor volumes is a challenging task, and depends on the specific wastewater composition. However, a general range of HRT for each reactor is listed below (WEF, 2007):

- First anoxic tank, 1-3 hours

- First aerobic tank, 4-12 hours

- Second anoxic tank, 2-4 hours

- Second aerobic tank, 0.5-1 hours

The function of the final aerobic tank, which is generally smaller than the other stages, is to aerate the wastewater to prevent denitrification in the clarification stage. Poor settling characteristics can arise if excess decay reactions occur in the settling tank (Linden, Hawkins, \& Bonislawsky, 2001).

\section{Bardenpho Process, 5 Stage}

The five stage Bardenpho reactor is a modification of the four stage configuration, and adds an anaerobic reactor to the process. When operating the four stage system, it was found that dead zones in the anoxic tank facilitated phosphorus removal from wastewater (Barnard J. , 2006). The zones lacked both oxygen and nitrate, which allowed for the production of PHB by PAOs. To exploit this discovery, an anaerobic vessel was added onto the beginning of the process, as shown in Figure 3-9. 


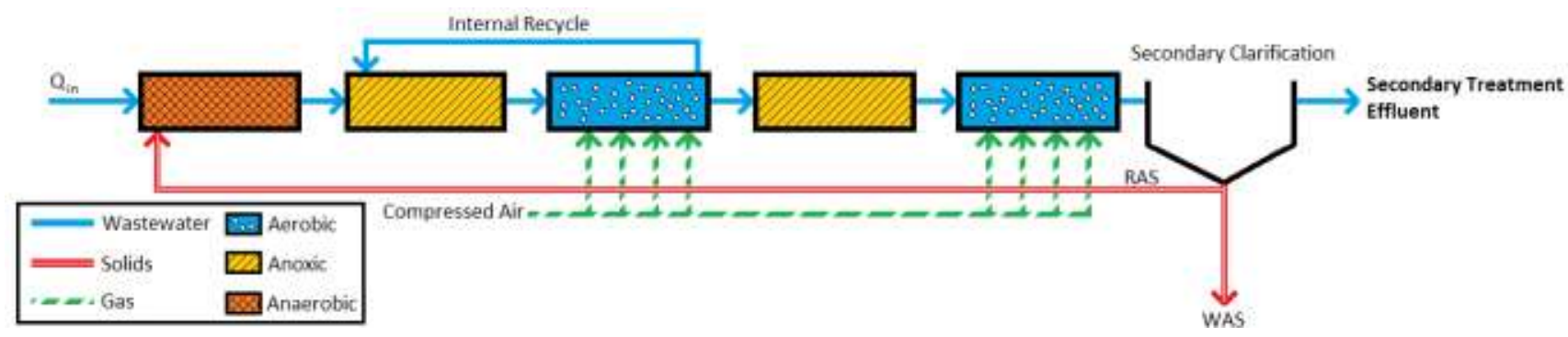

Figure 3-9: Five stage Bardenpho process

The five stage Bardenpho process is capable of removing phosphorus to meet most legislative requirements, although chemical addition is usually kept onsite to ensure compliance (US EPA, 2008). High removal rates are achievable when using multiple stage systems, although the capital and operational costs of treatment increases with more reactors and pumps. Typical COD, ammonia, TN and TP removal performance are around $86 \%, 99 \%, 94 \%$ and $60 \%$ respectively (Rachmani, 2013). Much like the four stage process, the final aerobic tank is necessary to ensure aerobic conditions in the clarifier. If anaerobic conditions occur in the clarifier, phosphorus release from the sludge into the liquid phase will occur.

\section{Oxidation Ditches}

Oxidation ditches are large wastewater treatment reactors, frequently in a circular or oval shapes. These reactors are generally suitable only for rural locations where an excess of land is available for construction. Because of the large size of the reactor, higher sludge and hydraulic residence times are possible. Moreover, they are resistant to high concentration shocks, and can be operated with reduced manpower (US EPA, 2000). A birds-eye view of the process is shown below.

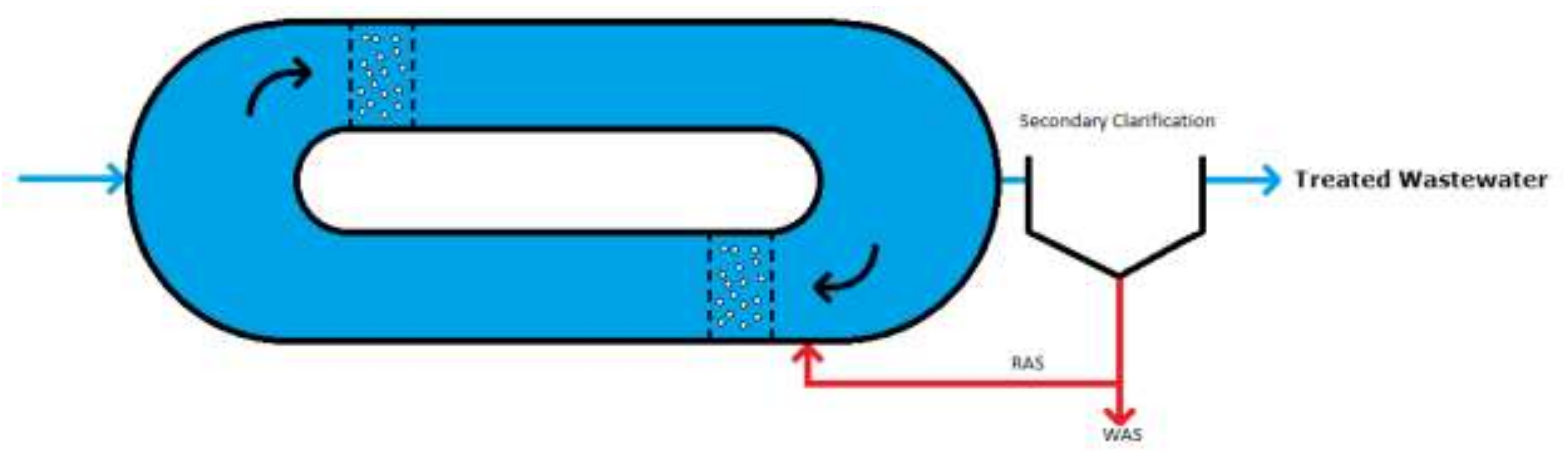

Figure 3-10: Oxidation ditch 
Depending on the scale of the process, oxidation ditches can consist of one or many rings. Through these rings, wastewater flows and receives intermittent aeration. As shown in Figure $3-10$, aeration is provided in two locations on the oxidation ditch. Through modification of operating conditions within the reactor, anoxic or anaerobic zones can be created to facilitate denitrification and phosphorus removal in the reactor. Much like the previously discussed processes, the removal performance depends on the configuration and order of anaerobic, anoxic or aerobic stages.

\section{Sequencing Batch Reactors}

Many of the multi-stage, continuous flow processes used by large scale treatment facilities are less effective, or too expensive to apply in some situations. For smaller wastewater treatment processes, which may encounter intermittent flows of wastewater, sequencing batch reactors may be more suitable. Instead of providing a series of reactors with varying operating conditions, through which wastewater flows, sequencing batch reactors provide changing conditions in a single reactor. This 5 stage cyclic process is shown in Figure 3-11, and operates as follows (Mazumder, 2002):

- Reactor fills with wastewater. Continuous mixing is provided. Approximately $25 \%$ of total cycle time.

- Wastewater is given time to react in aerobic, anoxic, and/or anaerobic conditions. Similar to continuous processes, repeating aerobic and anoxic conditions can be used to facilitate nitrogen removal. Repeating aerobic and anaerobic conditions can facilitate biological phosphorus removal. Approximately $35 \%$ of total cycle time.

- Reactor is allowed to settle in absence of mixing. Approximately $20 \%$ of total cycle time.

- Wastewater low in suspended solids is decanted from the reactor. Approximately $15 \%$ of total cycle time.

- Sludge is removed from the bottom of the reactor. Approximately $5 \%$ of total cycle time. 


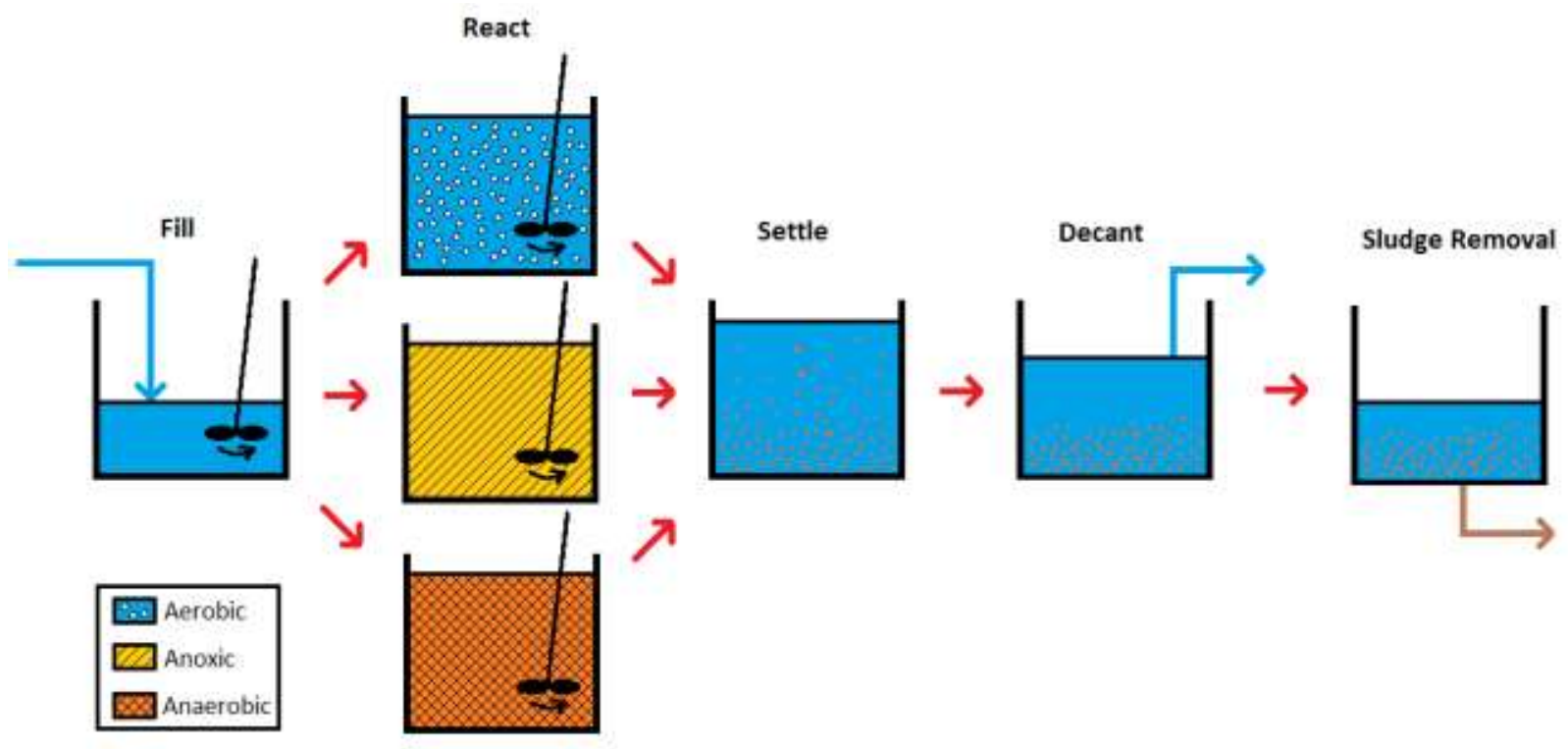

Figure 3-11: Sequencing Batch Reactor

Sequencing batch reactors can achieve very high levels of nutrient removal when treating small quantities of wastewater. For a SBR treating municipal wastewater in a configuration similar to the four stage Bardenpho process (anoxic/aerobic/anoxic/aerobic), COD, ammonia, TN and TP removal performance of $90 \%, 87 \%, 60 \%$ and $89 \%$, respectively, were observed ( $\mathrm{Li}, \mathrm{Ji}, \mathrm{Li}$, \& Song, 2010)

Additional anaerobic/anoxic/aerobic stages can easily be added to the SBR cycle to improve the nitrogen or phosphorus removal performance. Because of the flexibility of the process, wastewater of highly variable composition can be treated effectively. However, as the wastewater flow rate increases, SBRs become less economically viable (Mazumder, 2002)

\section{Comparison of Suspended Growth Processes}

A variety of processes have been shown which can be used for the removal of undesirable components from wastewater. However, many more reactor configurations exist, and some are just as effective as the discussed configurations. Hundreds of technologies are available for the treatment of wastewater. It is necessary to choose the appropriate technology to effectively treat any specific wastewater. Table 3-2 summarises the discussed suspended growth processes. 
Table 3-2: Suspended growth processes

\begin{tabular}{|c|c|c|c|c|c|}
\hline \multirow[t]{2}{*}{ Process } & \multirow{2}{*}{$\begin{array}{c}\text { COD } \\
\text { Removal }\end{array}$} & \multirow[t]{2}{*}{ Ammonia Removal } & \multirow{2}{*}{$\begin{array}{c}\text { TN } \\
\text { Removal }\end{array}$} & \multicolumn{2}{|c|}{ Reliable Phosphorus } \\
\hline & & & & Biological & Chemical \\
\hline Activated Sludge & $88 \%$ & $50 \%$ & $\mathrm{n} / \mathrm{a}$ & No & Yes \\
\hline MLE & $80 \%$ & - & $90 \%$ & No & Yes \\
\hline$A / O$ & $80 \%$ & $64 \%$ & - & $70 \%$ & As needed \\
\hline$A^{2} / 0$ & $85 \%$ & $75 \%$ & $55 \%$ & $78 \%$ & As needed \\
\hline UCT & $89 \%$ & $67 \%$ & $65 \%$ & $80 \%$ & As needed \\
\hline $\begin{array}{c}5 \text { Stage } \\
\text { Bardenpho }\end{array}$ & $86 \%$ & $99 \%$ & $94 \%$ & $60 \%$ & As needed \\
\hline
\end{tabular}

\subsection{Fixed Growth Systems}

Fixed growth processes offer many advantages to suspended growth processes. Primarily, fixed growth processes allow for greater concentrations of biomass within a reactor, as the biomass has been physically immobilized as biofilm. There is less concern for the washout of biomass, as is the case with suspended growth processes. Moreover, some additional benefits of fixed growth processes include (Gavrilescu \& Macoveanu, 2000):

- Higher biomass concentration

- Greater wastewater flow rates, above conventional biomass washout levels

- Greater internal gradients of physical and chemical conditions (dissolved oxygen, nutrient concentration, etc.)

- Ability to produce variety of physical biofilm characteristics incorporating different microorganisms

- Increased protection against contamination

There are five common configurations for biofilm reactors, which can be applied for the removal of contaminants from wastewater. As shown in Table 3-3, both anaerobic and aerobic conditions are possible in fixed growth processes (Gavrilescu \& Macoveanu, 2000). Note that many more processes exist for both aerobic and anaerobic conditions. 


\begin{tabular}{cc}
\hline Aerobic Process & Anaerobic Process \\
\hline Fluidized Bed Reactor & Fluidized Bed Reactor \\
\hline Rotating Biological Contactor & Anaerobic Downflow Filter \\
\hline Trickling Filter & Anaerobic Upflow Filter \\
\hline
\end{tabular}

\section{Rotating Biological Contactor}

Rotating biological contactors use circular disks attached to a rotating shaft as the surface for biofilm to attach and grow. These disks are partially submerged in wastewater, and the shaft rotates to supply the biofilm with oxygen and nutrients for growth. Typical submergence is around $40 \%$, with 2-3 rotations of the shaft per minute (Kapoor, Kuiper, Bedard, \& Gould, 2003). The regular exposure to the air provides the biofilm with the oxygen necessary for nitrification and COD removal.

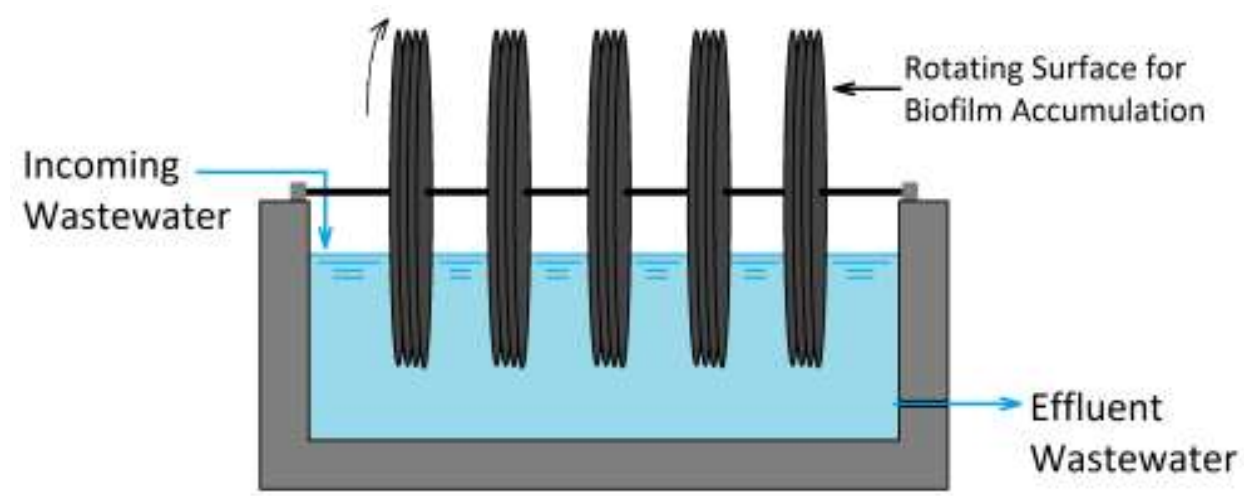

Figure 3-12: Rotating biological contactor

Sufficient oxygen may be available through the rotation of the biofilm disks through air, although high nutrient loadings may result in low dissolved oxygen concentration and impaired removal performance. For example, an RBC process treating municipal wastewater observed an increase in removal performance from $67.4 \%$ to $80.7 \%$ after supplemental aeration was provided (Surampalli \& Baumann, 1989). 
The use of completely submerged rotating biological contactors (to provide anoxic or anaerobic environments) has been investigated for the reduction of total nitrogen and phosphorus. Similar to the suspended growth processes, the removal performance depends on the configuration of the anoxic, anaerobic and aerobic stages in the process. When using rotating biological contactors instead of suspended growth processes, similar removal performance is observed (Su \& Ouyang, 1997). However, a number of advantages over suspended growth processes exist, including (Cortez, Teixeira, Oliveira, \& Mota, 2008):

- Reduced land requirements, easy construction and expansion

- Compact design

- No problems with odours, flies or pests

- High biomass concentration, high oxygen transfer efficiency

- No need for sludge recirculation

- Reduced operating costs

Due to the compact design of the RBC, scale up can be difficult. Moreover, the process takes longer to start up, as the biofilm population needs to be established on the packing material (Cortez, Teixeira, Oliveira, \& Mota, 2008).

\section{Anaerobic Upflow/Downflow Filters}

Anaerobic upflow filters are similar to packed bed reactors, where a cylindrical column is packed with a high surface area material. This packing material can be plastic rings, saddles, crushed stone, or any other similar material (Manariotis \& Grigoropoulos, 2006). In some cases, effective removal was observed in anaerobic upflow filters using bamboo rings or chicken skulls as packing (Tritt, 1992). Wastewater flows through the packed column, where the attached biofilm consumes the undesirable components.

Typically, anaerobic filters are used for the denitrification of nitrate, or the reduction of carbon compounds to methane. For most municipal treatment processes, these filters can be combined with fixed or suspended growth aerobic processes to achieve greater COD or TN removal (Manariotis \& Grigoropoulos, 2006). The low capital and operating cost of these 
reactors provide an alternative method for the cost effective removal of nutrients from wastewater. For example, a simple upflow filter with PVC rings as a packing material was able to remove $80 \%$ of COD from slaughterhouse wastewater (Rajakumar, Meenambal, Banu, \& Yeom, 2011).

\section{Fluidized Bed Reactors}

Fluidized bed reactors are a versatile technology that can be applied for the aerobic, anoxic or anaerobic treatment of wastewater. The technology utilizes the flow of water or gas past a solid carrier to impart motion on the carrier material. This flow results in an expanded bed of particles which move in a fluid-like manner. In addition to excellent mixing properties, the fluidized bed reactor has numerous advantages, including (Burghate \& Ingole, 2013):

- High availability of carrier surfaces for biomass attachment, creating high concentration of biomass in reactor.

- High concentration of biomass creates greater potential for nutrient removal at high flow rates.

- Typically vertical reactor configuration occupies small foot print.

- High retention of biomass carriers and solids reduces loading on secondary clarification.

- Many reactors capable of COD removal exceeding 90\% (Saravanane \& Murthy, 1999)

Fluidized bed reactors can utilize a variety of packing materials, including structured plastic materials, glass or plastic spheres, and ground inorganic materials such as aluminum silicate or activated carbon (Josyula, et al., 2010). For use in wastewater treatment, packing materials with density less than that of water are commonly used. A sample of fluidized bed packing materials are shown in Figure 3-13. 


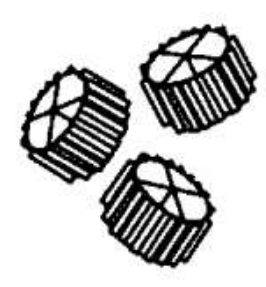

KMT (K1)

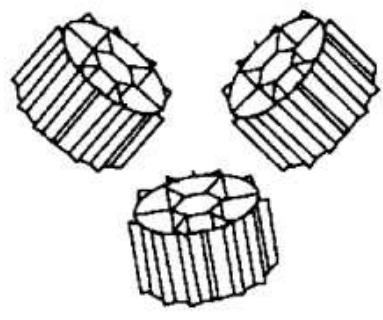

KMT (K2)

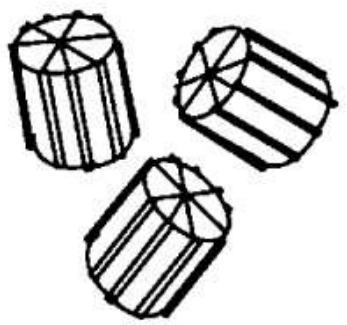

AWT

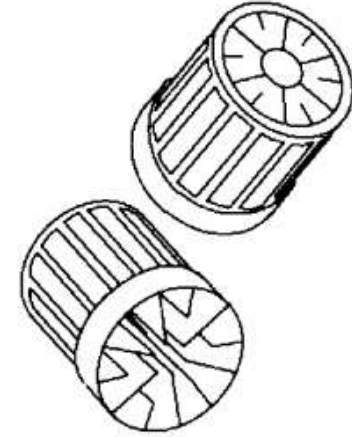

ANOX

Figure 3-13: Fluidized bed packing materials. From (Odegaard, Gisvold, \& Strickland, 1994).

The use of packing material with density less than $1.0 \mathrm{~g} / \mathrm{cm}^{3}$ is advantageous, as the reactor can be fluidized by applying a reduced flow of air. The airflow will cause the reactor to mix, while also providing aeration for aerobic processes. When compared to fluidized beds using dense packing, the total liquid and gaseous superficial velocities are reduced, thereby reducing the shear rate. A reduced shear rate is beneficial, as it allows for greater biomass retention. The physical properties of some packing materials are shown in Table 3-4.

Table 3-4: Carrier physical properties. From (Odegaard, Gisvold, \& Strickland, 1994).

\begin{tabular}{|c|c|c|c|c|}
\hline \multicolumn{2}{|c|}{ KMT (K1) } & KMT (K2) & AWT & $240 \mathrm{~m}^{2} / \mathrm{m}^{3}$ \\
\hline Total Surface Area & $690 \mathrm{~m}^{2} / \mathrm{m}^{3}$ & $550 \mathrm{~m}^{2} / \mathrm{m}^{3}$ & $450 \mathrm{~m}^{2} / \mathrm{m}^{3}$ & $190 \mathrm{~m}^{2} / \mathrm{m}^{3}$ \\
\hline Effective Surface Area & $500 \mathrm{~m}^{2} / \mathrm{m}^{3}$ & $315 \mathrm{~m}^{2} / \mathrm{m}^{3}$ & $310 \mathrm{~m}^{2} / \mathrm{m}^{3}$ & $7700 \mathrm{~mm}^{2} / \mathrm{piece}$ \\
\hline Effective Surface Area & $490 \mathrm{~mm}^{2} /$ piece & $1910 \mathrm{~mm}^{2} / \mathrm{piece}$ & $1500 \mathrm{~mm}^{2} /$ piece & 24 \\
\hline Carriers per Liter & 1030 & 159 & 203 & $0.95 \mathrm{~g} / \mathrm{cm}^{3}$ \\
\hline Density & $0.95 \mathrm{~g} / \mathrm{cm}^{3}$ & $0.95 \mathrm{~g} / \mathrm{cm}^{3}$ & 0.95 & 0.95 \\
\hline
\end{tabular}

A variety of packing materials can be used, depending on the conditions of the reactor. As shown in Table 3-4, the ANOX carrier is significantly larger than the other three carriers. This carrier provides substantial protected (internal) surface area $\left(7700 \mathrm{~mm}^{2} /\right.$ piece), which could be advantageous in some situations. When looking at anammox reactors, use of a large carrier is useful, as low shear conditions provide a large area for biofilm accumulation. This large accumulation of biofilm can provide significant protection for the slowly growing bacteria on the carrier surface. For example, the anammox biofilm can be covered by aerobic bacteria, preventing oxygen from reaching the inner regions thus reducing the anammox performance. 
In addition to using structured packing materials, fluidized beds can use a variety of solid supports onto which biofilm collects. Many successful fluidized beds use glass spheres, sand or granular activated carbon as support materials (Rodgers \& Zhan, 2003). The biomass covers the surface of these particles, creating granules of bacteria which can be fluidized using air or liquid flow. Depending on the reactor conditions, the size of particles may vary.

However, carriers or packing is not always necessary in fluidized beds. Some reactors, such as upflow sludge blanket reactors, use the natural tendency of biomass to form small granules to eliminate the need for packing materials. Depending on the shear stress and reactor conditions, biological entities will create networks of extracellular polymeric substances (EPS), which allow bacteria to group together and form granules. The size of the granules is dependent on the shear stress and chemical composition in the reactor. For example, it has been reported that the salt concentration in a reactor helps to create larger granules in a fluidized bed reactor ( $\mathrm{Li}$, et al., 2014). In order to optimize a specific fluidized bed reactor for the maximization of anammox activity, specific configurations should be investigated.

\subsection{Advanced Wastewater Reactors}

Like any bacterial entity, the anammox process requires specific reactor conditions. Primarily, the bacteria must be kept in anoxic conditions with reduced dissolved oxygen concentrations. Additionally, the bacteria must be provided with both ammonia and nitrite, at a stoichiometric ratio around 1:1.32 respectively (see equation 4). However, most wastewater streams contain primarily ammonia nitrogen, such as in landfill leachates, anaerobic digester supernatants or similar sources (Shalini \& Joseph, 2012). Therefore, the ammonia in wastewater must be partially oxidized to nitrite, without the accumulation of nitrate. The goal is to maximize total nitrogen removal from the wastewater stream, but the conflicting nature of the two bacteria one requiring oxygen to convert ammonia to nitrite, and the other being inactivated by oxygen - requires a unique reactor configuration. Some of the successful variations will be discussed.

\section{Sharon-Anammox}

The Sharon-Anammox reactor system is one of the early applications of the anammox technology for the treatment of ammonia in wastewater. The process uses two reactors for the 
removal of ammonia, the first being an aerobic system to partially oxidize ammonia, and the second being the anoxic ammonium oxidation (anammox) reaction. This system is described in Figure 3-14.

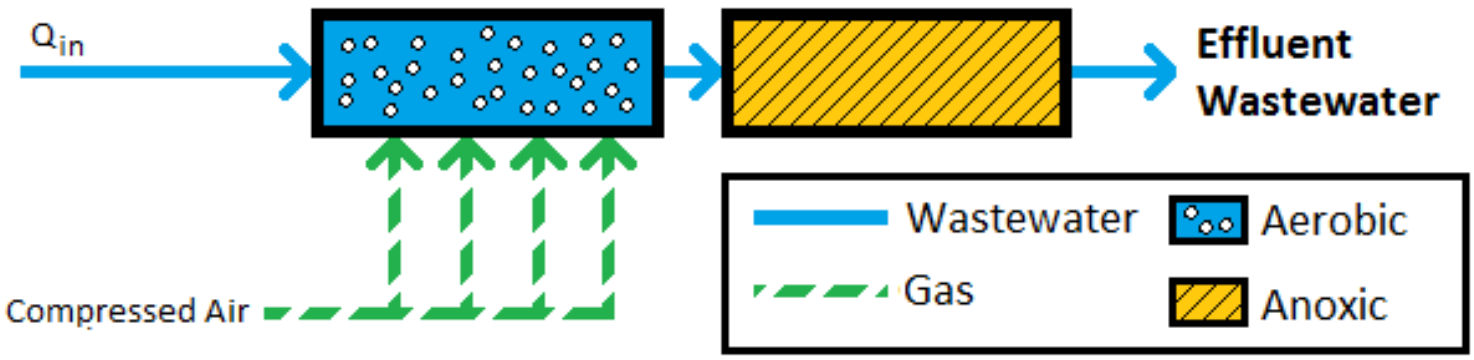

Figure 3-14: Sharon-Anammox reactor diagram

The primary objective of the Sharon reactor is to achieve partial nitrification of ammonia to nitrite, without further oxidation of nitrite to nitrate. This can be done by providing controlled periods of aeration, generally targeting a DO concentration of $3.5 \mathrm{mg} / \mathrm{L}$ (Claros, Serralta, Seco, Ferrer, \& Aguado, 2012). Additionally, no biomass retention is provided, shorter HRTs are targeted ( 1 day), and higher temperatures are maintained $\left(>30^{\circ} \mathrm{C}\right)$. Under these conditions, the growth rate of $\mathrm{AOBs}$ is higher than NOBs, and washout prevents the accumulation of NOBs (Wyffels, et al., 2004).

In situations where biomass retention cannot be avoided (i.e. fixed film reactors, membrane bioreactors), the accumulation of nitrite without nitrate production can be achieved by controlling the DO concentration. Generally, DO concentrations below $2.0 \mathrm{mg} / \mathrm{L}$ are suitable, although further reductions in DO only help to eliminate nitrite oxidation (Wyffels, et al., 2004). In this first reactor, the stoichiometric ratio of 1:1.32 is targeted for ammonia and nitrite.

After the partial oxidation of ammonia has been achieved, the ammonia/nitrite mixture is sent to a second reactor, which is held under anoxic conditions. Some smaller reactors use mixtures of argon and $\mathrm{CO}_{2}$ to both agitate the reactor, and to prevent $\mathrm{DO}$ from entering the reactor (Sliekers, Third, Abma, Kuenen, \& Jetten, 2003). However, this may not be feasible in larger reactors, due to the added cost of gas addition. Instead, the nitrogen gas produced in the anammox reaction can be collected and recycled to achieve a similar effect. An example of this method was used in the first Anammox reactor, shown in Figure 3-15. Sufficient nitrogen for 
mixing is produced when total nitrogen conversion exceeds $100 \mathrm{~kg} \mathrm{~N} /$ day. Note that the design treatment capacity is $500 \mathrm{~kg} \mathrm{~N} /$ day, with the largest measured treatment being $750 \mathrm{~kg} \mathrm{~N} /$ day (van der Star, et al., 2007).

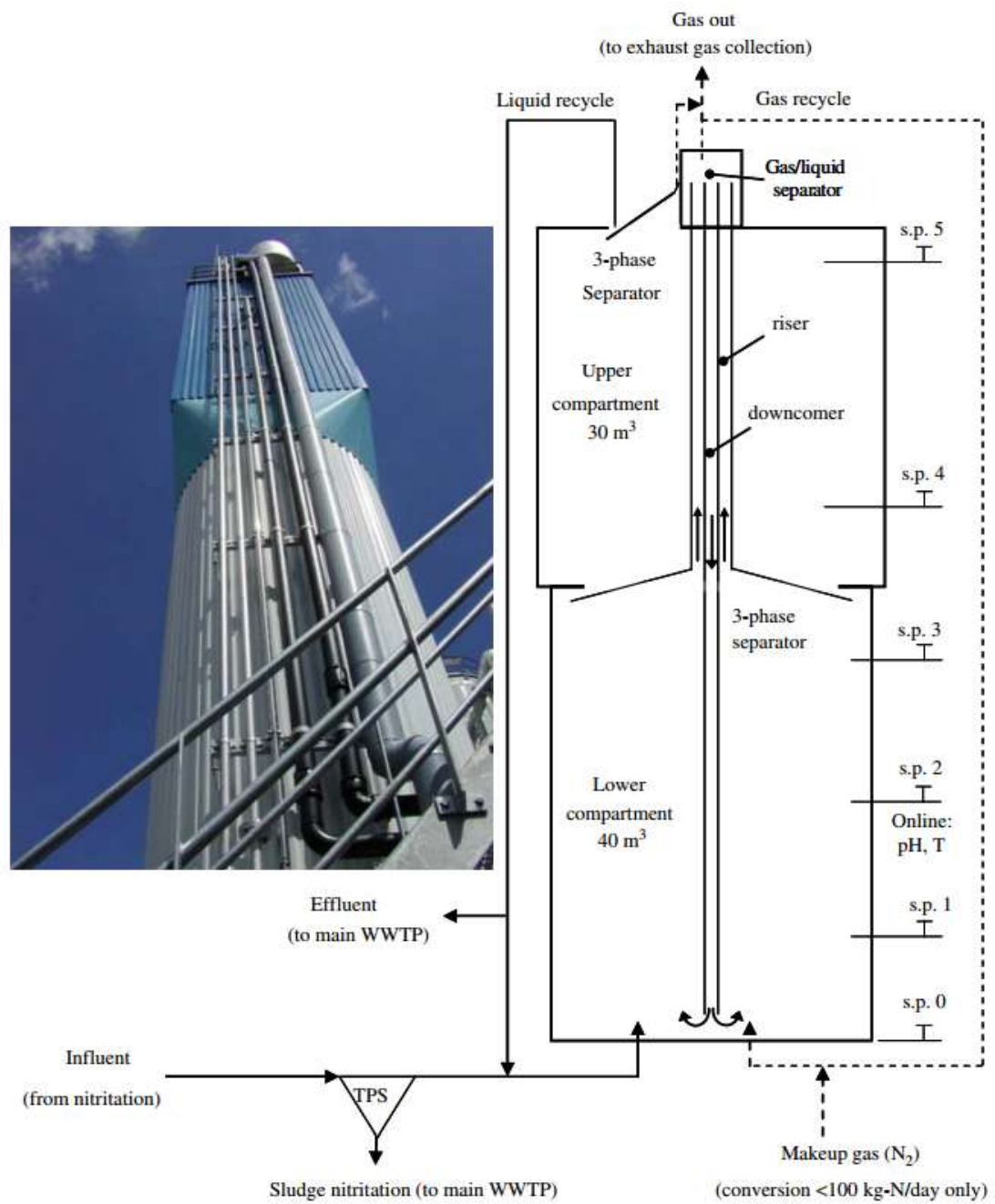

Figure 3-15: $70 \mathrm{~m}^{3}$ Anammox reactor in Rotterdam, from (van der Star, et al., 2007).

\section{DEMON Reactors}

Although the two stage Sharon-Anammox process is a proven technology, they are not as common as the single stage technologies. Most new anammox installations utilize a one stage process, with SBR reactors being the most common (Lackner, et al., 2014). One sort of SBR anammox reactor has been patented under the name DEMON, for deammonification, and uses 
intermittent aeration of the batch reactor to achieve partial nitrification and anammox in one vessel.

Generally the reactor is filled and aerated, while maintaining low DO concentrations (below 0.3 $\mathrm{mg} / \mathrm{L})$. The length of aeration is dependent on the $\mathrm{pH}$, where air flow increases until the $\mathrm{pH}$ reaches a minimum value. As shown in section 2.1, the aerobic oxidation of ammonia consumes alkalinity reducing the solution $\mathrm{pH}$ (see equation 1). Once the $\mathrm{pH}$ reaches a minimum value, air flow is eliminated, and the wastewater converts to anoxic conditions. In this phase, the anaerobic oxidation of ammonia occurs, and the $\mathrm{pH}$ of the solution is increased as a result of the consumption of $\mathrm{H}^{+}$(see equation 4). By controlling the flow of air into the system, ammonia can be removed using the deammonification process (Wett, et al., 2007).

The DEMON process allows both aerobic and anoxic bacteria to co-exist in a single vessel. By allowing for the high retention of solids, a substantial anammox population can collect in the reactor. However, there are other methods to achieve partial nitrification and anammox in a single reactor. In some cases, the continuous flow of wastewater can be treated in a single reactor.

\section{CANON Reactors}

Canon is an abbreviation for completely autotrophic nitrogen removal over nitrite, and operates in a similar method as the Sharon-anammox reactor. However, instead of using two vessels, one for each reaction, the Canon system operates in a single reactor. By supplying oxygen limited conditions to the reactor, the aerobic ammonia oxidizing bacteria can form a biofilm around the anaerobic bacteria, providing reduced DO concentrations on the interior of

the particle. Generally, DO concentrations below $1.0 \mathrm{mg} / \mathrm{L}$ are targeted in the bulk liquid, with values below $0.5 \mathrm{mg} / \mathrm{L}$ being ideal (Liu, et al., 2012).

Many different packing materials can be used in a Canon reactor, including structured plastic materials such as those shown in Figure 3-13 (See page 44), or any variety of glass, sand, or other materials. It is important to maintain reduced shear rates in the reactor, in order to allow the accumulation of biomass on the packing material. A thick biofilm is needed to prevent the diffusion of oxygen into the inner anoxic zones. Previous studies have found that increased 
shear causes the removal of outer biofilm layers, resulting in decreased anammox performance (Liu, et al., 2012). In order for the simultaneous partial nitrification and anammox removal to occur, careful control of the oxygen conditions and biofilm characteristics are needed.

\section{OLAND Reactors}

Oland reactors operate in a similar way as Canon reactors, in which the partial nitrification and anammox reactions occur in a single vessel. The term Oland is an abbreviation for oxygen limited autotrophic nitrification-denitrification, and is very similar to the Canon process. In most cases, the Oland and Cannon process can be described interchangeably, as the difference between the two occurs in the start-up process. For the Oland process, the reactor is initially fed with a controlled flow of air, and the underlying anaerobic biofilm layer slowly grows as the surface aerobic biomass consumes greater quantities of oxygen. In this way, the air supply in the reactor is limited, and the flow rate slowly increases with increasing AOB population (Wyffels I. S., 2004).

Unlike the Oland process, where oxygen is supplied from the start, the Canon reactor does not begin with any added oxygen. Instead, it begins as an anammox reactor, where ammonia and nitrite are provided under anoxic conditions. After the anammox reaction is occurring to a reasonable degree, oxygen is slowly added to replace nitrite as the oxidizing agent. The controlled flow of oxygen allows for an aerobic biofilm layer to grow on top of the anammox layer, creating the combined biofilm system (Wyffels I. S., 2004).

Typically, the Canon process results in a faster start up time than the Oland system. Because the ideal conditions for anammox are first provided in the Canon system, the slowly growing bacteria can reproduce in the most efficient conditions. Later, the faster growing AOB biofilm can be grown on the particle surface, creating an effective dual biofilm system. It is useful to mention that the Oland process was proposed earlier than the Canon system, with studies being published in 1997 and 2001, respectively (Wyffels I. S., 2004). The Cannon system is an improvement on the earlier method. 


\section{SNAD Process}

The SNAD process is similar to the Oland and Canon processes, but in addition to removing nitrogen compounds from wastewater, the SNAD process also removes COD. Simultaneous nitrification, anammox and denitrification is a combination of autotrophic ammonium oxidation (aerobic and anoxic), and heterotrophic nitrite and nitrate reduction. The method of establishing a SNAD reactor is similar to the Canon process, where an anammox population is first established in the reactor. Later, a controlled flow of air is provided to increase the DO, creating the Canon reactor. Finally, COD is introduced to the reactor, allowing heterotrophic denitrification to occur (Chen, Liu, Yang, Xue, \& Wang, 2009). In this way, the three groups of bacteria can co-exist in a biofilm reactor.

The SNAD process is advantageous, as it provides a route for the denitrification of nitrate, which is produced by the anaerobic oxidation of ammonia. In this way, greater removal of total nitrogen can occur in a single reactor. In some cases, if additional removal of nitrate is required, supplemental COD addition can provide substrate for greater denitrification.

\section{STAR Reactor}

The STAR reactor is an abbreviation for simultaneous treatment by an anammox/PAO reactor, and is a novel process for the removal of ammonia and phosphorus from wastewater. STAR utilizes a vertical configuration, reducing land requirements of the process while providing effective removal of phosphorus and ammonia. The reduced foot print of the reactor provides economic and logistic advantages when expanding or retrofitting existing treatment processes.

A 200 L/Day STAR reactor was developed and patented by researchers at Ryerson University (US Patent No. 61/826,676, 2013). Currently, a 20,000 L/Day demonstration plant is being designed for installation in a wastewater treatment plant in Durham Region, Ontario.

\section{Comparison of Reactors}

The performance of anammox reactors is dependent on the operating conditions of the process and quality of the wastewater. Greater detail on the various anammox processes will be discussed in Chapter 5. 


\subsection{Research Objectives}

The objective of the present study is to develop a three phase, fluidized bed bioreactor for the denitrification of wastewater. Additionally, the removal of ammonia, COD and total nitrogen (ammonia + nitrite + nitrate, abbreviated TN) will be investigated. The reactor must meet the following requirements:

1. Treatment will occur in a $700 \mathrm{~L}$, three phase fluidized bed reactor (FBR), as described in (Wan, 2006).

2. The FBR must contain an active population of anammox bacteria.

3. Three phase FBR will be fluidized by air.

4. Removal performance will be evaluated after a single pass through FBR.

In addition to the listed objectives for the reactor, a number of goals must be achieved, as follows:

1. Removal performance of ammonia from synthetic wastewater to be recorded over time

2. The contribution of ammonia removal by anammox bacteria, and traditional ammonia oxidizing bacteria is to be investigated

As this study focuses on the behaviour of anammox bacteria in an aerobic three phase fluidized bed reactor, a review of similar studies and reports will be provided. 


\subsection{Literature Review}

\subsection{Lab Scale Anammox Reactors}

Reactors using anammox bacteria have been the focus of many studies in the past 20 years. Since the discovery of anammox, early researchers investigated the mysterious new bacteria, uncovering details through long and tedious study. In 1995, after one of the first studies of the anammox phenomenon, Mulder et al. discovered that the bacteria would remove ammonia and nitrate from wastewater. Currently, it is accepted that anammox removes ammonia and nitrite, not nitrate. Although their research provided some invaluable data concerning the novel process, their conclusions were quickly revised. To date, this article has been cited in over 1100 publications, and the sludge produced from their research went on to seed the reactors for many more studies.

The discovery of a new ammonia oxidizing bacteria encouraged the greater investigation of many nitrifying reactors. In 1998, Helmer and Kunst first investigated a RBC plant treating landfill leachate, where total nitrogen removal of $83 \%$ was occurring in aerobic conditions. It was concluded that at DO concentrations below $1.0 \mathrm{mg} / \mathrm{L}$, nitrification and denitrification can occur simultaneously in a biofilm reactor. As the leachate wastewater was low in COD, it was assumed that autotrophic denitrification may be occurring. However, COD in the biofilm may have facilitated heterotrophic denitrification (Helmer \& Kunst, 1998). At the time, the participation of anammox in the reaction was not addressed.

In 1999, Helmer et al., reinvestigated the RBC plant using microbial analysis while considering anammox as a possible cause for total nitrogen removal. It was found that total nitrogen removal did not occur immediately, but instead started after a quantity of ammonia had converted to nitrite. It was concluded that this aerobic denitrification can occur only if ammonia and nitrite are present in an absence of COD. Further, 16S rRNA analysis identified bacteria that was similar to previous anammox samples (Helmer C. , et al., 1999). This collected data would be used to develop the Oland system, as shown in section 3.3 of this report (Third, Sliekers, Kuenen, \& Jetten, 2001). 
With greater knowledge of the fundamental anammox reaction, research could focus on optimizing anammox reactors to maximize the nitrogen removal rate (NRR). In the 1996 study of van de Graaf et al., a total nitrogen removal rate of $4.8 \mathrm{~kg} \mathrm{~N} / \mathrm{m}^{3} \cdot \mathrm{d}$ was achieved. At the time, high performing nitrifying reactors could achieve NRRs as high as $5.0 \mathrm{~kg} \mathrm{~N} / \mathrm{m}^{3} \cdot \mathrm{d}$ (van de Graaf, Bruijn, Robertson, Jetten, \& Kuenen, 1996). The achievable NRR in anammox reactors would quickly surpass nitrification reactors.

More recent Anammox reactors have achieved NRRs which are orders of magnitude greater than the reactors of the early 2000s. In 2011, Chen et al. achieved a NRR of $29.73 \mathrm{~kg} \mathrm{~N} / \mathrm{m}^{3} \cdot \mathrm{d}$ in a $1 \mathrm{~L}$ lab scale expanded granular sludge blanket reactor (EGSB). Synthetic wastewater was fed into the reactor at a high rate, providing a HRT of 0.3 hours. Although ammonia and nitrite removal performance were less than what had been seen in previous studies, at $71.77 \%$ and $86.51 \%$ respectively, the reactor could achieve $>90 \%$ removal by doubling the HRT. Moreover, the reactor was able to treat a variety of ammonia concentrations, ranging from 96-209 mg $\mathrm{NH}_{3}-\mathrm{N} / \mathrm{L}$ (Chen, Zheng, Tang, Wang, \& Ding, 2011).

In 2007, Tsushima et al. investigated a 0.8 L anaerobic upflow reactor utilizing nonwoven fabric sheets as a biofilm support material. By using this material for biomass attachment, a high concentration of bacteria could be maintained in the small reactor. Microbial analysis estimates $70 \%$ of the bacteria in the $0.8 \mathrm{~L}$ reactor was anammox, with an approximate VSS concentration of $16 \mathrm{~g} / \mathrm{L}$. This high concentration resulted in a NRR of $26.0 \mathrm{~kg} \mathrm{~N} / \mathrm{m}^{3} \cdot \mathrm{d}$ at a HRT of 0.24 hours. The TN removal was 58\% (Tsushima, Ogasawara, Kindaichi, Satoh, \& Okabe, 2007).

A comparison of various lab or pilot scale anammox reactors is shown in Table 5-1. For most of the anoxic anammox reactors, very high NRRs can be achieved in low HRTs. When ideal conditions are provided for anammox, exceptional removal rates are observed. However, when anammox is operated in aerobic conditions, such as in OLAND, CANON or SNAD, reduced performance occurs. Although the aerobic processes are single reactor systems, they sacrifice removal performance by avoiding the two stage system. 
Table 5-1: Lab scale and pilot scale anammox reactors

\begin{tabular}{|c|c|c|c|c|c|c|c|}
\hline \multirow[b]{2}{*}{ Details } & \multirow[b]{2}{*}{ Reactor Type } & \multirow[b]{2}{*}{$\begin{array}{l}\text { Reactor } \\
\text { Volume }\end{array}$} & \multirow[b]{2}{*}{$\begin{array}{c}\text { HRT } \\
\text { (Hours) }\end{array}$} & \multirow[b]{2}{*}{$\begin{array}{c}\text { NRR } \\
\text { (kg N/m3 day) }\end{array}$} & \multicolumn{2}{|c|}{ Total Nitrogen Removal } & \multirow[b]{2}{*}{ Source } \\
\hline & & & & & $\begin{array}{l}\text { Ammonia } \\
\text { Removal }\end{array}$ & $\begin{array}{l}\text { Nitrite } \\
\text { Removal }\end{array}$ & \\
\hline Anammox & EGSB & $1 \mathrm{~L}$ & 1.5 & 18.65 & $71.7 \%$ & $90.1 \%$ & (Chen, Zheng, Shen, \& Mahmood, 2011) \\
\hline Anammox & EGSB & $8 \mathrm{~L}$ & 0.98 & 15.8 & \multicolumn{2}{|c|}{$92 \%$} & (Chen, et al., 2010) \\
\hline Anammox & FBR & $2.5 \mathrm{~L}$ & 4.2 & 4.8 & - & - & $\begin{array}{c}\text { (van de Graaf, Bruijn, Robertson, Jetten, } \\
\text { \& Kuenen, 1996) }\end{array}$ \\
\hline Anammox & FBR & $23 \mathrm{~L}$ & 4.2 & 1.5 & - & - & $\begin{array}{c}\text { (Mulder, van de Graaf, Robertson, \& } \\
\text { Kuenen, 1995) }\end{array}$ \\
\hline Anammox & FBR & $2.5 \mathrm{~L}$ & 3.5 & 1.5 & $84 \%$ & $99 \%$ & $\begin{array}{c}\text { (Strous, van Gerven, Zheng, Kuenen, \& } \\
\text { Jetten, 1997) }\end{array}$ \\
\hline Anammox & $\begin{array}{c}\text { FBR, } \\
\text { Fixed Bed }\end{array}$ & $6 \mathrm{~L}$ & 0.4 & 20.7 & \multicolumn{2}{|c|}{$75 \%$} & (Ma, Hira, Li, Chen, \& Furukawa, 2011) \\
\hline Anammox & Fixed Bed & $0.8 \mathrm{~L}$ & 0.24 & 26.0 & \multicolumn{2}{|c|}{$58 \%$} & $\begin{array}{c}\text { (Tsushima, Ogasawara, Kindaichi, Satoh, } \\
\text { \& Okabe, 2007) }\end{array}$ \\
\hline Anammox & Fixed Bed & $2 \mathrm{~L}$ & 2.21 & 5.41 & $68.4 \%$ & $95.0 \%$ & (Ren-Cun \& Zheng, 2009) \\
\hline Anammox & Fixed Bed & $2 \mathrm{~L}$ & 6 & 1.1 & $88 \%$ & $99 \%$ & $\begin{array}{c}\text { (Strous, van Gerven, Zheng, Kuenen, \& } \\
\text { Jetten, 1997) }\end{array}$ \\
\hline Anammox & Gas Lift & $1.8 \mathrm{~L}$ & 6.7 & 8.9 & \multicolumn{2}{|c|}{93} & $\begin{array}{c}\text { (Sliekers, Third, Abma, Kuenen, \& } \\
\text { Jetten, 2003) }\end{array}$ \\
\hline Anammox & SBR & $2.2 \mathrm{~L}$ & 12 & 0.71 & $90 \%$ & $97 \%$ & (Tang, Zheng, Ding, \& Lu, 2014) \\
\hline Anammox & SBR & $2.8 \mathrm{~L}$ & 12 & - & $97.07 \%$ & $99.27 \%$ & (Du, et al., 2014) \\
\hline Anammox & UASB & $1.1 \mathrm{~L}$ & 0.11 & 76.7 & \multicolumn{2}{|c|}{$55.9 \%$} & (Tang, et al., 2011) \\
\hline Anammox & UASB & $1 \mathrm{~L}$ & 0.3 & 29.73 & $71.77 \%$ & $86.51 \%$ & $\begin{array}{c}\text { (Chen, Zheng, Tang, Wang, \& Ding, } \\
\text { 2011) }\end{array}$ \\
\hline Anammox & UASB & $0.7 \mathrm{~L}$ & 24 & 1.21 & $94 \%$ & $98.5 \%$ & (Zhang, et al., 2012) \\
\hline Anammox & UASB & $1.0 \mathrm{~L}$ & 120 & 0.66 & $62 \%$ & $100 \%$ & (Ahn, Hwang, \& Min, 2004) \\
\hline Anammox & UASB & $5.0 \mathrm{~L}$ & 20 & 0.464 & $69.0 \%$ & $92.8 \%$ & $\begin{array}{l}\text { (Jin, Ma, Mahmood, Yang, \& Zheng, } \\
\text { 2011) }\end{array}$ \\
\hline Anammox & UASB & $1.5 \mathrm{~L}$ & 18 & 0.3 & $87.5 \%$ & $86.5 \%$ & (Nozhevnikova, et al., 2012) \\
\hline
\end{tabular}




\begin{tabular}{|c|c|c|c|c|c|c|c|}
\hline Details & Reactor Type & $\begin{array}{l}\text { Reactor } \\
\text { Volume }\end{array}$ & $\begin{array}{c}\text { HRT } \\
\text { (Hours) }\end{array}$ & $\begin{array}{c}\text { NRR } \\
\text { (kg N/m3 day) }\end{array}$ & $\begin{array}{l}\text { Ammonia } \\
\text { Removal }\end{array}$ & $\begin{array}{c}\text { Nitrite } \\
\text { Removal }\end{array}$ & Source \\
\hline Anammox & $\begin{array}{l}\text { UASB, } \\
\text { Staged }\end{array}$ & $8.6 \mathrm{~L}$ & 3 & 5.34 & $77.7 \%$ & $92.7 \%$ & (Ji, et al., 2014) \\
\hline $\begin{array}{l}\text { Sharon- } \\
\text { Anammox }\end{array}$ & SBR & $2.2 \mathrm{~L}$ & 72 & 6.5 & $74.1 \%$ & $77.6 \%$ & (Li-Dong, et al., 2012) \\
\hline $\begin{array}{l}\text { Sharon- } \\
\text { Anammox }\end{array}$ & SBR, CSTR & $2.0 \mathrm{~L}, 1.5 \mathrm{~m}^{3}$ & 48 & 2.4 & \multicolumn{2}{|c|}{$92 \%$} & $\begin{array}{c}\text { (Fux, Boehler, Huber, Brunner, \& } \\
\text { Siegrist, 2002) }\end{array}$ \\
\hline CANON & CSTR & $2 \mathrm{~L}$ & 14 & 0.11 & \multicolumn{2}{|c|}{$92 \%$} & (Third, Sliekers, Kuenen, \& Jetten, 2001) \\
\hline CANON & Gas Lift & $1.8 \mathrm{~L}$ & 10 & 1.5 & \multicolumn{2}{|c|}{$42 \%$} & $\begin{array}{c}\text { (Sliekers, Third, Abma, Kuenen, \& } \\
\text { Jetten, 2003) }\end{array}$ \\
\hline CANON & Gas Lift & $1.8 \mathrm{~L}$ & 8 & 1.5 & $70 \%$ & - & (Liu, et al., 2012) \\
\hline CANON & SBR & $2.9 \mathrm{~L}$ & 4 & 1.2 & \multicolumn{2}{|c|}{$84 \%$} & $\begin{array}{c}\text { (Winkler, Kleerebezem, \& van } \\
\text { Loosdrecht, 2012) }\end{array}$ \\
\hline CANON & SBR & $2 \mathrm{~L}$ & 24 & 0.11 & \multicolumn{2}{|c|}{$92 \%$} & (Third, Sliekers, Kuenen, \& Jetten, 2001) \\
\hline OLAND & $\mathrm{RBC}$ & $50 \mathrm{~L}$ & 18.5 & 0.61 & \multicolumn{2}{|c|}{$84 \%$} & (Windey, Bo, \& Verstraete, 2005) \\
\hline OLAND & RBC & $44 \mathrm{~L}$ & 17 & 1.06 & \multicolumn{2}{|c|}{$89 \%$} & (Pynaert, et al., 2003) \\
\hline OLAND & $\mathrm{RBC}$ & 3.6L & 16 & 0.642 & \multicolumn{2}{|c|}{$79 \%$} & $\begin{array}{c}\text { (Clippeleir, Yan, Verstraete, \& } \\
\text { Vlaeminck, 2011) }\end{array}$ \\
\hline OLAND & SBR & $2 \mathrm{~L}$ & 4 & 1.03 & \multicolumn{2}{|c|}{$74 \%$} & $\begin{array}{l}\text { (Schaubroeck, Bagchi, Carballa, } \\
\text { Verstraete, \& Vlaeminck, 2012) }\end{array}$ \\
\hline SNAD & Gas Lift & $1.0 \mathrm{~L}$ & 55.4 & 0.346 & \multicolumn{2}{|c|}{$98.4 \%$} & (Kelusar, Nerurkar, \& Desai, 2013) \\
\hline SNAD & $\mathrm{RBC}$ & $1.2 \mathrm{~L}$ & 6 & 0.24 & \multicolumn{2}{|c|}{$70 \%$} & (Chen, Liu, Yang, Xue, \& Wang, 2009) \\
\hline SNAD & SBR & $2.5 \mathrm{~L}$ & 24 & 2.14 & \multicolumn{2}{|c|}{$93 \%$} & (Daverey, Su, Huang, \& Lin, 2012) \\
\hline SNAD & SBR, MBBR & $2.5 \mathrm{~L}$ & 24 & 0.35 & \multicolumn{2}{|c|}{$96 \%$} & (Daverey, Chen, Sung, \& Lin, 2014) \\
\hline
\end{tabular}


Du et al. studied a 2.8L SBR at varying carbon to nitrogen $(\mathrm{C} / \mathrm{N})$ ratios. Initially, the reactor had been operating without organic carbon, and was removing $71.4 \%$ of TN. Although ammonia and nitrite removal were both above 95\%, remaining nitrate from previous cycles reduced the overall TN removal. When the $\mathrm{C} / \mathrm{N}$ ratio was increased to 1 , the $\mathrm{TN}$ removal increased to $77.46 \%$. In this case, Anammox removed $68.13 \%$ of the TN, heterotrophic denitrifiers removed $6.87 \%$, and the remaining $2.46 \%$ was removed through other sources. As the $\mathrm{C} / \mathrm{N}$ removal increased to 2, Anammox accounted for $71.86 \%$ of the measured $93.14 \% \mathrm{TN}$ removal, and heterotrophic denitrification removed $19.70 \%$. However, when $\mathrm{C} / \mathrm{N}$ reached 4 , Anammox was responsible for $19.27 \%$ of the $70.16 \%$ TN removed, and heterotrophs were responsible for 48.35\% (Du, et al., 2014).

Based on the results of Du et al., Anammox performance was relatively unimpaired at $\mathrm{C} / \mathrm{N}$ values below 4. However, once sufficient COD was available to allow full denitrification, the contribution of Anammox was reduced. A similar study was performed by Camchoi, Nitisoravut \& Schmidt, where three parallel $200 \mathrm{~mL}$ UASB reactors operated at varying COD concentrations. At $\mathrm{C} / \mathrm{N}$ ratios of 0.9 and $1.4, \mathrm{TN}$ removal rates were above $90 \%$. However, as $\mathrm{C} / \mathrm{N}$ ratios increased above 2.0, TN removal was reduced by approximately $15 \%$. Although Anammox performance can be impacted by high $\mathrm{C} / \mathrm{N}$ ratios, Anammox and heterotrophic denitrifiers can operate simultaneously in wastewater containing COD.

In a 2006 study by Zhu, Hu \& Liang, six parallel 6.8L anaerobic SBRs were used to investigate Anammox performance under six different $\mathrm{C} / \mathrm{N}$ ratios. Ratios tested range from 0 to 3.38. It was found that Anammox and heterotrophic denitrifiers can operate in the same reactor with and without the presence of COD. In all reactors, nitrite was consumed rapidly, as is expected. However, COD and ammonia removal rates were reduced with increasing COD ratios. The limited supply of nitrite prevented the anaerobic removal of ammonia, in addition to reducing the total COD consumed through denitrification. Moreover, in all reactors containing COD, nitrate accumulation was significantly reduced. The ideal $\mathrm{C} / \mathrm{N}$ ratio was around 0.82 (Zhu, Hu, \& Liang, 2006). 
In 2004, Anh, Hwang and Min reported on their study of a 1L UASB reactor treating piggery wastewater with a $\mathrm{C} / \mathrm{N}$ ratio above 11 . Over $90 \%$ of the nitrogen in the wastewater was in the form of ammonia. Instead of using an aerobic stage to oxidize ammonia, nitrite solution was added to provide the necessary ratio for favourable anammox activity. It was found that ammonia removal around $65 \%$ could be achieved, with $100 \%$ removal of nitrite and minimal nitrate accumulation. Approximately $40 \%$ of the COD was removed from the wastewater. Although much of the total nitrogen removal could be attributed to heterotrophic denitrification, it was determined that approximately $50 \%$ of incoming ammonia was a removed by anammox. The remainder was removed through fermentation (Ahn, Hwang, \& Min, 2004). Based on the results of their study, Anh, Hwang and Min concluded that anammox bacteria does not compete with heterotrophic denitrifiers. Other researchers question this claim (Chamchoi, Nitisoravut, \& Schmidt, 2008).

A lab scale RBC (44L, $6.3 \mathrm{~m}^{2}$ disk surface area, 50\% submersion of disk) was investigated in the study of Pynaert et al., 2003, and found the system capable of reasonable total nitrogen removal. While RBCs are generally used to facilitate aerobic reactions, the slow rotation speed of 2.5 RPM alongside high submergence allowed for Anammox bacteria to function in the reactor, providing $89 \%$ removal of TN. The researchers found a NRR of $1.06 \mathrm{~kg} \mathrm{~N} / \mathrm{m}^{3} \cdot \mathrm{d}$, or $7.4 \mathrm{~g}$ $\mathrm{N} / \mathrm{m}^{2} \cdot \mathrm{d}$ when considering the disk surface area (Pynaert, et al., 2003). Microbial analysis indicated the biofilm was primarily ammonia oxidizers, with Anammox dispersed in clusters throughout.

In an earlier study, Pynaert et al. identified the slow RBC rotation speed as a limiting factor in the performance of their reactor. By limiting the rotation speed to 2-3 RPM, compared to the typical values of 5-20 RPM, the ammonia oxidizing capacity was much lower than optimal values. In the study, the RBC oxidized $1350 \mathrm{mg} \mathrm{N} / \mathrm{m}^{2} \cdot \mathrm{d}$, compared to the optimal value of 6000 $\mathrm{mg} \mathrm{N} / \mathrm{m}^{2} \cdot \mathrm{d}$ (Pynaert, Sprengers, Laenen, \& Verstraete, 2002). However, this reduced RPM is necessary to maintain sufficiently low DO concentrations in the reactor. The low DO concentration results in a selection of ammonia oxidizing bacteria, and a reduced penetration of oxygen into the biofilm. 


\subsection{Kinetic Modeling of Anammox}

The concentration of oxygen has a large impact on the performance of anammox. Previous researchers have found that the removal performance is reduced once dissolved oxygen exceeds $0.1 \mathrm{mg} / \mathrm{L}$ (Third, et al., 2005). To quantify the change in removal performance, two modifications to the Activated Sludge Model 1 (ASM1) can be used. The first modification was published by Dapena-Mora et al. in 2004, and proposes two pathways for anammox growth and decay. The following term shows the growth rate of anammox is dependent on the oxygen concentration, $S_{o}$ :

$$
\begin{gathered}
\rho_{\text {ANgrowth }}=\mu_{A N}^{M A X}\left(\frac{K_{O, A N}}{K_{O, A N}+S_{O}}\right)\left(\frac{S_{N O 2}}{K_{N O 2, A N}+S_{N O 2}}\right)\left(\frac{S_{N H}}{K_{N H, A N}+S_{N H}}\right) X_{A N} \\
\rho_{A N \text { decay }}=b_{A N} X_{A N}
\end{gathered}
$$

The anammox model requires the modification by Wyffels, et al., where the single combined nitrite and nitrate term from ASM1 is separated into two separate variables, and the generalized nitrifying reaction is separated into ammonium oxidation and nitrite oxidation. The complete model is given in the appendices, and includes a number of small modifications to kinetic parameters and coefficients. For example, the following terms show how the $A O B$ and NOB growth terms are separated into two independent reactions.

$$
\begin{gathered}
\rho_{\text {AOBgrowth }}=\mu_{N H}^{M A X}\left(\frac{S_{O}}{K_{O, N H}+S_{O}}\right)\left(\frac{S_{N H 3}}{K_{N H 3, N H}+S_{N H 3}}\right) X_{N H} \\
\rho_{N O B g r o w t h}=\mu_{N O}^{M A X}\left(\frac{S_{O}}{K_{O, N O}+S_{O}}\right)\left(\frac{S_{H N O 2}}{K_{H N O 2, N O}+S_{H N O 2}}\right) X_{N O}
\end{gathered}
$$

The above parameters and variables have been described in section 2.5 , where the details for ASM1 were first given. When the proposed model is applied to the stoichiometric matrix form (See ASM1), the grid shown in Table 5-2 results. This grid can be combined with the ASM1 matrix to develop a model which considers both autotrophic nitrificiation and denitrification, as well as heterotrophic denitrification. The values for parameters identified by Cema et al. are shown in Table 5-3. 


\begin{tabular}{|c|c|c|c|c|c|c|c|c|}
\hline $\begin{array}{l}\text { Name: } \\
\text { Symbol: } \\
\text { Unit: }\end{array}$ & $\begin{array}{c}\text { Ammonium } \\
\mathrm{S}_{\mathrm{NH}} \\
\mathrm{gNm}^{-3}\end{array}$ & $\begin{array}{l}\text { Nitrite } \\
\mathrm{SNO}_{2} \\
\mathrm{gNm}^{-3}\end{array}$ & $\begin{array}{l}\text { Nitrate } \\
\mathrm{SNO}_{3} \\
\mathrm{gNm}^{-3}\end{array}$ & $\begin{array}{c}\text { Nitrogen gas } \\
\mathrm{S}_{\mathrm{N}_{2}} \\
\mathrm{gNm}^{-3}\end{array}$ & $\begin{array}{c}\text { Anammox } \\
X_{\mathrm{AN}} \\
\text { gCOD m-3 }\end{array}$ & $\begin{array}{c}\text { Slowly } \\
\text { degradable } \\
\text { substrate } \\
X_{\mathrm{s}} \\
\text { gCODm }^{-3}\end{array}$ & $\begin{array}{c}\text { Inert } \\
x_{i} \\
\text { gCOD m } m^{-3}\end{array}$ & $\begin{array}{l}\text { Process rate } \\
\qquad 000 \mathrm{~m}^{-3} \mathrm{~d}^{-1}\end{array}$ \\
\hline $\begin{array}{l}\text { Growth of } X_{A N} \\
\text { Decay of } X_{A N}\end{array}$ & $\begin{array}{l}-1 / Y_{A N-f o m} \\
i_{\text {nam }}-f_{\text {Nos }}\end{array}$ & $-\left(1.52+1 / Y_{A N}\right)$ & 1.52 & $2 / Y_{A N}$ & -1 & $(1-f)$ & $f_{i}$ & $\begin{array}{l}\text { Pgrowth } \\
\text { Plocay }\end{array}$ \\
\hline
\end{tabular}

Table 5-3: Kinetic parameters for anammox with ASM1. (Cema, Sochacki, Zubiatowicz, Gutwinski, \& Surmacz-Gorska, 2012)

\begin{tabular}{|c|c|c|}
\hline Parameter & Unit & Value \\
\hline $\boldsymbol{K}_{\boldsymbol{N O 2 , A N}}$ & $\mathrm{gN} / \mathrm{m}^{3}$ & 2.00 \\
\hline $\boldsymbol{K}_{\boldsymbol{O}, A N}$ & $\mathrm{gO}_{2} / \mathrm{m}^{3}$ & 0.7 \\
\hline $\boldsymbol{K}_{\boldsymbol{N H}, A N}$ & $\mathrm{gN} / \mathrm{m}^{3}$ & 0.08 \\
\hline $\boldsymbol{Y}_{A N}$ & $\mathrm{gCOD} / \mathrm{gN}$ & 0.150 \\
\hline $\boldsymbol{i}_{\boldsymbol{N} X \boldsymbol{B} \boldsymbol{A}}$ & $\mathrm{gCOD} / \mathrm{gCOD}$ & 0.0562 \\
\hline $\boldsymbol{i}_{\boldsymbol{N X P}}$ & $\mathrm{gN} / \mathrm{gCOD}$ & 0.06 \\
\hline
\end{tabular}

Based on the $\mathrm{K}_{\mathrm{O}, \mathrm{AN}}$ value proposed by Cema et al., one can make some preliminary estimations of the impact of oxygen on anammox performance. When compared to anaerobic conditions (DO $<0.1 \mathrm{mg} / \mathrm{L}$ ), where anammox performance is greatest, DO concentrations exceeding 0.7 $\mathrm{mg} / \mathrm{L}$ result in a $50 \%$ reduction in growth. As oxygen concentration reaches $1.5 \mathrm{mg} / \mathrm{L}$, anammox growth is reduced to $30 \%$. Therefore, in order to achieve reliable and effective nutrient removal, anammox must be protected from oxygen.

Many researchers use nitrogen, argon or other oxygen displacing gasses to ensure that anammox is always kept in anaerobic conditions. However, on an industrial scale, this is not always feasible. In order to successfully create a single reactor for partial nitrification and anammox (i.e. CANON, SNAD, OLAND etc.), the anaerobic bacteria must covered by an oxygen consuming aerobic biofilm. This theory has been successfully applied by many researchers, using sludge granules, free-flowing biofilm carriers or stationary surfaces for biofilm accumulation. However, in the study of Xiao, Xiao and Xiang, 2014, the impact of dissolved 
oxygen on sludge granules was investigated and simulated using fundamental principles. In this case, $r_{u t}$ is the DO consumption rate, $q$ is the max DO consumption rate, $S_{f}$ is the DO concentration, $\mathrm{X}_{\mathrm{f}}$ is the biofilm density, and $\mathrm{K}$ is the affinity coefficient.

$$
r_{u t}=-q\left(\frac{S_{f}}{K+S_{f}}\right) X_{f}
$$

Additionally, the diffusion of oxygen in biofilm can be approximated using Fick's second law, as shown below. Note that the diffusion rate of oxygen, $D_{f}$, is approximated as $0.8 D_{02}$, were $D_{02}$ is the bulk dissolved oxygen diffusivity (Xiao, Xiao, \& Xiang, 2014):

$$
r_{d i f}=D_{f} \frac{d^{2} S_{f}}{d r^{2}}
$$

Combining the two equations and solving allows for the determination of the dissolved oxygen concentration in the biofilm. The generalized dissolved oxygen profile is shown in Figure 5-1. Based on the results of simulation, Xiao, Xiao and Xiang determined that the size of the biomass granule determined the likelihood of anammox performance. Particles exceeding $500 \mu \mathrm{m}$ contained anammox, accounting for $68 \%$ of the ammonia removal. Comparatively, $35 \%$ of the ammonia removal occurring in smaller particles $(<500 \mu \mathrm{m})$ was attributed to anammox.

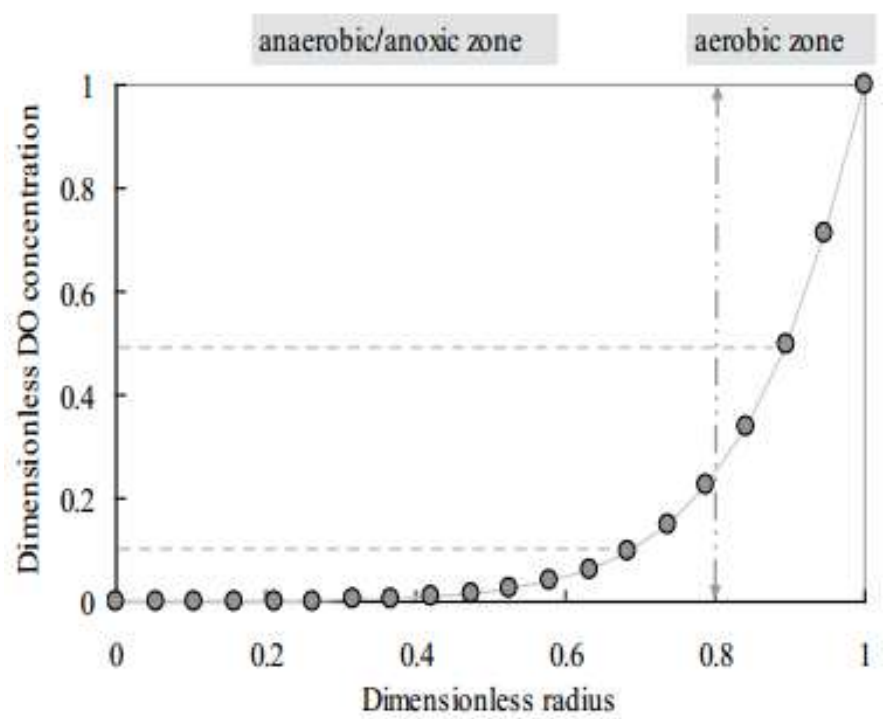

Figure 5-1: Dimensionless oxygen distribution in biofilm (Xiao, Xiao, \& Xiang, 2014) 
In a similar study, Picioreanu, van Loosdrecht and Heijnen investigated the DO profile in sludge granules ( $3 \mathrm{~mm}$ diameter), observing similar trends. The researchers found that the bulk DO was consumed after a short distance into the particle, providing favourable conditions for anaerobic and anoxic bacteria to reproduce. This behaviour is shown in Figure 5-2.

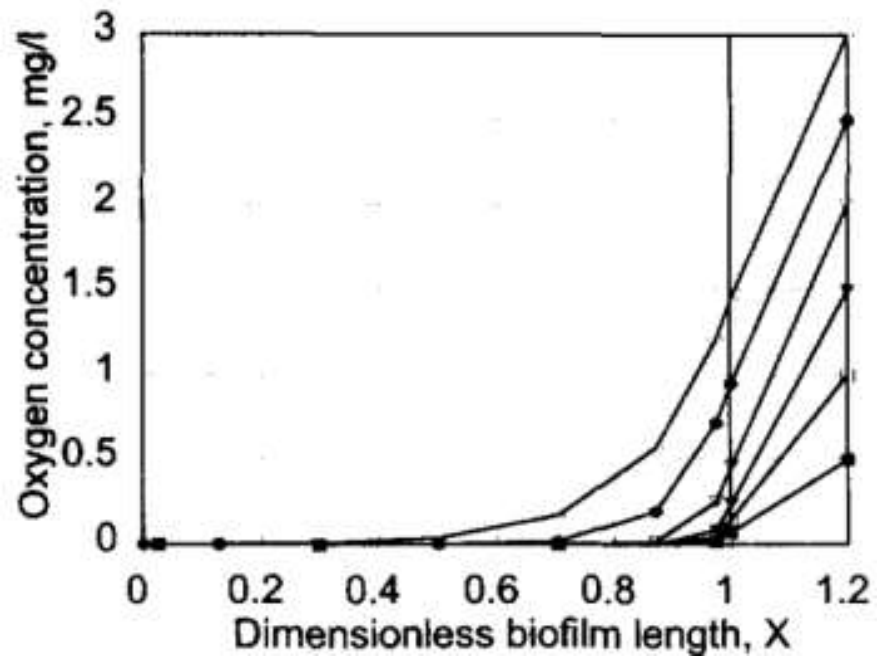

Figure 5-2: DO profile in spherical sludge granules, from (Picioreanu, van Loosdrecht, \& Heijnen, 1997)

Additionally, the study investigated the profile of ammonia, nitrite and nitrate in the spherical sludge granules. It was found that no concentration profile is observed for the three nitrogen compounds in the biofilm system (Picioreanu, van Loosdrecht, \& Heijnen, 1997). The lack of a concentration profile can be attributed to a number of causes. Primarily, the rate of consumption of oxygen in wastewater is much more rapid than the reaction rate of ammonia, nitrite or nitrate. Because of this, oxygen becomes the limiting reagent in the biofilm system, and is quickly consumed.

When performing kinetic modeling, the assumption of a uniform dispersion of biological materials is usually made. It is difficult to incorporate the spatial distribution of various bacteria into the calculations. Instead, experimental studies can be performed to investigate the profile of the various compounds in the biofilm. In the study performed by Tsushima et al., 2007, it was found that there is a definite concentration profile for ammonia, nitrite and nitrate in a fully anaerobic anammox biofilm, as shown in Figure 5-3. This measured data is contradictory to the previous kinetic models, but may be explained by investigating the spatial distribution of 
bacteria in the biofilm. In this case, the first $0-1 \mathrm{~mm}$ of biofilm contains $89 \%$ anammox, whereas the 1-3 $\mathrm{mm}$ and 3-4 $\mathrm{mm}$ of biofilm contain only $74 \%$ and $72 \%$ anammox, respectively (Tsushima, Ogasawara, Kindaichi, Satoh, \& Okabe, 2007). The remaining bacteria was determined to be a variety of $\mathrm{AOBs}$ in the nitrosomonas genus.
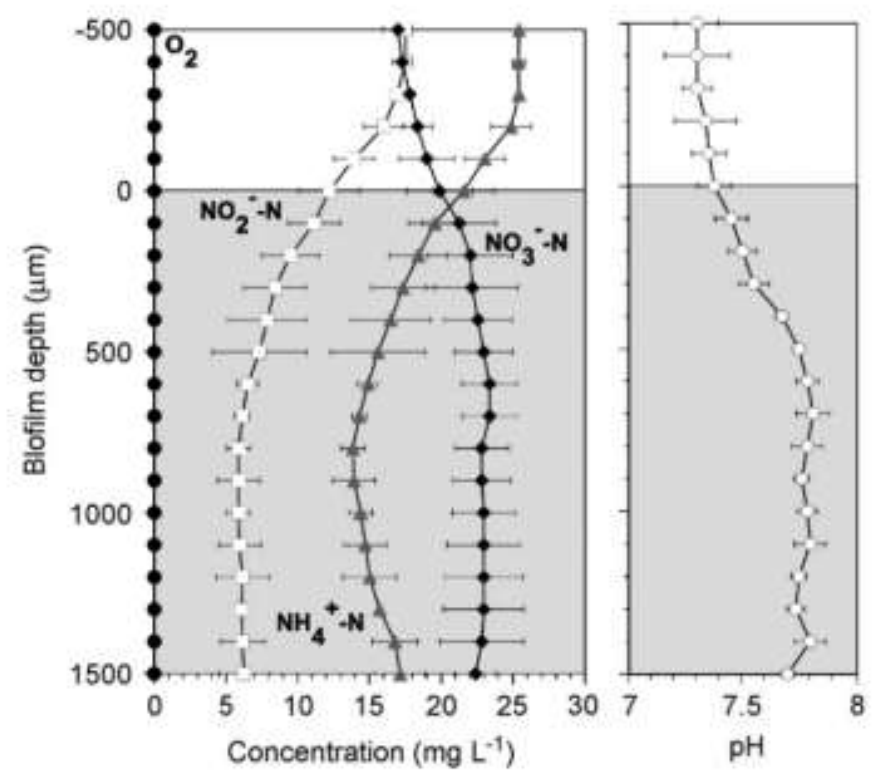

Figure 5-3: Steady state profile of ammonia, nitrite, nitrate, oxygen and pH in biofilm. From (Tsushima, Ogasawara, Kindaichi, Satoh, \& Okabe, 2007)

Calculations similar to the work of Xiao, Xiao and Xiang and Picioreanu, van Loosdrecht and Heijnen can be performed to maximize the nitrogen removing potential of a reactor. This is most useful to investigate the DO profile, as the distribution of anammox will depend on the surrounding oxygen concentration. Because the granule size or biofilm thickness can be controlled by the reactor operating conditions and shear rate, it is useful to investigate the characteristics of different biofilm granules.

An, $\mathrm{Xu}$, Yang and Li investigated the performance of anammox granules of three different diameters, including $670 \mu \mathrm{m}, 1050 \mu \mathrm{m}$ and $1840 \mu \mathrm{m}$, in three separate SBRs. It was found that the larger granules were more resilient to shocks in nutrient concentrations or temperatures. However, due to the reduced specific surface area, the larger granules observed reduced anammox performance. The smaller granules showed greater nitrogen removal, but were more susceptible to reduced performance due to nutrient shock (An, Xu, Yang, \& Li, 2013). 
In order to quantify the impact that air flow rate had on biofilm characteristics, Tavares, Santanna \& Capdeville measured the biofilm accumulation on spherical biofilm carriers at varying air flow rates. It was found that the total biomass accumulation on the particles was a function of the air flow rate, where a greater mass was able to accumulate at lower flow rates. The higher shear rate at increased air flow discouraged the accumulation of biomass. The study also investigated the COD removal performance, polysaccharide concentration and protein concentration in the biofilm. It was found that COD removal performance remained around $82 \%$ for all three trials, and that the protein to polysaccharide ratio remained constant for all trials (Tavares, Santanna, \& Capdeville, 1995).

\subsection{Full Scale Anammox Reactors}

In 2002, Fux et al. investigated a pilot scale Sharon-Anammox reactor (combined volume $5 \mathrm{~m}^{3}$ ), which was able to consistently treat the supernatant from the anaerobic digester effluent of a treatment plant. In this case, the Sharon reactor was required to oxidize an appropriate amount of ammonia, as to achieve the proper ratio of nitrite to ammonia. Fux et al. showed that it is possible to consistently treat a variable inlet concentration to remove a large portion of TN from digester supernatant streams (92\%). Based on the success of the pilot plant, a $500 \mathrm{~m}^{3}$ reactor of similar design was proposed (Fux, Boehler, Huber, Brunner, \& Siegrist, 2002).

By 2004, the $500 \mathrm{~m}^{3}$ reactor proposed in the study of Fux et al., was fully operational. The upscaling process took 2 years to complete, primarily due to the slow growth rate of the anammox biomass. The $500 \mathrm{~m}^{3}$ SBR in Austria utilizes the DEMON technology, and is able to remove $89.3 \%$ of incoming ammonia, or $83.9 \%$ of the incoming total nitrogen (Wett B. , 2006). The anammox process was developed in a pre-existing reactor, replacing a conventional nitrification/denitrification system. As a result of the implementation of the anammox process, greater TN removal was observed, and total cost of treatment was reduced. Total air demand was reduced from $109 \mathrm{~m}^{3} / \mathrm{kg} \mathrm{N}$ to $29 \mathrm{~m}^{3} / \mathrm{kg} \mathrm{N}$, and treatment cost was reduced to $0.79 \mathrm{kWh} / \mathrm{kg}$ N (Wett B. , 2006).

Similarly, the first full scale anammox reactor, a $70 \mathrm{~m}^{3}$ gas lift reactor built in Rotterdam, NL, resulted in more effective nitrogen removal at the WWTP with a minimal reactor footprint (10 
$\mathrm{m}^{2}$ ) (van der Star, et al., 2007). The internal configuration of this reactor is shown in Figure 3-15 (See page 47). The reactor treats the effluent from an anaerobic digester with ammonia concentrations around $1200 \mathrm{mg} \mathrm{N} / \mathrm{L}$ and flow rates between $2-8 \mathrm{~m}^{3} /$ hour. After passing through a Sharon reactor, the wastewater enters the anammox reactor, removing over $10 \mathrm{~kg}$ $\mathrm{N} / \mathrm{m}^{3}$ day, or $75 \mathrm{~kg}-\mathrm{N} / \mathrm{m}^{2}$ day (footprint), with no supplementary carbon sources or air addition. Because the anammox reaction produces nitrogen gas, the reactor can be mixed by the recycle of effluent nitrogen (van der Star, et al., 2007).

Currently, there exists many full scale anammox reactors. Most reactors are single stage, combined partial nitrification and anammox systems, with the SBR being the most common configuration. A variety of the full scale reactors are shown in Table 5-4.

The size of the anammox reactors can vary significantly, depending on the type of wastewater being treated. In some factory settings, where excess space is available, massive anammox reactors have been built. In Tongliao, China, a $6600 \mathrm{~m}^{3}$ anammox reactor has been built for the treatment of wastewater produced in the industrial Monosodium Glutamate (MSG) production (Lackner, et al., 2014). It is common to see anammox reactors applied for the treatment of MSG wastewater, as the effluent wastewater can have ammonia concentrations exceeding 15,000 $\mathrm{mg} / \mathrm{L}$, and C:N ratios below what is needed for heterotrophic denitrification (Li-Dong, et al., 2012).

However, when compared to the lab and pilot scale processes, full scale processes show reduced nitrogen removal rates (NRR). When reviewing the reactors summarized in Table 5-1 (see page 54, 55), small anammox reactors can have NRRs exceeding $75 \mathrm{~kg}-\mathrm{N} / \mathrm{m}^{3}$ day. The small scale processes allows for greater control of the reaction and influent conditions, creating higher NRRs. This is much more difficult to replicate in full scale processes, especially when the reactor volume exceeds $100 \mathrm{~m}^{3}$. Generally, full scale anammox reactors have NRRs in the range of 0.3 to $2.0 \mathrm{~kg}-\mathrm{N} / \mathrm{m}^{3}$ day. As observed in Table 5-4, some reactors are above or below this value, depending on the operating conditions. Typically, purely anoxic anammox reactors have greater removal rates, and combined aerobic/anoxic processes (CANON, DEMON, OLAND etc) have reduced NRRs. This is a result of the inhibition of the anammox reaction by oxygen. 
Table 5-4: Full scale anammox reactors

\begin{tabular}{|c|c|c|c|c|c|c|}
\hline Reactor Type & Reactor Volume & Details & Location & $\begin{array}{c}\text { NRR } \\
(\mathrm{kg} / \mathrm{m} 3 \text { day })\end{array}$ & $\begin{array}{l}\text { Date in } \\
\text { Operation }\end{array}$ & Source \\
\hline SBR & $500 \mathrm{~m}^{3}$ & DEMON & $\begin{array}{l}\text { WWTP Strass, } \\
\text { Austria }\end{array}$ & 0.6 & 2004 & (Wett B. , 2006) \\
\hline SBR & $3000 \mathrm{~m}^{3}$ & DEMON & Alexandria, USA & 0.42 & 2013 & (Lackner, et al., 2014) \\
\hline SBR & $400 \mathrm{~m}^{3}$ & DEMON & $\begin{array}{l}\text { Glarnerland, } \\
\text { Switzerland }\end{array}$ & 0.40 & 2006 & (Lackner, et al., 2014) \\
\hline SBR & $\begin{array}{c}22,000 \mathrm{~m}^{3} \\
\text { (six reactors) }\end{array}$ & DEMON & Blue Plains, USA & 0.58 & 2014 & $\begin{array}{l}\text { (Figdore, Wett, Hell, \& Murthy, } \\
\text { 2001) (Lackner, et al., 2014) }\end{array}$ \\
\hline SBR & $606 \mathrm{~m}^{3}$ & DEMON & $\begin{array}{l}\text { Thun, } \\
\text { Switzerland }\end{array}$ & 0.67 & 2008 & (Lackner, et al., 2014) \\
\hline SBR & $134 \mathrm{~m}^{3}$ & DEMON & $\begin{array}{l}\text { Plettenber, } \\
\text { Germany }\end{array}$ & 0.5 & 2008 & (Lackner, et al., 2014) \\
\hline UASB & $5400 \mathrm{~m}^{3}$ & Anammox & $\begin{array}{l}\text { Wulumuq, } \\
\text { China }\end{array}$ & 2.0 & 2011 & (Lackner, et al., 2014) \\
\hline UASB & $600 \mathrm{~m}^{3}$ & Anammox & $\begin{array}{l}\text { Olburgen, } \\
\text { Netherlands }\end{array}$ & 1.8 & 2006 & (Lackner, et al., 2014) \\
\hline UASB & $70 \mathrm{~m}^{3}$ & Anammox & $\begin{array}{l}\text { Rotterdam, } \\
\text { Netherlands }\end{array}$ & 10 & 2002 & (van der Star, et al., 2007) \\
\hline UASB & $560 \mathrm{~m}^{3}$ & Anammox & Shaoxing, China & 1.6 & 2011 & (Ni \& Zhang, 2013) \\
\hline UASB & $1760 \mathrm{~m}^{3}$ & Anammox & Coventry, UK & 2.3 & 2011 & (Ni \& Zhang, 2013) \\
\hline UASB & $6600 \mathrm{~m}^{3}, 4100 \mathrm{~m}^{3}$ & Anammox & Tongliao, China & 2.0 & 2010 & (Lackner, et al., 2014) \\
\hline MBBR & $300 \mathrm{~m}^{3}$ & CANON & Malmo, Sweden & 1.0 & 2011 & (Lackner, et al., 2014) \\
\hline MBBR & $140 \mathrm{~m}^{3}$ & CANON & $\begin{array}{l}\text { Grindsted, } \\
\text { Denmark }\end{array}$ & 0.7 & 2013 & (Lackner, et al., 2014) \\
\hline MBBR & $600 \mathrm{~m}^{3}$ & CANON & $\begin{array}{l}\text { Holbæk, } \\
\text { Denmark }\end{array}$ & 0.2 & 2012 & (Lackner, et al., 2014) \\
\hline
\end{tabular}




\begin{tabular}{|c|c|c|c|c|c|c|}
\hline Reactor Type & Reactor Volume & Details & Location & $\begin{array}{c}\text { NRR } \\
\text { (kg/m3 day) }\end{array}$ & $\begin{array}{c}\text { Date in } \\
\text { Operation }\end{array}$ & Source \\
\hline RBC & $6 \mathrm{~m}^{3}$ & OLAND & $\begin{array}{c}\text { Sneek, } \\
\text { Netherlands }\end{array}$ & 0.9 & 2012 & (Lackner, et al., 2014) \\
\hline RBC & $240 \mathrm{~m}^{3}$ & OLAND & Pitsea, UK & 1.7 & - & (Lackner, et al., 2014) \\
\hline RBC & $80 \mathrm{~m}^{3}$ & OLAND & $\begin{array}{c}\text { Mechernich, } \\
\text { Germany }\end{array}$ & 0.6 & - & (Lackner, et al., 2014) \\
\hline Activated Sludge & $1400 \mathrm{~m}^{3}$ & CANON & $\begin{array}{l}\text { Stockholm, } \\
\text { Sweden }\end{array}$ & 0.3 & 2007 & (Lackner, et al., 2014) \\
\hline Activated Sludge & $230 \mathrm{~m}^{3}$ & CANON & $\begin{array}{l}\text { Hattingen, } \\
\text { Germany }\end{array}$ & 0.5 & 2003 & (Lackner, et al., 2014) \\
\hline Activated Sludge & $384 \mathrm{~m}^{3}$ & SNAD & Taiwan, Japan & - & 2006 & (Wang, et al., 2010) \\
\hline $\begin{array}{c}\text { Multi Stage, } \\
\text { Activated Sludge }\end{array}$ & $\begin{array}{c}1509 \mathrm{~m}^{3} \\
\text { (3 stages) }\end{array}$ & Anammox & Budrio, Italy & 0.23 & 2010 & (Lackner, et al., 2014) \\
\hline $\begin{array}{c}\text { Multi Stage, } \\
\text { Activated Sludge }\end{array}$ & $\begin{array}{c}5310 \mathrm{~m}^{3} \\
\text { (3 stages) }\end{array}$ & Anammox & $\begin{array}{c}\text { Boxtel, } \\
\text { Netherlands }\end{array}$ & 0.17 & 2014 & (Lackner, et al., 2014) \\
\hline $\begin{array}{c}\text { Multi Stage, } \\
\text { Activated Sludge }\end{array}$ & $\begin{array}{c}7920 \mathrm{~m}^{3} \\
\text { (3 stages) }\end{array}$ & Anammox & $\begin{array}{l}\text { Bergen op } \\
\text { Zoom, } \\
\text { Netherlands }\end{array}$ & 0.09 & 2009 & (Lackner, et al., 2014) \\
\hline
\end{tabular}


As the anammox technology becomes more developed, more variations in reactor types will be investigated. As shown in Figure 5-4, the number of installations quickly grew after the initial discovery of the processes, and now exceeds 100 worldwide. Applications in the treatment of municipal and industrial wastewater show how the anammox process can result in significant cost savings. Initially, the two stage partial nitrification and anammox process was used for municipal wastewater treatment as a side stream process. More recently, the one stage process is becoming more common than the two stage process, with SBRs being the most common reactor configuration (Lackner, et al., 2014). The potential cost savings makes attractive the study of anammox in unique conditions, including in the main stream treatment of wastewater (Winkler, Kleerebezem, \& van Loosdrecht, 2012).

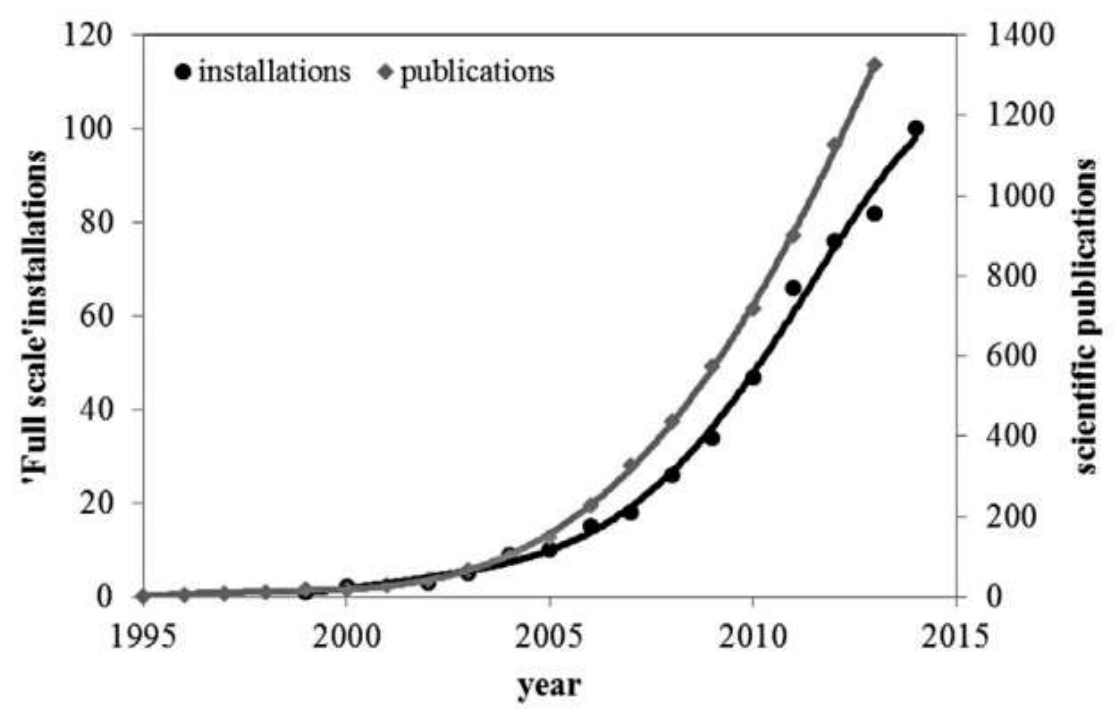

Figure 5-4: Number of full scale anammox reactors, and publications. From (Lackner, et al., 2014) 


\subsection{Apparatus and Procedure}

\subsection{Reactor Configuration}

The present experimental work occurred in a $0.70 \mathrm{~m}^{3}$, three phase fluidized bed bioreactor, as described in the study of Wan, 2006. The reactor is cylindrical with a height of $2.5 \mathrm{~m}$ and a diameter of $0.60 \mathrm{~m}$. Wastewater is fed through three points around the perimeter of the base of the column (see Figure 6-1). Three disk shape fine air diffusers are located at the base of the reactor, supplying the reactor with air. In the study of Wan, 2006, three additional tube type air diffusers were installed $1.2 \mathrm{~m}$ above the base of the reactor. However, they were removed for this study. The reactor dimensions are summarised in Table 6-1.

Table 6-1: Three phase fluidized bed reactor description, from (Wan, 2006)

\section{Fluidized Bed Reactor Physical Dimensions}

\begin{tabular}{|l|l|}
\hline Height & $2.5 \mathrm{~m}$ \\
\hline Diameter & $0.60 \mathrm{~m}$ \\
\hline Total reactor volume & $0.70 \mathrm{~m}^{3}$ \\
\hline Reactor working volume & $0.56 \mathrm{~m}^{3}$ \\
\hline Fluidized Bed Reactor Air Supply & 3 \\
\hline Number of disk type diffusers & \\
\hline Diameter of diffusers & $0.277 \mathrm{~m}$ \\
\hline Air flow rate per diffuser & $3.0 \mathrm{Sm}^{3} / \mathrm{hr}$ \\
\hline Average oxygen transfer efficiency & $12 \%$ \\
\hline
\end{tabular}

The physical configuration of the reactor is shown in Figure 6-1. Note that an additional hand hole had been added to the reactor, and is located approximately $0.80 \mathrm{~m}$ from the base of the reactor. A 2" and 1.5" ball valve was added to the face of the upper and lower hand holes, which allows for the removal of biomass carriers from the reactor. For most of the study, the treated wastewater effluent left through the valve on the upper hand hold of the reactor, limiting the working reactor volume to $0.56 \mathrm{~m}^{3}$. Accumulated materials physically blocked the upper drainage ports, causing the reactor to be prone to leakage into the ceiling. This prevented the full $0.70 \mathrm{~m}^{3}$ working volume from being used. 


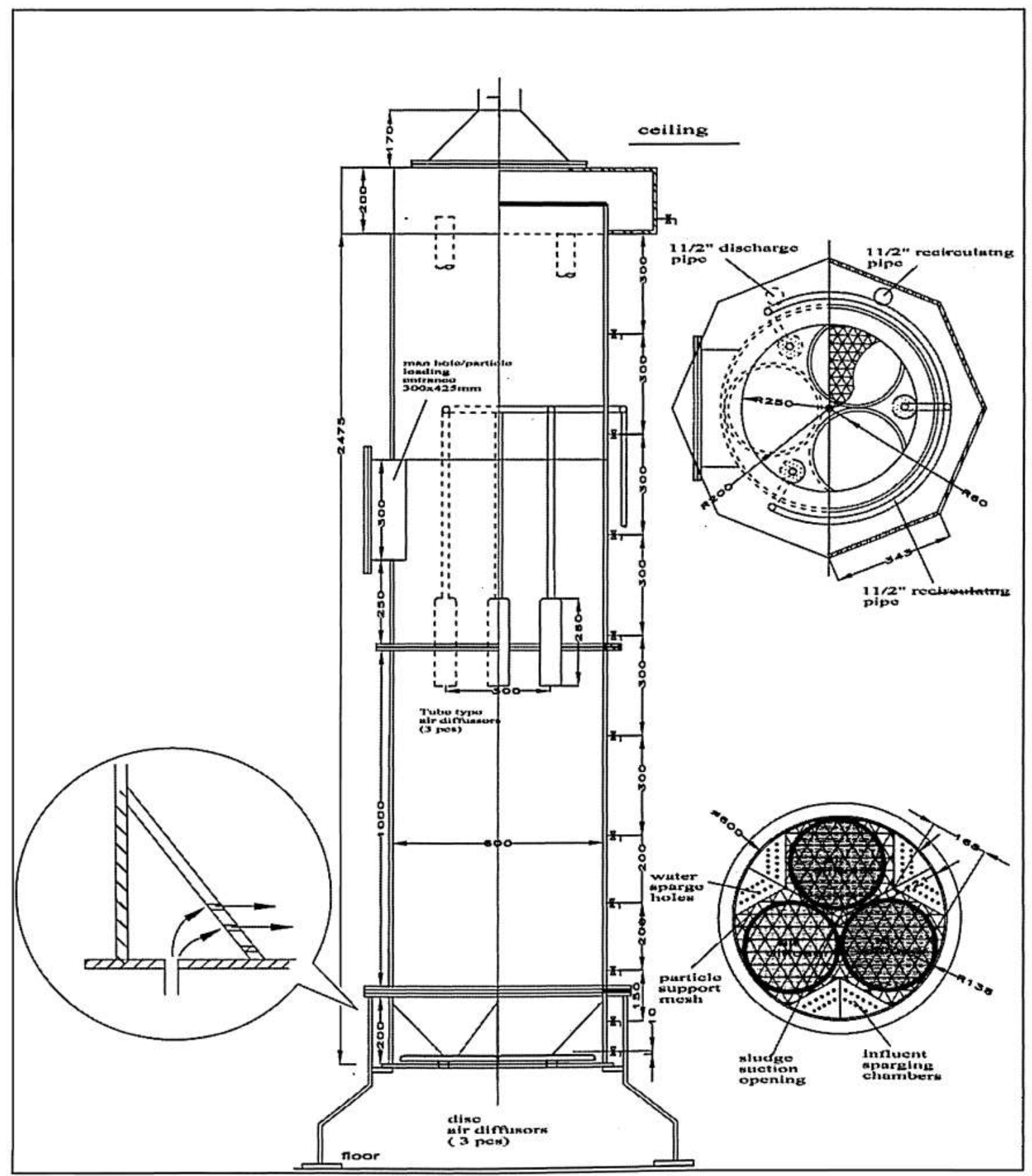

Figure 6-1: Three phase fluidized bed reactor physical configuration, from (Wan, 2006) 
As shown in Figure 6-1, the reactor has 12 sampling ports for the removal of wastewater. Table 6-2 outlines the distance from each sampling point to the base of the reactor. Due to the filling volume of the reactor, only sampling ports 1-8 were submerged in liquid. Sampling port 2 was inoperable.

Table 6-2: Position of the sampling ports in the fluidized bed reactor

\begin{tabular}{|c|c|c|c|}
\hline Sampling Port & Distance from the air diffuser & Sampling Port & Distance from the air diffuser \\
\hline $\mathbf{1}$ & $0.01 \mathrm{~m}$ & $\mathbf{7}$ & $1.25 \mathrm{~m}$ \\
\hline $\mathbf{2}$ & $0.10 \mathrm{~m}$ & $\mathbf{8}$ & $1.55 \mathrm{~m}$ \\
\hline $\mathbf{3}$ & $0.25 \mathrm{~m}$ & $\mathbf{9}$ & $1.85 \mathrm{~m}$ \\
\hline $\mathbf{4}$ & $0.45 \mathrm{~m}$ & $\mathbf{1 0}$ & $2.15 \mathrm{~m}$ \\
\hline $\mathbf{5}$ & $065 \mathrm{~m}$ & $\mathbf{1 1}$ & $2.45 \mathrm{~m}$ \\
\hline $\mathbf{6}$ & $0.95 \mathrm{~m}$ & $\mathbf{1 2}$ & Effluent line \\
\hline
\end{tabular}

Synthetic wastewater is supplied to the reactor using a $1.5 \mathrm{hp}$ progressive cavity pump, flow rate 3.4 to 35.6 LPM. The pump removed liquid from a $4.5 \mathrm{~m}^{3}$ feed tank, where the synthetic wastewater was prepared as needed. Effluent from the FBR can be sent to the drain, or collected in a $0.6 \mathrm{~m}^{3}$ recycle tank. Liquid in the recycle tank can be pumped back into the reactor, using the same influent ports around the circumference of the base. The generalized flow diagram of the process is shown in Figure 6-2. The recycle pump is a $0.5 \mathrm{hp}$ Neptune proportioning pump, with a maximum flow rate of 10 LPM. Supplementary diagrams of the piping and layout of the laboratory are shown in Figures 6-4 and 6-5. 


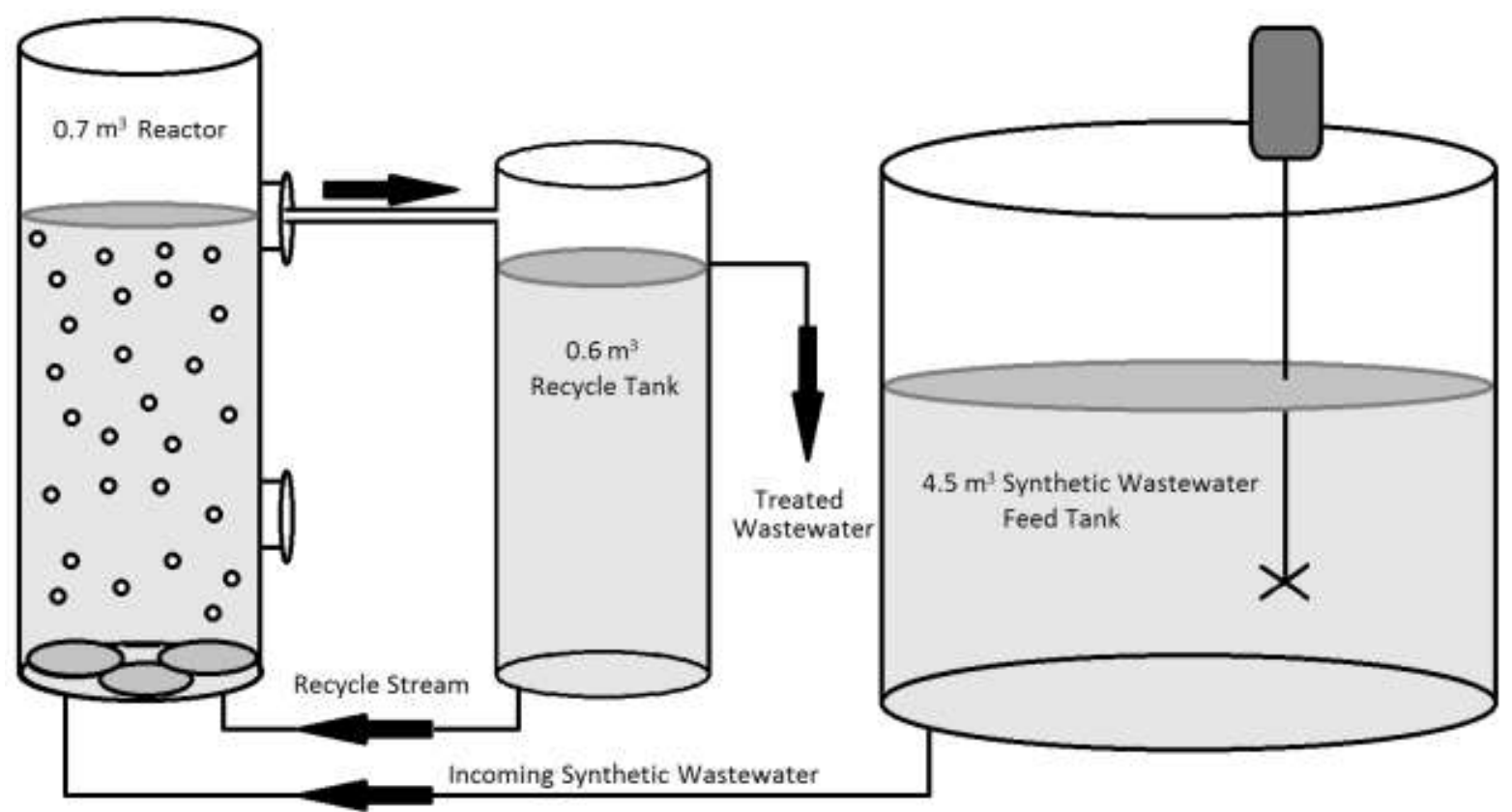

Figure 6-2: Three phase fluidized bed reactor, recycle and feed tank

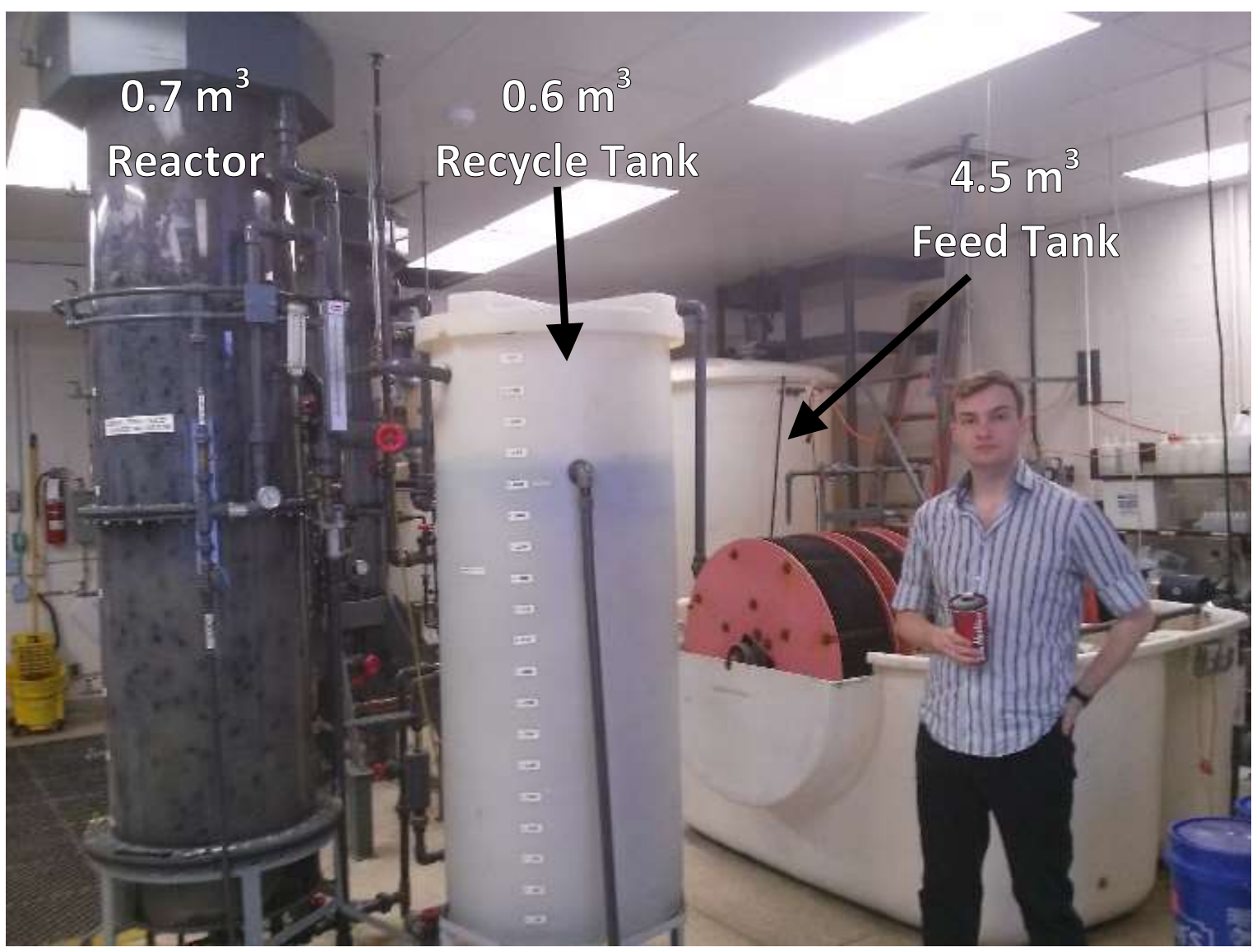

Figure 6-3: Three phase FBR size comparison 


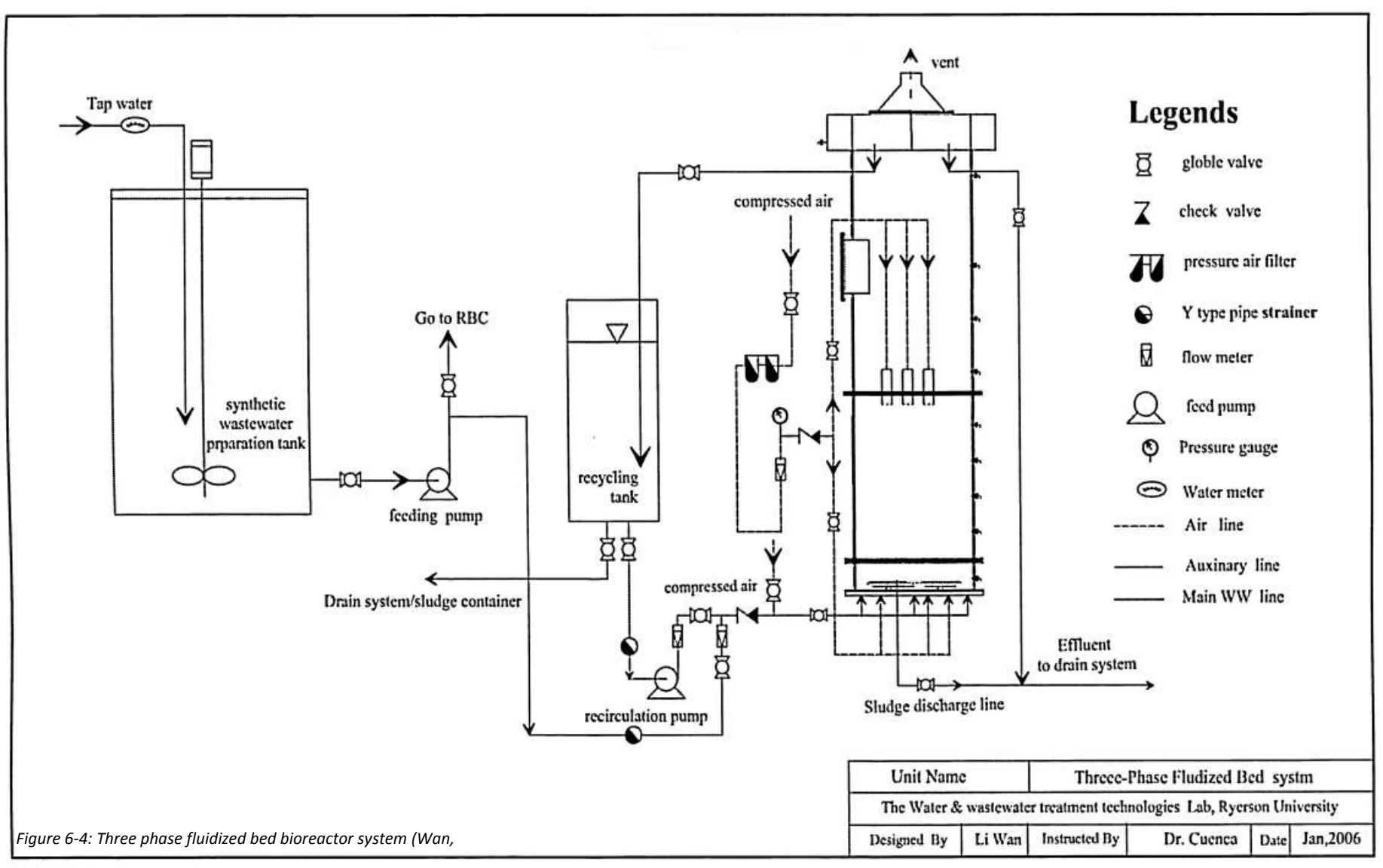




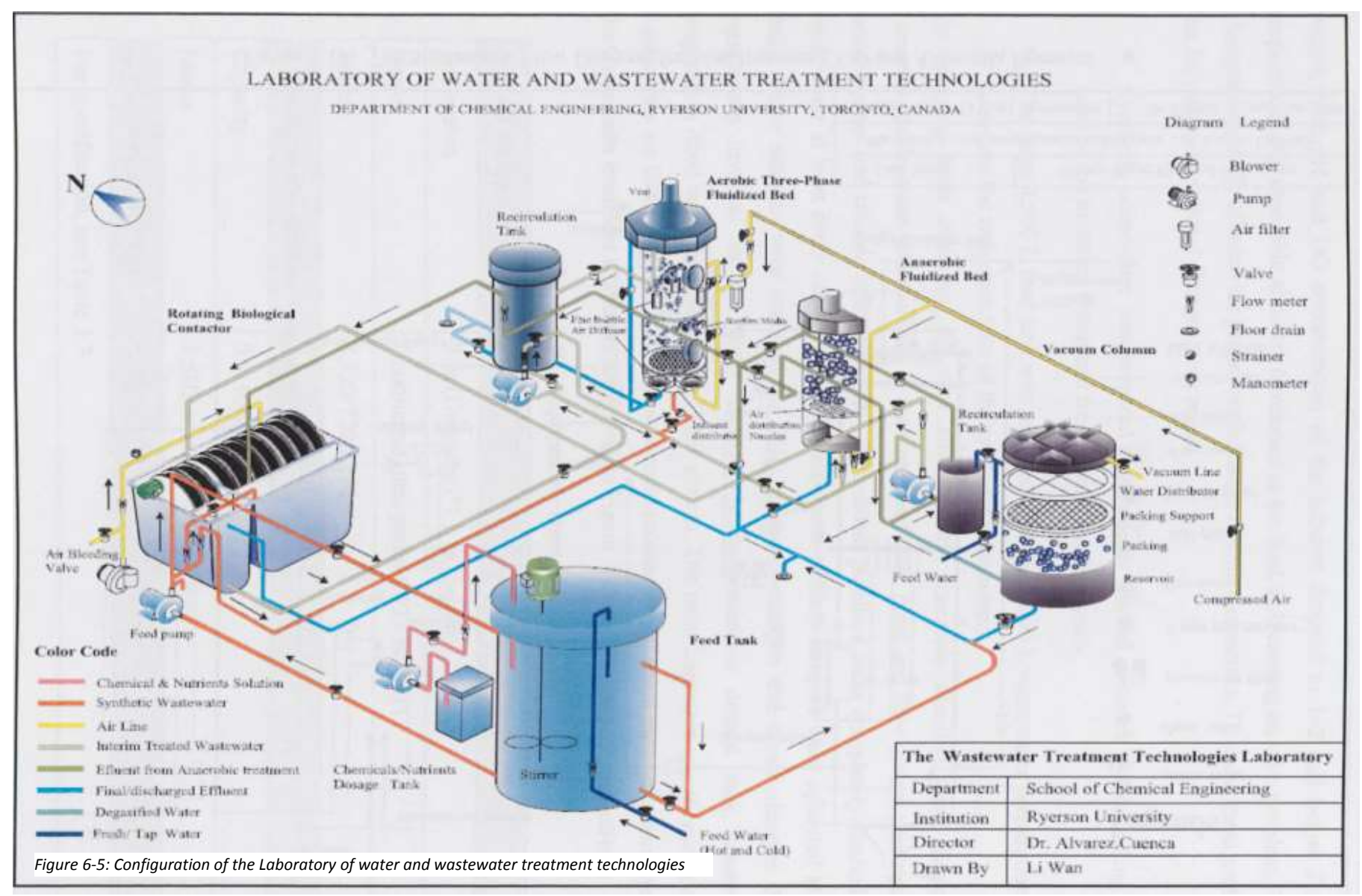


The FBR was packed with Hydroxyl-Pac media, the physical properties of which are shown in Table 6-3. When supplied with moderate amounts of air, the reactor was readily fluidized. The range of fluidization was evaluated in the study by Wan, 2006, where the floating bed height, and dead zone height (the groupings of stationary particles at the top of the reactor, and the bottom of the reactor, respectively) were compared to the supplied gas velocity. The fluidization range is shown in Figure 6-7. At low air flow rates, a portion of the packing remains floating on the liquid surface. As the air flow rate increases beyond the full fluidization range, a portion of the particles sink to the bottom of the reactor and become stagnant.

Table 6-3: Hydroxyl-pac media physical properties, from (Wan, 2006)

\begin{tabular}{|l|l|}
\hline Height & $15 \mathrm{~mm}$ \\
\hline Diameter & $22 \mathrm{~mm}$ \\
\hline Density & $0.95 \mathrm{~g} / \mathrm{cm}^{3}$ \\
\hline Total surface area & $588 \mathrm{~m}^{2} / \mathrm{m}^{3}$ \\
\hline Protected internal surface area & $402 \mathrm{~m}^{2} / \mathrm{m}^{3}$ \\
\hline $\begin{array}{l}\text { Liquid volume occupied per } \\
\text { volume packing (volume ratio) }\end{array}$ & $0.138 \mathrm{~m}^{3} / \mathrm{m}^{3}$ \\
\hline Design filling ratio & $50 \%$ \\
\hline
\end{tabular}

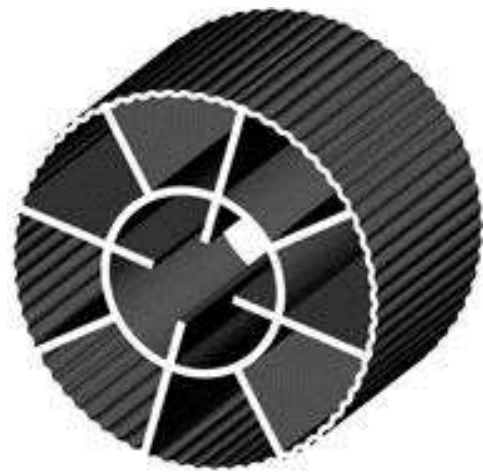

Figure 6-6: Hydroxyl-Pac Media

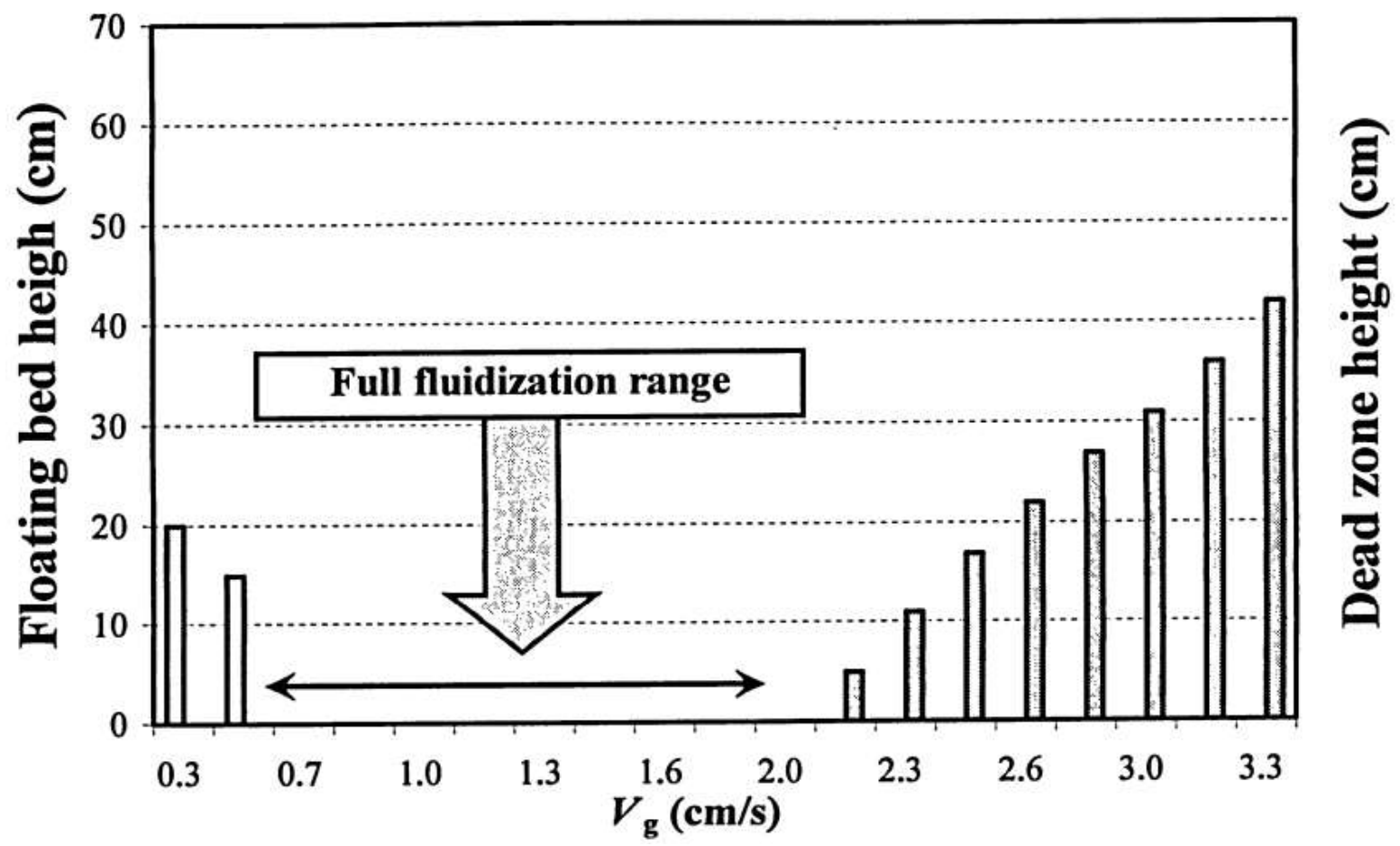

Figure 6-7: Range of fluidization in the three phase FBR for a packing ratio of 0.5 (Wan, 2006) 
When evaluated by Wan, the three phase fluidized bed showed excellent oxygen transfer capabilities. A volumetric oxygen transfer coefficient ( $\left.\mathrm{K}_{\mathrm{L}} \mathrm{a}\right)$ of $0.023 \mathrm{~s}^{-1}$ was calculated when testing the reactor with clean tap water. This can be compared to coefficients measured from similar fluidized beds, ranging from 0.003 to $0.015 \mathrm{~s}^{-1}$ (Wan, 2006).

In order to provide mixing in the reactor when aeration was undesired, a submersible pump was dropped on top of the air diffusers. The $1 / 4 \mathrm{hp}$ pump operated at a constant flow rate, with no control for variation in flow. Physical modification to the reactor to install an alternative agitation device was impractical.

\subsection{Synthetic Wastewater}

Two different synthetic wastewater concentrations were used in this study. Initially, a wastewater containing $120 \mathrm{mg} / \mathrm{L} \mathrm{NH}_{3}-\mathrm{N}, 500 \mathrm{mg} / \mathrm{L} \mathrm{COD}$ and $10 \mathrm{mg} / \mathrm{L} \mathrm{TP}$ was used. The concentration and chemical formula of the added chemicals is shown in Table 6-4. This wastewater composition will be referred to as synthetic wastewater $A$.

\begin{tabular}{|c|c|}
\hline$\left(\mathrm{NH}_{4}\right)_{2} \mathrm{SO}_{4}$ & $556.0 \mathrm{mg} / \mathrm{L}$ \\
\hline Sucrose & $445.2 \mathrm{mg} / \mathrm{L}$ \\
\hline $\mathrm{KH}_{2} \mathrm{PO}_{4}$ & $56.7 \mathrm{mg} / \mathrm{L}$ \\
\hline $\mathrm{NaHCO}_{3}$ & $884.2 \mathrm{mg} / \mathrm{L}$ \\
\hline $\mathrm{CaCO}_{3}$ & $204.2 \mathrm{mg} / \mathrm{L}$ \\
\hline $\mathrm{MgSO}_{4} \circ 7 \mathrm{H}_{2} \mathrm{O}$ & $200 \mathrm{mg} / \mathrm{L}$ \\
\hline EDTA & $15 \mathrm{mg} / \mathrm{L}$ \\
\hline $\mathrm{FeCl}_{3} \circ 6 \mathrm{H}_{2} \mathrm{O}$ & $4.45 \mathrm{mg} / \mathrm{L}$ \\
\hline $\mathrm{MnCl} \circ 4 \mathrm{H}_{2} \mathrm{O}$ & $1.08 \mathrm{mg} / \mathrm{L}$ \\
\hline $\mathrm{ZnCl}_{2}$ & $0.201 \mathrm{mg} / \mathrm{L}$ \\
\hline $\mathrm{H}_{3} \mathrm{BO}_{4}$ & $0.014 \mathrm{mg} / \mathrm{L}$ \\
\hline
\end{tabular}

Synthetic wastewater A was used for the batch operation of the reactor. Later, while operating the reactor with a continuous flow of wastewater, COD was increased to $1200 \mathrm{mg} / \mathrm{L}$. This was done to ensure that sufficient soluble COD was entering the reactor. While being held in the 4.5 $\mathrm{m}^{3}$ holding tank, significant growth was observed, reducing the soluble COD concentration. In some cases, an unpleasant odour emanated from the tank, causing disruptions in the nearby 
laboratories/classrooms. To prevent the production of odours, the holding tank was aerated to prevent anaerobic conditions. This aeration encouraged further growth in the feed tank.

In addition to changing the COD concentration, additional trace elements were added into the reactor. These concentrations were chosen to be consistent with other researchers, and help to simulate values observed in typical wastewater. The chemical formula and concentration of all components in synthetic wastewater B is shown in Table 6-5.

\begin{tabular}{|c|c|}
\hline$\left(\mathrm{NH}_{4}\right)_{2} \mathrm{SO}_{4}$ & $556.0 \mathrm{mg} / \mathrm{L}$ \\
\hline Sucrose & $1068.0 \mathrm{mg} / \mathrm{L}$ \\
\hline $\mathrm{KH}_{2} \mathrm{PO}_{4}$ & $56.7 \mathrm{mg} / \mathrm{L}$ \\
\hline $\mathrm{NaHCO}_{3}$ & $528.5 \mathrm{mg} / \mathrm{L}$ \\
\hline $\mathrm{CaCO}_{3}$ & $207.0 \mathrm{mg} / \mathrm{L}$ \\
\hline $\mathrm{MgSO}_{4}{ }^{\circ} 7 \mathrm{H}_{2} \mathrm{O}$ & $200 \mathrm{mg} / \mathrm{L}$ \\
\hline EDTA & $15 \mathrm{mg} / \mathrm{L}$ \\
\hline $\mathrm{FeCl}_{3} \circ 6 \mathrm{H}_{2} \mathrm{O}$ & $6.25 \mathrm{mg} / \mathrm{L}$ \\
\hline $\mathrm{ZnSO}_{4}{ }^{\circ} 7 \mathrm{H}_{2} \mathrm{O}$ & $0.43 \mathrm{mg} / \mathrm{L}$ \\
\hline $\mathrm{CuSO}_{4} \circ 5 \mathrm{H}_{2} \mathrm{O}$ & $0.25 \mathrm{mg} / \mathrm{L}$ \\
\hline $\mathrm{CoCl} \cdot 6 \mathrm{H}_{2} \mathrm{O}$ & $0.24 \mathrm{mg} / \mathrm{L}$ \\
\hline $\mathrm{NiCl}_{2} \circ 6 \mathrm{H}_{2} \mathrm{O}$ & $0.19 \mathrm{mg} / \mathrm{L}$ \\
\hline $\mathrm{H}_{3} \mathrm{BO}_{4}$ & $0.014 \mathrm{mg} / \mathrm{L}$ \\
\hline
\end{tabular}

\subsection{Sampling Methodology}

As a general indicator of reactor performance, $\mathrm{DO}, \mathrm{pH}$, temperature, $\mathrm{NH}_{3}-\mathrm{N}, \mathrm{NO}_{2}-\mathrm{N}, \mathrm{NO}_{3}-\mathrm{N}$ and COD concentrations of the inlet and outlet wastewater were measured as needed. These tests will be referred to as the standard tests. TP, TSS, TVSS, and soluble COD concentrations were measured less frequently, and oxygen consumption rate, biomass concentration on packing material, and polysaccharide concentration of the biomass was measured on three occasions, from three different sample points in the reactor.

\begin{tabular}{|c|c|}
\hline Standard Tests & Additional Tests \\
\hline $\mathrm{DO}$ & Total Phosphorus \\
\hline Temperature & TSS \\
\hline $\mathrm{pH}$ & TVSS \\
\hline $\mathrm{NH}_{3}-\mathrm{N}$ & Polysaccharide Concentration \\
\hline $\mathrm{NO}_{2}-\mathrm{N}$ & Oxygen Consumption Rate \\
\hline $\mathrm{NO}_{3}-\mathrm{N}$ & Biomass Concentration \\
\hline $\mathrm{COD}$ & Soluble COD \\
\hline
\end{tabular}


After substantial process changes had been made, standard tests were performed more frequently (i.e. 2-3 days). Generally, standard tests were performed every 3-5 days. In most cases, only the inlet and outlet concentrations were measured. However, some measurements of the removal profile along the height of the reactor were collected. Each test was performed using the following procedures:

\section{Dissolved Oxygen, pH, Temperature}

$\mathrm{DO}, \mathrm{pH}$ and temperature were all measured using the VWR B4OPCID bench top meter. The DO and temperature were measured in a single probe (platinum cathode, silver anode, VWR catalog number 89231-624). The DO was calibrated using water saturated air as a reference. The $\mathrm{pH}$ probe was calibrated using the 3.0 and $9.0 \mathrm{pH}$ standards available in the lab. As the standards were consumed, calibration occurred with 2.0 and $10.0 \mathrm{pH}$ standards. Initially, pH was measured using a 'Red Rod' sensor (VWR catalog number 89231-580), although it was later replaced by an $\mathrm{Ag} / \mathrm{AgCl}$ probe (VWR catalog number 89231-604) due to breakage.

\section{Ammonia, Nitrite, Nitrate, COD, Total Phosphorus}

$\mathrm{NH}_{3}-\mathrm{N}, \mathrm{NO}_{2}-\mathrm{N}, \mathrm{NO}_{3}-\mathrm{N}, \mathrm{COD}$, soluble COD and TP were all measured using test kits and the VWR DR 2700 portable spectrophotometer. To measure soluble COD, wastewater was filtered and used with the COD test kit. Ammonia, nitrate, and phosphorus testing all required use of test tubes pre-prepared by VWR. COD tests also used test tubes, but required the samples to be held at $150^{\circ} \mathrm{C}$ for 2 hours. Nitrite testing required the mixing of powdered reagent with the sample. Further details of each method is shown in Table 6-6.

Table 6-6: Testing methods for COD, nitrogen compounds and phosphorus

\begin{tabular}{|l|l|c|l|}
\hline Parameter & \multicolumn{1}{c|}{ Method } & Range & $\begin{array}{c}\text { VWR Catalog } \\
\text { Number }\end{array}$ \\
\hline $\mathbf{N H}_{\mathbf{3}}-\mathbf{N}$ & Salicylate & $0-50 \mathrm{mg} \mathrm{N} / \mathrm{L}$ & CA97009-572 \\
\hline $\mathbf{N O}_{2}$ & Ferrous Sulphate & $2-250 \mathrm{mg} / \mathrm{L}$ & CA21075-69 \\
\hline $\mathbf{N O}_{3}$ & Chromotropic Acid & $0-30 \mathrm{mg} / \mathrm{L}$ & $97009-576$ \\
\hline $\mathbf{C O D}$ & Dichromate & $20-1500 \mathrm{mg} / \mathrm{L}$ & CA97009-538 \\
\hline $\mathbf{P O}_{4}$ & Molybdovanadate & $1-100 \mathrm{mg} / \mathrm{L}$ & CA11024-870 \\
\hline
\end{tabular}




\section{Total Suspended Solids, Total Volatile Suspended Solids}

TSS, and TVSS were measured using standard methods (APHA, AWWA, WEF, 2012).

Wastewater samples were filtered using glass filter paper, and dried at $105^{\circ} \mathrm{C}$ overnight to determine TSS. Dried samples were placed in $550^{\circ} \mathrm{C}$ oven for a few hours (or until no weight change was observed) to determine TVSS.

\section{Oxygen Consumption Rate}

Oxygen consumption rate was determined using standard methods (APHA, AWWA, WEF, 2012). When the OCR was to be measured, biomass covered packing was collected from three different locations within the reactor (fully fluidized, partially fluidized, and stationary sections within the FBR). Seven average looking pieces of packing were selected, and placed in an Erlenmeyer flask sitting on a mixing plate. The flask was saturated with oxygen using a controlled flow of air, and the DO concentration was measured over time. The reported OCR is the slope of the line of best fit for each trial.

\section{Biomass Concentration on Packing Materials}

Data on biomass concentration on the packing materials was collected from three different points in the reactor. Much like the OCR, samples were collected from the fully fluidized, partially fluidized and stationary sections in the reactor. Stationary and partially fluidized samples were collected through the upper hand hole on the reactor (reactor was partially drained to facilitate sampling). Fully fluidized particles were collected through the lower sampling port (2" valve on the lower arm hole cover). Care was taken to ensure samples were representative of the biofilm accumulation in each area of the reactor. For each sample location, three particles were removed and measured.

Pictures were collected of each sample, and wet weights of carriers and attached biomass were recorded. Samples were then placed in a $105^{\circ} \mathrm{C}$ oven overnight. Dry weight of the carrier and biomass were recorded. Unfortunately, the carrier material could not withstand temperatures sufficient to allow for determination of total volatile solids concentration. 
After removal from the oven, biomass was physically removed from the carriers using high pressure water, compressed air, and physical scrubbing. To ensure the residual water did not interfere with the carrier weight, samples were returned to the oven overnight. The weight of dry, empty biomass carriers was then recorded.

\section{Polysaccharide concentration}

Using the samples collected for total biomass weight determination, biomass was collected for determination of total polysaccharide concentration. Two of the three pieces from each sample point were tested, providing an average measured value for each sample point. Using the method of Liu, Wong and Dutka, 1973 the polysaccharide concentration could be determined using the DR 2700 portable spectrophotometer. The method is summarized as follows:

1) Approximately $2-50 \mathrm{mg}$ of dried biomass is added to a test tube

2) $1 \mathrm{ml}$ of distilled water is added to each test tube

3) $1 \mathrm{ml}$ of a $10 \%$ phenol solution is added to each test tube

4) $5 \mathrm{ml}$ of concentrated sulphuric acid is quickly added to each test tube, targeting the liquid surface

5) Test tubes are sealed and well mixed, and allowed to sit for 20 minutes

6) Samples are compared against a blank test tube, at a wavelength of $485 \mathrm{~nm}$

7) Concentration of polysaccharide is determined by comparison against a standard curve

Initially, a standard curve was determined using known concentrations of starch in solution. The absorbance of $0,50,100,150,200,250$ and $300 \mu \mathrm{g}$ starch/mL water were measured and found to agree with literature values (Liu, Wong, \& Dutka, 1973). Note that great care must be taken when using phenol and concentrated sulphuric acid, due to the potential safety risk.

\subsection{Reactor Operating Procedure}

The three phase fluidized bed bioreactor was operated first in a batch mode, followed by a continuous mode with wastewater flow rates ranging from $0.5-1.3 \mathrm{~L} / \mathrm{min}$. Initially, the reactor was inoculated with biomass from the STAR reactor (Reza \& Alvarez-Cuenca, 2013). Sludge was collected from the effluent of the STAR reactor, and added to the FBR according to the schedule 
shown in Table 6-7. The biomass from the STAR reactor was known to contain anammox bacteria, and had an approximate TSS of $1600 \mathrm{mg} / \mathrm{L}$, TVSS of $850 \mathrm{mg} / \mathrm{L}$.

Table 6-7: Sludge addition to the reactor

\begin{tabular}{|c|c|}
\hline Day & Quantity Added \\
\hline Day 1 & $25 \mathrm{~L}$ \\
\hline Day 4 & $25 \mathrm{~L}$ \\
\hline Day 5 & $42 \mathrm{~L}$ \\
\hline Day 6 & $40 \mathrm{~L}$ \\
\hline
\end{tabular}

For the batch stage of operation, the FBR was filled to approximately $50 \%$ liquid capacity $(0.35$ $\mathrm{m}^{3}$ ). Plastic biomass carriers occupied $30 \%$ of the bulk liquid volume $\left(0.11 \mathrm{~m}^{3}\right)$. The total liquid volume increased as sludge and chemicals were added to the batch reactor. Generally, chemicals were added when the measured concentration was $50 \%$ of the target synthetic wastewater concentration (Synthetic Wastewater A). The $\mathrm{pH}$ was maintained in the range of 7.5-8.2 by the addition of $\mathrm{NaHCO}_{3}$ or concentrated $\mathrm{H}_{2} \mathrm{SO}_{4}$.

The batch phase lasted for 50 days, after which removal of ammonia and nitrite was observed. Once sufficient nitrogen removal was measured, the continuous addition of synthetic wastewater began. For the first 18 days, a large recycle flow rate was maintained. After sufficient biofilm had accumulated on the plastic carrier material, the removal performance of the reactor was evaluated after a single pass of wastewater through the reactor. The time spent at each flow rate is shown in Table 6-8.

Table 6-8: Operation methodology for batch and continuous flow

\begin{tabular}{|c|c|}
\hline Days & Operation \\
\hline $\mathbf{1 - 5 0}$ & Batch \\
\hline $\mathbf{5 1 - 6 9}$ & $0.5 \mathrm{~L} / \mathrm{min}, 5: 1$ Recycle \\
\hline $\mathbf{7 0 - 9 1}$ & $1.3 \mathrm{~L} / \mathrm{min}$, No Recycle \\
\hline $\mathbf{9 2 - 1 1 7}$ & $1.0 \mathrm{~L} / \mathrm{min}$, No Recycle \\
\hline $\mathbf{1 1 8 - 1 5 9}$ & $0.5 \mathrm{~L} / \mathrm{min}$, No Recycle \\
\hline
\end{tabular}


The first 160 days of operation investigated the removal performance of the three phase fluidized bed biofilm reactor. After sufficient data had been collected, the investigation of the biofilm characteristics begun. The average biofilm mass on each carrier, the polysaccharide concentration in the biomass and oxygen consumption rate were measured for three different air flow rates. In each case, sufficient time was given to achieve steady state operation. The time spent at each operating condition is shown in Table 6-9.

Table 6-9: Time spent for investigation of biofilm characteristics in three phase fluidized bed biofilm reactor

\begin{tabular}{|c|c|c|}
\hline \multicolumn{1}{c}{ Days } & \multicolumn{1}{c|}{ Liquid Flow Rate } & \multicolumn{1}{c|}{ Airflow and Superficial Air Velocity } \\
\hline $\mathbf{2 0 4 - 2 2 2}$ & $0.5 \mathrm{~L} / \mathrm{min}$, No Recycle & 3 SCFM (5.1 SCMH), $0.47 \mathrm{~cm} / \mathrm{s}$ \\
\hline $\mathbf{2 2 3 - 2 3 7}$ & $0.5 \mathrm{~L} / \mathrm{min}$, No Recycle & $1 \mathrm{SCFM}(1.7 \mathrm{SCMH}), 0.16 \mathrm{~cm} / \mathrm{s}$ \\
\hline $\mathbf{2 3 8 - 2 7 2}$ & $0.5 \mathrm{~L} / \mathrm{min}$, No Recycle & $0.5 \mathrm{SCFM}(0.85 \mathrm{SCMH}), 0.078 \mathrm{~cm} / \mathrm{s}$ \\
\hline
\end{tabular}

Finally, on day 298, an investigation of the reactor performance under reduce DO conditions with no added COD begun. Initially, the sugar was removed from the synthetic wastewater, and the airflow was reduced. Fifteen days later, the airflow was eliminated, and the incoming wastewater was passed through a deaeration column to reduce the DO concentration. On day 343 , the last data point was collected. After this point, insufficient resources were available to continue the operation of the reactor. The operation under reduced DO concentrations is summarized in Table 6-10.

Table 6-10: Time spent for the investigation of anammox performance under reduced COD, DO concentrations

\begin{tabular}{|c|c|c|}
\hline Days & Action & Result \\
\hline $\mathbf{2 9 8}$ & $\begin{array}{c}\text { Sugar addition to synthetic } \\
\text { wastewater eliminated }\end{array}$ & $\begin{array}{c}\text { Substantial reduction in } \\
\text { COD concentration }\end{array}$ \\
\hline $\mathbf{3 1 3}$ & $\begin{array}{c}\text { Wastewater passed } \\
\text { through deaeration column } \\
\mathbf{3 4 3}\end{array}$ & $\begin{array}{c}\text { Substantial reduction in } \\
\text { DO concentration }\end{array}$ \\
\hline
\end{tabular}




\subsection{Results and Discussion}

\subsection{Batch Operation}

Batch operation of the three phase fluidized bed reactor began on Sept 6, 2013 (Day 1). Initially, 0.5 SCFM $(0.85 \mathrm{SCMH}$, superficial velocity of $0.078 \mathrm{~cm} / \mathrm{s})$ of air was provided to gently mix the reactor and to facilitate the partial oxidation of ammonia to nitrite. As no nitrite was provided with the incoming wastewater, aeration was necessary. When anoxic periods were desired, the $1 / 4 \mathrm{hp}$ submersible pump was activated to provide mixing. After being activated on day 8 , the submersible pump was left running for the remainder of the batch operation. As shown in Figure 7-1, aeration was provided as needed (represented by grey shading). Recall that ammonia was added to the batch reactor as it was consumed, typically when measured values were $50 \%$ of the target concentration, resulting in the zig-zag pattern observed in Figure 7-1.

After the first period of aeration, where 0.5 SCFM $(0.85 \mathrm{SCMH})$ of air was supplied, it was found that the minimum air supply which ensured sufficient mixing (i.e. no stationary particles on the water surface) would result in DO concentrations approaching saturation. This high DO concentration resulted in nitrate accumulation in the reactor, reaching values exceeding measurable values. Therefore, airflow during later aeration periods used the minimum noticeable air flow rate. This flow rate was well below measurable values, but resulted in DO concentrations typically below $2.0 \mathrm{mg} / \mathrm{L}$. During periods without aeration, DO concentrations were generally $0.2-0.5 \mathrm{mg} / \mathrm{L}$.

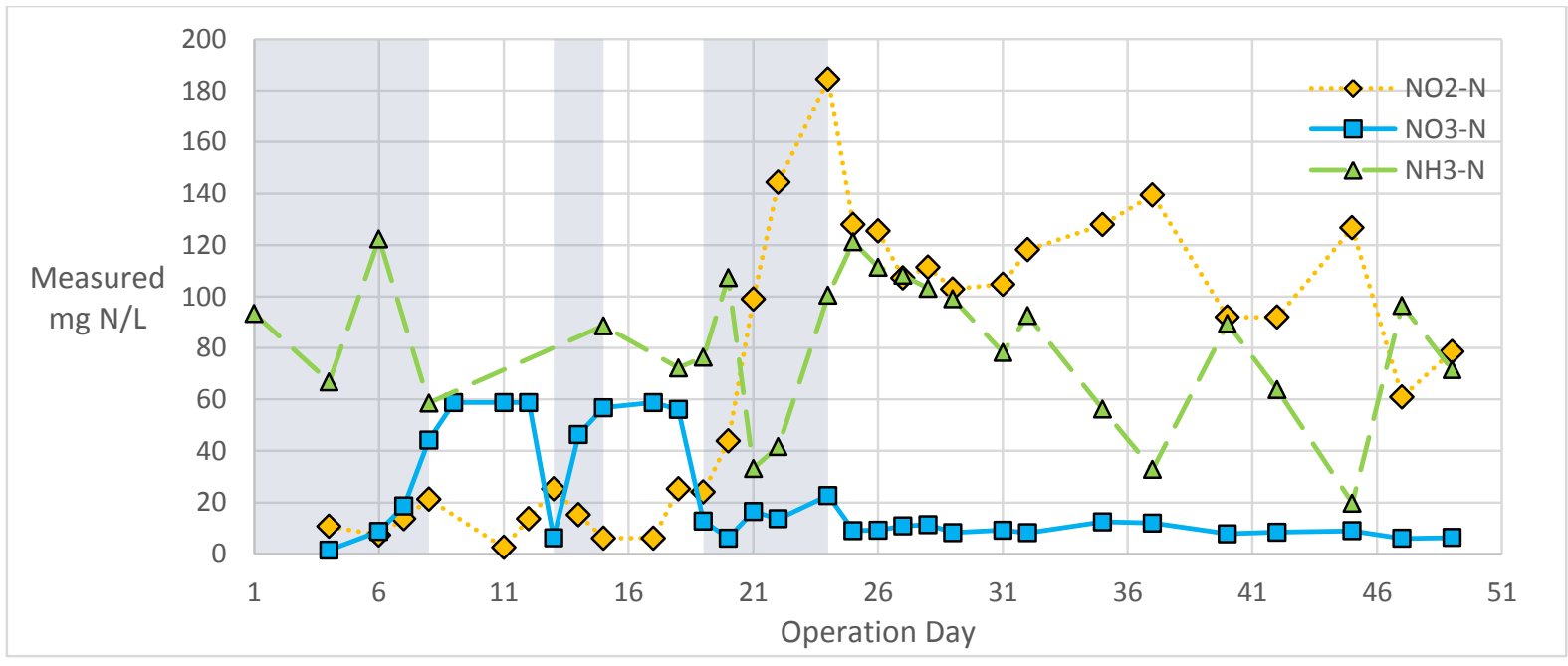

Figure 7-1: Batch operation of FBR. Grey shading represent days where aeration was provided 
The reduced DO concentration in the reactor helped the growth of ammonium oxidizing bacteria (AOBs) over nitrite oxidizing bacteria (NOBs, see section 2.1). Many studies have described the process in which a large population of AOBs can be produced without allowing for NOBs to gain a significant population. Specifically in SHARON reactors, maintaining a low DO concentration for a significant time will result in nitrite accumulation with minimal nitrate production (Paredes, et al., 2007). Moreover, review of kinetic models such as ASM1 and its modifications show how low DO favours nitrite accumulation.

Using the modified ASM models proposed by Wyffels, et al. and Dapena-Mora et al., the impact of low DO on AOB and NOB populations can be simulated. The full stoichiometric matrix of this model is available in the appendices, and greater explanation for the model is given in section 5.0 (Wyffels, et al., 2004). Generally, the oxygen half-saturation coefficients used for NOBs are in the range of 1.2-1.5 mg/L, compared to values of 0.2-0.4 mg/L for AOBs (Peng \& Zhu, 2006). That is, AOBs are much more functional in lower DO systems. Quantitative evaluation of this behaviour is shown in Figure 7-2, which compares the relative growth of NOBs over two days.

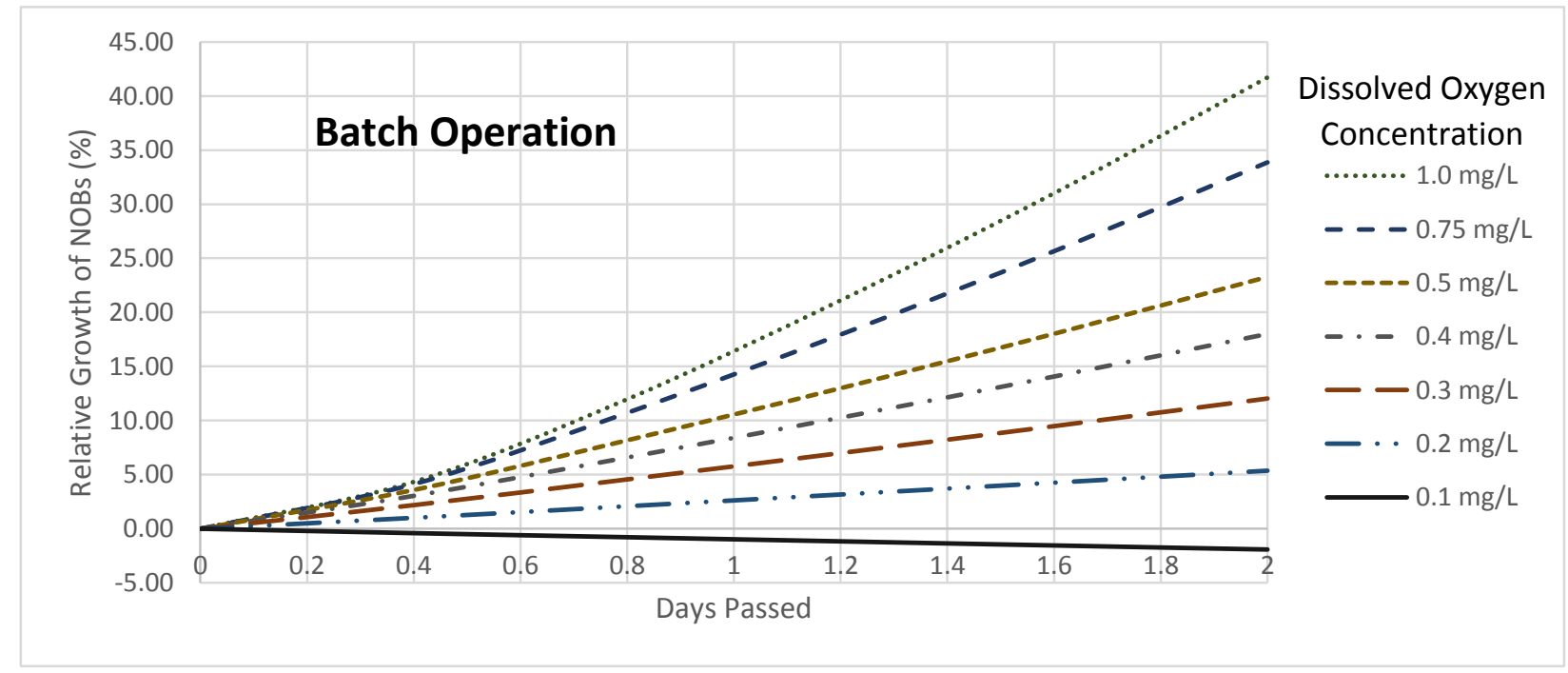

Figure 7-2: Predicted relative growth of NOBs in a batch system over 2 days at varying DO concentrations

At DO concentrations below $0.1 \mathrm{mg} / \mathrm{L}$, the NOB population decreases over time. This reduction in NOB population is a result of the decay rate of the bacteria (governed by the $b_{N O} x_{N O}$ term in ASM1) becoming larger than the growth rate. When DO begins to exceed $1.0 \mathrm{mg} / \mathrm{L}$, more 
substantial growth is observed. This behaviour can be compared to AOB growth, as shown in Figure 7-3. Over the same 2 days of operation, AOB populations increase substantially.

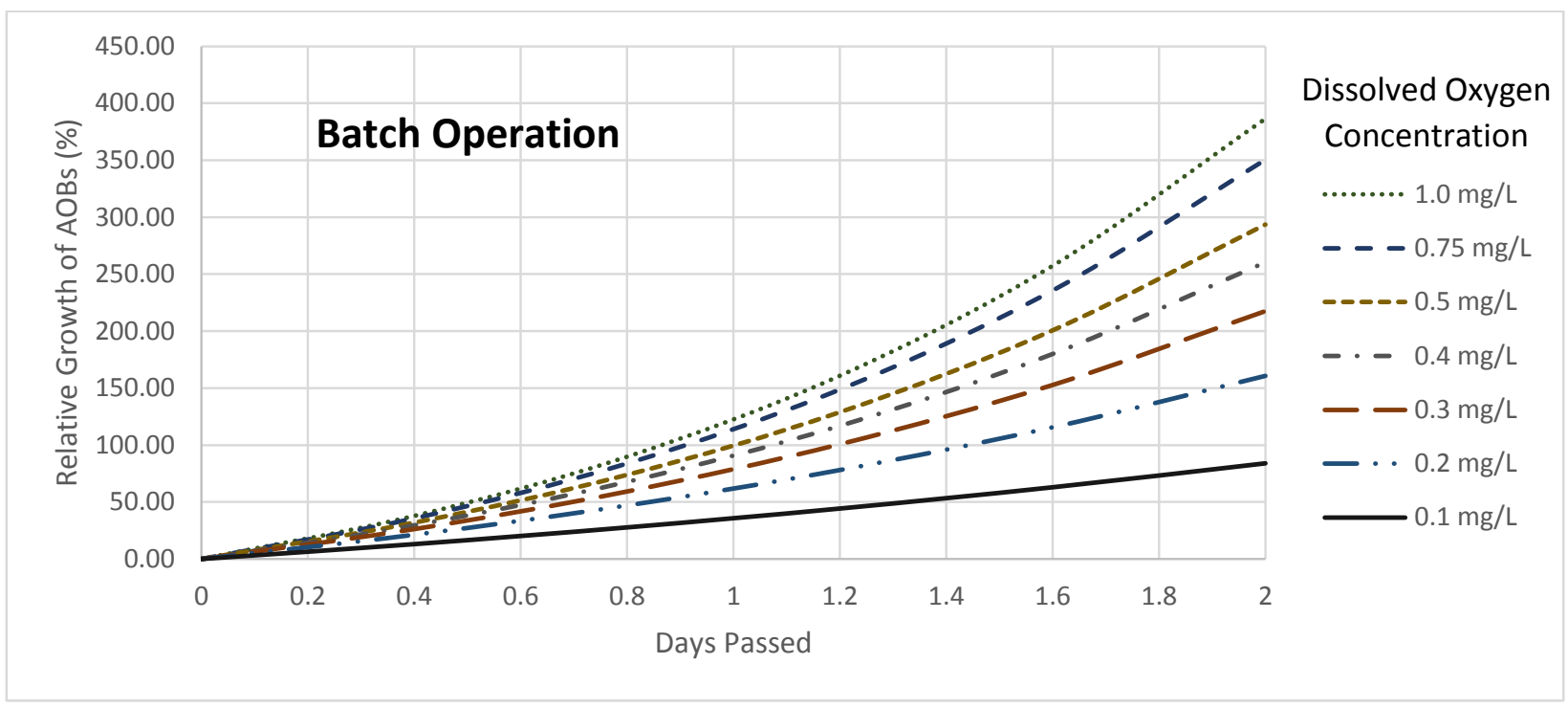

Figure 7-3: Predicted relative growth of AOBs in a batch system over 2 days at varying DO concentrations

The ASM calculations assume identical initial concentrations of AOBs and NOBs, and simulates conditions observed in the batch fluidized bed (Synthetic wastewater A, $0.56 \mathrm{~m}^{3}$ ), perfectly mixed reactor. However, the model does not consider biofilm processes. Instead, the model simulates uniform distribution of biomass with no resistance to the diffusion of oxygen. As the biomass inside the reactor is expected to collect on the surface of the packing material, increased resistance to oxygen diffusion will occur. As a result, the microbial populations will experience a further reduction of $D O$, increasing the selection of AOBs.

The long period of low DO provided to the reactor after day 24 helped to further reduce the NOB population. As observed in Figure 7-1, the AOB population dominates NOB, with a reduction of ammonia without the accumulation of nitrate. Even during periods of aeration, nitrate production was minimal ( $\sim 3.6 \mathrm{mg} \mathrm{NO}_{3}{ }^{-} \mathrm{N} / \mathrm{L}$ day between days $\left.20-24\right)$. Therefore, the production of nitrate under anoxic conditions can be used to identify the presence of anammox in the reactor.

During two periods, between days 42 and 45 , and 47 and 49, nitrate production was observed alongside total nitrogen removal. In between these periods, no significant changes in COD was 
observed, and no chemicals were added. The two periods under investigation are shown in Tables 7-1 and 7-2. During the two time periods, DO concentrations were in the range of 0.10 $\mathrm{mg} / \mathrm{L}$ to $0.30 \mathrm{mg} / \mathrm{L}$.

Table 7-1:Nitrogen removal performance, Day 42-45

\begin{tabular}{|l|c|c|c|}
\hline Day & $\mathbf{4 2}$ & $\mathbf{4 5}$ & Change \\
\hline $\mathbf{N H}_{\mathbf{3}}-\mathbf{N}, \mathbf{m g} / \mathrm{L}$ & 63.8 & 19.7 & -44.1 \\
\hline $\mathbf{N O}_{\mathbf{2}}-\mathbf{N}, \mathbf{m g} / \mathrm{L}$ & 92.0 & 126.7 & +34.7 \\
\hline $\mathbf{N O}_{\mathbf{3}}-\mathbf{N}, \mathbf{m g} / \mathrm{L}$ & 8.4 & 9.0 & +0.6 \\
\hline $\mathbf{T N}, \mathbf{m g} / \mathbf{L}$ & 164.2 & 155.4 & 8.8 \\
\hline
\end{tabular}

Table 7-2:Nitrogen removal performance, Day 47-49

\begin{tabular}{|l|c|c|c|}
\hline Day & $\mathbf{4 7}$ & $\mathbf{4 9}$ & Change \\
\hline $\mathbf{N H}_{\mathbf{3}}-\mathbf{N}, \mathbf{m g} / \mathrm{L}$ & 96.5 & 71.5 & -25.0 \\
\hline $\mathbf{N O}_{\mathbf{2}}-\mathbf{N}, \mathbf{m g} / \mathrm{L}$ & 60.9 & 78.6 & +17.7 \\
\hline $\mathbf{N O}_{\mathbf{3}}-\mathbf{N}, \mathbf{m g} / \mathrm{L}$ & 6.0 & 6.4 & +0.4 \\
\hline $\mathbf{T N}, \mathbf{~ m g} / \mathbf{L}$ & 163.4 & 156.5 & 6.9 \\
\hline
\end{tabular}

With a suppressed NOB population and low DO concentration, the production of nitrate by anammox is likely. Using the stoichiometry of equation 4 (see section 2.1), where $0.26 \mathrm{~mol}$ of nitrate is produced per mol of ammonia consumed, and anammox being the only source of nitrate, it can be calculated that up to $5 \%$ of the ammonia removal between days 42 and 45 is a result of anammox. For the period between day 47 and 49 , up to $6 \%$ of ammonia removal can be attributed to anammox. Realistically, the actual removal rates of ammonia by anammox are less than $5 \%$ or $6 \%$, as there are many different bacteria operating simultaneously in this reactor. Therefore, further evaluation into the reaction system can provide greater understanding of the contribution of anammox towards the total ammonia removal.

As an investigative tool, the ASM can be applied to this situation. The model was configured to the same operating conditions as the reactor during days $47-49$, with DO held at $0.30 \mathrm{mg} / \mathrm{L}$, total volume $0.56 \mathrm{~m}^{3}$, no inlet or outlet flow, and the same initial concentration of nitrogen compounds. As the biomass concentrations were not measured in this case, values were adjusted within typical values to match observed behaviour. The results of simulation are shown in Table 7-3. 
Table 7-3: Simulated results for nitrogen compounds removed between days 47-49

\begin{tabular}{|l|c|c|c|}
\hline \multirow{2}{*}{ Component } & \multicolumn{2}{c|}{ Measured } & Simulated \\
\cline { 2 - 4 } & Initial & Final & Final \\
\hline $\mathbf{N H}_{\mathbf{3}}-\mathbf{N}, \mathbf{m g} / \mathbf{L}$ & 96.5 & 71.5 & 71.8 \\
\hline $\mathbf{N O}_{\mathbf{2}}-\mathbf{N}, \mathbf{m g} / \mathbf{L}$ & 60.9 & 78.6 & 79.7 \\
\hline $\mathbf{N O}_{\mathbf{3}}-\mathbf{N}, \mathbf{m g} / \mathbf{L}$ & 6.0 & 6.4 & 6.7 \\
\hline $\mathbf{T N}, \mathbf{m g} / \mathbf{L}$ & 163.4 & 156.5 & 158.2 \\
\hline
\end{tabular}

As shown in Table 7-3, similar removal performance is observed in the ASM simulations when compared to the measured results. However, a larger nitrate concentration was calculated, which may be a result of the assumed uniform distribution of biofilm. In this case, anammox removed $3.2 \%$ of the ammonia, with the remainder being converted by AOBs. This value is less than what was observed during experimentation, and can be attributed to nitrate production from sources other than anammox. If the model were to consider the biofilm systems present in the reactor, along with the diffusion of oxygen, it is possible that simulated results would be closer to measured values.

When observing the removal of TN from the reactor, anammox is responsible for $94 \%$ of the removal, with the remainder being attributed to microorganism growth. The contribution of anammox to ammonia removal and nitrate production in the reactor is shown in Figure 7-4.

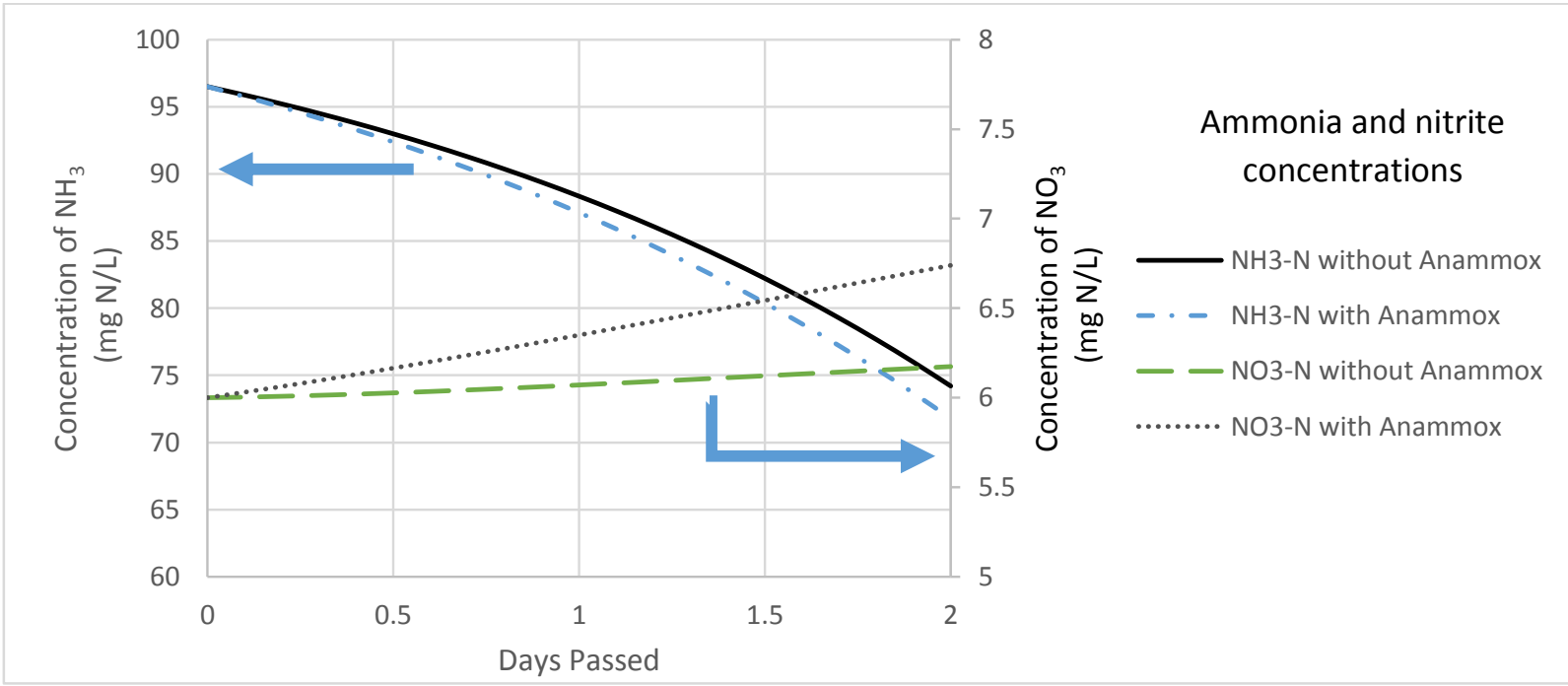

Figure 7-4: Predicted concentration profile simulated by ASM1 during batch operation, Day 47-49 
When applying the same conditions during simulation for the period in between days 42 to 45 similar results are seen, as shown in Table 7-4. The similarity of the predicted profiles to experimental values suggests that the modified ASM1 is a useful tool for the investigation of anammox activity in the reactor. However, to verify the presence of anammox with greater certainty, further evaluation is needed. This was achieved by configuring the anammox reactor to operate with a continuous feed of synthetic wastewater.

Table 7-4: Simulated results for nitrogen compounds removed between days 42-45

\begin{tabular}{|l|c|c|c|}
\hline \multirow{2}{*}{ Day } & \multicolumn{2}{c}{ Measured } & Simulated \\
\hline $\mathbf{N H}_{\mathbf{3}}-\mathbf{N}, \mathbf{m g} / \mathbf{L}$ & 63.8 & 19.7 & 22.3 \\
\hline $\mathbf{N O}_{\mathbf{2}}-\mathbf{N}, \mathbf{m g} / \mathbf{L}$ & 92.0 & 126.7 & 124.3 \\
\hline $\mathbf{N O}_{\mathbf{3}}-\mathbf{N}, \mathbf{m g} / \mathbf{L}$ & 8.4 & 9.0 & 9.5 \\
\hline $\mathbf{T N}, \mathbf{m g} / \mathbf{L}$ & 164.2 & 155.4 & 156.1 \\
\hline
\end{tabular}

\subsection{Continuous Operation}

Continuous flow of wastewater into the three phase fluidized bed bioreactor began 51 days after the start-up of the reactor. With liquid effluent leaving from the valve located on the arm hole cover, the total liquid volume in the reactor was approximately $0.56 \mathrm{~m}^{3}$. The incoming wastewater flow rate was set at $0.5 \mathrm{~L} / \mathrm{min}$, with the recycle flow rate at $2.5 \mathrm{~L} / \mathrm{min}$. The two flow rates were chosen as they were the lowest flow rates which could be reliably maintained using the available equipment. Initially, the reactor was mixed with the 1/4 hp submersible pump with minimal aeration. The $0.6 \mathrm{~m}^{3}$ recycle tank was not mixed, and operated as a sedimentation tank.

After 8 days of operation, the volatile suspended solids (TVSS) concentration in the reactor had decreased to $110 \mathrm{mg} / \mathrm{L}$, from an initial concentration of $450 \mathrm{mg} / \mathrm{L}$. Moreover, little accumulation of biofilm was observed on the packing material. After physically scraping the carrier, it was clear that biomass had accumulated, although it was not immediately obvious from visual inspection. It was suspected that the high sheer exerted by the submersible pump was preventing the accumulation of biomass on the carrier. Using the method of Tchobanoglous et al., the average sheer in the reactor caused by the submersible pump was $730 \mathrm{~s}^{-1}$. To compare, the average sheer from a physical mixer is estimated at $200 \mathrm{~s}^{-1}$. Similarly, 
average sheer from mixing via aeration is approximately $140-200 \mathrm{~s}^{-1}$ (Tchobanoglous, Burton, \& Stensel, 2002). Note that these values are the average sheer in the reactor. It is expected that the measured sheer immediately adjacent to the pump effluent would be greater.

To prevent the washout of biomass from the reactor, the submersible pump was removed. The minimum possible aeration was provided to fully mix the reactor. In addition to the aeration of the reactor, aeration of the $4.5 \mathrm{~m}^{3}$ feed tank was necessary at this time. A foul smell was being produced in the feed tank, as a result of the long residence time and anaerobic conditions. To prevent the production of foul odours, which interrupted operations in the adjacent research laboratories, aeration of the feed tank was necessary.

After the removal of the submersible pump, biofilm quickly accumulated on the inner surfaces of the packing material. By providing the minimum air flow rate necessary to fluidize the biomass carriers (1.5 SCFM, 2.5 SCMH), the reduced sheer provided favourable conditions for biofilm growth. The initial removal performance at $0.5 \mathrm{~L} / \mathrm{min}$ incoming flow rate with a 5:1 recycle ratio is shown in Figure 7-5. Note that the initial ammonia removal performance is around $90 \%$.

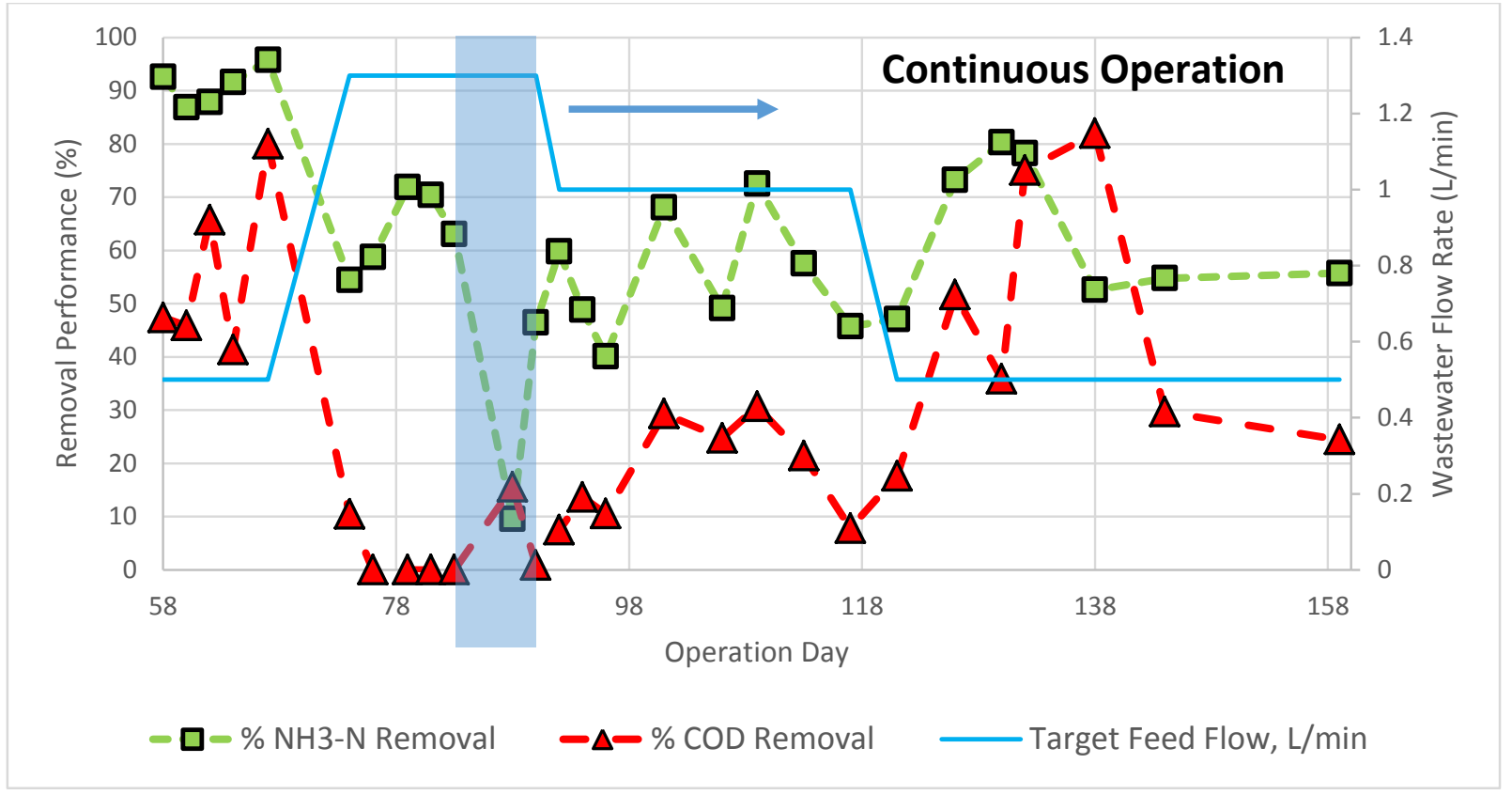

Figure 7-5: Removal performance for continuous operation of three phase fluidized bed bioreactor. Shading represents period of process upset. 
Because of the positive initial results, the recycle flow was halted. In the 5 days after the recycle flow ended, 2 measurements were taken at a flow rate of $0.5 \mathrm{~L} / \mathrm{min}$ (not shown on Figure 7-5). Similar ammonia removal was observed, although COD removal performance had decreased. Therefore, the incoming wastewater flow rate was increased to $1.3 \mathrm{~L} / \mathrm{min}$ with no recycle flow. This flow rate was chosen as it was similar to the total incoming flow rate when recycle flow was used $(0.5 \mathrm{~L} / \mathrm{min}$ synthetic wastewater $+2.5 \mathrm{~L} / \mathrm{min}$ recycle). However, the total flow of 3 $\mathrm{L} / \mathrm{min}$ was not applied, as the feed tank could empty after less than one day of operation. Moreover, sufficient chemical reagent was not available to allow for such a high flow rate over a long period of time. As a compromise, $1.3 \mathrm{~L} / \mathrm{min}$ was chosen.

As shown in Figure 7-5, reasonable ammonia removal was observed at $1.3 \mathrm{~L} / \mathrm{min}$, with up to $70 \%$ reductions being measured. However, minimal COD removal was observed at this flow rate. The substantial decrease in ammonia removal performance on day 90 was a result of a process upset, where the incoming flow rate reached over $4.0 \mathrm{~L} / \mathrm{min}$. During this time, the feed tank emptied, and the pump ran dry. The extensive surface aeration caused by the mixer in the feed tank resulted in substantially reduced incoming ammonia concentration, and therefore a reduced removal performance. Further, the low COD removal while at $1.3 \mathrm{~L} / \mathrm{min}$ suggested a reduction in HRT.

After poor COD removal had been observed at $1.3 \mathrm{~L} / \mathrm{min}$, the flow rate was reduced to 1.0 L/min (Day 92). Increased COD and ammonia removal performance was observed, although ammonia removal rarely exceeded $70 \%$, and COD rarely exceeded $30 \%$ removal. Similarly, when the incoming flow rate was later reduced to $0.5 \mathrm{~L} / \mathrm{min}$, greater increases in ammonia and COD removal were observed. However, the removal performance was unreliable at most flow rates. One source of variation was the bacterial contamination which occurred in the synthetic wastewater feed tank.

The growth and accumulation of biomass in the feed tank caused a variable inlet concentration, primarily impacting the COD concentration. Generally, the soluble COD concentration was approximately $30-50 \%$ of the incoming COD concentration, with the remaining insoluble COD being included in biomass. However, when measurements were taken 2-3 days after the tank 
had been cleaned, and fresh synthetic wastewater added, greater removal performance was observed. This is shown on day 132 (tank cleaned 2 days prior), and on day 126 (tank cleaned 2 days prior).

When the operation of a full scale wastewater treatment plant is considered, much of the insoluble COD would be removed during the sedimentation stage. In this study, during continuous operation, samples were taken from the effluent of the fluidized bed reactor. No sedimentation was provided prior to sampling. However, when soluble COD was measured continuously, over longer periods of time, removal of soluble COD to levels below $200 \mathrm{mg} / \mathrm{L}$ were typical.

In addition to the measurement of ammonia and COD removal in the reactor, the removal of total nitrogen (TN) was considered. A summary of the three parameters is shown in Figure 7-6. The hydraulic residence times (HRT) shown on the x-axis corresponds to wastewater flow rates of $1.3 \mathrm{~L} / \mathrm{m}, 1.0 \mathrm{~L} / \mathrm{m}, 0.5 \mathrm{~L} / \mathrm{m}$ and $0.5 \mathrm{~L} / \mathrm{m}$ with recycle, respectively. As the HRT of the process increases, the removal performance of the reactor increases.

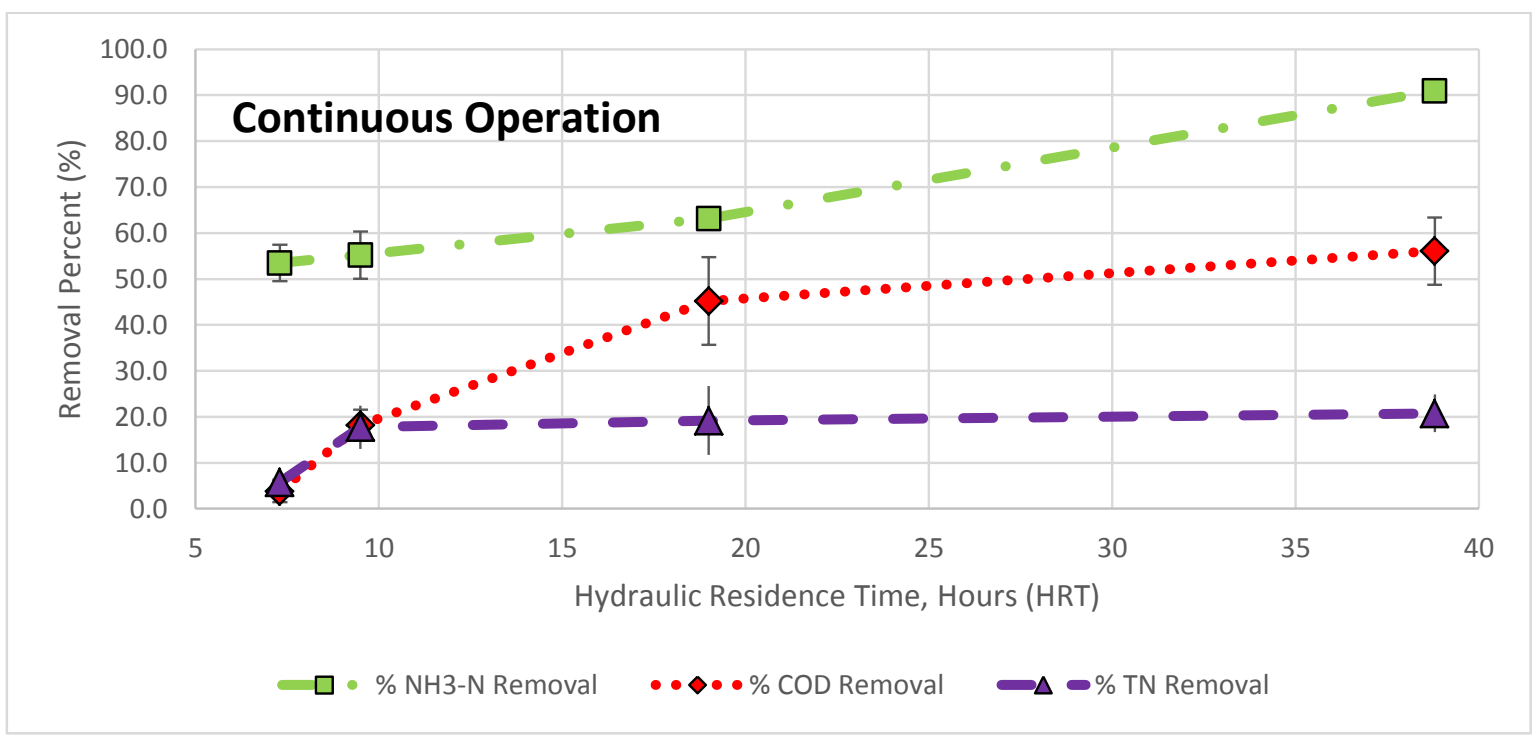

Figure 7-6: Removal performance of ammonia, COD and total nitrogen in the three phase fluidized bed bioreactor

The TN removal observed throughout the study suggests that anammox was operating in the reactor. The anaerobic zones provided by biofilm accumulation could create conditions in which anammox can perform well. As shown previously, anammox operates favourably in conditions 
with reduced DO concentrations. This behaviour is shown in Figure 7-7, where the ammonia removal performance is compared against DO concentration over time. This figure uses the modified ASM1 model discussed previously. It considers a $0.56 \mathrm{~m}^{3}$ perfectly mixed batch reactor with a dominant anammox population. Note that the use of the ASM1 is an investigative tool, but does not consider the diffusion of oxygen as is expected in a biofilm system.

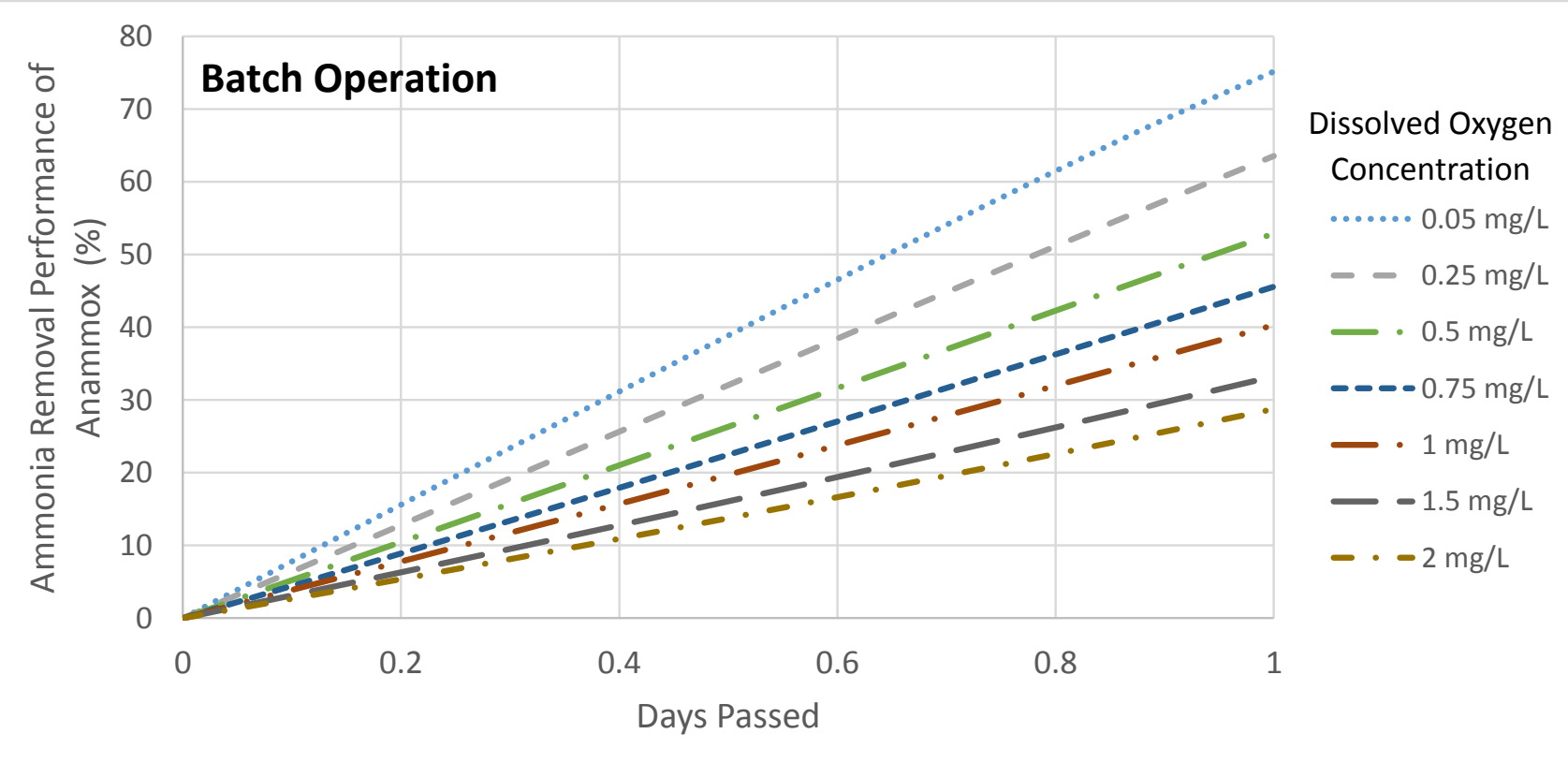

Figure 7-7: Comparison of anammox performance at various DO concentrations

Anammox is able to operate in environments with DO concentrations below $1.0 \mathrm{mg} / \mathrm{L}$.

However, as DO concentrations increase, removal performance is reduced. Similar research studies have found that anammox reactors observe decreased performance at DO concentrations above $1.0 \mathrm{mg} / \mathrm{L}$ (Davery, et al., 2013). Therefore, successful operation of a wastewater reactor containing anammox must utilize a biofilm system which includes zones of reduced DO (anoxic zones). Fortunately, in this study, biofilm quickly accumulated on the surface of the packing material after the submersible pump had been deactivated. The typical accumulation of biofilm on the fluidized biomass carriers is shown in Figure 7-8. Because the diffusion of oxygen from the bulk of the liquid into the biomass carrier is strongly limited by the 
biofilm, the typical bulk DO of $4.0-7.0 \mathrm{mg} / \mathrm{L}$ (Average of $\sim 5.5 \mathrm{mg} / \mathrm{L}$ ) will not result in such high DO concentrations on the biomass on the packing.

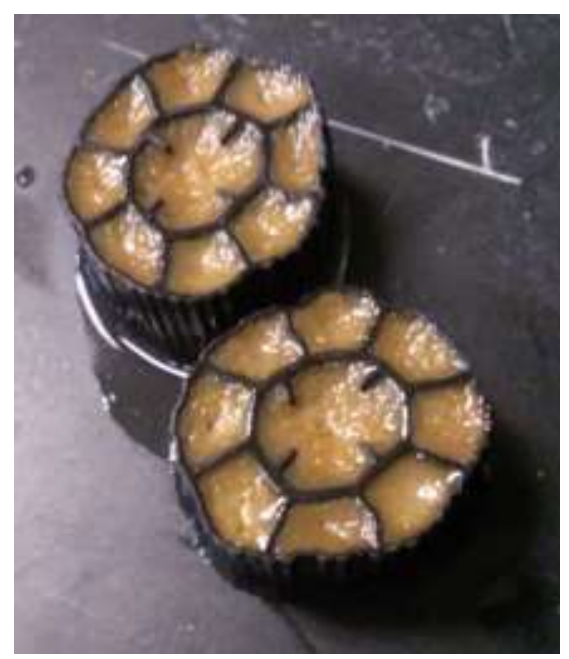

Figure 7-8: Typical biofilm accumulation on carriers in three phase fluidized bed bioreactor

Using the diffusion models proposed by Picioreanu, van Loosdrecht, \& Heijnen, 1997 and Xiao, Xiao, \& Xiang, 2014 (see section 5.0), along with biofilm characteristics measured in this study, it is possible to approximate the dissolved oxygen concentration in the biofilm carrier along the z-axis (see Figure 7-9). As shown in Figure 7-10, the dissolved oxygen concentration is substantially reduced in the inner areas of the carrier. The areas in which the DO concentration is less than $1 \mathrm{mg} / \mathrm{L}$ can provide conditions favourable to anammox growth. Further, it has been shown previously that the soluble nitrogen compounds required for anammox reproduction are not substantially limited by diffusion through biomass (Picioreanu, van Loosdrecht, \& Heijnen, 1997).

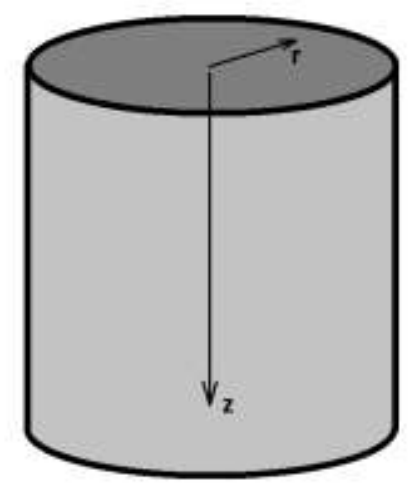

Figure 7-9: Coordinate system for DO analysis 


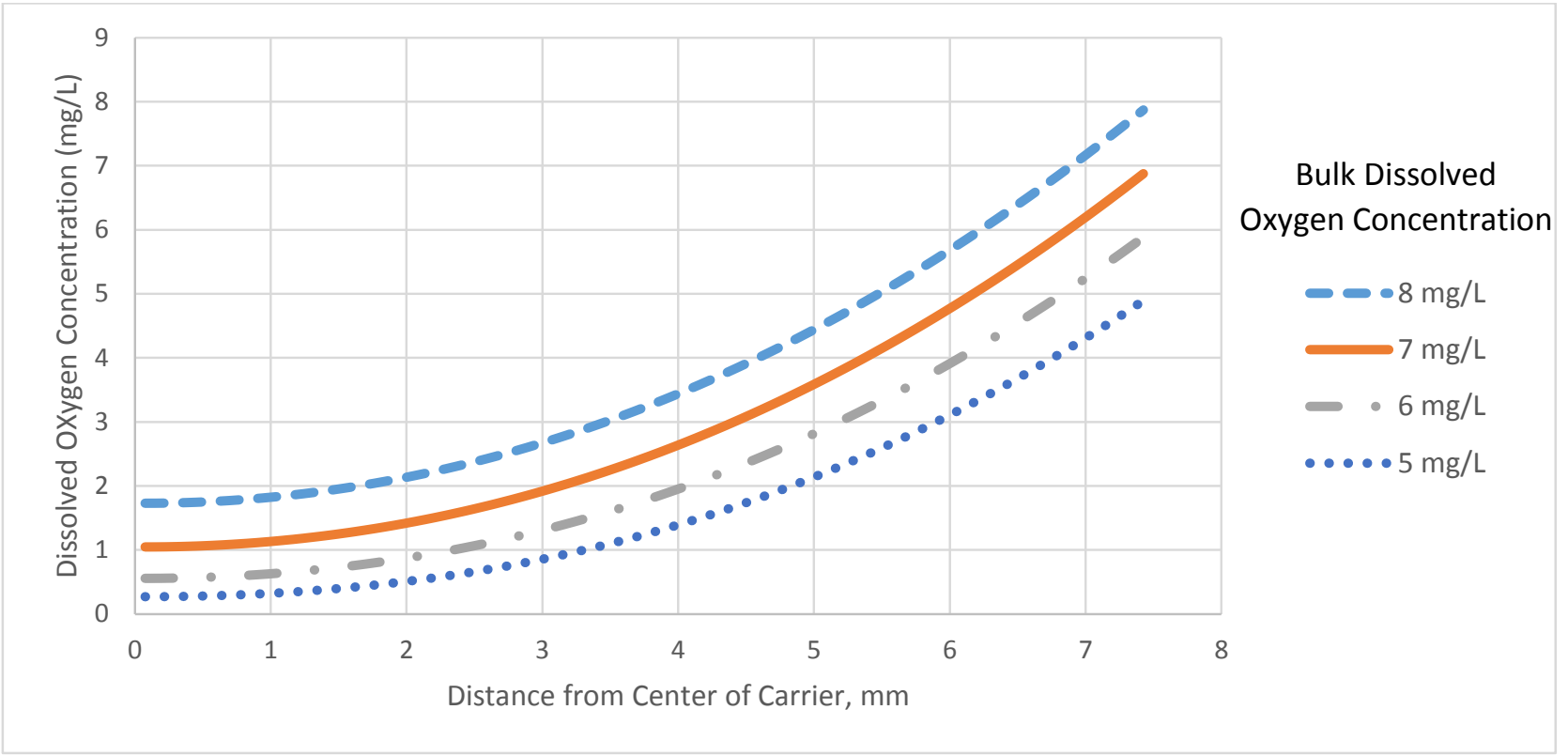

Figure 7-10: Dissolved oxygen profile in biomass carrier

To determine the DO profile in the biofilm, the following assumptions are made:

- One dimensional model is considered (along z-axis), effects of inner walls is neglected

- Biomass particles assumed to be $15 \mathrm{~mm}$ in length. Symmetrical DO profile is expected

- Oxygen diffusivity in biofilm is $80 \%$ of the diffusion of oxygen in water (Xiao, Xiao, \& Xiang, 2014)

- Half saturation coefficient and maximum growth rate for AOBs are used (Picioreanu, van Loosdrecht, \& Heijnen, 1997)

- Mass transfer effects in interface between bulk liquid and biofilm surface is negligible (Xiao, Xiao, \& Xiang, 2014)

- The average biomass concentration measured from three different air flow rates, at three different locations in the reactor is used (see Figure 7-13, page 99)

As shown in Figure 7-10, the anoxic conditions exist for anammox to remove ammonia and nitrite in the reactor. By looking at the total nitrogen removal and nitrate production in the aerobic reactor, an estimation of the ammonia removal by anammox can be calculated. During the majority of the operation up until day 160, nitrate accumulation was minimal. As shown in Table 7-5, the nitrate in the effluent wastewater was generally below $15 \%$ of the total nitrogen 
in the effluent. The remainder of the nitrogen was in the form of ammonia or nitrite. This nitrogen removal alongside low nitrate accumulation is characteristic of anammox behaviour.

Table 7-5: Summary of nitrogen removal and nitrate production in three phase fluidized bed bioreactor

\begin{tabular}{|c|c|c|c|c|c|}
\hline Flow & HRT & $\% \mathrm{NH}_{3}-\mathbf{N}$ & $\%$ TN & $\begin{array}{c}\text { Outlet } \\
\mathrm{NO}_{3}-\mathrm{N} / \mathrm{TN}, \%\end{array}$ & $\begin{array}{c}\% \mathrm{NH}_{3}-\mathrm{N} \text { removal } \\
\text { by Anammox }\end{array}$ \\
\hline $1.3 \mathrm{~L} / \mathrm{min}$ & $7.3 \mathrm{Hr}$ & $53.5 \pm 8.0$ & $5.7 \pm 2.4$ & $5.5 \pm 0.6$ & $4.8 \pm 2.2$ \\
\hline $1 \mathrm{~L} / \mathrm{min}$ & $9.5 \mathrm{Hr}$ & $55.2 \pm 4.0$ & $17.7 \pm 4.7$ & $10.1 \pm 1.9$ & $14.2 \pm 3.7$ \\
\hline $0.5 \mathrm{~L} / \mathrm{min}$ & $19.0 \mathrm{Hr}$ & $63.1 \pm 5.2$ & $19.2 \pm 7.5$ & $13.9 \pm 2.0$ & $13.4 \pm 4.9$ \\
\hline $0.5 \mathrm{~L} / \mathrm{min}$, Recycle & $38.8 \mathrm{Hr}$ & $90.9 \pm 1.6$ & $20.8 \pm 4.1$ & $11.0 \pm 1.2$ & $12.4 \pm 2.5$ \\
\hline
\end{tabular}

Using equation 4 (see section 2.1), $1.02 \mathrm{~mol}_{\text {of }} \mathrm{N}_{2}$, or $2.04 \mathrm{~mol}$ of nitrogen atoms are removed per mol of ammonia consumed by anammox. By comparing the total nitrogen removed to the stoichiometric anammox behaviour, the total contribution of ammonia oxidation by nitrite via anammox can be estimated. With the exception of the $1.3 \mathrm{~L} / \mathrm{min}$ flow rate, where a high HRT reduced the total removal performance, anammox generally contributed $13 \%$ of the ammonia removal. The remainder of the ammonia removal is a result of $A O B s$ oxidizing ammonia with oxygen.

Additionally, a small portion of the ammonia removal is a result of incorporation into biomass (see equation 5). The theoretical maximum ammonia removal of $7.5 \%$ of the soluble COD change limits the ammonia removal via incorporation into biomass (Sedlak, 1991). This is based on the yield coefficient of biomass reproduction, and the average composition of nitrogen in biomass.

Although anammox is not the dominant bacteria in the reactor, the observed removal performance is consistent with previous researchers. The aerobic environment combined with the higher COD concentration increases the competition between the various bacteria in the system. Following the observations of Du, et al., 2014 and Zhu, Hu, \& Liang, 2006, anammox performance is reduced in systems with higher COD concentrations. However, the bacteria remains competative, and is able to operate alongside COD consuming bacteria. 
Further, the higher DO concentrations in the reactor require anammox to be covered by a protective aerobic biofilm. As shown in simulation and in previous studies, anammox will operate in aerobic systems. However, the area which anammox can operate under anoxic conditions is reduced. Despite this reduced area, behaviour which is consistent with anammox is observed.

In a portion of the biomass carriers, a noticeable deep red colour was observed. This red or carmine colour is typical of the presence of anammox (Ali, et al., 2013). Approximately $20 \%$ of the carriers had the noticeably different colour, as shown in Figure 7-11.

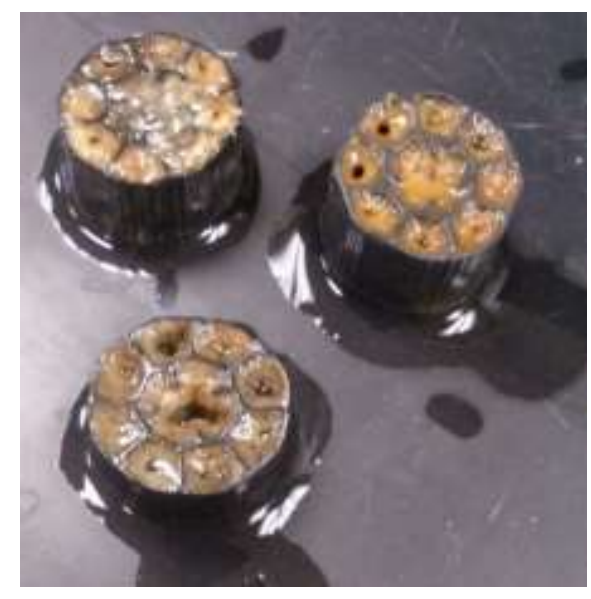

Figure 7-11: Red colour observed on biomass carriers, 3SCFM (5.1 SCMH)

Finally, the nitrogen removal rate (NRR) measured in the current study can be compared to the work of other researchers. As shown in Table 7-6, the NRR was highest at a flow rate of $1 \mathrm{~L} / \mathrm{min}$, with an average value of $1.22 \mathrm{~kg} \mathrm{~N} /\left(\mathrm{m}^{3} \mathrm{~d}\right)$. The NRR at $0.5 \mathrm{~L} / \mathrm{min}$ with recycle was substantially lower, as a result of the increased HRT. Note that the NRR is calculated by dividing the total TN removal (mg/L) by the HRT, causing the NRR to decrease with increases in HRT. Additionally, the NRR at $1.3 \mathrm{~L} / \mathrm{min}$ was reduced due to the lower TN removal performance, as discussed previously.

\begin{tabular}{|c|c|c|}
\hline Flow & HRT & $\begin{array}{c}N R R \\
k g-N /\left(m^{3} d\right)\end{array}$ \\
\hline $0.5 \mathrm{~L} / \mathrm{min}$, Recycle & $38.8 \mathrm{Hr}$ & $0.36 \pm 0.09$ \\
\hline $0.5 \mathrm{~L} / \mathrm{min}$ & $19.0 \mathrm{Hr}$ & $0.73 \pm 0.35$ \\
\hline $1 \mathrm{~L} / \mathrm{min}$ & $9.5 \mathrm{Hr}$ & $1.22 \pm 0.34$ \\
\hline $1.3 \mathrm{~L} / \mathrm{min}$ & $7.3 \mathrm{Hr}$ & $0.56 \pm 0.24$ \\
\hline
\end{tabular}


The NRR observed at $1.0 \mathrm{~L} / \mathrm{min}$ and $0.5 \mathrm{~L} / \mathrm{min}$ were measured alongside reasonable ammonia (up to $80 \%$ ) and TN removal ( 20\%), suggesting these flow rates are within the useful operating range of this reactor. As shown in future evaluation, the $0.5 \mathrm{~L} / \mathrm{min}$ flow rate observes consistent removal of nitrogen compounds from the fluidized bed. To compare the performance of this reactor against other studies, the NRR of $0.5 \mathrm{~L} / \mathrm{min}$ and $1.0 \mathrm{~L} / \mathrm{min}$ will be listed in Table 7-7.

Table 7-7: NRR comparison of the present study against previous studies

\begin{tabular}{|c|c|c|c|c|c|l|}
\hline Details & $\begin{array}{c}\text { Reactor } \\
\text { Type }\end{array}$ & $\begin{array}{c}\text { Reactor } \\
\text { Volume }\end{array}$ & $\begin{array}{c}\text { HRT } \\
\text { (Hours) }\end{array}$ & $\begin{array}{c}\text { NRR } \\
\text { (kg N/m3 } \\
\text { day) }\end{array}$ & \multicolumn{1}{c|}{ TN Removal } & \multicolumn{1}{c|}{ Source } \\
\hline Fluidized Bed & FBR & $0.56 \mathrm{~m}^{3}$ & 9.5 & $0.73-1.22$ & $17.7 \%-19.2 \%$ & (This Study,2014) \\
\hline OLAND & SBR & $2 \mathrm{~L}$ & 4 & 1.03 & $74 \%$ & $\begin{array}{l}\text { (Schaubroeck, Bagchi, Carballa, } \\
\text { Verstraete, \& Vlaeminck, 2012) }\end{array}$ \\
\hline CANON & Gas Lift & $1.8 \mathrm{~L}$ & 10 & 1.5 & $42 \%$ & $\begin{array}{l}\text { (Sliekers, Third, Abma, Kuenen, } \\
\text { \& Jetten, 2003) }\end{array}$ \\
\hline CANON & CSTR & $2 \mathrm{~L}$ & 14 & 0.11 & $92 \%$ & $\begin{array}{l}\text { (Third, Sliekers, Kuenen, \& } \\
\text { Jetten, 2001) }\end{array}$ \\
\hline SNAD & Gas Lift & $1.0 \mathrm{~L}$ & 55.4 & 0.346 & $98.4 \%$ & $\begin{array}{l}\text { (Kelusar, Nerurkar, \& Desai, } \\
\text { 2013) }\end{array}$ \\
\hline SNAD & $\begin{array}{c}\text { SBR, } \\
\text { MBBR }\end{array}$ & $2.5 \mathrm{~L}$ & 24 & 0.35 & $96 \%$ & $\begin{array}{l}\text { (Daverey, Chen, Sung, \& Lin, } \\
\text { 2014) }\end{array}$ \\
\hline Anammox & EGSB & $8 \mathrm{~L}$ & 0.98 & 15.8 & $92 \%$ & (Chen, et al., 2010) \\
\hline Anammox & $\begin{array}{c}\text { FBR, } \\
\text { Fixed }\end{array}$ & $6 \mathrm{~L}$ & 0.4 & 20.7 & $75 \%$ & $\begin{array}{l}\text { (Ma, Hira, Li, Chen, \& Furukawa, } \\
\text { 2011) }\end{array}$ \\
\hline Anammox & Gas Lift & $1.8 \mathrm{~L}$ & 6.7 & 8.9 & $93 \%$ & $\begin{array}{l}\text { (Sliekers, Third, Abma, Kuenen, } \\
\text { \& Jetten, 2003) }\end{array}$ \\
\hline CANON & MBBR & $140 \mathrm{~m}^{3}$ & - & 1.0 & - & (Lackner, et al., 2014) \\
\hline OLAND & RBC & $6 \mathrm{~m}^{3}$ & - & 0.9 & - & (Lackner, et al., 2014) \\
\hline DEMON & SBR & $134 \mathrm{~m}^{3}$ & - & 0.5 & - & (Lackner, et al., 2014) \\
\hline Anammox & UASB & $70 \mathrm{~m}^{3}$ & - & 10 & - & (van der Star, et al., 2007) \\
\hline
\end{tabular}

As shown in Table 7-7, the NRR of the three phase fluidized bed is comparable to similar reactors. The measured NRR between 0.73 and $1.22 \mathrm{~kg} \mathrm{~N} /\left(\mathrm{m}^{3}\right.$ day) is in the same range as other Canon, Oland, Demon and SNAD reactors on the laboratory and full scale. However, the reactor has a NRR substantially less than any purely anaerobic anammox reactor. As we know, DO in the reactor decreases the performance of anammox, but allows for partial nitrification and anammox to occur simultaneously in a single reactor. Further optimization is needed to improve the TN removal. Primarily, greater time is needed to increase the total anammox population in the reactor. Typical lab scale anammox reactors operate for many months or 
years. As the reactor size increases, the amount of time necessary to reach steady state also increases. For example, the first full scale anammox reactor took over three years to start up, and was fed biomass from smaller reactors (from 5L, to $300 \mathrm{~L}$, to $2400 \mathrm{~L}$, to 500,000L) (van der Star, et al., 2007). In the case of this reactor, many more months of study are necessary to increase the $\mathrm{TN}$ removal rates.

\subsection{Biomass Evaluation}

After the removal performance of the reactor at four different liquid flow rates was measured, it was desirable to evaluate the biofilm characteristics at various air flow rates (constant liquid flow rate). After day 160, the reactor could no longer be fluidized by 1.5 SCFM (2.5 SCMH), requiring the air flow rate to be increased. The subsequent increase to 4.5 SCFM (7.5 SCMH, the minimum flow rate which mixed the reactor) reduced the accumulation of biomass on the carrier material, increased the nitrate accumulation in the reactor, and decreased the total nitrogen removal.

On day 204, the air flow rate was set at 3.0 SCFM (5.1 SCMH), and the system was allowed to equilibrate over 18 days. Following this, the air flow was set at 1.0 SCFM (1.7 SCMH) for 14 days, and 0.5 SCFM (0.85 SCMH) for 34 days. In each case, the biofilm accumulation on the carrier material was measured, the polysaccharide concentration of the biofilm was determined, and the oxygen removal rate of the carriers were observed. In each of the three air flow rates, samples were taken from three locations. These locations are shown in Figure 7-12. The determination of the three locations was based on the similar characteristics observed in each area. 


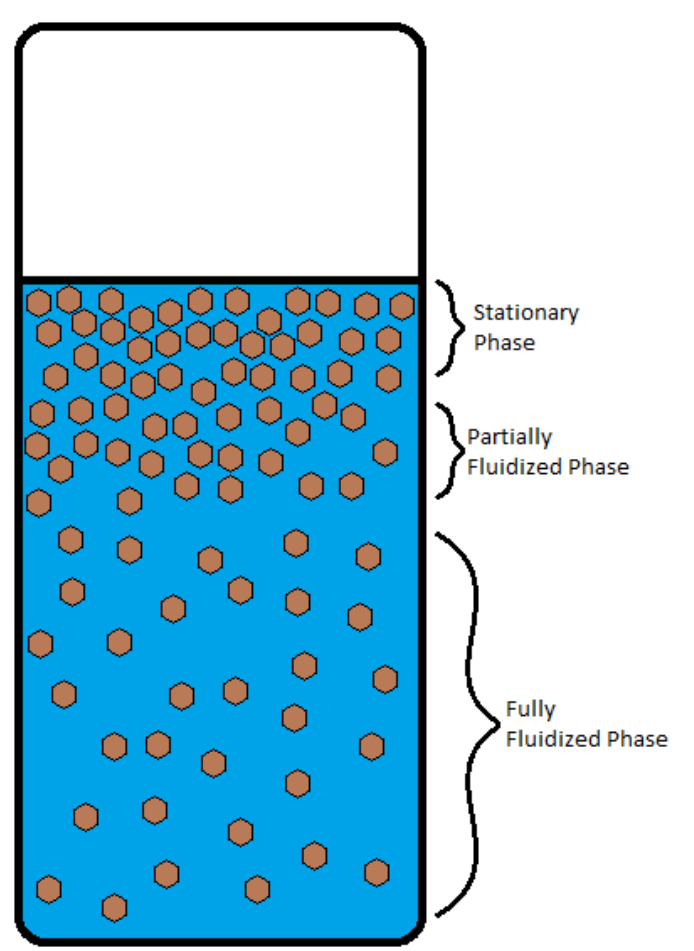

Figure 7-12: Sample locations from three phase fluidized bed bioreactor

The determination of the three different sample locations was based on the similar characteristics observed in each area. The particles in the upper stationary phase did not move, and were able to accumulate more biomass on the inner and outer carrier surfaces. The collection of carriers in the upper portion of the reactor (from 0-20 $\mathrm{cm}$ ) prevented particles in the stationary phase from moving in the reactor. Particles in the partially fluidized phase (20-35 $\mathrm{cm}$ ) were frequently stationary, but occasionally moved around and mixed with the liquid. The local hydrodynamic forces were not constant in the large reactor, which allowed for different portions of the partially fluidized phase to mix over time. The fully fluidized phase was consistently mixed in the reactor, and carriers could be present at any location below the partially fluidized phase.

It was found that the air flow rate had a substantial impact on all measured properties of the biofilm. As shown in Figure 7-13, the density of the biomass accumulation in the plastic carrier decreased along the height of the reactor. This decrease is obvious in in the stationary and fully fluidized areas in the reactor, although a differing trend was observed in the partially fluidized region at $1 \mathrm{SCFM}(1.7 \mathrm{SCMH})$. In this case, the measured biomass concentration in the 
stationary and partially fluidized regions at 1 SCFM $(1.7 \mathrm{SCMH})$ were very similar $\left(33.3 \mathrm{~g} / \mathrm{m}^{3} \mathrm{vs}\right.$ $32.5 \mathrm{~g} / \mathrm{m}^{3}$, respectively), and could be a result of the sampling method. When collecting partially fluidized particles, they were physically removed by reaching through the stationary region.

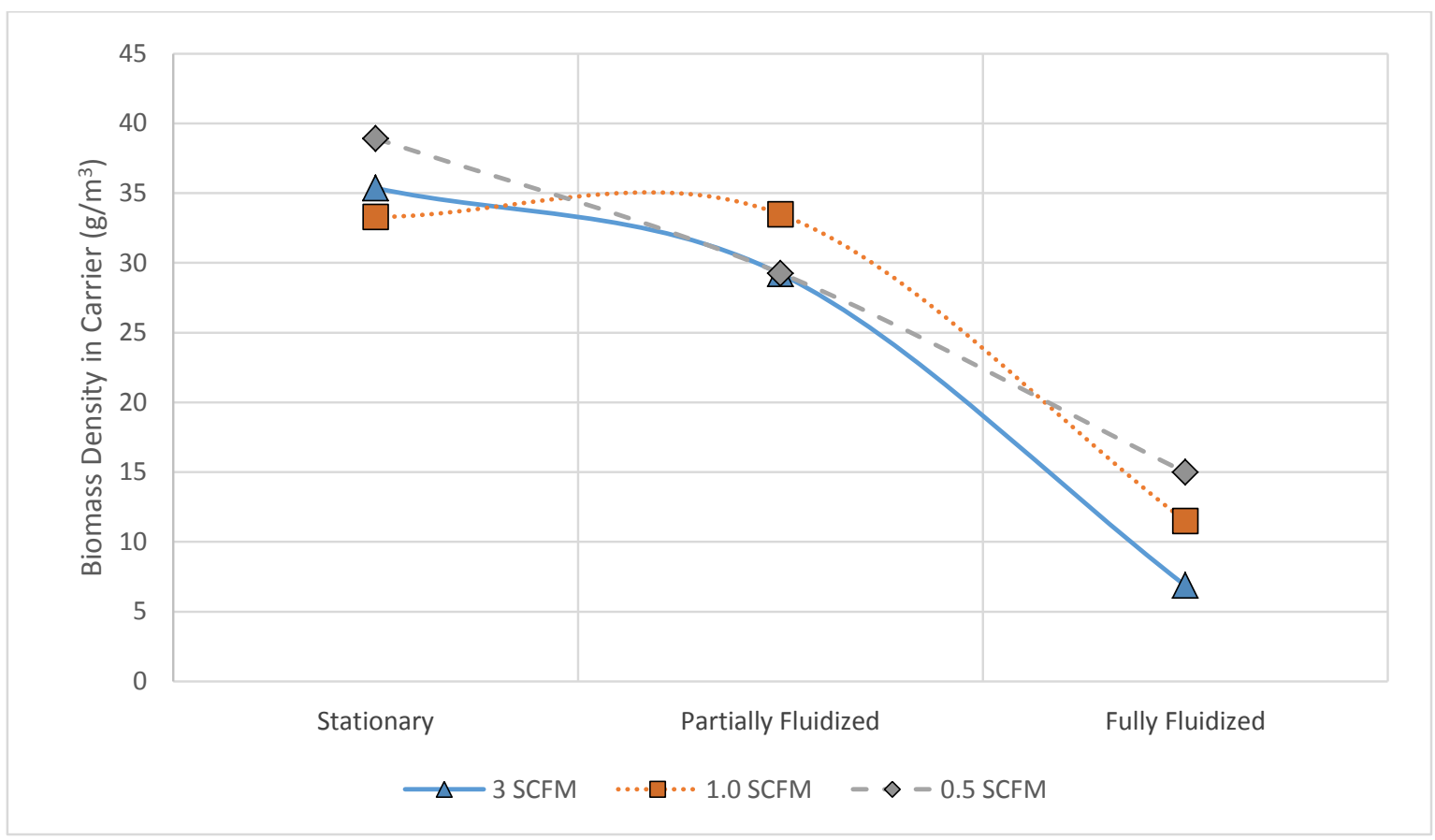

Figure 7-13: Biofilm density at three different locations and air flow rates

When observing the fully fluidized region, it is clear that the air flow rate had an impact on the quantity of accumulated biomass. The high air flow rate of 3.0 SCFM (5.1 SCMH) prevented the gross accumulation of biomass on the carriers, compared to the reduced air flow rate of 0.5 SCFM (0.85 SCMH), which allowed for more than double the biomass accumulation.

The effect of the air flow rate on biomass accumulation can be further discussed by investigating the polysaccharide (PS) concentration in the biomass. PS in biofilms are essential in maintaining the physical stability of the structure, and greater concentrations prevent the erosion of cells from the carrier material (Sutherland, 2001). As shown in Figure 7-14, there is an obvious trend of increasing PS concentration with both the air flow rate and physical location within the reactor. The fully fluidized biofilm at 3 SCFM (5.1 SCMH) was measured to have the highest concentration of PS within the attached biofilm. This high concentration is 
necessary to ensure the biofilm remains attached to the plastic carrier under high shear conditions.

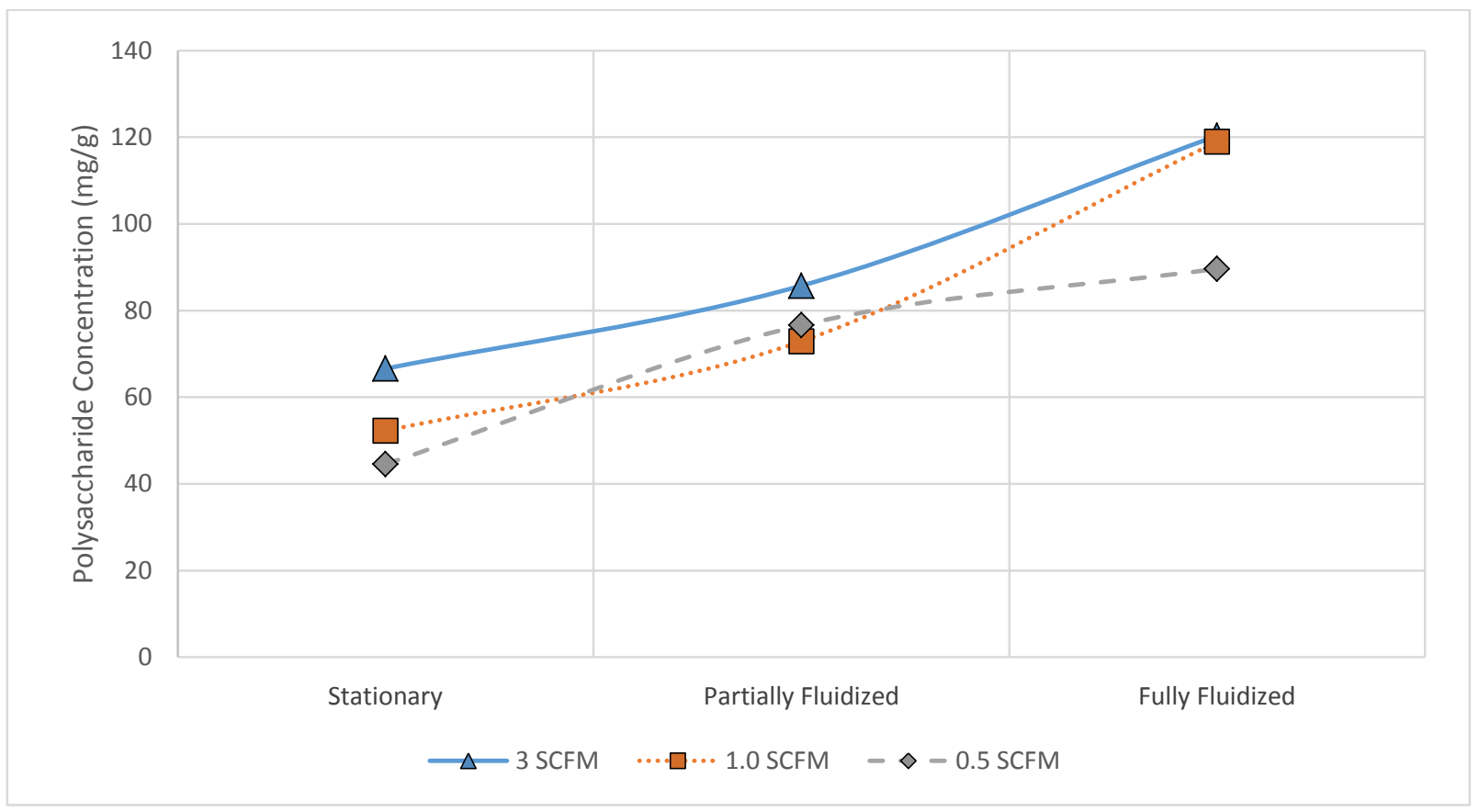

Figure 7-14: Polysaccharide concentration in biomass

The particles in the stationary region of the reactor had reduced concentrations of PS, when compared to the partially/fully fluidized regions. As the stationary particles were not directly exposed to high shear conditions which occurred next to the air diffusers, and did not physically move in the reactor, the necessary PS concentration was reduced. However, the higher air flow rates introduced greater liquid velocity (and shear), resulting in an increasing trend of PS concentration with increasing air flow rates. The increased PS concentration was necessary to maintain the physical stability of the biofilm at higher air flow rates.

When comparing measured PS concentrations to similar studies, the values from this study fall within the expected range. In the study of Tang et al., 2011, the researchers found that a PS concentration of $71.8 \mathrm{mg} / \mathrm{g}$ biomass was typical for anammox granules in a UASB reactor. This value is similar to the stationary/partially fluidized region in the three phase fluidized bed reactor of this study, but much lower than what was measured in the fluidized region. In the fully fluidized region, increased air flow rates would cause greater shear, simulating the growth 
of PS on the carriers. However, reduced PS concentration would be observed under the conditions expected in a lab scale UASB reactor. The granules in the UASB reactor have approximate densities of $1030 \mathrm{~kg} / \mathrm{m}^{3}$, and can be fluidized with reduced liquid flow rates. Moreover, Tang et al., found that the polysaccharide concentration increased as the hydrodynamic shear increased in the UASB reactor, similar to what was observed in this study (Tang, et al., 2011).

However, in the case of this study, it is expected that the majority of the biomass is aerobic, nitrifying biomass. Moreover, the shear rates in this pilot scale fluidized bed reactor are greater than in most lab scale reactors, as a result of the higher air flow rates that are required to fluidize the particles. Despite this, the observed behaviours in pilot scale processes can be compared to this larger scale reactor. In the study of Ma, et al., 2012, the PS concentration of aerobic granules in a 1.5 L SBR were measured under varying conditions. It was found that the PS concentration varied between 15 and $80 \mathrm{mg} / \mathrm{g}$, with the PS concentration increasing under conditions of shock, such as sudden changes in chemical or physical conditions (Ma, Quan, \& Li, 2013).

The oxygen consumption rate (OCR) of the biofilm is another parameter which can be used to investigate the performance in the reactor. As shown in Figure 7-15, the particles sampled during higher air flow rates had reduced OCR. With the abundance of dissolved oxygen, the biomass did not need to maintain a high OCR. As the air flow rate decreased, the OCR increased. Because oxygen was less available at reduced air flow rates, OCR increased to ensure sufficient oxygen was available for the biological materials. The maximum oxygen consumption rate occurred at the minimum air flow rate of 0.5 SCFM $(0.85 \mathrm{SCMH})$. 


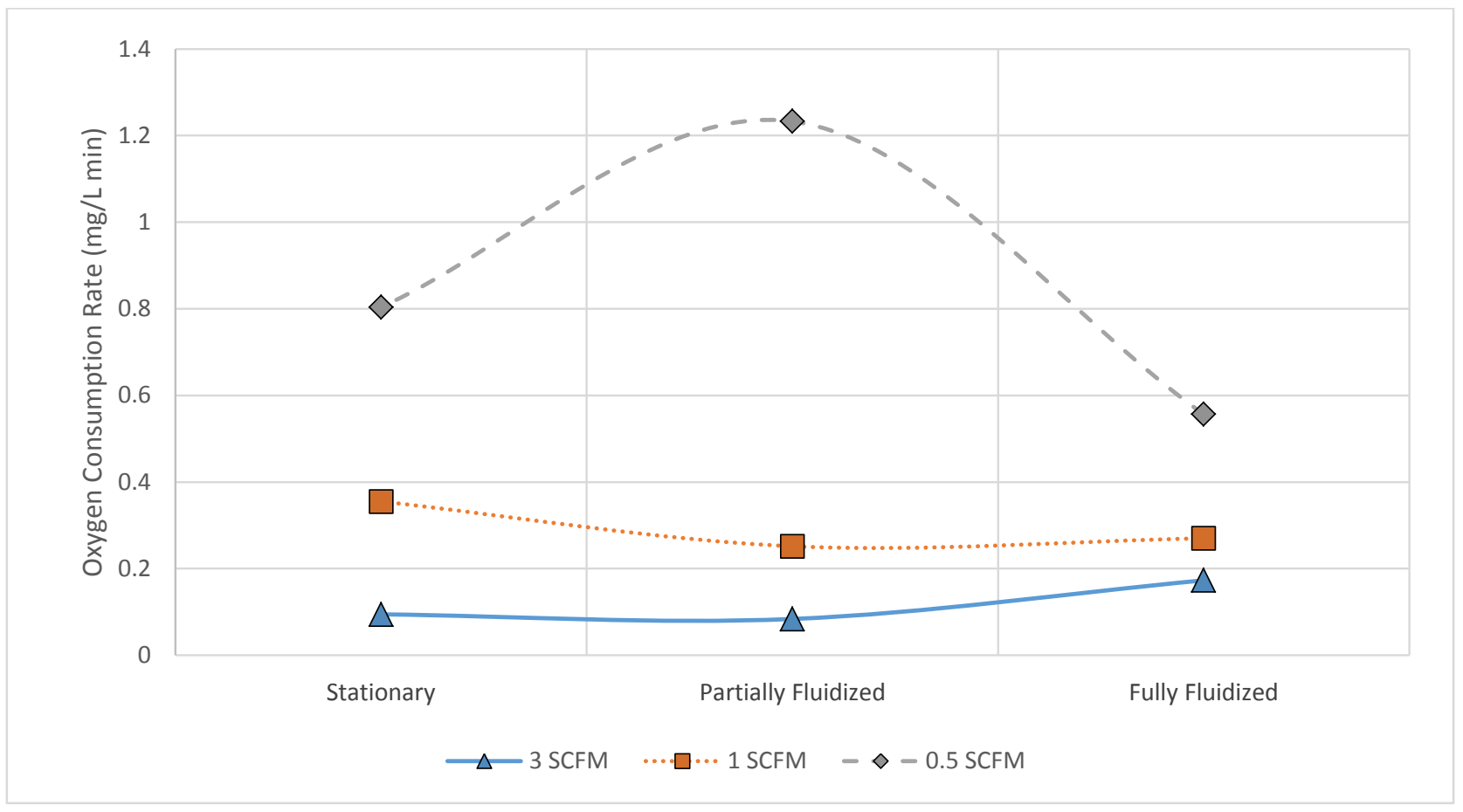

Figure 7-15: Oxygen consumption rate at varying air flow rates, $\mathrm{mg} / \mathrm{L} \mathrm{min}$

As a result of the continued exposure to a high air flow rate, the reactor operated with substantial nitrate accumulation during the period of study concerned with biofilm properties (days 204-272). The total nitrogen removal rate during this time was decreased, as a result of the high oxygen concentrations in the bulk wastewater.

\subsection{Further Evidence of Anammox Behaviour}

The evaluation of the three phase fluidized bed bioreactor has shown that anammox has contributed to the removal of total nitrogen from the incoming wastewater. However, the high DO concentration and presence of COD reduces the contribution of anammox. Therefore, to further investigate the anammox process performance, a final trial was carried out to determine the extent of nitrogen removal under low DO conditions with no COD.

The COD addition to the incoming wastewater (as sugar) was eliminated on day 298 of operation, and the airflow to the reactor was reduced. This resulted in a rapid reduction of incoming COD concentrations, with DO of the inlet and outlet wastewater in the range of 1-4 $\mathrm{mg} / \mathrm{L}$. Minor agitation was provided by the minimal air flow, although the reactor was no longer fully fluidized. 
To further reduce the DO concentration in the reactor, the incoming wastewater was passed through a deaeration column (beginning on day 313), before being pumped into the three phase fluidized bed reactor. Unfortunately, the pump attached to the deaeration column was large (minimum flow $30 \mathrm{~L} / \mathrm{min}$ ), requiring very high recycle rates in the column. Although this allowed the removal of DO from wastewater, the continuous agitation, high HRT and exposure to air caused the partial oxidation of ammonia to nitrite. Typically, the nitrite concentration was equal to or greater than the ammonia concentration, although ammonia could be added to ensure the incoming wastewater contained sufficient ammonia. The highest measured nitrite concentration was double the ammonia concentration.

As a result of the use of the deaeration column, the oxygen concentration in the bioreactor was kept below $0.25 \mathrm{mg} / \mathrm{L}$. Negligible agitation was provided, and the reactor operated as an upflow anaerobic fixed bed reactor. The removal performance of total nitrogen over 30 days is shown in Figure 7-16.

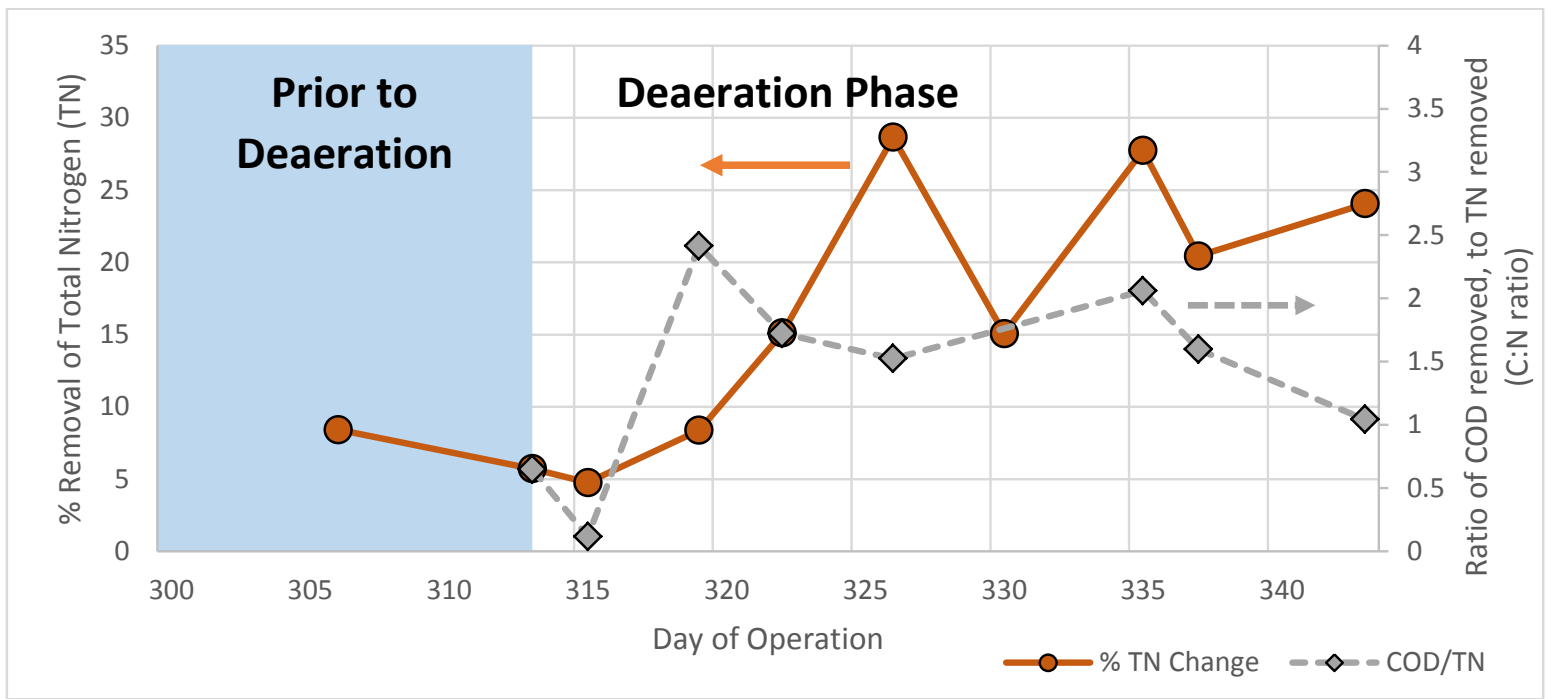

Figure 7-16: Removal performance of total nitrogen after deaeration column used (shaded area shows period where deaeration column was not in use)

When the dissolved oxygen concentration was reduced below $0.25 \mathrm{mg} / \mathrm{L}$, total nitrogen removal performance showed significant increases. The highest measured TN removal was 28.6\%. However, as reduced COD concentrations were provided in the synthetic wastewater, the TN removal can be attributed primarily to anammox. As investigated in Section 2.1, a 
theoretical ratio of 3:1 C:N is necessary for the removal of TN by heterotrophic denitrifiers. Depending on the carbon source, higher ratios are necessary. As shown in Figure 7-16, TN was removed from the reactor with a C:N ratio below 2.5 . On the final measured datapoint, $24 \%$ of the incoming total nitrogen was removed ( $48 \mathrm{mg} \mathrm{N} / \mathrm{L}$ ), with a COD reduction of only $50 \mathrm{mg} / \mathrm{L}$. The removal performance observed in this final study is characteristic of anammox bacteria. 


\subsection{Conclusions}

The investigation of the anammox process in a three phase fluidized bed bioreactor shows that anammox can operate in aerobic conditions. Beginning with a batch mode of operation, anammox was observed to remove up to $5.5 \pm 0.5 \%$ of the ammonia from wastewater. When performing simulation using the modified ASM1 model, anammox was found to remove $3.2 \%$ of ammonia. The 50 days of batch operation under reduced DO conditions helped to establish a nitrifying population, with minimal accumulation of nitrate.

Following the batch mode of operation, the continuous feeding of the three phase fluidized bed bioreactor begun. Four different flow rates, including $0.5 \mathrm{~L} / \mathrm{min}$ with recycle, $1.3 \mathrm{~L} / \mathrm{min}, 1.0$ $\mathrm{L} / \mathrm{min}$ and $0.5 \mathrm{~L} / \mathrm{min}$ were evaluated. It was found that the maximum ammonia and total nitrogen removal occurred when operating at $0.5 \mathrm{~L} / \mathrm{min}$ with recycle, where $90.9 \pm 1.6 \%$ and $20.8 \pm 4.1 \%$ were calculated, respectively. At a flow rate of $0.5 \mathrm{~L} / \mathrm{min}$ without recycle, $63.1 \pm 5.2 \%$ of ammonia and $19.2 \pm 7.5 \%$ of total nitrogen were removed after a single pass through the reactor. It was determined that up to $13.4 \pm 4.9 \%$ of the ammonia removal could be attributed to anammox.

To further investigate the extent of anammox performance in the reactor, the air flow to the three phase fluidized bed reactor was eliminated, allowing for anoxic conditions. The reactor operated as an upflow filter, with a wastewater flow rate of $0.5 \mathrm{~L} / \mathrm{min}$. Under anoxic conditions, the simultaneous removal of ammonia and nitrite were observed without a substantial reduction of COD. In all cases, the C:N ratio of removed components was below 2.5, with average values around 1.5. This behaviour is characteristic of anammox performance. Additionally, the biomass in the reactor was observed to have a deep red or carmine colour, which is typical of anammox bacteria.

In conclusion, the study of anammox performance in a three phase fluidized bed bioreactor has found:

- Anammox contributed up to $5.5 \pm 0.5 \%$ of ammonia removal during the batch phase. Simulations using the modified ASM1 model showed that anammox contributed $3.2 \%$ of the ammonia removal. 
- With the continuous addition of wastewater, anammox contributed up to $13.4 \pm 4.9 \%$ of the ammonia removal.

- The highest ammonia and TN removals of $90.9 \pm 1.6 \%$ and $20.8 \pm 4.1 \%$ were measured with high recycle flow rates. Ammonia and TN removals of $63.1 \pm 5.2 \%$ and $19.2 \pm 7.5 \%$ were measured after a single pass through the reactor.

- It was determined that anoxic zones exist within the biomass carriers. The diffusion of oxygen from the bulk liquid through the biomass resulted in DO concentrations below $1.0 \mathrm{mg} / \mathrm{L}$ in the inner portion of the biomass carrier.

- The addition of COD to the reactor was eliminated, and the wastewater was passed through a deaeration column, reducing the bulk DO concentration below $0.25 \mathrm{mg} / \mathrm{L}$. The reduction of bulk DO increased the TN removal to a maximum value of $28.6 \%$. The removal of TN without COD requires an active anammox population in the reactor.

- The biofilm on the biomass carriers was observed to have a pale red or carmine colour, which is characteristic of anammox bacteria.

The anammox process investigated in this study shows that there is a low cost method for the integration of anammox bacteria into aerobic reactor systems. Treatment of wastewater requires only a single pass through the three phase fluidized bed reactor. Further, the ability to start up and fluidize the reactor with air, instead of nitrogen or air/nitrogen mixtures, provides a novel method for the cost effective denitrification of wastewater. Further investigation is both necessary and worthwhile, as improved removal efficiencies are expected over time.

\subsection{Recommendations}

It is clear that anammox is contributing to the removal of total nitrogen in this reactor, although it is necessary to further improve the performance. To look at the possibility of another microorganism different from anammox to be responsible for the denitrification process would be unrealistic, and would demand an extended and expensive period of research. Due to the large size of the reactor and slow growth rate of the anammox bacteria, further study is necessary to fully optimize the process. Furthermore, a number of recommendations are suggested for future research. This includes: 
- Fluidization using nitrogen gas produced by the anammox reaction should be investigated. The continuous recycle of effluent gases could help to increase the control of DO concentrations in the reactor, or could provide a fully anoxic environment.

- Alternative biomass carriers should be evaluated. Using carriers with density greater than water could allow for fluidization using high liquid flow rates. 
Appendices 
Table 0-1: Modified ASM1 Function

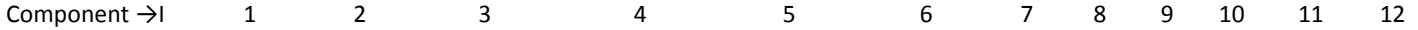

\begin{tabular}{|c|c|c|c|c|c|c|c|c|c|c|c|c|c|c|}
\hline $\begin{array}{r}\text { Process } \\
\downarrow J\end{array}$ & & $\mathrm{~S}_{0}$ & $\mathrm{~S}_{\mathrm{s}}$ & $\mathrm{S}_{\mathrm{NH}}$ & $\mathrm{S}_{\mathrm{NO2}}$ & $\mathrm{S}_{\mathrm{NO} 3}$ & $\mathrm{~S}_{\mathrm{N} 2}$ & $x_{H}$ & $X_{N H}$ & $\mathrm{X}_{\mathrm{NO}}$ & $X_{A N}$ & $x_{s}$ & $x_{i}$ & \\
\hline 1 & $\begin{array}{c}\text { Hydrolysis of } \\
\text { entrapped organics }\end{array}$ & & 1 & & & & & & & & & -1 & & $k_{H} \frac{X_{S} / X_{H}}{K_{x}+X_{S} / X_{H}}$ \\
\hline 2 & $\begin{array}{l}\text { Growth of } \\
\text { heterotrophs }\end{array}$ & $-\frac{\left(1-Y_{H}\right)}{Y_{H}}$ & $-\frac{1}{Y_{H}}$ & $-i_{n b m}$ & & & & 1 & & & & & & $\mu_{H}^{\max } \frac{S_{o}}{K_{O, H}+S_{O}} \frac{S_{S}}{K_{S, H}+S_{S}} X_{H}$ \\
\hline 3 & $\begin{array}{c}\text { Decay of } \\
\text { heterotrophs }\end{array}$ & & & $i_{n b m}-f_{p} i_{n x i}$ & & & & -1 & & & & $\left(1-f_{i}\right)$ & $f_{i}$ & $b_{H} X_{H}$ \\
\hline 4 & $\begin{array}{c}\text { Growth of } \\
\text { heterotrophs on } \\
\text { nitrate }\end{array}$ & & $-\frac{1}{Y_{H, N O 3}}$ & $-i_{n b m}$ & $\frac{\left(1-Y_{H, N O 3}\right)}{1.14 Y_{H, N O 3}}$ & $-\frac{\left(1-Y_{\mathrm{H}, \mathrm{NO} 3}\right)}{1.14 Y_{\mathrm{H}, \mathrm{NO} 3}}$ & & 1 & & & & & & $\mu_{H}^{M A X} \eta_{N O 3}\left(\frac{K_{O, H}}{K_{O, H}+S_{O}}\right)\left(\frac{s_{N O 3}}{K_{N O 3, H}+S_{N O 3}}\right)\left(\frac{s_{S}}{K_{S, H}+S_{S}}\right) X_{H}$ \\
\hline 5 & $\begin{array}{c}\text { Growth of } \\
\text { heterotrophs on } \\
\text { nitrite }\end{array}$ & & $-\frac{1}{Y_{H, \mathrm{NO} 2}}$ & $-i_{n b m}$ & $-\frac{\left(1-Y_{H, N O 2}\right)}{1.71 Y_{H, N O 2}}$ & & $\frac{\left(1-Y_{H, N O 2}\right)}{1.71 Y_{H, N O 2}}$ & 1 & & & & & & $\mu_{N H}^{M A X} \eta_{N O 2}\left(\frac{K_{O, H}}{K_{O, H}+S_{O}}\right)\left(\frac{S_{N O 2}}{K_{N O 2, H}+S_{N O 2}}\right)\left(\frac{S_{S}}{K_{S, H}+S_{S}}\right) X_{H}$ \\
\hline 6 & $\begin{array}{c}\text { Growth of aerobic } \\
\text { ammonia oxidizing } \\
\text { bacteria }\end{array}$ & $-\frac{\left(3.43-Y_{N H}\right)}{Y_{N H}}$ & & $-\frac{1}{Y_{N H}}-i_{n b m}$ & $\frac{1}{Y_{N H}}$ & & & & 1 & & & & & $\mu_{N H}^{M A X}\left(\frac{s_{O}}{K_{O, N H}+S_{O}}\right)\left(\frac{s_{N H 3}}{K_{N H 3, N H}+S_{N H 3}}\right) X_{N H}$ \\
\hline 7 & $\begin{array}{c}\text { Decay of aerobic } \\
\text { ammonia oxidizing } \\
\text { bacteria }\end{array}$ & & & $i_{n b m}-f_{p} i_{n x i}$ & & & & & -1 & & & $\left(1-f_{i}\right)$ & $f_{i}$ & $b_{N H} X_{N H}$ \\
\hline 8 & $\begin{array}{l}\text { Growth of aerobic } \\
\text { nitrite oxidizing } \\
\text { bacteria }\end{array}$ & $-\frac{\left(1.14-Y_{N H}\right)}{Y_{N H}}$ & & $-i_{n b m}$ & $-\frac{1}{Y_{N O}}$ & $\frac{1}{Y_{N O}}$ & & & & 1 & & & & $\mu_{N O}^{M A X}\left(\frac{s_{O}}{K_{O, N O}+S_{O}}\right)\left(\frac{s_{\mathrm{HNO}^{\prime}}}{K_{\mathrm{HNO}, \mathrm{NO}+S_{\mathrm{HNO} 2}}}\right) X_{N O}$ \\
\hline 9 & $\begin{array}{c}\text { Decay of aerobic } \\
\text { nitrite oxidizing } \\
\text { bacteria }\end{array}$ & & & $i_{n b m}-f_{p} i_{n x i}$ & & & & & & -1 & & $\left(1-f_{i}\right)$ & $f_{i}$ & $b_{N O} X_{N O}$ \\
\hline 10 & $\begin{array}{l}\text { Growth of } \\
\text { anammox }\end{array}$ & & & $-\frac{1}{Y_{A N}}-i_{n x b a}$ & $-1.52-\frac{1}{Y_{A N}}$ & 1.52 & $\frac{2}{Y_{A N}}$ & & & & 1 & & & $\mu_{A N}^{M A X}\left(\frac{K_{O, A N}}{K_{O, A N}+S_{O}}\right)\left(\frac{s_{N O 2}}{K_{N O 2, A N}+S_{N O 2}}\right)\left(\frac{s_{N H}}{K_{N H, A N}+S_{N H}}\right) X_{A N}$ \\
\hline 11 & Decay of anammox & & & $i_{n x b a}-f_{p} i_{n x p}$ & & & & & & & -1 & $\left(1-f_{i}\right)$ & $f_{i}$ & $b_{A N} X_{A N}$ \\
\hline
\end{tabular}




\section{The following Matlab code was used for the solving of the modified ASM1 function, described in Table}

0-1.

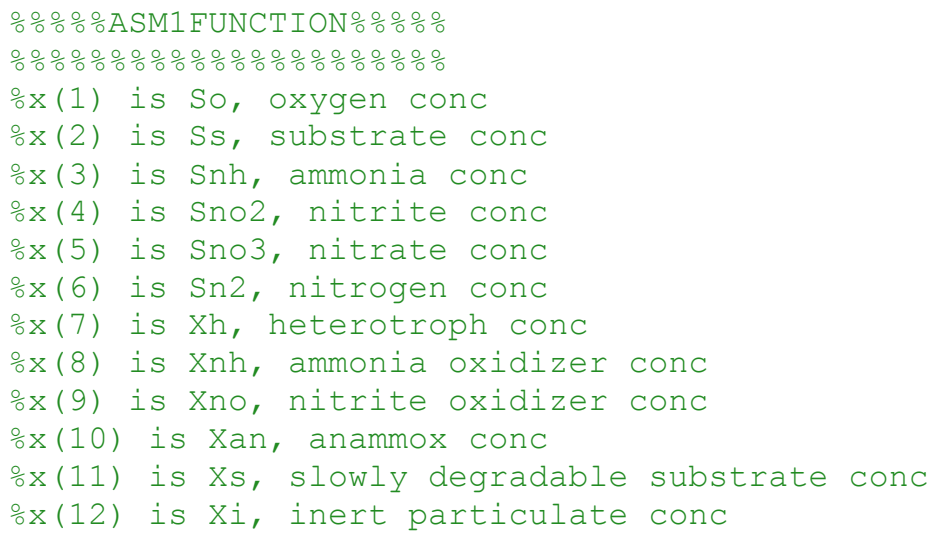




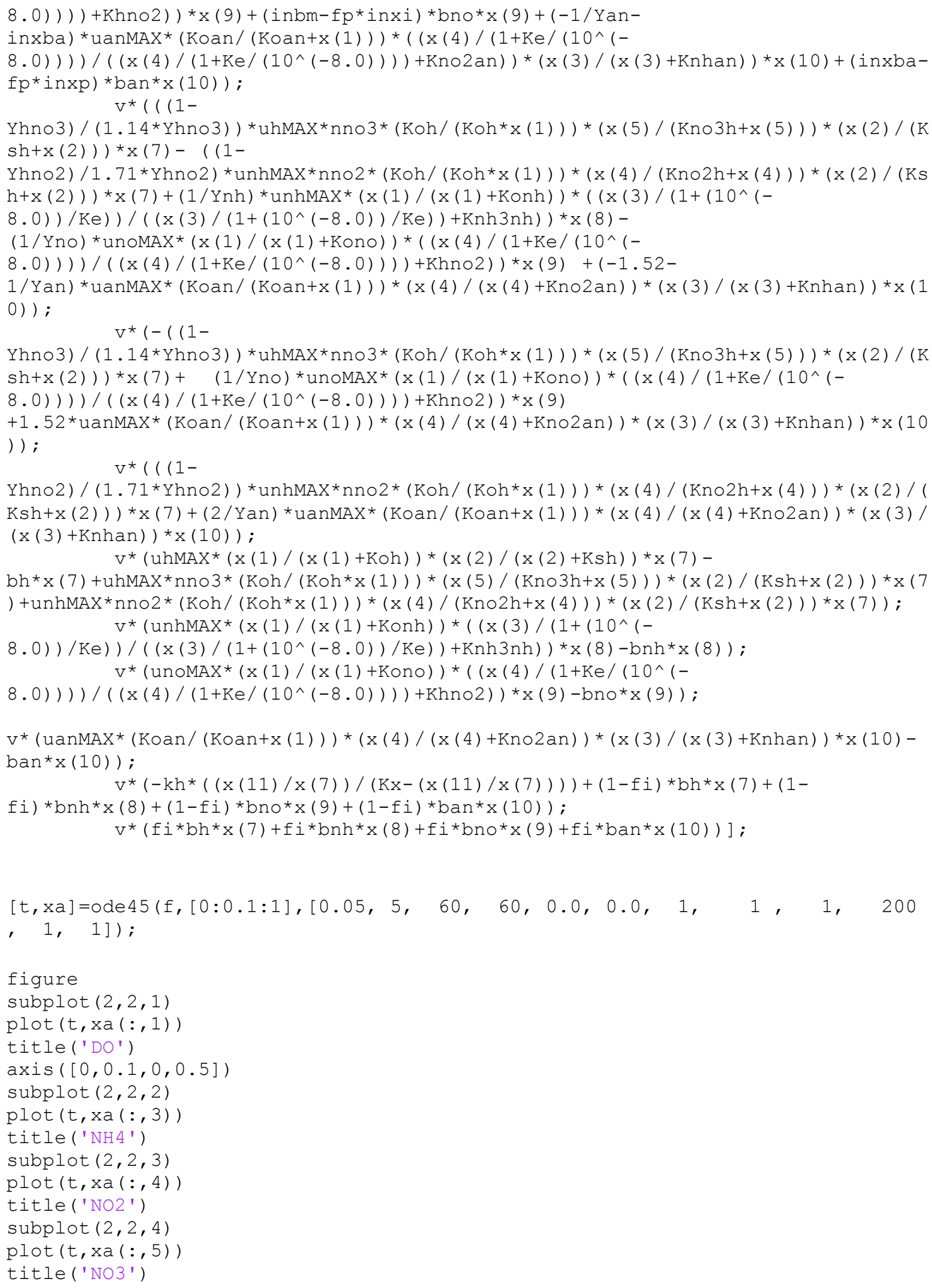


xa (length $(t), 3)$

xa (length $(t), 4$ )

xa (length $(t), 5$ )

The following code was used to define the various kinetic parameters used in the modified ASM1 function. Table 0-2 describes each value, and the source.

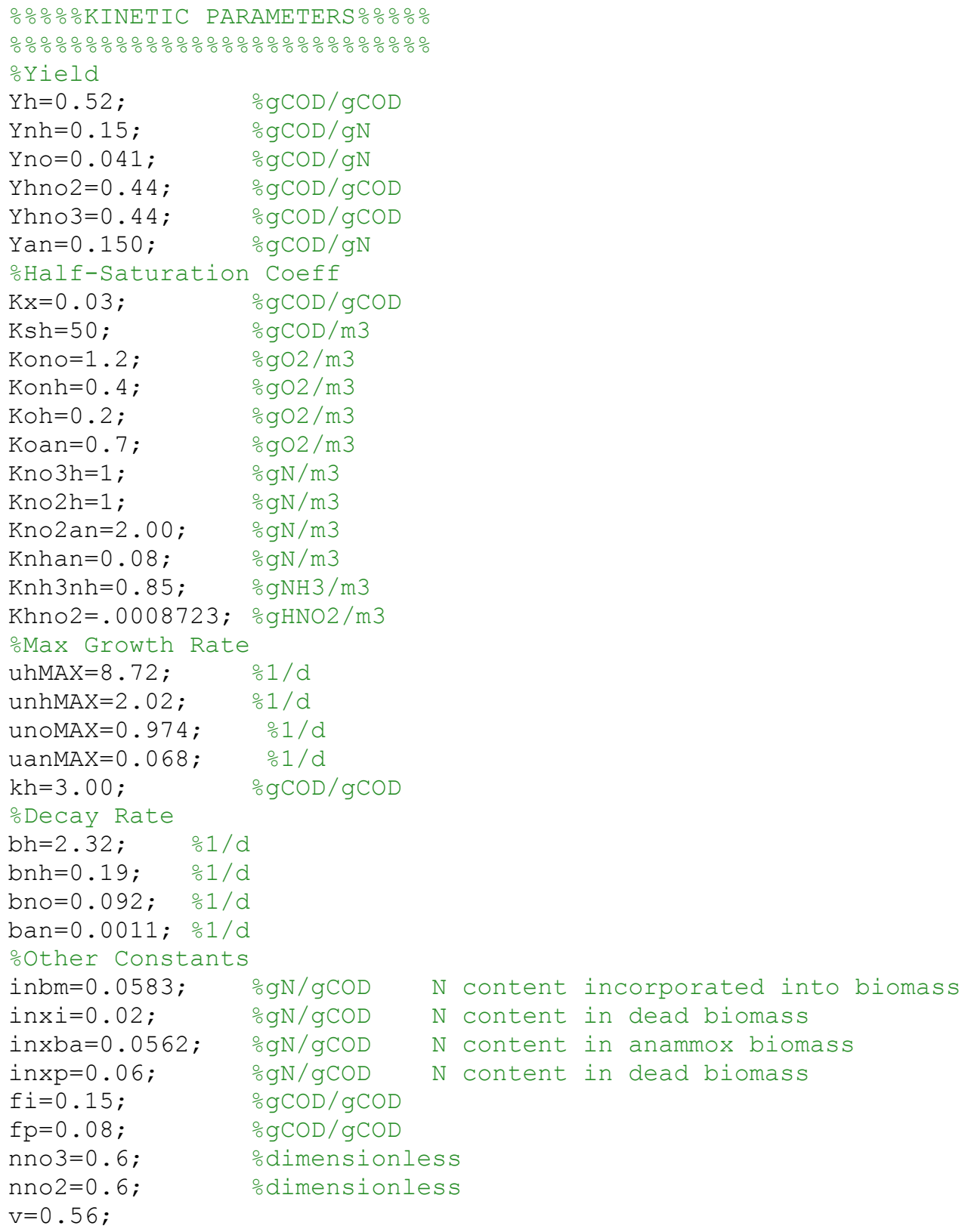


Table 0-2: Description of kinetic parameters for modified ASM1 function

\begin{tabular}{|c|c|c|}
\hline Parameter & Value & Source \\
\hline \multicolumn{3}{|c|}{ Yield Coefficients } \\
\hline Yh, Heterotrophic yield on oxygen & $0.52 \mathrm{gCOD} / \mathrm{gCOD}$ & (Wyffels, et al., 2004) \\
\hline Ynh, Autotrophic yield of AOBs & $0.15 \mathrm{gCOD} / \mathrm{gN}$ & (Wyffels, et al., 2004) \\
\hline Yno, Autotrophic yield of NOBs & 0.041 gCOD/gN & (Wyffels, et al., 2004) \\
\hline Yhno2, Heterotrophic yield on nitrite & 0.44 gCOD/gCOD & (Wyffels, et al., 2004) \\
\hline Yhno3, Heterotrophic yield on nitrate & 0.44 gCOD/gCOD & (Wyffels, et al., 2004) \\
\hline Yan, Autotrophic yield of Anammox & $0.15 \mathrm{gCOD} / \mathrm{gN}$ & (Cema, et al., 2012) \\
\hline \multicolumn{3}{|c|}{ Half-Saturation Coefficients } \\
\hline Kx, Coefficient for slowly biodegradable substrate & $0.03 \mathrm{gCOD} / \mathrm{gCOD}$ & (Wyffels, et al., 2004) \\
\hline Ksh, Substrate coefficient for heterotrophs & $50.0 \mathrm{gCOD} / \mathrm{m}^{3}$ & (Wyffels, et al., 2004) \\
\hline Kono, Oxygen coefficient for NOB & $1.2 \mathrm{gO}_{2} / \mathrm{m}^{3}$ & (Peng \& Zhu, 2006) \\
\hline Konh, Oxygen coefficient for $A O B$ & $0.4 \mathrm{gO}_{2} / \mathrm{m}^{3}$ & (Peng \& Zhu, 2006) \\
\hline Koh, Oxygen coefficient for heterotrophs & $0.2 \mathrm{gO}_{2} / \mathrm{m}^{3}$ & (Wyffels, et al., 2004) \\
\hline Koan, Oxygen coefficient for anammox & $0.7 \mathrm{gO}_{2} / \mathrm{m}^{3}$ & (Cema, et al., 2012) \\
\hline Kno3h, Nitrate coefficient for heterotrophs & $1.00 \mathrm{gN} / \mathrm{m}^{3}$ & (Wyffels, et al., 2004) \\
\hline Kno2h, Nitrite coefficient for heterotrophs & $1.00 \mathrm{gN} / \mathrm{m}^{3}$ & (Wyffels, et al., 2004) \\
\hline Kno2an, Nitrite coefficient for anammox & $2.00 \mathrm{gN} / \mathrm{m}^{3}$ & (Cema, et al., 2012) \\
\hline Knhan, Ammonia coefficient for anammox & $0.08 \mathrm{gN} / \mathrm{m}^{3}$ & (Cema, et al., 2012) \\
\hline Knh3nh, Ammonia coefficient for AOB & $0.85 \mathrm{gNH}_{3} / \mathrm{m}^{3}$ & (Wyffels, et al., 2004) \\
\hline Khno2, Nitrite coefficient for NOB & $0.0008723 \mathrm{gHNO}_{2} / \mathrm{m}^{3}$ & (Wyffels, et al., 2004) \\
\hline \multicolumn{3}{|c|}{ Maximum Growth Rates } \\
\hline uhMAX, Max growth rate for heterotrophs & $8.72 \mathrm{~d}^{-1}$ & (Wyffels, et al., 2004) \\
\hline unhMAX, Max growth rate for AOBs & $2.02 \mathrm{~d}^{-1}$ & (Wyffels, et al., 2004) \\
\hline unoMAX, Max growth rate for NOBs & $0.974 \mathrm{~d}^{-1}$ & (Wyffels, et al., 2004) \\
\hline uanMAX, Max growth rate for anammox & $0.068 \mathrm{~d}^{-1}$ & (Dapena-Mora, et al., 2004) \\
\hline Kh, Max hydrolysis rate & $3.00 \mathrm{~d}^{-1}$ & (Wyffels, et al., 2004) \\
\hline
\end{tabular}




\section{Decay Coefficients}

\begin{tabular}{|l|l|l|}
\hline bh, Decay coefficient for heterotrophs & $2.32 \mathrm{~d}^{-1}$ & (Wyffels, et al., 2004) \\
\hline bnh, Decay coefficient for AOBs & $0.19 \mathrm{~d}^{-1}$ & (Wyffels, et al., 2004) \\
\hline bno, Decay coefficient for NOBs & $0.092 \mathrm{~d}^{-1}$ & (Wyffels, et al., 2004) \\
\hline ban, Decay coefficient for anammox & $0.0011 \mathrm{~d}^{-1}$ & (Dapena-Mora, et al., 2004) \\
\hline \multicolumn{2}{|c|}{ Other Coefficients } \\
\hline inbm, Ammonia incorporated into biomass, anammox & $0.0583 \mathrm{gN} / \mathrm{gCOD}$ & (Dapena-Mora, et al., 2004) \\
\hline inxi, Nitrogen content in inert materials & $0.02 \mathrm{gN} / \mathrm{gCOD}$ & (Wyffels, et al., 2004) \\
\hline inxba, Nitrogen content in anammox biomass & $0.0562 \mathrm{gN} / \mathrm{gCOD}$ & (Cema, et al., 2012) \\
\hline inxp, Ammonia incorporated into biomass, autotrophs & $0.06 \mathrm{gN} / \mathrm{gCOD}$ & (Cema, et al., 2012) \\
\hline fi, production of inert from decay of heterotrophs & $0.15 \mathrm{gCOD} / \mathrm{gCOD}$ & (Wyffels, et al., 2004) \\
\hline fp, production of inert from decay of autotrophs & $0.08 \mathrm{gCOD} / \mathrm{gCOD}$ & (Dapena-Mora, et al., 2004) \\
\hline nno3, Anoxic reduction factor, nitrate & 0.6, dimensionless & (Wyffels, et al., 2004) \\
\hline nno2, Anoxic reduction factor, nitrite & 0.6, dimensionless & (Wyffels, et al., 2004) \\
\hline V, Reactor Volume & $0.56 \mathrm{~m}{ }^{3}$ & (This Study, 2014) \\
\hline
\end{tabular}




\section{References}

Ahn, Y., Hwang, I., \& Min, K. (2004). ANAMMOX and Partial Denitrification in Anaerobic Nitrogen Removal from Piggery Waste. Water Science and Technology, 145-153.

Ali, M., Chai, L., Tang, C., Zheng, P., Min, X., Yang, Z., . . Song, Y. (2013). The Increasing Interest of ANAMMOX Research in China: Bacteria, Process Development, and Application. BioMed Research International, 21.

Alvarez-Cuenca, M., \& Reza, M. (2013). US Patent No. 61/826,676.

An, P., Xu, X., Yang, F., \& Li, Z. (2013). Comparison of the Characteristics of Anammox Granules of Different Sizes. Biotechnology and Bioprocess Engineering, 446-454.

APHA, AWWA, WEF. (2012). Standard Methods for the Examination of Water and Wastewater. Washington, DC: American Public Health Association, American Water Works Association, Water Environment Fedaration.

Argaman, Y., Barnard, J., Daigger, G., Eckenfelder, W., Hermanowicz, S., Jenkins, D., . . Stensel, H. (1991). Phosphorus and Nitrogen Removal from Municipal Wastewater: Principle and Practice. New York: The Soap and Detergent Association.

Barnard, J. (1975). US Patent No. 3964998.

Barnard, J. (2006). Biological Nutrient Removal: Where We Have Been, Where We Are Going? WEFTEC (pp. 1-25). Dallas, Texas: Water Environment Federation.

Bitton, G. (1998). Formula Handbook for Environmental Engineers and Scientists. New York: John Wiley \& Sons.

Broda, E., \& Dv. (1977). Two Kinds of Lithotrophs Missing in Nature. Zeitschrift fur Allgemeine Microbiologie, 491-493.

Burghate, S., \& Ingole, N. (2013). Fluidized Bed Biofilm Reactor - A Novel Wastewater Treatment Reactor. International Journal of Research in Environmental Science and Technology, 145-155.

Canto, C., Ratusznei, S., Rodrigues, J., Zaiat, M., \& Foresti, E. (2012). Biological Removal of Nitrogen Compounds from Wastewaters: Conventional and Non-Conventional Processes. In N. Savaglio, \& R. Puopolo, Denitrification: Processes, Regulation and Ecological Significance (pp. 1-62). New York: Nova Science Publishers.

CBSNews. (2014, August 3). Showering declared potential hazard in Toledo, Ohio. Retrieved from CBSNews.com: http://www.cbsnews.com/news/showering-declared-potentialhazard-in-toledo-ohio/ 
CCME. (2006). Municipal Wastewater Effluent in Canada. Ottawa: Canadian Council of Ministers of the Environment.

Cema, G., Sochacki, A., Zubiatowicz, J., Gutwinski, P., \& Surmacz-Gorska, J. (2012). Start-up, Modelling and Simulation of the Anammox Process in a Membrane Bioreactor. Chemical and Process Engineering, 639-650.

Chamchoi, N., Nitisoravut, S., \& Schmidt, J. (2008). Inactivation of ANAMMOX Communities under Concurrent Operation of Anaerobic Ammonium Oxidation (ANAMMOX) and Denitrification. Bioresource Technology, 3331-3336.

Chen, H., Liu, S., Yang, F., Xue, Y., \& Wang, T. (2009). The Development of Simultaneous Partial Nitrification, Anammox and Denitrification (SNAD) Process in a Single Reactor for Nitrogen Removal. Bioresource Technology, 1548-1554.

Chen, J., Ji, Q., Zheng, P., Chen, T., Wang, C., \& Mahmood, Q. (2010). Flotation and Control of Granular Sludge in a High-Rate Anammox Reactor. Water Research, 3321-3328.

Chen, T., Zheng, P., Shen, L. D., \& Mahmood, Q. (2011). Kinetic Characteristics and Microbial Community of Anammox-EGSB Reactor. Journal of Hazardous Materials, 28-35.

Chen, T., Zheng, P., Tang, C., Wang, S., \& Ding, S. (2011). Performance of ANAMMOX-EGSB Reactor. Desalination, 281-287.

CIELAP. (2009). CIELAP Brief on Biosolids Management in Ontario. Toronto: Canadian Institute for Environmental Law and Policy.

City of Ottawa. (2011). Sewer Use Program: Guide for Discarging Wastewater From Industrial Facilities. Ottawa: City of Ottawa.

Claros, J., Serralta, J., Seco, A., Ferrer, J., \& Aguado, D. (2012). Real-time Control Strategy for Nitrogen Removal via Nitrite in a SHARON Reactor Using $\mathrm{pH}$ and ORP sensors. Process Biochemistry, 1510-1515.

Clippeleir, H., Yan, X., Verstraete, W., \& Vlaeminck, S. (2011). OLAND is Feasable to Treat Sewage-Like Nitrogen Concentrations at Low Hydraulic Residence Times. Applied Microbial Biotechnology, 1537-1545.

Cortez, S., Teixeira, P., Oliveira, R., \& Mota, M. (2008). Rotating Biological Contactors: A Review on Main Factors Affecting Performance. Reviews in Environmental Science and Biotechnology, 155-172.

Daigger, G., \& Boltz, J. (2011). Trickling Filter and Trickling Filter-Suspended Growth Process Design and Operation: A State-of-the-Art Review. Water Environment Research, 388404. 
Dapena-Mora, A., van Hulle, S., Campos, J., Mendez, R., Vanrolleghem, P., \& Jetten, M. (2004). Enrichment of Anammox Biomass from Municipal Activated Sludge: Experimental and Modelling Results. Journal of Chemical Technology and Biotechnology, 1421-1428.

Daverey, A., Chen, Y., Sung, S., \& Lin, J. (2014). Effect of Zinc on Anammox Activity and Performance of Sumultaneous Partial Nitrification, Anammox and Denitrification (SNAD) Process. Bioresource Technology, 105-110.

Daverey, A., Su, S., Huang, Y., \& Lin, J. (2012). Nitrogen Removal from Opto-Electronic Wastewater using the Simultaneous Partial Nitrification, Anaerobic Ammonium Oxidation and Denitrification (SNAD) Process in a Sequencing Batch Reactor. Bioresource Technology, 225-231.

Davery, A., Su, S., Huang, Y., Chen, S., Sung, S., \& Lin, J. (2013). Partial Nitrification and Anammox Processes: A Method for High Strength Optoelectronic Industrial Wastewater Treatment. Water Research, 2929-2937.

Davies, P. (2005). The Biological Basis of Wastewater Treatment. North Lanarkshire, Scotland: Strathkelvin Instruments.

de-Bashan, L., \& Bashan, Y. (2004). Recent Advances in Removing Phosphorus from Wastewater and Its Future Use as Fertilizer (1997-2003). Water Research, 4222-4246.

Du, R., Peng, Y., Cao, S., Wu, C., Weng, D., Wang, S., \& He, J. (2014). Advanced Nitrogen Removal with Simultaneous Anammox and Denitrification in Sequencing Batch Reactor. Bioresource Technology, 316-322.

EAWAG Aquatic Research. (2008). Compendium of Sanitation Systems and Technologies. Dubendorf, Switzerland: EAWAG Aquatic Research.

Figdore, B., Wett, B., Hell, M., \& Murthy, S. (2001). Deammonification of Dewatering Sidestream from Thermal Hydrolysis-Mesophillic Anaerobic Digestion Process. Proceedings of the Water Environment Federation, 1037-1052.

Fisheries and Oceans Canada. (2005). Survey of Recreational Fishing in Canada: Selected Results for the Great Lakes Fishery. Ottawa: Fisheries and Oceans Canada.

Fux, C., Boehler, M., Huber, P., Brunner, I., \& Siegrist, H. (2002). Biological Treatment of Ammonium-Rich Wastewater by Partial Nitration and Subsequent Anaerobic Ammonium Oxidation (Anammox) in a Pilot Plant. Journal of Biotechnology, 295-306.

Gavrilescu, M., \& Macoveanu, M. (2000). Attached-Growth Process Engineering in Wastewater Treatment. Bioprocess Engineering, 95-106. 
Gell, K., Ruijter, F., Kuntke, P., Graaf, M., \& Smit, A. (2011). Safety and Effectiveness of Struvite from Black Water and Urine as Phosphorus Fertilizer. Journal of Agricultural Science, 6780.

Gerardi, M. (2002). Nitrification and Denitrification in the Activated Sludge Process. New York: John Wiley and Sons, Inc.

Government of Canada. (1985). Fisheries Act. Ottawa: Government of Canada.

Government of Canada. (2012). Wastewater Systems Effluent Regulations. Ottawa, Ontario: Government of Canada.

Grunditz, C., \& Dalhammar, G. (2000). Development of Nitrification Inhibition Assays Using Pure Cultures of Nitrosomonas and Nitrobacter. Water Research, 433-440.

Gujer, W., Henz, M., Mino, T., \& van Loosdrecht, M. (2000). Activated Sludge Model No. 3. In M. Henze, W. Gujer, T. Mino, \& M. van Loosdrecht, Activated Sludge Models ASM1, ASM2, ASM2d and ASM3 (pp. 99-121). London: IWA Publishing.

Gujer, W., Henze, M., Mino, T., Matsuo, T., Wentzel, M., \& Marais, G. (1994). The Activated Sludge Model No.2: Biologival Phosphorus Removal. Water Science and Technology, 111.

Helmer, C., Kunst, S., Juretschko, S., Schmid, M., Schleifer, K., \& Wagner, M. (1999). Nitrogen Loss in a Nitrifying Biofilm System. Water Science and Technology, 13-21.

Helmer, S., \& Kunst, S. (1998). Simultaneous Nitrification/Denitrification in an Aerobic Biofilm System. Water Science and Technology, 183-187.

Henze, M., Grady, C., Gujer, W., Marais, G., \& Matsuo, T. (2000). Activated Sludge Model No. 1. In M. Henze, W. Gujer, T. Mino, \& M. van Loosdrecht, Activated Sludge Models ASM1, ASM2, ASM2d and ASM3 (pp. 1-38). London: IWA Publishing.

Henze, M., Gujer, W., Mino, T., Matsuo, T., Wentzel, M., Marais, G., \& van Loosdrecht, M. (1999). Activated Sludge Model No.2D ASM2D. Water Science and Technology, 165-182.

Henze, M., Harremoes, P., Arvin, E., \& Jansen, J. (2002). Wastewater Treatment: Biological and Chemical Processes. Heidelberg: Springer-Verlag.

Hu, B., Zheng, P., Tang, C., Chen, J., E, B., Zhang, L., . . Kartal, B. (2010). Identification and Quantification of Anammox Bacteria in Eight Nitrogen Removal Reactors. Water Research, 5014-5020.

Ibrahim, H., Qiang, H., Al-Rekabi, W., \& Yang, Q. (2012). Improvements in Biofilm Processes for Wastewater Treatment. Pakistan Journal of Nutrition, 610-636.

IJC. (2014). A Balanced Diet for Lake Erie. Washington DC: International Joint Commission. 
Jeganathan, J. (2011). Process Optimization of Chemical Phosphorus Removal in Wastewater Treatment Facilities. Influents, 73-75.

Jetten, M. (2008). The Microbial Nitrogen Cycle. Environmental Microbiology, 2903-2909.

Ji, Y., Xing, B., Yang, G., Ni, W., Guo, L., \& Jin, R. (2014). Performance and Hydrodynamic Features of a Staged Up-Flow Anammox Sludge Blanket (SUASB) Reactor. Chemical Engineering Journal, 298-304.

Jin, R., Ma, C., Mahmood, Q., Yang, G., \& Zheng, P. (2011). Anammox in a UASB Reactor Treating Saline Wastewater. Process Safety and Environmental Protection, 342-348.

Jin, R., Yang, G., Yu, J., \& Zheng, P. (2012). The Inhibition of the Anammox Process: A Reviw. Chemical Engineering Journal, 67-79.

Jinlong, Z., Ying, D., Xiujuan, Y., \& Zi-Peng, X. (2012). Effect of Bioaugmentation on the Enhanced Biological Denitrification in Subsurface Wastewater Infiltration Systems (SWIS) and Biofilter. In N. Savaglio, \& R. Puopolo, Denitrification: Processes, Regulation and Ecological Significance (pp. 103-132). New York: Nova Science Publishers.

Josyula, K., Liu, H., Liang, J., Lerner, R., Sheng, Z., \& Liu, Y. (2010). Biofilm Fixed Film Systems. Water Environment Research, 1124-1158.

Junfeng, D., Guyuan, L., \& Xiang, L. (2007). Kinetic Analysis of Anaerobic Phosphorus Release During Biological Phosphorus Removal Process. Frontiers of Environmental Science \& Engineering, 233-239.

Kahn, F., \& Ansari, A. (2005). Eutrophication: An Ecological Vision. The Botanical Review, 449482.

Kane, D., Conroy, J., Richards, R., Baker, D., \& Culver, D. (2014). Re-eutrophication of Lake Erie: Corrleations between Tributary Nutrient Loads and Phytoplankton Biomass. Journal of Great Lakes Research.

Kapoor, A., Kuiper, A., Bedard, P., \& Gould, W. (2003). Use of a Rotating Biological Contactor for Removal of Ammonium from Mining Effluents. The European Journal of Mineral Processing and Environmental Protection, 88-100.

Kartal, B., Kuenen, J., \& van Loosdrecht, M. (2010). Sewage Treatment with Anammox. Science, 702-703.

Kelusar, R., Nerurkar, A., \& Desai, A. (2013). Development of a Simultaneous Partial Nitrification, Anaerobic Ammonia Oxidation and Denitrification (SNAD) Bench Scale Process for Removal of Ammonia from Effluent of a Fertilizer Industry. Bioresource Technology, 390-397. 
Lackner, S., Gilbert, E., Vlaeminck, S., Joss, A., Horn, H., \& van Loosdrecht, M. (2014). Full-scale Partial Nitritation/Anammox Experiences: An Application Survey. Water Research, 292303.

Lee, J., Jutidamrongphan, W., Park, K., Moon, S., \& Park, C. (2012). Advanced Treatment of Wastewater from Food Waste Disposer in Modified Ludzack-Ettinger Type Membrane Bioreactor. Environmental Engineering Research, 59-63.

Li, C., Ji, M., Li, X., \& Song, Y. (2010). Full-scale Anoxic-Aerobic SBR System for Simultaneous Nitrogen and Phosphorus Removal from Municipal Wastewater. International Conference on Bioinformatics and Biomedical Engineering (pp. 1-4). Chengdu: Institute of Electrical and Electronics Engineers.

Li, J., Yu, L., Yu, D., Wang, D., Zhang, P., \& Ji, Z. (2014). Performance and Granulation in an Upflow Anaerobic Sludge Blanket (USAB) Reactor Treating Saline Sulfate Wastewater. Biodegradation, 127-136.

Li-Dong, S., An-Hui, H., Ren-Cun, J., Dong-Qing, C., Ping, Z., Xiang-Yang, X., \& Bao-Lan, H. (2012). Enrichment of Anammox Bacteria from Three Sludge Sources for the Startup of Monosodium Glutamate Industrial Wastewater Treatment System. Journal of Hazardous Materials, 193-199.

Linden, K., Hawkins, J., \& Bonislawsky, M. (2001). Evaluation of Performance and Operational Costs for Three Biological Nutrient Removal Schemes at a Full-Scale Wastewater Treatment Plant. Durham, North Carolina: Water Resources Research Institute of The University of North Carolina.

Liu, D., Wong, P., \& Dutka, B. (1973). Determination of Carbohydrate in Lake Sediment by a Modified Phenol-Sulphuric Acid Method. Water Research, 741-756.

Liu, T., Zeng, H., Li, X., Zeng, T., Chang, X., Cai, Y., \& Zhang, J. (2012). Biodiversity and Quantification of Functional Bacteria in a Completely Autotrophic Nitrogen-Removal over Nitrite (CANON) Process. Bioresource Technology, 399-406.

Liu, Y. (2007). Overview of Some Theoretical Approaches for Derivation of the Monod Equation. Applied Microbial Biotechnology, 1241-1250.

Ma, J., Quan, X., \& Li, H. (2013). Application of High OLR-Fed Aerobic Granules for the Treatment of Low-Strength Wastewater: Performance, Granule Morphology and Microbial Community. Journal of Environmental Sciences, 1549-1556.

Ma, Y., Hira, D., Li, Z., Chen, C., \& Furukawa, K. (2011). Nitrogen Removal Performance of a Hybrid Anammox Reactor. Bioresource Technology, 6650-6656.

Makareqicz, J., \& Bertram, P. (1991). Evidence for the Restoration of the Lake Erie Ecosystem. BioScience, 216-223. 
Manariotis, I., \& Grigoropoulos, S. (2006). Municipal-Wastewater Treatment Using UpflowAnaerobic Filters. Water Environment Research, 233-242.

Manariotis, I., \& Grigoropoulos, S. (2006). Municipal-Wastewater Treatment Using UpflowAnaerobic Filters. Water Environment Research, 233-242.

Marbek. (2010). Economic Value of Protecting the Great Lakes. Ottawa: Ontario Ministry of the Environment.

Marti, N., Bouzas, A., Seco, A., \& Ferrer, J. (2008). Struvite Precipitation Assessment in Anaerobic Digestion Processes. Chemical Engineering Journal, 67-74.

Mazumder, D. (2002). Applicability of the Sequencing Batch Reactor for Wastewater Treatment. International Journal of Environment and Pollution, 255-265.

McGrath, J., \& Quinn, J. (2003). Microbial Phosphate Removal and Polyphosphate Production from Wastewaters. Advances in Applied Microbiology, 75-100.

Milia, S., Cappai, G., Perra, M., \& Carucci, A. (2012). Biologial Treatment of Nitrogen-Rich Refinery Wastewater By Partial Nitrification (SHARON) Process. Environmental Technology, 1477-1483.

Monod, J. (1949). The Growth of Bacterial Cultures. Annual Review of Microbiology, 371-394.

Moreno, O. (1987). Design of the Step-Feed Activated Sludge Process. Montreal: McGill University.

Mulder, A. (1989). United States of America Patent No. US5078884 A.

Mulder, A., van de Graaf, A., Robertson, L., \& Kuenen, J. (1995). Anaerobic Ammonium Oxidation Discovered in a Denitrifying Fluidized Bed Reactor. FEMS Microbiology Ecology, 177-184.

Musig, Y., \& Boyd, C. (1980). Comparison of Polyphosphate and Orthophosphate as Fertilizers for Fish Ponds. Aquaculture, 135-138.

New Mexico Environment Department. (2007). Wastewater Systems Operator Certification Study Manual. Santa Fe: New Mexico Environment Department.

Ni, S., \& Zhang, J. (2013). Anaerobic Ammonium Oxidation: From Laboratory to Full-Scale Application. BioMed Research International, 1-10.

North, R., Guildford, S., Smith, R., Havens, S., \& Twiss, M. (2007). Evidence for Phosphorus, Nitrogen and Iron Colimitation of Phytoplankton Communities in Lake Erie. American Society of Limnology and Oceanography, 315-328. 
Nozhevnikova, A., Litti, Y., Nekrasova, V., Kulichevskaya, I., Grigoryeva, N., Kulikov, N., \& Zubov, M. (2012). Anaerobic Ammonium Oxidation (Anammox) in Immobilized Activated Sludge Biofilms during the Treatment of Weak Wastewater. Microbiology, 28-38.

Odegaard, H., Gisvold, B., \& Strickland, J. (1994). The Influence of Carrier Size and Shape in Moving Bed Biofilm Process. Water Science and Technology, 157-165.

Oehmen, A., Lemos, P., Carvalho, G., Yuan, Z., Keller, J., Blackall, L., \& Reis, M. (2007). Advances in Enhanced Biological Phosphorus Removal: From Micro to Macro Scale. Water Research, 2271-2300.

Oleszkiewicz, J., \& Barnard, J. (2006). Nutrient Removal Technology in North America and the European Union: A Review. Water Quality Research Journal of Canada, 449-462.

Paredes, D., Kuschk, P., Mbwette, T., Stange, F., Muller, R., \& Koser, H. (2007). New Aspects of Microbial Nitrogen Transformations in the Context of Wastewater Treatment. Engineering in Life Sciences, 13-25.

Park, J., \& Jung, D. (2011). Removal of Total Phosphorus (TP) from Municipal Wastewater Using Loess. Desalination, 104-110.

Peng, Y., \& Zhu, G. (2006). Biological Nitrogen Removal with Nitrification and Denitrification via Nitrite Pathway. Applied Microbial Biotechnology, 15-26.

Picioreanu, C., van Loosdrecht, M., \& Heijnen, J. (1997). Modelling the Effect of Oxygen Concentration on Nitrite Accumulation in a Biofilm Airlift Suspension Reactor. Water Science and Technology, 147-156.

Province of Ontario. (1990). Environmental Protection Act. Toronto: Province of Ontario.

Province of Ontario. (1990). Ontario Water Resources Act. Toronto: Province of Ontario.

Province of Ontario. (1993). Ontario Regulation 537/93. Toronto: Province of Ontario.

Province of Ontario. (1993). Ontario Regulation 760/93. Toronto: Province of Ontario.

Province of Ontario. (1995). Ontario Regulation 63/95 Environmental Protection Act. Toronto: Province of Ontario.

Province of Ontario. (2002). Nutrient Management Act. Toronto: Province of Ontario.

Province of Ontario. (2002). Nutrient Management Act. Toronto: Province of Ontario.

Province of Ontario. (2006). Clean Water Act. Toronto: Province of Ontario.

Pynaert, K., Smets, B., Wyffels, S., Beheydt, D., Siciliano, S., \& Verstraete, W. (2003).

Characterization of an Autotrophic Nitrogen-Removing Biofilm from a Highly Loaded 
Lab-Scale Rotating Biological Contactor. Applied and Environmental Microbiology, 36263635.

Pynaert, K., Sprengers, R., Laenen, J., \& Verstraete, W. (2002). Oxygen-Limited Nitrification and Denitrification in a Lab-Scale Rotating Biological Contactor. Environmental Technology, 353-362.

Qiao, S., Nishiyama, T., Fujii, T., Bhatti, Z., \& Furukawa, K. (2012). Rapid Startup and High Rate Nitrogen Removal from Anaerobic Sludge Digester Liquid using a SNAP Process. Biodegradation, 157-164.

Qiu, Y., Shi, H., \& He, M. (2010). Nitrogen and Phosphorus Removal in Municipal Wastewater Treatment Plants in China: A Review. International Journal of Chemical Engineering, 110.

Rachmani, A. (2013). Cost and Performance Comparison of a Membrane Bioreactor (MBR) Plant and a Bardenpho Plant for Wastewater Treatment. Hamilton, New Zealand: University of Waikato.

Ragsdale \& Associates. (2008). Wastewater System Operator's Manual. Albuquerque: Ragsdale \& Associates.

Rajakumar, R., Meenambal, T., Banu, J., \& Yeom, I. (2011). Treatment of Poultry Slaughterhouse Wastewater in Upflow Anaerobic Filter Under Low Upflow Velocity. International Journal of Envrionmental Science and Technology, 1735-1472.

Ren-Cun, J., \& Zheng, P. (2009). Kinetics of Nitrogen Removal in High Rate Anammox Upflow Filter. Journal of Hazardous Materials, 652-656.

Reza, M., \& Alvarez-Cuenca, M. (2013). Analysis of a Vertical Bioreactor for Denitrification and Biological Phosphorus Removal from Wastewater. Chemical Engineering \& Process Techniques , 1006-1014.

Rodgers, M., \& Zhan, X. (2003). Moving-Medium Biofilm Reactors. Reviews in Environmental Science and Biotechnology, 213-224.

Saravanane, R., \& Murthy, D. (1999). Application of Anaerobic Fluidized Bed Reactors in Wastewater Treatment: A Review. Environmental Management and Health , 97-117.

Sarria, N., Victoria, J., Lozada, P., \& Parra, C. (2011). Performance of a Contact Stabilization Process for Domestic Wastewater Treatment of Cali, Colombia. DYNA, 98-107.

Satoh, H., Oshima, K., Suda, W., Ranasinghe, P., Li, N., Gunawardana, E., . . Mino, T. (2013). Bacterial Population Dynamics in a Laboratory Activated Sludge Reactor Monitored by Pyrosequencing of 16S rRNA. Microbes and Environments , 65-70. 
Savaglio, N., \& Puopolo, R. (2012). Denitrification: Processes, Regulation and Ecological Significance. New York: Nova Science Publishers.

Schaubroeck, T., Bagchi, S. C., Carballa, M., Verstraete, W., \& Vlaeminck, S. (2012). Successful Hydraulic Strategies to Start Up OLAND Sequencing Batch Ractors at Lab Scale. Microbial Biotechnology, 403-414.

Sedlak, R. (1991). Phosphorus and Nitrogen Removal from Municipal Wastewater. New York: The Soap and Detergent Association.

Shalini, S., \& Joseph, K. (2012). Nitrogen Management in Landfill Leachate: Application of SHARON, ANAMMOX and Combined SHARON-ANAMMOX process. Waste Management, 2385-2400.

Sliekers, A., Third, K., Abma, W., Kuenen, J., \& Jetten, M. (2003). CANON and Anammox in a Gas-Lift Reactor. FEMS Microbiology Letters, 339-344.

Smolders, G., van der Meij, J., van Loosdrecht, M., \& Heijnen, J. (1995). A Structured Metabolic Model for Anaerobic and Aerobic Stoichiomery and Kinetics of the Biological Phosphorus Removal Process. Biotechnology and Bioengineering, 227-287.

Strous, M., van Gerven, E., Zheng, P., Kuenen, J., \& Jetten, M. (1997). Ammonium Removal from Concentrated Waste Streams with the Anaerobic Ammonium Oxidation (Anammox) Process in Different Reactor Configurations. Water Research, 1955-1962.

Su, J., \& Ouyang, C. (1997). Advanced Biological Enhanced Nutrient Removal Process By The Addition of Rotating Biological Contactors. Water Science and Technology, 153-160.

Surampalli, R., \& Baumann, R. (1989). Supplemental Aeration Enhanced Nitrification in a Secondary RBC Plant. Water Pollution Control, 200-207.

Sutherland, I. (2001). The Biofilm Matrix - An Immobilized but Dynamic Microbial Enviornment. Trends in Microbiology, 222-227.

Tang, C., Zheng, P., Ding, S., \& Lu, H. (2014). Enhanced Nitrogen Removal from Ammonium-Rich Wastewater Containing High Organic Contents by Coupling with Novel High-Rate ANAMMOX Granules Addition. Chemical Engineering Journal, 454-461.

Tang, C., Zheng, P., Wang, C., Mahmood, Q., Zhang, J., Chen, X., . . Chen, J. (2011). Performance of High-Loaded ANAMMOX UASB Reactors Containing Granular Sludge. Water Research, 135-144.

Tavares, C., Santanna, G., \& Capdeville. (1995). The Effect of Air Superficial Velocity on Biofilm Accumulation in a Three-Phase Fludized Bed Reactor. Water Research, 2293-2298.

Tchobanoglous, G., Burton, F., \& Stensel, H. (2002). Wastewater Engineering: Treatment and Reuse. New York: Metcalf \& Eddy Inc. 
The Associated Press. (2014, July 10). Significant algae bloom predicted for Lake Erie. Retrieved from 13ABC.com: http://www.13abc.com/story/25987909/significant-algae-bloompredicted-for-lake-erie

The Council of the European Communities. (1991). Council Directive 91/271/EEC of 21 May 1991 concerning urban waste-water treatment . Brussels: The Council of the European Communities.

The Government of Canada; The Government of the United States of America. (2013). Great Lakes Water Quality Agreement. Washington: The United States of America.

Third, K., Paxman, J., Schmid, M., Strous, M., Jetten, M., \& Cord-Ruwisch, R. (2005). Enrichment of Anammox from Activated Sludge and Its Application in the CANON Process. Microbial Ecology, 236-244.

Third, K., Sliekers, A., Kuenen, J., \& Jetten, M. (2001). The CANON System (Completely Autotrophic Nitrogen-Removal Over Nitrite) Under Ammonium Limitation Interaction and Competition Between Three Groups of Bacteria. Systematic and Applied Microbiology, 588-596.

Toronto Water. (2013). Ashbridges Bay Wastewater Treatment Plant Annual Report. Toronto: Toronto Water.

Tritt, W. (1992). The Anaerobic Treatment of Slaughterhouse Wastewater in Fixed Bed Reactors. Bioresource Technology , 201-207.

Tsushima, I., Ogasawara, Y., Kindaichi, T., Satoh, H., \& Okabe, S. (2007). Development of HighRate Anaerobic Ammonium-Oxidizing (Anammox) Biofilm Reactors. Water Research, 1623-1634.

Twiss, M., Auclair, J., \& Charlton, M. (2000). An Investigation into Iron-Stimulated Phytoplankton Productivity in Epipelagic Lake Erie During Thermal Stratification using Trace Metal Clean Techniques. Canadian Journal of Fisheries Aquatic Sciences, 86-95.

Ueno, Y., \& Fujii, M. (2001). Three Years Experience of Operating and Selling Recovered Struvite from Full-Scale Plant. Environmental Technology, 1373-1381.

US EPA. (1993). Manual: Nitrogen Control. Washington DC: US Environmental Protection Agency.

US EPA. (2000). Wastewater Technology Fact Sheet: Oxidation Ditches. Washington: United States Environmental Protection Agency.

US EPA. (2000). Wastewater Technology Fact Sheet: Trickling Filters. Washington DC: United States Environmental Protection Agency. 
US EPA. (2008). Municipal Nutrient Removal Technologies Reference Document. Washington D.C.: United States Environmental Protection Agency.

US EPA. (2013). Wastewater Treatment Fact Sheet: External Carbon Sources for Nitrogen Removal. Washington DC: United States Environmental Protection Agency.

van de Graaf, A., Bruijn, P., Robertson, L., Jetten, M., \& Kuenen, J. (1996). Autotrophic Growth of Anaerobic Ammonium-Oxidizing Micro-Organisms in a Fluidized Bed Reactor. Microbiology, 2187-2196.

van de Graaf, A., Mulder, A., de Bruijn, P., Jetten, M., Robertson, L., \& Kuenen, J. (1995). Anaerobic Oxidation of Ammonium is a Biologically Mediated Process. Applied and Environmental Microbiology, 1246-1251.

van der Star, W., Abma, W., Blommers, D., Mulder, J., Tokutomi, T., Strous, M., . . van Loosdrecht, M. (2007). Startup of Reactors for Anoxic Ammonium Oxidation: Experiences from the First Full-Scale Anammox Reactor in Rotterdam. Water Research, 4149-4163.

Vangsgaard, A., Mutlu, A., Gernaey, K., Smets, B., \& Sin, G. (2013). Calibration and Validation of a Model Describing Complete Autotrophic Nitrogen Removal in a Granular SBR System. Journal of Chemical Technology and Biotechnology, 2007-2015.

Volcke, E. (2006). Modelling, Analysis and Control of Partial Nitration in a SHARON Reactor. Ghent, Belgium: Ghent University.

Walker, C., de la Torre, J., Klotz, M., Urakwa, H., Pinel, N., Arp, D., . . Stahl, D. (2010). Nitrosopumilus Maritimus Genome Reveals Unique Mechanisms for Nitrification and Autotropy in Globally Distributed Marine Crenarchaea. Proceedings of the National Academy of Sciences of the United States of America, 8818-8823.

Wan, L. (2006). Simultaneous Removal of COD and Ammonia from high-strength wastewater in a three-phase fluidized bed reactor. Toronto: Ryerson University.

Wang, C., Lee, P., Kumar, M., Huang, Y., Sung, S., \& Lin, J. (2010). Simultaneous Partial Nitrification, Anaerobic Ammonium Oxidation and Denitrifitication (SNAD) in a Full-Scale Landfill-Leachate Treatment Plant. Journal of Hazardous Materials, 622-628.

Wang, Z., Liu, B., Liu, Y., \& Wan, F. (2012). Evaluation of Biological Removal Efficiency in a UCT Process Treating Municipal Wastewater During Start-up Stage. Journal of Environmental Biology, 459-464.

Water Maxim. (2014). Rotating Biological Contactor (RBC). Retrieved from Water Maxim: http://www.watermaxim.co.uk/rotating-biological-contactors.php 
WEF. (2007). Operation of Municipal Wastewater Treatment Plants. Alexandria: Water Environment Fedaration.

Weston, Roy F. Inc. (1985). Emerging Technology Assessment of Phostrip, A/O and Bardenpho Processes for Biological Phosphorus Removal. Cincinnati: Environmental Protection Agency.

Wett, B. (2006). Solved Upscaling Problems for Implementing Deammonification of Rejetion Water. Water Science and Technology, 121-128.

Wett, B., Hell, M., Nyhuis, G., Puempel, T., Takacs, I., \& Murthy, S. (2010). Syntrophy of Aerobic and Anaerobic Ammonia Oxidisers. Water Science and Technology, 1915-1922.

Wett, B., Murthy, S., Takacs, I., Hell, M., Bowden, G., Deur, A., \& O'Shaughnessy, M. (2007). Key Parameters for Control of DEMON Deammonification Processes. Washington, DC: District of Columbia Water and Sewer Authority.

Wett, B., Rostek, R., Rauch, W., \& Ingerle, K. (1998). pH-Controlled Reject-Water-Treatment. Water Science and Technology, 165-178.

Wik, T. (2003). Trickling Filters and Biofilm Reactor Modelling. Reviews in Environmental Science and Biotechnology, 193-212.

Wilson, T., \& McGettigan, J. (2006). A Critical New Look at Nutrient Removal Processes. WEFTEC (pp. 3491-3501). Dallas: Water Environment Fedaration.

Windey, K., Bo, I., \& Verstraete, W. (2005). Oxygen-Limited Autotrophic DitrificationDenitrification (OLAND) in a Rotating Biological Contactor Treating High-Salinity Wastewater. Water Research, 4512-4520.

Winkler, M., Kleerebezem, R., \& van Loosdrecht, M. (2012). Integration of Anammox into the Aerobic Granular Sludge Process for Main Stream Wastewater Treatment at Ambient Temperatures. Water Research, 136-144.

Wyffels, I. S. (2004). Feasibility of Combined Autotrophic Nitrogen Removal Processes for the Treatment of High-Strength Nitrogen Wastewater. Ghent: Ghent University.

Wyffels, S., S, v. H., Boeckx, P., Vlocke, E., van Cleemput, O., Vanrolleghem, P., \& Verstraete, W. (2004). Modeling and Simulation of Oxygen-Limited Partial Nitration in a MembraneAssisted Bioreactor (MBR). Biotechnology and Bioengineering, 531-542.

Xiao, Y., Xiao, Q., \& Xiang, S. (2014). Modeling of Simultaneous Partial Nitrification, Anammox and Denitrification Process in a Single Reactor. Environmental and Analytical Toxicology, $1-6$.

Yang, K., Li, Z., Zhang, H., Qian, J., \& Chen, G. (2010). Municipal Wastewater Phosphorus Removal by Coagulation. Environmental Technology, 601-609. 
Yilmazel, Y., \& Demirer, G. (2013). Nitrogen and Phosphorus Recovery From Anaerobic Codigestion Residues of Poultry Manure and Maize Silage via Struvite Precipitation. Waste Management \& Research, 791-804.

Young, H., \& Young, J. (1988). Hydraulic Characteristics of Upflow Anaerobic Filters. Journal of Environmental Engineering, 621-638.

Zhang, J., Zhang, Y., Li, Y., Zhang, L., Qiao, S., Yang, F., \& Quan, X. (2012). Enhancement of Nitrogen Removal in a Novel Anammox Reactor Packed with Fe Electrode. Bioresource Technology, 102-108.

Zhu, J., Hu, Y., \& Liang, H. (2006). Correlation of Anaerobic Ammonium Oxidation and Denitrification. Journal of Environmental Science, 227-231. 